\title{
Fluor-Hanford 3013 Digital Radiography \\ Dead Zone Mitigation Project \\ Pressure Test Report
}

Technical Report

WSRC-TR-2003-00485

SRTC/EES Job Number 22804

November 2003

Prepared by:

Kenneth M. Gibbs, Ph. D.

Westinghouse Savannah River Company

Contributions from:

David Immel

Benjamin Meers, III

Richard Poland

Westinghouse Savannah River Company

Dennis Douglas

Vista Engineering Technologies, Inc.

Richard Szempruch

Fluor-Hanford 


\section{Fluor-Hanford 3013 Digital Radiography \\ Dead Zone Mitigation Project \\ Pressure Test Report}

Technical Report

WSRC-TR-2003-00485

SRTC/EES Job Number 22804

November 2003

Prepared by:

Kenneth M. Gibbs, Ph. D.

Westinghouse Savannah River Company

Contributions from:

David Immel

Benjamin Meers, III

Richard Poland

Westinghouse Savannah River Company

Dennis Douglas

Vista Engineering Technologies, Inc.

Richard Szempruch

Fluor-Hanford 
This document was prepared in conjunction with work accomplished under Contract No. DE-AC09-96SR18500 with the U. S. Department of Energy.

\section{DISCLAIMER}

This report was prepared as an account of work sponsored by an agency of the United States Government. Neither the United States Government nor any agency thereof, nor any of their employees, makes any warranty, express or implied, or assumes any legal liability or responsibility for the accuracy, completeness, or usefulness of any information, apparatus, product or process disclosed, or represents that its use would not infringe privately owned rights. Reference herein to any specific commercial product, process or service by trade name, trademark, manufacturer, or otherwise does not necessarily constitute or imply its endorsement, recommendation, or favoring by the United States Government or any agency thereof. The views and opinions of authors expressed herein do not necessarily state or reflect those of the United States Government or any agency thereof.

This report has been reproduced directly from the best available copy.

Available for sale to the public, in paper, from: U.S. Department of Commerce, National Technical Information Service, 5285 Port Royal Road, Springfield, VA 22161, phone: (800) 553-6847, fax: (703) 605-6900

email: orders@ntis.fedworld.gov

online ordering: http://www.ntis.gov/help/index.asp

Available electronically at http://www.osti.gov/bridge

Available for a processing fee to U.S. Department of Energy and its contractors, in paper, from: U.S. Department of Energy, Office of Scientific and Technical Information, P.O. Box 62, Oak Ridge, TN 37831-0062,

phone: (865)576-8401,

fax: (865)576-5728

email: $\underline{\text { reports@ adonis.osti.gov }}$ 


\section{$\underline{\text { Table of Contents }}$}

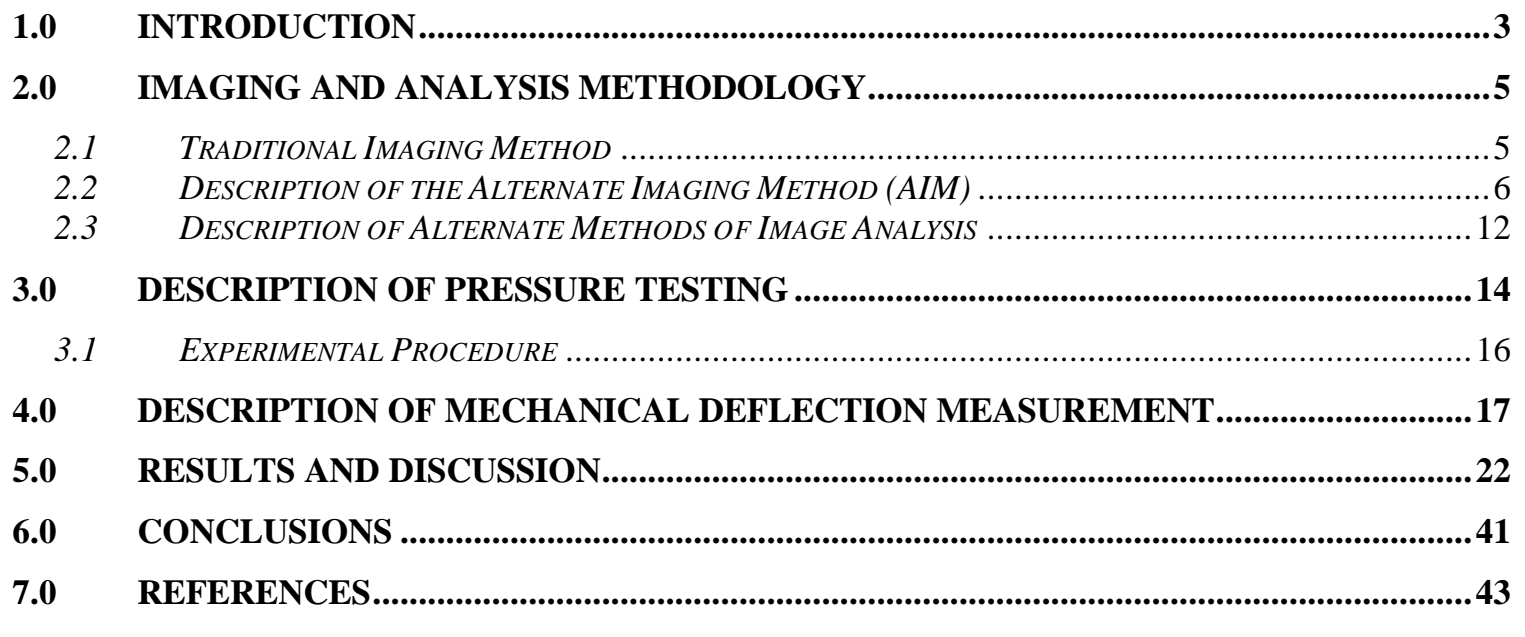

APPENDIX 1 : PRESSURE TEST MECHANICAL DEFLECTION DATA AND

CALCULATIONS

APPENDIX 2 : SPREADSHEET DATA SUPPORTING THEPRESSURE TEST GRAPHS FOR

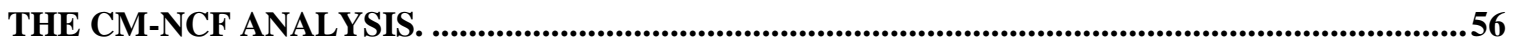

APPENDIX 3 : PRESSURE TEST GRAPHS FOR THE MD-CF ANALYSIS................................68 APPENDIX 4 : SPREADSHEET DATA SUPPORTING THE PRESSURE TEST GRAPHS FOR

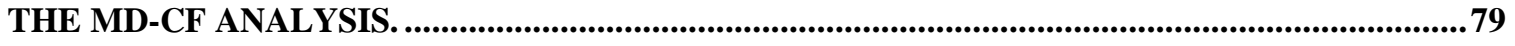

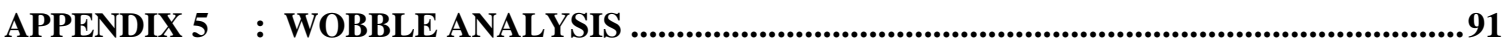




\subsection{Introduction}

The use of digital radiographic measurement of lid deflection as an indication of pressurization of the 3013 inner can was first reported by the Savannah River Technology Center (SRTC) in Reference [1]. The conclusions of this report were that for cans with relatively large initial concavity, lid deflection could be used to meet the 3013 standard (DOE-STD-3013-2000) requirement for a nondestructive indication of a pressurization of 100 psig.

In January of 2001, the Engineered Equipment and Systems (EES) department, within SRTC, was requested to supply Fluor-Hanford with a digital radiography (DR) system for the purpose of measuring lid deflection. Job number 22804 was established and a folder in EES Document Control (Folder \# 22804) was opened for the purpose of documenting this work. The system was delivered and installed by mid-year 2001.

Subsequent to the delivery of this system, a similar system was installed in the FB-Line at the Savannah River Site (SRS). During acceptance testing of the FB-Line system in the Spring of 2003, it was confirmed that for some cans the DR measured lid deflection could become insensitive to the change in lid deflection when compared to actual mechanical measurements. The basic explanation of this phenomenon is that characteristics of the lid geometry such as tilt and wobble, which will be defined later, can obfuscate the bottom of the lid where the deflection is measured. To illuminate this point further, Figure 1 shows the ideal imaging geometry with a relatively large concavity, symmetrical lid. In this view, the central ray of the x-ray source is tangent to the point of maximum deflection of the bottom of the lid. Under these conditions, the DR system accurately measures the lid deflection. The dead zone can be effectively illustrated in a simplified way in Figure 2. This figure shows a severely tilted lid, exaggerated for illustrative clarity, that is initially concave. The x-ray image of the lid would appear elliptical, with the top portion of the ellipse formed by the leading edge of the can and the lower portion of the ellipse formed by the trailing edge. The lower profile does not accurately describe the lid deflection as it does in Figure 1, and hence the deflection is not accurately measured. It can be seen from the projected image of the lid in Figure 2, that the point of maximum deflection is hidden in the shadow of the lid. This shadow is the dead zone.

SRTC/EES began working with Fluor-Hanford, in April 2003 to identify possible alternatives of imaging and data analysis to mitigate this problem. Fluor-Hanford Plutonium Finishing Plant (PFP), with input from EES, issued a test plan for the mitigation of the dead zone issue in July 2003 (Reference [2]). The test plan outlined two major activities. The first was to establish the equivalency of the Hanford, 305-A, and FB-Line DR systems. Successful demonstration of equivalency would then allow further development of dead zone mitigating techniques on the 305-A system rather than on the Hanford system. This would be more efficient and most cost effective. The equivalency was successfully demonstrated and the results were documented by Fluor-Hanford/Vista 
Engineering Technologies in Reference [3]. Therefore, subsequent technique development was performed on the 305-A system.

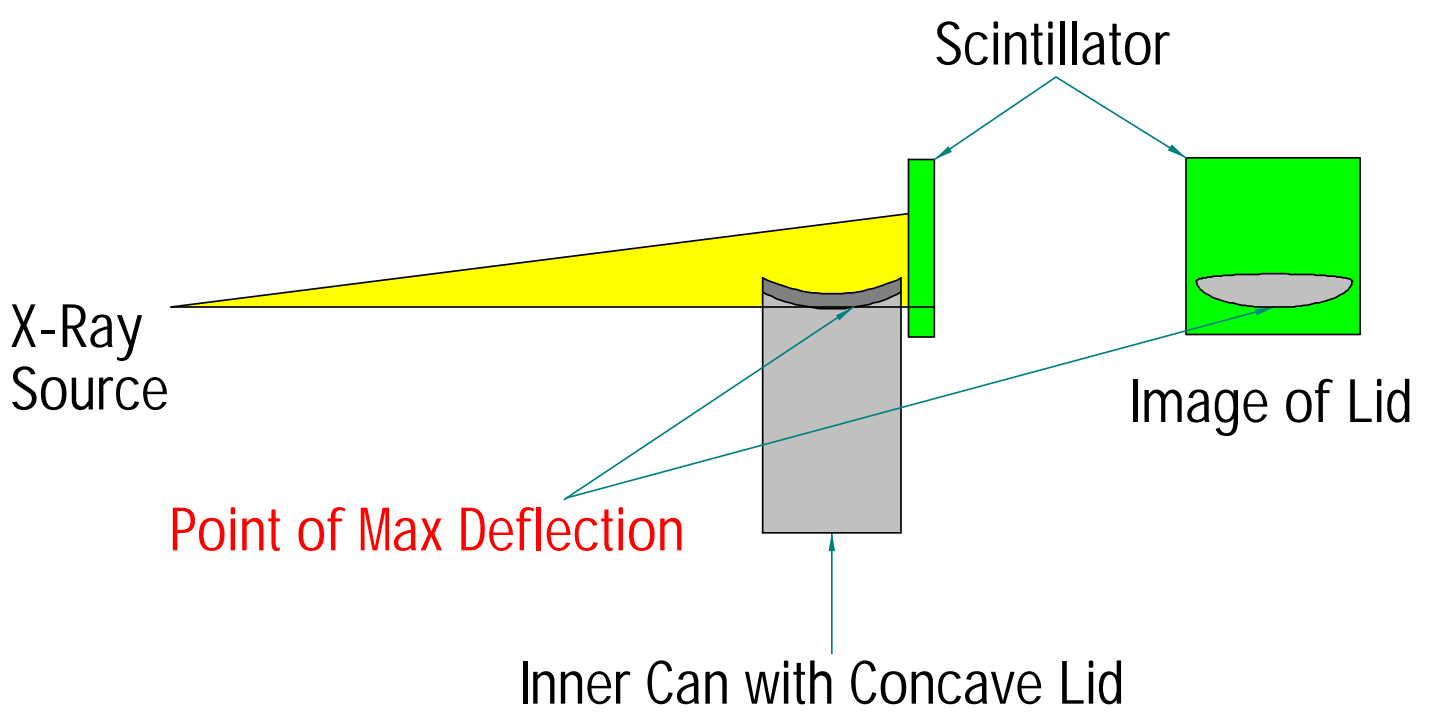

Figure 1: Ideal imaging geometry where lid deflection is correctly measured.

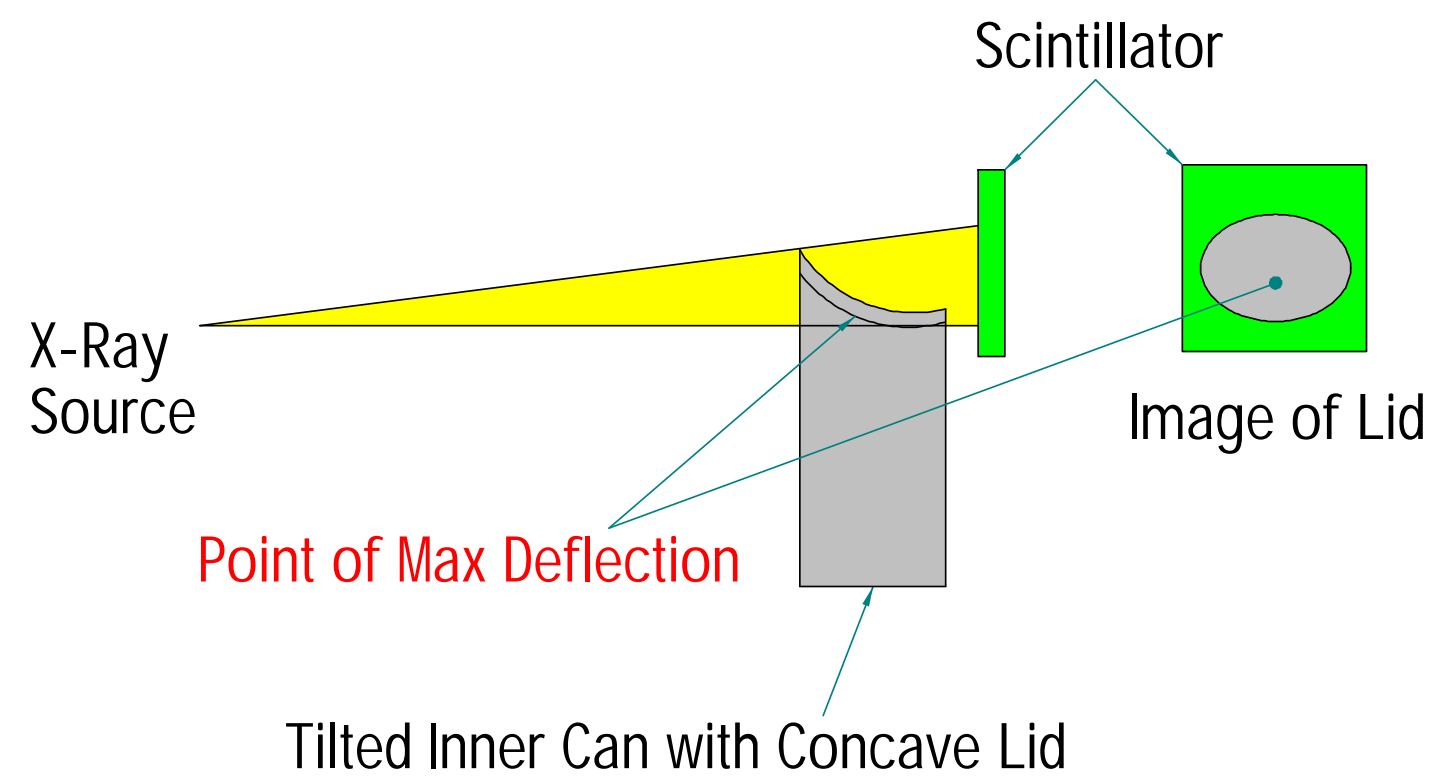

Figure 2: Illustration of how a severely tilted lid affects the deflection measurement. The point of maximum deflection is not imaged. 
The second major activity was the pressure testing of ten cans. The purpose for these pressure tests was to intentionally create the dead zone phenomenon, so that alternate imaging methods (AIM) and alternate analysis methods (AAM) could be developed and tested on radiologically "clean" cans that were forced into the dead zone. The AAM's are attractive because they can be implemented on existing data, alleviating the need to re-image. An additional benefit of the pressure tests was that the results could be used to confirm and augment the pressure-deflection coefficient (i.e., the slope of the deflection vs. pressure curve in the linear region before the onset of plastic deformation) previously established.

The purpose of this report is to document the results of the pressure testing and the efficacy of the alternate imaging and analysis methods developed to mitigate the dead zone problem. Prior to review of the results, a review of the current method and an introduction to the newly developed methods and techniques will be provided.

\subsection{Imaging and Analysis Methodology}

For this set of pressure testing, two imaging methods were employed. The first method was the method currently used at Hanford and FB-Line and will be referred to as the Traditional Imaging Method (TrM). The second method was the alternate imaging method (AIM) deemed most likely to succeed by the DR team. This was the "Optimal View" method, which was previously referred to as the "Select BTC Angle" method identified in the dead zone mitigation test plan, Reference [2]. In addition, the alternate analysis techniques developed will be discussed in this section. First, the traditional imaging method will be reviewed, and then a complete discussion on the alternate imaging and analysis will be presented.

\subsection{Traditional Imaging Method}

Prior to the discussion of the new imaging and analysis techniques it will be valuable to describe the traditional imaging and analysis method. In the traditional imaging the DR system automatically locates the burr ring gap of the inner can. The burr ring gap is then aligned toward the x-ray source, establishing the 0 -degree rotation index, as shown in Figure 3.

The system then acquires images at the $0,90,180$, and 270 degree orientations. At each orientation, the can height is automatically adjusted so that the center of the bottom of the lid is aligned with the calibrated center pixel of the CCD camera. This procedure effectively removes the component of the stage tilt that lies along the x-ray source-toscintillator axis and the geometric enlargement that results as a consequence of the divergence angle of the $x$-ray beam. The images are used to construct profiles for the top and bottom of the lid. 


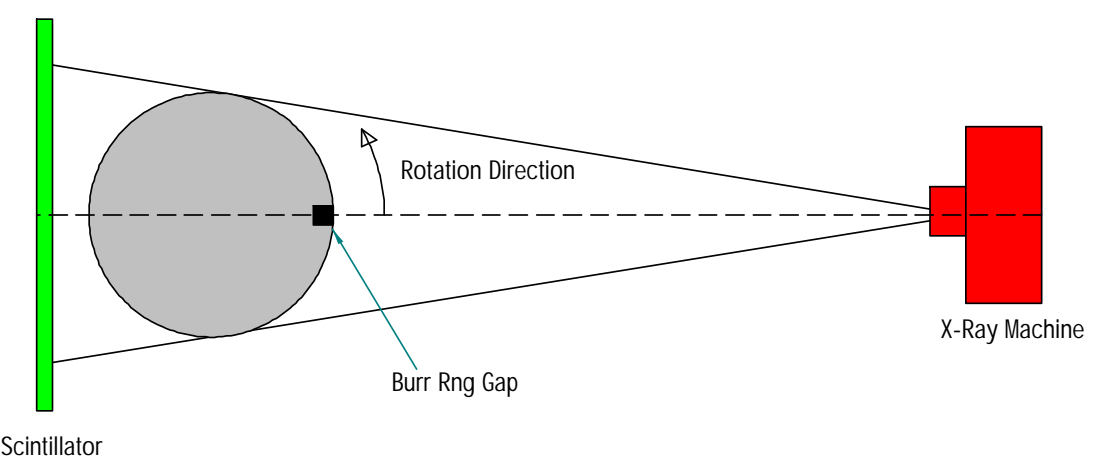

\section{Figure 3: Plan view of "Traditional" imaging geometry with burr ring oriented toward $x$-ray source at the 0-degree view.}

The extreme edges of the lid profile are not well defined as the x-ray penetration through the larger thickness of steel in the vicinity of the cylindrical wall is greatly reduced. Therefore, the profiles are extrapolated from an approximate 3.8-inch span, which may vary from can to can, to a consistent 4.5 -inch span. This is important because the deflection reference line is established by the endpoints of this span. Thus if this span were to vary, the deflection measurements would vary as well.

Additionally, the corners of the 4.5-inch span are generally not level due to a small amount of left-right tilt in the lid or the system components supporting the can. This tilt is removed via a software correction so that the resulting profiles are "level" at the corners. The deflection is then measured as the perpendicular distance from the imaginary reference line "drawn" between the "leveled" corners to the point of maximum deflection on the profile. A similar image analysis of the top of the lid profile is also performed. Previously, use of the current production version of the ADRIS software (V1.2) limited the top deflection values to be "for information only" because insufficient validation testing had been performed for this part of the code. The results presented in this document, however, provide an adequate basis for validation of the top deflection values, as will be seen. For a concave lid (lid curvature into the inner can) the deflection is a negative value and for convex lids the deflection is positive.

The bottom deflection values for all four orientations are then averaged to obtain the "reported" value of the deflection. The top profiles and deflection values are also reported but are not used in the lid deflection calculations. Figure 4 shows an example of a typical hardcopy report that is created after each can inspection. In addition to this report, the original image files are archived for future analysis. As a result, this historical data can be reanalyzed at a later date using newly developed analysis techniques without the need to re-image the cans.

\subsection{Description of the Alternate Imaging Method (AIM)}

The original approach to the DR deflection measurement was predicated on the assumption of concave lids that would remain concave during pressurization so that the 
3013 standard requirement of a nondestructive indication of pressurization of $100 \mathrm{psig}$ would be satisfied. For "well behaved" lids, those with large concavity relative to the lid tilt, the lid does not enter the dead zone below 100 psig. In that situation, one view would have been sufficient, but the software was designed to look at the can in four views at $0,90,180$, and 270 degrees. As shown earlier, when the lid is flat or nearly flat and there is a relatively large (compared to the deflection) tilt, one or more of these four views may be corrupted by the "dead zone." Therefore, the result of the averaging process will be distorted by one or more corrupted views.

To counteract this problem, a new model was proposed that takes into account that the lid may have an appreciable tilt in the source-to-scintillator direction as illustrated in Figure 2. This model will be called the Optimal View Method. This is one of a few approaches that were suggested in the dead zone mitigation test plan (Reference [2]). This technique is conceptually simple. It basically consists of finding the best angle or "optimal angle" to view the can so that the deflection measurement is not affected by the tilt of the lid. This is accomplished by using the "tilt" values which are calculated and reported by the ADRIS system (see Figure 4). It must be emphasized that the analysis to determine the

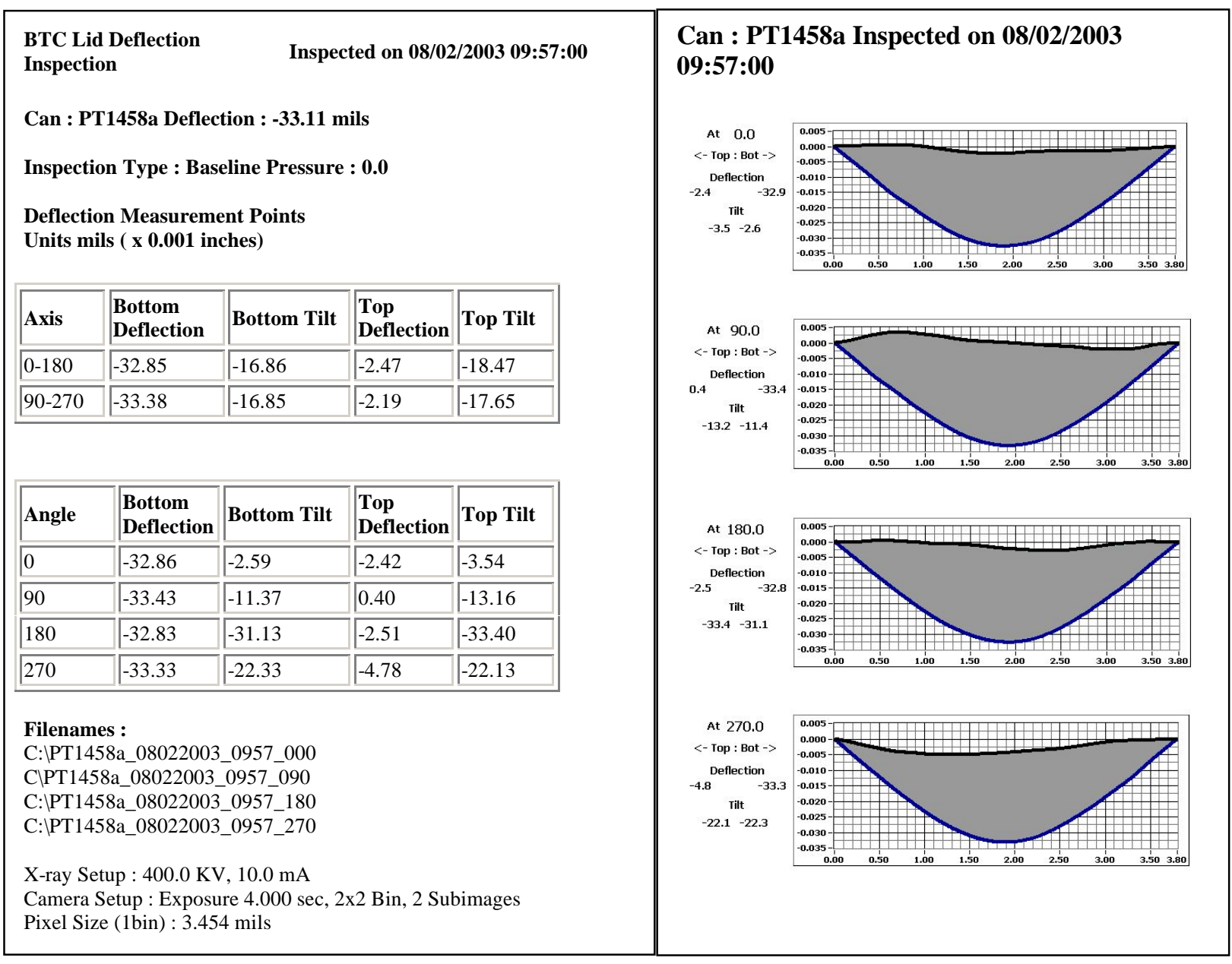

Figure 4: Typical hardcopy of report created with each deflection inspection. 
optimal angle uses the tilt values and not the deflection values. Although the concept is simple, the actual methodology is a little more complicated and warrants a complete discussion here.

First, a few terms and definitions must be introduced to fully explain this new model. This is best accomplished with the use of a couple of sketches. Consider the top portion of Figure 5. It depicts a can with a lid that appears to "wobble" as it is rotated as seen in the sequence of sketches. Thus, if the height of a point on the perimeter of the lid was mapped as a function of rotation angle, it would appear to be sinusoidal in functional form. The lower portion of this figure shows the impact a superposition of a constant left-to-right tilt of the rotary stage or other hardware below the can. It should be noted that tilt in the orthogonal direction is largely removed by the calibration procedure used for the DR system, provided that any changes in this tilt between calibrations are small. This constant tilt is referred to as "slant" in the context of the present model. Tilt, as defined within this model, is the sum of the constant slant and the view-angle dependent wobble.

\section{Wbble}

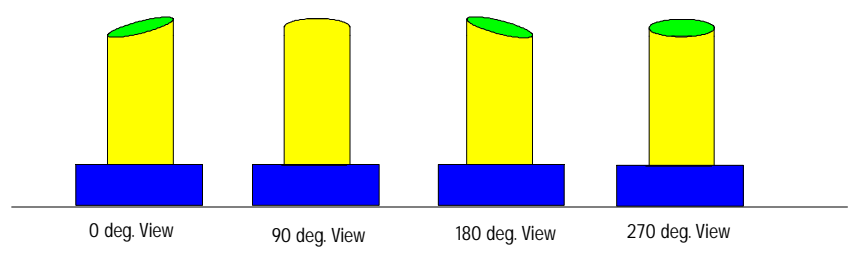

Sant + Vtbble

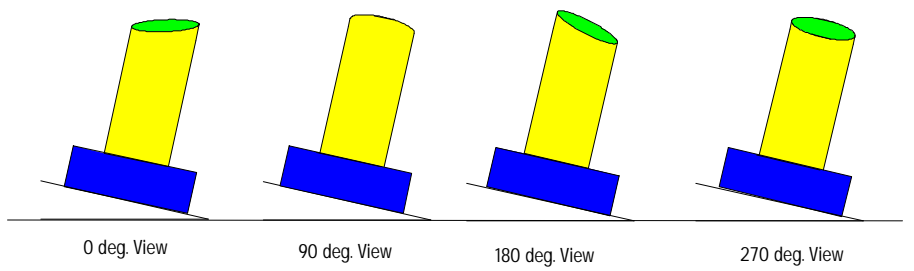

Figure 5: Illustration of tilt, wobble, and slant.

Mathematically, the model can be expressed as follows:

$$
\mathrm{T}(\theta)=\mathrm{S}+\mathrm{W}(\theta, \phi)
$$

where

$\mathrm{T}(\theta)=$ tilt as a function of view angle

$\mathrm{S}=$ slant (constant side-to-side component of tilt)

$\mathrm{W}(\theta, \phi)=$ wobble (variable component of tilt)

$\theta=$ view angle

$\phi=$ phase angle. 
It has also been assumed that $\mathrm{W}(\theta, \phi)=\mathrm{A}^{*} \sin (\theta+\phi)$, where $\mathrm{A}$ is defined as the amplitude of the wobble. Substitution for $\mathrm{W}(\theta, \phi)$ yields:

$$
T(\theta)=S+A^{*} \sin (\theta+\phi)
$$

The relationship between the parameters above is shown graphically in Figure 6. The four tilt values for Can PT1458 are shown as blue dots on the graph below. The solid red curve is the fit derived from the model above. The solid blue horizontal line shows the slant which is the constant part of the tilt. The amplitude is the maximum deviation between the solid red curve and the solid blue line. The phase angle is depicted as the angular displacement between where the solid red sinusoid and dotted blue sinusoid cross the horizontal blue line. In this case, the phase is +69 degrees, which means that the phase is "advanced" with respect to the dotted blue curve. The phase of the sinusoid would likewise be "retarded" if the phase angle were negative. Note that the view angle

Slant, Amplitude and Phase Determination

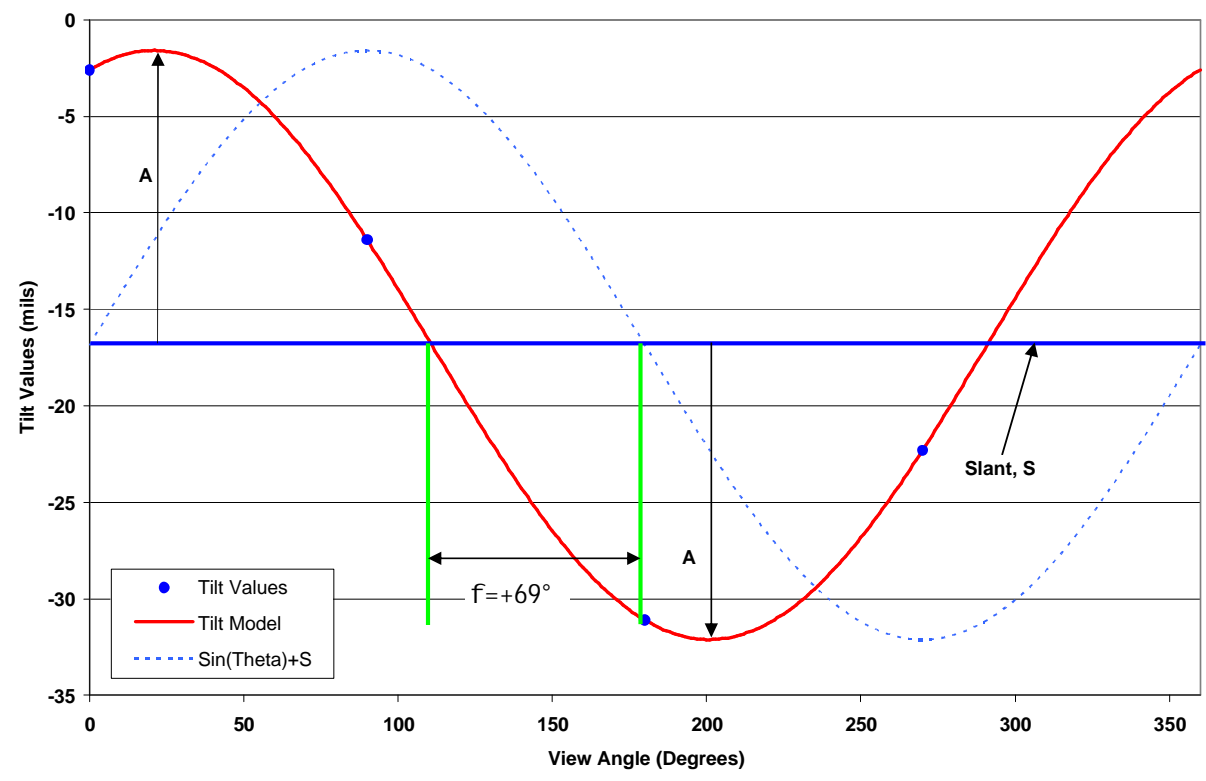

Figure 6: Illustration of the Optimal View Model showing the relationship between slant, phase angle, view angle, and wobble amplitude.

of maximum tilt is given by $\theta+\phi=90$. The view with the maximum tilt is the optimal view angle, $\theta_{\text {opt }}$. Therefore, once the phase angle $\phi$ is known the optimal view angle is obtained from the following equation.

$$
\theta_{\text {opt }}=90-\phi
$$

For example, if $\phi$ is +69 degrees then the view angle of maximum tilt is about 21 degrees. Thus, 21 degrees would be the optimal view angle, yielding the minimum dead zone. In reference to Figure 6, the optimal view angles are indicated in the two locations with the 
arrows labeled "A". These locations are at 21 degree and 201 degrees $(21+180$ degrees).

Since the traditional software was being used for the pressure tests and 21 degrees is not one of the four cardinal views, the following procedure was used to obtain the desired optimal view. Looking at the top of a 3013 can, the burr ring is in the twelve o'clock position and is centered in the 0 degree view. The 90 degree view corresponds to the 3 o'clock position. Thus, 21 degrees is roughly at the 1 o'clock position. It was arbitrarily decided to put the view of maximum tilt at the 90 degree view. To do this, the stage is rotated the negative value of the phase angle, in this case -69 degrees, which in the ADRIS is a clockwise rotation. This has the effect of moving the position of optimal view at 21 degrees to the 3 o'clock position (or 90 degree view). The index on the rotary stage is then reset to zero. Now when the traditional software is run, the 90 and 270 views will have maximum left-right tilt, minimum fore-aft tilt, and a zero or minimal dead zone. Conversely, the 0 and 180 views will have minimal left-right tilt and maximum dead zone because most of the tilt will be along the source-to-scintillator axis. The 90 and 270 views at the optimal alignment are then averaged to obtain the deflection at the optimum angle. This procedure will be automated in future versions of the ADRIS software, and thus will be "transparent" to the operators.

The calculations needed for using this model will now be discussed. The first requirement of the model is to obtain the slant, $S$. This is accomplished using TrM to obtain the values of tilt measured by the DR system at the four views, given in Table 1 below. These values correspond to the graph in Figure 6.

Table 1: View angle and DR measured tilt values for use in sample calculations (from bottom tilt values in Figure 4).

\begin{tabular}{|c|c|}
\hline$\theta$ & Tilt \\
(mils) \\
\hline 0 & -2.59 \\
\hline 90 & -11.37 \\
\hline 180 & -31.13 \\
\hline 270 & -22.33 \\
\hline
\end{tabular}

Substituting each of the 4 cardinal view angles into Eqn. (2) and applying some trigonometric relations results in the following relationships:

$\mathrm{T}(0)=\mathrm{S}+\mathrm{A}^{*} \sin (0+\phi)=\mathrm{S}+\mathrm{A}^{*} \sin (\phi)$

$\mathrm{T}(90)=\mathrm{S}+\mathrm{A}^{*} \sin (90+\phi)=\mathrm{S}+\mathrm{A}^{*} \sin (90+\phi)=\mathrm{S}+\mathrm{A}^{*} \cos (\phi)$

$\mathrm{T}(180)=\mathrm{S}+\mathrm{A}^{*} \sin (180+\phi)=\mathrm{S}+\mathrm{A}^{*} \sin (180+\phi)=\mathrm{S}-\mathrm{A}^{*} \sin (\phi)$

$\mathrm{T}(270)=\mathrm{S}+\mathrm{A}^{*} \sin (270+\phi)=\mathrm{S}+\mathrm{A}^{*} \sin (270+\phi)=\mathrm{S}-\mathrm{A}^{*} \cos (\phi)$

It can then be shown that

$$
S=\left[\frac{T(0)+T(180)}{2}\right] \text { or } \quad S=\left[\frac{T(90)+T(270)}{2}\right]
$$


Insertion of the values in Table 1 into Eqn. (3) results in a value of -16.85 mils for $\mathrm{S}$.

$$
S=\left[\frac{-2.6-31.1}{2}\right]=-16.85 \text { or } \quad S=\left[\frac{-11.4-22.3}{2}\right]=-16.85
$$

Now that a value for $\mathrm{S}$ has been determined, $\mathrm{W}(\theta, \phi)$ can be found from the following relationships obtained using a rearranged form of Eqn. (1):

$$
\begin{gathered}
\mathrm{W}_{0}=\mathrm{W}(0, \phi)=\mathrm{T}(0)-\mathrm{S}=-2.6-(-16.85)=14.25 \\
\mathrm{~W}_{90}=\mathrm{W}(90, \phi)=\mathrm{T}(90)-\mathrm{S}=-11.4-(-16.85)=5.45 \\
\mathrm{~W}_{180}=\mathrm{W}(180, \phi)=\mathrm{T}(180)-\mathrm{S}=-31.1-(-16.85)=-14.25 \\
\mathrm{~W}_{270}=\mathrm{W}(270, \phi)=\mathrm{T}(270)-\mathrm{S}=-22.3-(-16.85)=-5.45
\end{gathered}
$$

Now the phase angle $(\phi)$, and amplitude (A) must be found. Let

$$
\begin{aligned}
& \mathrm{W}_{0}=\mathrm{W}(0, \phi)=\mathrm{A} \sin (\phi) \\
& \mathrm{W}_{90}=\mathrm{W}(90, \phi)=\mathrm{A} \sin (90+\phi)=\mathrm{A} \cos (\phi) \\
& \mathrm{W}_{180}=\mathrm{W}(180, \phi)=\mathrm{A} \sin (180+\phi)=-\mathrm{A} \sin (\phi) \\
& \mathrm{W}_{270}=\mathrm{W}(270, \phi)=\mathrm{A} \sin (270+\phi)=-\mathrm{A} \cos (\phi)
\end{aligned}
$$

It can then be shown that using the equations for $\mathrm{W}_{0}$ and $\mathrm{W}_{180}$, that

$$
\sin (\phi)=\left(\mathrm{W}_{0}-\mathrm{W}_{180}\right) / 2 \mathrm{~A}
$$

and using the equations for $\mathrm{W}_{90}$ and $\mathrm{W}_{270}$, that

$$
\cos (\phi)=\left(\mathrm{W}_{90}-\mathrm{W}_{270}\right) / 2 \mathrm{~A} \text {. }
$$

Using these two new equations to solve for $\phi$, we find:

$$
\phi=\tan ^{-1}\left[\frac{\left(W_{0}-W_{180}\right)}{\left(W_{90}-W_{270}\right)}\right]
$$

Insertion of the values from Table 1 into Eqn. (4) yields the phase angle.

$$
\phi=\tan ^{-1}\left[\frac{14.25-(-14.25)}{(5.45-(-5.45))}\right]=\tan ^{-1}(2.6147)=69.07^{\circ}
$$

It should be noted, that the same result is obtained by using the ratio of $\mathrm{W}_{0}$ and $\mathrm{W}_{90}$ only. In this case the numerical values are redundant, however, this is not always the case and using all four values gives a better estimate of the phase angle. This phase angle is then used to obtain the optimal alignment as described above. 
The amplitude (A) of the wobble, can be determined by substitution into any of the $\mathrm{W}_{\theta}$ equations above. For example, $\mathrm{W}_{0}=\mathrm{A} \sin (\phi)$ yields the following when solved for $\mathrm{A}$ :

$$
\mathrm{A}=\mathrm{W}_{0} / \sin (\phi)=14.25 / \sin (69.07)=15.26 \text { mils }
$$

The amplitude is not explicitly used in the method but its value provides some insights. Comparison of the magnitude of the wobble amplitude and the magnitude of the lid deflection will indicate whether there is a dead zone issue. For example, if the wobble amplitude is 15 mils and the lid deflection is - 30 mils (concave), then the wobble of the lid will not present a problem. Conversely, if the wobble amplitude were 60 mils then the wobble of the lid will create a dead zone and the optimal view method will be necessary.

The last issue associated with this method is to use the tilt values obtained in the AIM orientation to calculate the "residual phase." Ideally, the residual phase would be zero, but in reality it usually is not. The reason for this is that a point on the lid does not perfectly describe a sine wave as it is rotated. This is most likely due to warp of the lid, which is defined as deviation of the lid from a flat form. If the residual phase is not zero, the technique can be repeated iteratively to reduce the residual phase and obtain a more accurate measure of the deflection. In practice, it was found that the technique is relatively insensitive to residual phase and improvements to the deflection measure were generally second order corrections; nonetheless, a maximum residual phase of ten degrees is sought.

In a few cases, it was found that the iterative method resulted in an oscillating residual phase. For example, after the first iteration the residual phase angle may have been +15 degrees. Therefore the rotary stage was rotated -15 degrees and the AIM method was repeated. The residual phase was then computed to be -15 degrees. This would then require a +15 degree rotation, thus ending up at the starting point. Rather than continue this process, the second set of AIM data was used. From a practical standpoint though, the iterative process generally improved the deflection measure when compared to mechanical, and even for the cases where the residual phase oscillated the DR measured deflection tracked the mechanical measurements.

\subsection{Description of Alternate Methods of Image Analysis}

The overall program to mitigate the dead zone included efforts to evaluate alternate methods of analyzing the image data acquired by the ADRIS in order to optimize measurement capabilities. The various methods evaluated are described below.

\subsubsection{Summation Method}

In addition to the two imaging techniques, the data have been analyzed by the traditional analysis (TrA) and various alternate analysis method (AAM) techniques. As mentioned earlier, TrA averages the four bottom deflection values only. For AAM, a technique called Summation has been tested. The summation technique involves adding the top and bottom deflections before calculating the change in deflection from the baseline. The 
concept evolved from the following rationale. Given an initially concave lid, the bottom profile will be responsive to pressurization, but the top also being concave will be hidden from view by the perimeter of the lid and will remain fairly constant. Conversely, when the lid becomes convex the top will be responsive but the bottom profile will be hidden from view and will remain constant. Thus, by summing the top and bottom there will always be some response. Furthermore, by calculating and plotting the change in deflection from the baseline deflection value, contributions to the sum by a fairly constant top or bottom will be cancelled. This will be shown to be true when the pressure test data are reviewed later in this report. It should be noted that the summation technique was used in the pressure tests reported in this document, but for other purposes such as relating Hanford baseline measurements to the initial surveillance deflection values summation may not be as appropriate.

\subsubsection{Center Measure}

The traditional analysis method finds the maximum lid deflection regardless of where it occurs in the lid profile. Over time when a can becomes pressurized, the location of this maximum deflection may change, especially when the lid approaches flat and transitions to convex. Furthermore, the locations of maximum deflection for the top and bottom profiles may be different which impacts the use of the summation technique. As an alternative to the maximum deflection approach, the data was also analyzed such that the deflections were measured in the center $10 \%$ of the lid diameter. This technique will be referred to as Center Measure.

\subsubsection{Selected View Technique}

In line with the reasoning associated with the optimal view concept, the phase angle can be used to "select" the two views of the traditional 4 views that have the least, although not optimal, dead zone. This method will be referred to as the Selected View technique. For example, if the phase angle is 0 degrees then the 90 and 270 views have the maximum tilt and minimal dead zone and are the favored views. If the phase angle is 90 , then the 0 and 180 views have the maximum tilt and minimal dead zone and are the favored views. For a phase angle of 45 degrees, all images are about equally affected by the dead zone. Thus, for a phase angle between 0 and 45 the 90 and 270 views are used and for a phase angle between 45 and 90 the 0 and 180 views are used. In general, the closer the phase angle is to 0 or 90 the better the result, and the worst result is when the phase angle is 45 degrees. Furthermore, the impact of a phase angle deviation, from the 0 or 90 degree ideals, increases as the wobble amplitude increases. For example, if the wobble amplitude is near zero (i.e., a level lid) then the phase is not important because there is no dead zone. As the amplitude becomes significant compared to the deflection, the more sensitive the technique will be to the phase angle.

\subsubsection{Alternative Span Widths for Measurement Basis}

In the current version of the ADRIS software (V1.2), an extrapolation of the lid profile is performed to locate the inside corners of the lid at a 4.5-inch span. The details of corner 
finding extrapolation have been detailed in References [4] and [5]. The corner points are used to establish a "virtual" reference line from which the deflection is measured. The distance between the corner points is the measurement span width. Since the software cannot detect the profiles near the corner of the inner can because of the high x-ray attenuation in this region, the software extrapolates the profiles from the span that is reliably found to the 4.5 -inch span. The span from which this extrapolation occurs may vary from can-to-can. The software uses the slope calculated from the extreme $20 \%$ of data at the edges of the reliably measured profile to perform a linear extrapolation to the inside corner of the inner can lid at a diameter of about 4.5 inches. (This was established to match the can lid outer diameter.) The data were analyzed with a 4.5 -inch span and a 3.8-inch span. The 3.8-inch span corresponds to the span on which the mechanical measurement was made as will be discussed in the Section 4.0.

\subsection{Description of Pressure Testing}

The ten cans that were used in the pressure tests were welded at SRS using the EES Department developmental bagless transfer can (BTC) welding machine. Fluor-Hanford supplied the cans and lids from several different production lots, so as to provide independent samples. The original intent with the fabrication of these cans was to obtain relatively flat lids, which have been seen to exhibit the dead zone phenomenon in production.

After welding, each can was imaged on the DR system to determine concavity. It was found that even though the flattest lids were selected for welding the resulting cans had initial concavity in the -17 to -31 mil range. Due to this result, it was decided to add a large intentional tilt on the lids of two additional cans, so that they would be in the dead zone at or near ambient pressure. This was achieved by the application of a force (using elastic bands) near the top of the threaded rod that is used to insert the lid into the can. The tilt values were measured as 56 and 68 mils and were about a factor of 3 larger than the initial deflections. For the remaining eight cans, higher pressure was required to force them into the dead zone due to the large initial concavity. Consequently, the pressure tests were conducted from 0 psig to a maximum of 280 psig in some cases.

Table 2 lists the serial numbers of the 10 lid/can combinations that were part of the pressurization tests. The pressure test results are reported by the lid serial number. After the lids were welded to the can, a hole was drilled in the bottom of the can near the center to accept a pressure tap in the form of $1 / 4$-inch diameter steel tube. The steel tubes were hand welded to the bottom of the cans. Figure 7 shows a schematic diagram of the setup of the pressurization apparatus used in the tests. This figure shows the BTC inserted in a 3013 shell, which was secured to a rotary stage. The rotary stage has an opening or aperture to allow clearance of the pressure tap. The purpose of the 3013 outer shell was to provide similar radiographic conditions as the actual 3013 package. A flexible (polyethylene) tube connected the pressure tap on the can and the balance of the pressurization apparatus outside of the x-ray shielding enclosure. The polyethylene tube penetrates the enclosure through an existing baffle for electrical cabling. The pressure 
Table 2: List of Lid/Can Serial Numbers used in Pressure Tests.

\begin{tabular}{|c|c|c|}
\hline No. & Lid S/N & Can S/N \\
\hline 1 & P1458 & H7675 \\
\hline 2 & P1947 & H7674 \\
\hline 3 & P1958 & H7670 \\
\hline 4 & P1962 & H7676 \\
\hline 5 & P2714 & H7656 \\
\hline 6 & P3370 & H7664 \\
\hline 7 & P3373 & H7659 \\
\hline 8 & P3379 & H7669 \\
\hline 9 & P3381 & H7662 \\
\hline 10 & P3382 & H7673 \\
\hline
\end{tabular}

source for the experiments was a nitrogen gas cylinder. The system was protected from over pressurization by a 300 psig pressure relief valve (PRV). Pressure measurements were made using a Druck DPI 602 pressure transducer ( 0 to 300 psig range). The remaining components were a shut-off valve, isolation valve, and vent valve.

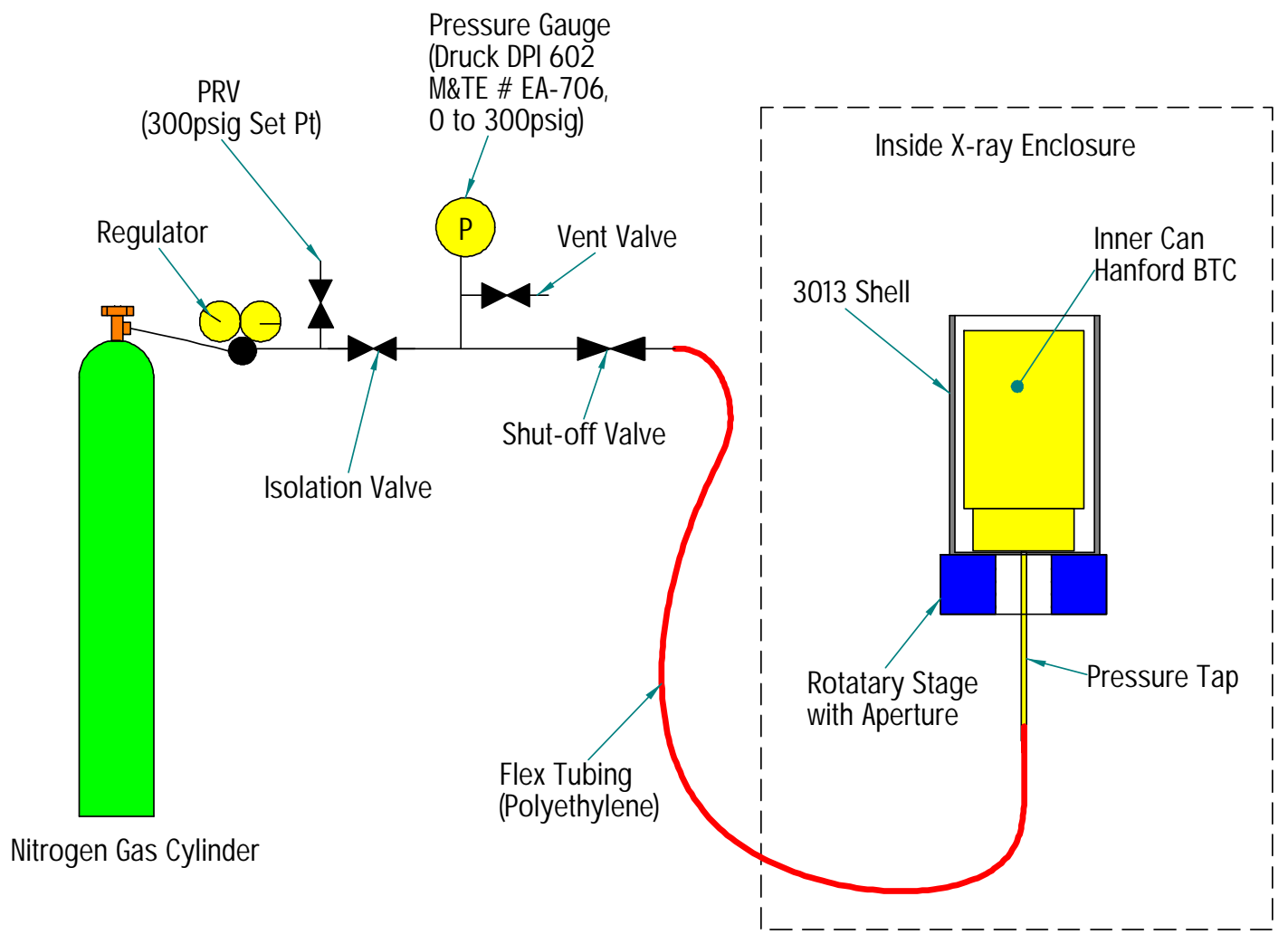

Figure 7: Schematic diagram of the experimental setup for can pressurization. 


\subsection{Experimental Procedure}

The detailed standard procedure used for the 10 can test is listed below:

1) The can was loaded in the DR booth inside a 3013 outer can shell, which was attached to the rotary stage as shown in Figure 7. Loading also included connection of the pressure tap to the flexible tubing of the pressurization apparatus.

2) With the x-ray machine and ADRIS software running, the burr ring gap was "zeroed" by pressing the ADRIS "Zero Button." This aligned the burr ring gap on the source-to-scintillator axis closest to the x-ray machine. The rotary stage position index was automatically reset to zero at this location. This orientation was previously shown in Figure 3, which also shows the direction of positive rotation as being counterclockwise when viewed from the top of the can.

3) A deflection inspection was performed using the current ADRIS software by pressing the "DefInsp Button." This inspection will be referred to as the Traditional Inspection.

4) After the traditional inspection was completed, the rotary stage was in the 270 degree position. Normally, the next can would be loaded and zeroed as described above, but in these tests there was additional imaging work to be performed. Thus, it was necessary to re-orient the burr ring to the zero degree position (oriented toward the x-ray source) to provide a known starting position for the other imaging techniques. The stage control software was used to rotate the rotary stage -270 degrees or back to the zero degree index.

5) The tilt values acquired from the traditional imaging at the four cardinal views $(0$, 90,180 , and 270 degrees) were used to determine the phase, amplitude, and slant of the can lid. This procedure has been thoroughly explained in a previous section of this report. This calculation process was automated by creating a LabVIEW program to perform the analysis by reading the data files directly. This sped up the process and reduced the chances for calculation errors.

6) The rotary stage was rotated an amount equal to the magnitude of the calculated phase angle but in the opposite direction using the stage control software. For example, if the phase angle was +75 degrees, the stage was rotated -75 degrees, which in the convention of this stage is a clockwise rotation. The reason for this rotation will be explained in the next step.

7) The rotary stage index was reset to "zero" without moving the rotary stage. Thus, the burr ring gap was not in the zero degree location (i.e., along the sourcescintillator axis) as was the case in the traditional inspection, which zeroed the burr ring. The combination of the negative phase angle rotation and resetting the 
stage index had the net effect of placing the maximum tilt in the 90 degree view. Hence, the 0-180 axis had the largest "dead zone" and the 90-270 axis had minimal or no "dead zone."

8) A deflection inspection was performed using the traditional software in this "optimized" stage alignment. This inspection will be referred to as the AIM Inspection. Under these conditions, the 90-270 axes provided an accurate deflection measurement and were used as the AIM measurements. Conversely, the 0-180 axes were most corrupted by the tilt of the lid and were not used, but are reported for completeness.

9) The residual phase angle was calculated using the AIM tilt values. If the residual phase was less than ten degrees then Step 10 was performed. If the residual phase was greater than about 10 degrees, another iteration was performed by returning to Step 6. If it was determined that the residual phase was oscillating, as described previously, iterations were discontinued and Step 10 was performed. In either case, the final set of deflection data was used.

10) After the AIM DR deflection measurements were made, the $x$-ray machine was deactivated to allow entry into the $x$-ray machine shielded enclosure (booth). The vertical stage (z-axis) was raised 1.55 inches so that three dial indicators contacted the top of the lid. The dial indicator readings were recorded manually at the $0,90,180$, and 270 AIM locations by rotation of the stage under the stationary dial indicators. Due to the position of the stage at the beginning of the inspection (optimized for AIM), the mechanical measurement coincide with the AIM axes for deflection values. The vertical axis was lowered 1.55 inches to remove the dial indicators from contact with the lid in preparation for the next step. Explanation of the dial indicator setup used to make the mechanical lid deflection measurements is fully documented in Section 4.0 of this report.

11) Following the dial indicator readings, the pressure was increased to the next pressure step and the process was repeated starting at Step 2. The size of the pressure step was varied relative to the lid flatness. For instance, when the lid approached being near flat or it seemed to entering the dead zone, the pressure step was reduced to approximately 10 psig to provide higher resolution data in this area of interest. Outside the area of interest, the pressure steps were generally larger usually 20 to $50 \mathrm{psig}$. In addition, each can had a different initial deflection, and the region of interest varied so that pressure range for the smaller pressure step had to be determined interactively during the test. If this was the last pressure step, the can was vented to relieve the pressure and unloaded from the DR booth and the process was repeated from Step 1 on a new can.

\subsection{Description of Mechanical Deflection Measurement}

Provisions were made to perform mechanical measurements of the lid deflection for comparison with the DR measured deflection, to judge the efficacy of the newly 
developed techniques. This section provides a thorough description of the mechanical measurement apparatus and analysis to arrive at the lid deflection measure. All of the raw data and calculations for the mechanical lid deflection are provided in Appendix 1 for review. In Appendix 1 there is one page for each can. On each page there are two tables. Table A contains the raw data which includes the can serial number, the date and time the data was collected, the internal pressure of the can in psig, and three dial indicator readings at each of the four cardinal views. Table B contains the necessary calculations to arrive at the final mechanical deflection measures. These calculations will be described in detail below. The apparatus for measuring mechanical deflection is shown below in Figure 8.

The dial indicators were labeled P1, P2, and P3. P2 was located in the center of the lid. $\mathrm{P} 1$ and $\mathrm{P} 3$ were located on the diameter of the lid near the burr ring. The center-to-center distance between P1 and P3 was 3.8 inches. Figure 8 shows that dial indicators P1 and P3 define a reference line for the lid that works for tilted or untilted lids.

Prior to making deflection readings, the dial indicators were adjusted to "zero" reading on a steel "dimensional flat." This was accomplished by lowering the vertical stage from the DR position by the thickness of the dimensional flat (about 0.5 inches). The dimensional flat was placed on top of the 3013 outer shell. The vertical stage was driven up 1.55 inches. The value of 1.55 inches was selected so that all three dial indicators were well within their reading range, and would remain responsive to the lid within the expected variation range. For example, if the stage is not raised enough it would be possible for the dial indicators to stop responding as they disengage from the surface of the lid due to tilt of the lid. The dials on all three indicators were rotated to provide a "zero" reading on the dimensional flat. The vertical stage was lowered 1.55 inches and the dimensional flat was removed. The stage was then raised the thickness of the dimensional flat to return the vertical axis to the DR position.

Subsequent to the "flat calibration" differences in dial indicator reading then describe the lid shape. It should be noted that dial indicator readings between measurements cannot

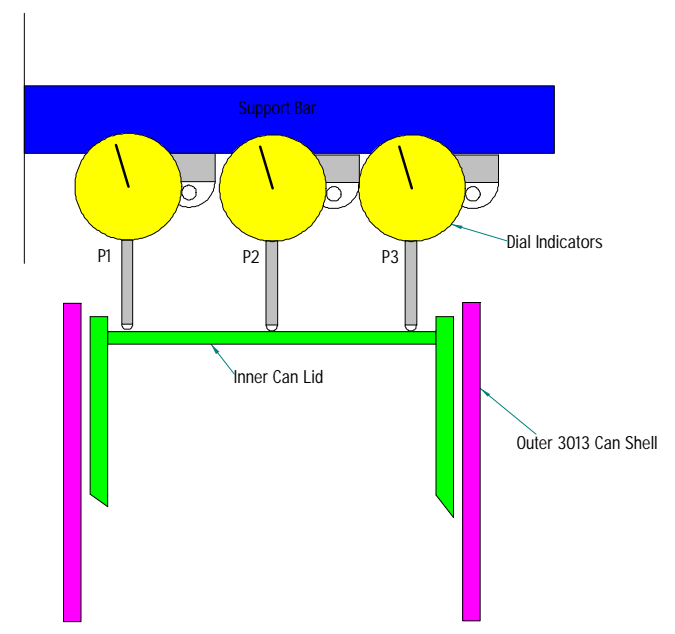

Figure 8: Schematic diagram of dial indicator setup. 
be directly compared. The reason for this was that the ADRIS software automatically adjusted the can height to ensure that the bottom of the inner can lid was tangent to the xray beam center line. Thus, the ending vertical stage position varied slightly before the stage was moved up the fixed 1.55 inches to make the dial indicator readings. This slight difference in starting location does not impact the quality of the readings. But it does preclude comparison of the raw measurements. However, the calculated lid deflection can be compared.

As mentioned in the previous section, the dial indicator readings were made after the AIM deflection inspection in each of the four cardinal views. Thus at each pressure step there are a total of twelve readings. These values were recorded by hand on data sheets and later were manually entered into the Excel spreadsheets containing the DR pressure test results for each can tested.

The process for calculating lid deflection from the dial indicator readings will now be described. For an untilted lid, as shown in Figure 9(a), the readings on P1 and P3 will be identical and the difference between $\mathrm{P} 2$ and either P1 or P3 will yield the lid deflection. For a tilted lid, as shown in Figure 9(b), the line between P1 and P3 describes a tilted reference line. The deflection is then measured between $\mathrm{P} 2$ and the midpoint value between the $\mathrm{P} 1$ and $\mathrm{P} 3$ readings.
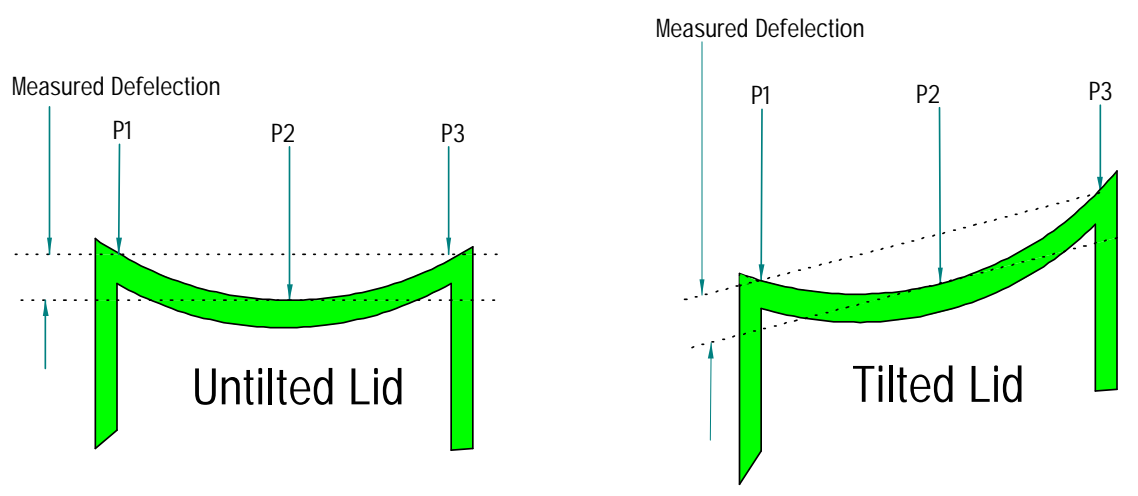

Figure 9: (a) Lid with no tilt. (b) Lid with tilt.

At this point, it is worthwhile to illustrate the calculation of lid deflection from the raw data. Table 3 shows a set of dial indicator readings, which were extracted from Appendix 1, Table A for S/N P1458 in the 0 degree view at 0 psig. It should be noted that the dial indicator readings increase as the can lid moves in the upward direction. Thus, for a concave, untilted lid P2 will be the smallest reading as is the case in Table 3.

\section{Table 3: Dial Indicator Readings (in units of inches) for Can P1458 (0 degree view and 0 psig)

\begin{tabular}{|c|c|c|}
\hline P1 & P2 & P3 \\
\hline 0.4290 & 0.3990 & 0.4305 \\
\hline
\end{tabular}

In the orientation that these readings were made, lid tilt is defined as: 


$$
\text { Tilt }=\mathrm{P} 1-\mathrm{P} 3=0.4290-0.4305=-0.0015
$$

The center value between $\mathrm{P} 1$ and $\mathrm{P} 3$ to be used as the reference for the deflection at P2 is:

$$
\text { Center }=1 / 2(\text { Tilt })+\mathrm{P} 3=1 / 2(-0.0015)+0.4305=0.4298
$$

Finally, the deflection is calculated as:

$$
\text { Deflection }=\mathrm{P} 2-\text { Center }=0.3990-0.4298=-0.0307 \text { inch or }-30.7 \text { mils }
$$

Note that the minus sign indicates a concave lid. The values calculated in Eqns. 5, 6, and 7 are recorded in Table B under the 0 degree view with the appropriate column headings of "tilt, center, and deflection."

These calculations are repeated in Table B for the 90, 180, and 270 degree views for each pressure step. The last three columns, in Table B, show the average deflection (converted from inches to mils) for the 0-180 axes, the 90-270 axes, and the overall average. The overall averages, in the last column, were the values used for comparison with DR.

Also included in Appendix 1, Figure A1.1 is a printout from a sample spreadsheet (P3382) in which the cell numbers and formulas are explicitly shown. This page can be used to verify that the calculations were performed as indicated in this document.

A final point must be made regarding the deflection measurement as depicted in Figure 9. In that figure, the $\mathrm{P} 2$ displacement is not measured perpendicular to the reference line between P1 and P3 for a tilted lid. However, because the actual amplitude of the tilt is small relative to the can diameter, no correction needs to be made. This can be shown to be true by examination of Figure 10. The maximum tilt amplitude in the pressure test can population was less than 70 mils or 0.07 inches. Using a diameter of 4.5 inches, the tilt angle $\alpha$ is obtained from $\arctan (0.07 / 4.5)$ or $0.891^{\circ}$. The corrected value for $\mathrm{P} 2$ is denoted as $\mathrm{P} 2$ ', and is given by $(\mathrm{P} 2) \cos (\alpha)$ or $0.9999 \mathrm{P} 2$. Thus, ignoring this correction in the deflection calculations is justified.

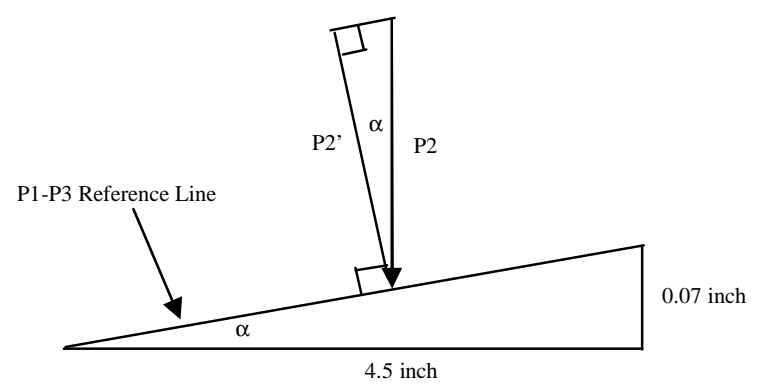

Figure 10: Diagram showing lid tilt angle and correction for P2 nonperpendicularity. 
Lastly, Figure 11 and Figure 12 show the dial indicator setup in the DR position and the mechanical deflection measurement position respectively.

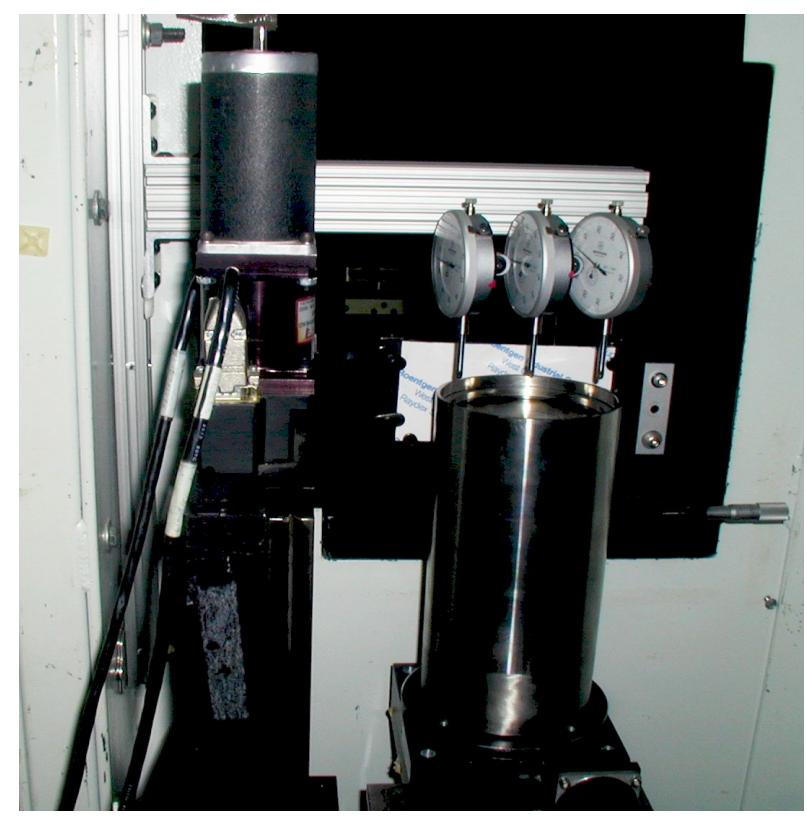

Figure 11: Photo of BTC inside outer 3013 shell in DR position; dial indicators above.

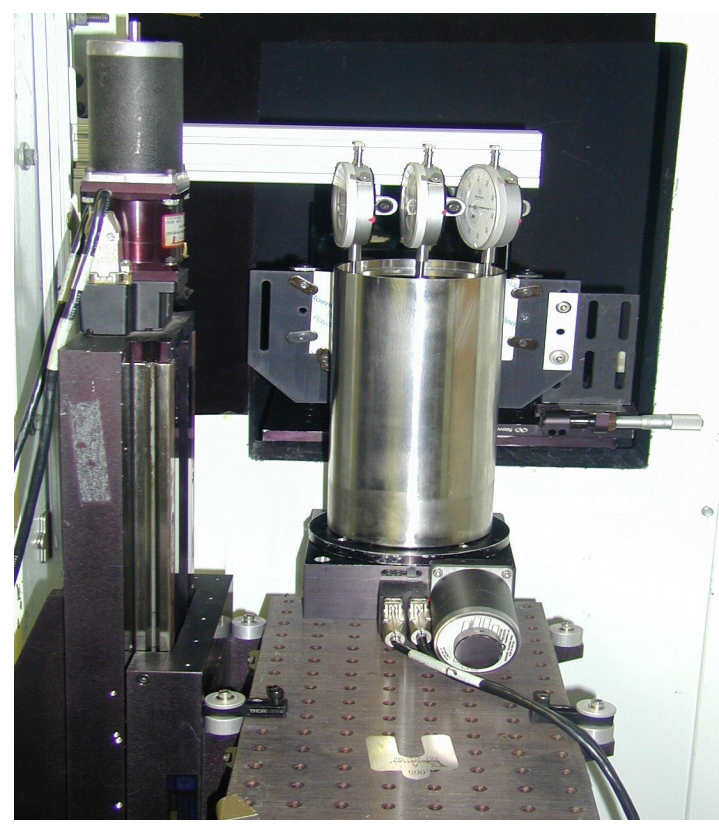

Figure 12 Digital photo with can in position for dial indicator measurements. 


\subsection{Results and Discussion}

Two sets of imaging data, traditional and AIM, were collected using the experimental procedure outlined above. These two sets of data were processed in two ways. The first analysis method employed the maximum deflection algorithm and the 4.5-inch corner finding (MD-CF) algorithms which are currently utilized in the ADRIS software. These results were available in the inspection reports generated immediately following data collection.

The second analysis method utilized the center measure algorithm and 3.8-inch span with no corner finding extrapolation (CM-NCF). To be precise, NCF means that the profile was not extrapolated to a span of 4.5 inches, but there may or may not have been an extrapolation to the 3.8-inch span. This analysis was performed off-line after data collection by running the raw images through the Deflection Inspection Player, a LabVIEW program that allows alternate processing of the raw data. This program has a button which allows the user to select between the maximum deflection and center measure algorithms and also allows the user to set the lid diameter (3.8 or 4.5 inches). The span for the top and bottom profiles for the CM-NCF analysis was 3.8 inches. This span corresponds to the span between the P1 and P3 dial indicators, which comprise the mechanical deflection reference line span. Consequently, the mechanical data should correlate best to the CM-NCF results for two reasons.

First, the center measure algorithm restricts the deflection measurement to the center $10 \%$ of the profile, essentially in the area of the P2 dial indicator. Conversely, the maximum deflection algorithm searches for the maximum deflection value regardless of its location on the profile. It should be expected that a larger deviation between mechanical and DR measured deflection will result when there is no assurance that the two measurements are made physically in the same area on the lid.

Second, the absolute deflection depends on the span for the reference line. This is illustrated in Figure 13. The solid blue curve is an actual lid profile obtained using corner finding (i.e., 4.5 -inch span). This curve shows an initial deflection of -33.6 mils. The dotted blue curve shows a profile for a pressurized (simulated) can also on the 4.5 -inch span. Here the deflection is measured as -16.8 mils. Thus, the change in deflection is measured as +16.8 mils. The solid red curve is the exact same profile as the solid blue curve except that it is truncated to a span of 3.8 inches. Since the reference line is always the horizontal line between the endpoints of the profile, the entire profile is essentially shifted upwards. This has the effect of reducing the measured deflection to -26.6 mils as shown below. In addition, the pressurized profile yields a deflection of -13.3 mils for a change in deflection of +13.3 mils. Hence, it is clear that the span selected impacts both the absolute measure of the deflection as well as the measured change in deflection from baseline. This illustration drives home the point that to make a valid comparison between mechanical and DR measured deflection requires both measurements to be made on the same span, or some appropriate adjustment be made to either the DR or mechanical value. The normalization factor can be estimated as the ratio of $(-33.6 /-26.6)$ or 1.263. 
This is approximately equivalent to the $1.19(4.51 / 3.8)$ factor discussed in [VET-TM1178-04 and VET-TM-1178-06].

\section{Illustration of Reference Line Effect}

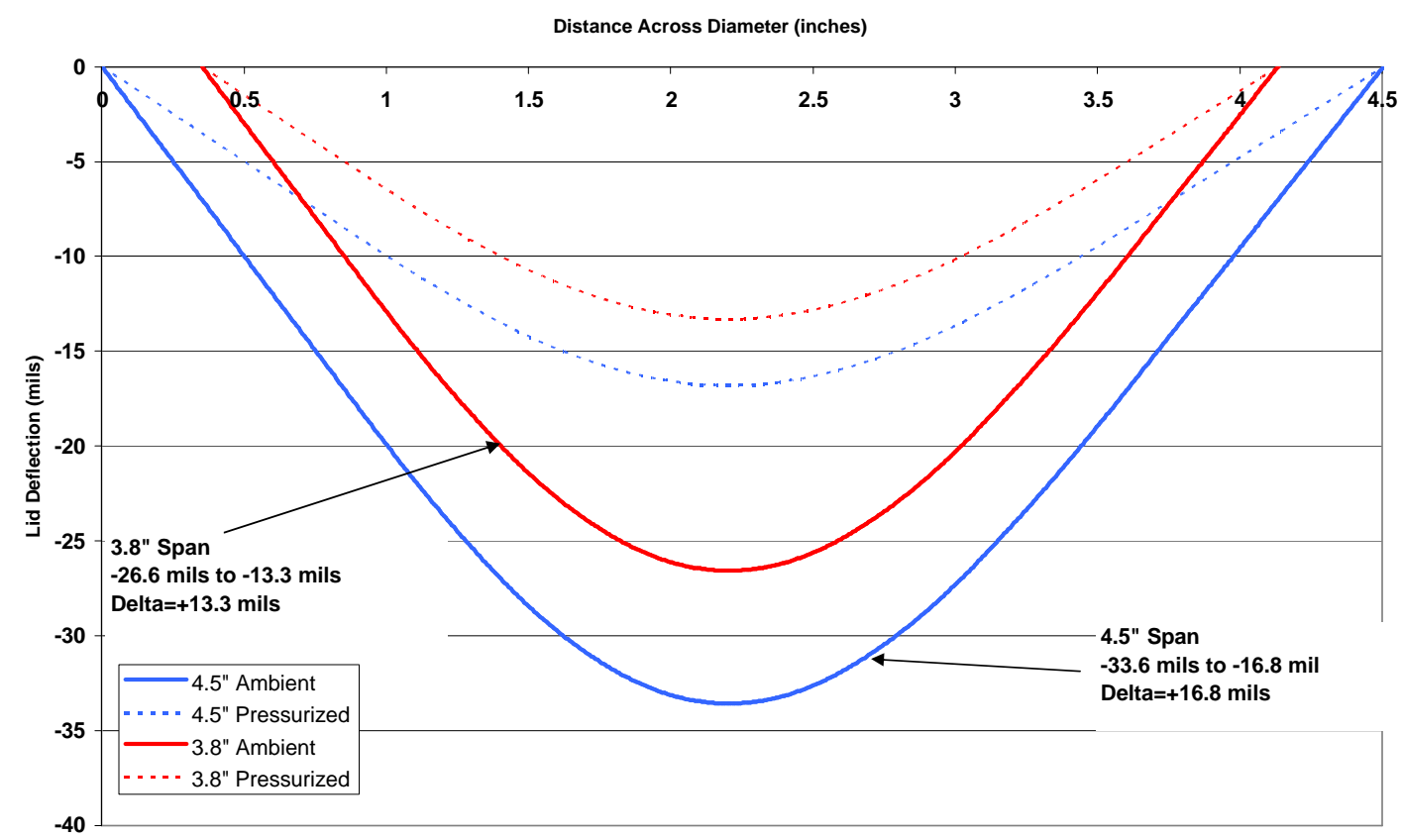

Figure 13: Illustration of the effect of profile span on the magnitude of the absolute and change in deflection.

Within each category of analysis (MD-CF and $\mathrm{CM}-\mathrm{NCF}$ ) the results for the traditional imaging method with traditional analysis (TrM-TrA), traditional imaging method with alternate analysis method (TrM-AAM), the alternate imaging method (optimal view) with alternate analysis (AIM-AAM), and mechanically measured deflection were compared graphically. The mechanical deflection data has been discussed in Section 4.0, but a description of the other curves will be described below.

The traditional imaging with traditional analysis (TrM-TRA) consisted of averaging the deflection measured from the bottom profile for the four cardinal views $(0,90,180,270$ degrees).

Traditional imaging with alternate analysis (TrM-AAM) involved the use of the summation and selected view techniques previously described. Recall that summation involves the addition of the top and bottom deflection rather than just the bottom deflection values. The selected view method utilizes the phase angle to discriminately choose two views and discard two views. The preferred axes depend on the magnitude of the phase angle. If the phase angle is less than 45 degrees then the 90 and 270 axes are preferred, and if the phase angle is greater than 45 degrees the 0 and 180 axes are preferred. Once the favored axes are determined, the two views are averaged for the top 
and bottom profiles and then the top and bottom averages are summed. It should be noted that this description of the method applies to the SRS pressure test data only. Hanford may opt to apply an alternative selected view methodology for the disposition of their 3013 containers.

Alternate imaging with alternate analysis (AIM-AAM) used the data collected at the optimal view determined by the phase angle. Here AAM involved averaging the 90 and 270 axes, which have a minimal dead zone, for the top and for the bottom deflections. The resulting top and bottom averages were then summed to obtain the DR measured deflection. A summary of the imaging and analysis techniques discussed above is provided in Table 4 for convenient reference.

Table 4: Description of the abbreviation for the Imaging and Analyses Performed.

\begin{tabular}{|c|l|}
\hline Label & \multicolumn{1}{c|}{ Description of Analysis } \\
\hline TrM-TrA & $\begin{array}{l}\text { Traditional imaging method with the traditional analysis. The } \\
\text { traditional analysis averages the 0,90,180,270 views for the bottom } \\
\text { profile only. }\end{array}$ \\
\hline TrM-AAM & $\begin{array}{l}\text { Traditional imaging technique with alternate analysis. Here AAM } \\
\text { includes the summation (of the top and bottom deflections values) } \\
\text { and selected axis algorithms. Here the favorable axis depends on the } \\
\text { phase angle. The favorable axes are the 90-270 axes if the absolute } \\
\text { value of the phase angle is < 45 degrees, or the 0-180 axes if the } \\
\text { absolute value of the phase angle is > 45 degrees. }\end{array}$ \\
\hline AIM-AAM & $\begin{array}{l}\text { Alternate Imaging Method (AIM) was used to obtain these } \\
\text { measurements and the Alternate Analysis (AAM) method was used } \\
\text { for data analysis. Here AAM refers to summation of the top and } \\
\text { bottom deflections. For the technique developed for AIM, the 90- } \\
\text { 270 axes are used for the deflection measurement. }\end{array}$ \\
\hline
\end{tabular}

The graphs illustrating the comparison of techniques within the CM-NCF category will be provided within this section of the document. The supporting spreadsheets which show all calculations necessary to arrive at the graphs from the raw data are contained in Appendix 2. The graphs and supporting spreadsheet for the MD-CF category are provided in Appendix 3 and 4, respectively, for completeness, but it should be emphasized that the CM-NCF results show better correlation with the mechanical deflection measurements for the reasons discussed above.

Before reviewing the graphs for the 10 pressure tests with the CM-NCF analysis, it will be instructive to examine a sample Excel worksheet to see the progression from raw data to the curves on the charts. Figure 14 depicts a sample spreadsheet for S/N P1458 for the $\mathrm{CM}-\mathrm{NCF}$ analysis. This is indicated in the tables by the headings. The 3.8-inch span indicates that there was no corner finding $(\mathrm{NCF})$ and center deflection measure is specified (CM). 
The data in Figure 14(a) is populated from a log file that is created at the time the data is analyzed by the ADRIS software or in the case of post processing when the Deflection Inspection Player is run. In this case the traditional imaging data was run through the Player with the Center Measure Button selected and the span reduced to 3.8 inches, which effectively turns-off corner finding and restricts the deflection measurement region to the center $10 \%$. The first three columns in Figure 14(a) list the can $\mathrm{S} / \mathrm{N}$, date and time the data was collected. The fourth column shows the pressure in units of psig for the test. The next eight columns represent the deflection and tilt values in mils for the bottom profile at the four cardinal views. The last eight columns provide the same information as the previous eight except for the top profile. There are no formulas in this table only raw data.

The data in Figure 14(b) is the same as the data in Figure 14(a) except that it is populated by the DR data taken with the AIM (optimal view) technique. The values in Figure 14(c) are calculated from the raw data in Figure 14(a) and (b).

To assist in the explanation of the values in Figure 14(c)and (d), a sample spreadsheet is included in Appendix 2 as Figure A2.1 that shows the row and column assignments and cell formulas used in the underlying spreadsheets. The formulas follow the algorithms which have been fully explained previously. All the entries in Tables A and B of Figure A2.1 are numbers from the log files and thus there are no formulas to review. Also, it should be noted that when the "view formulas" format is used the time and date fields revert to an incomprehensible code unique to Excel.

In Table C of Figure A2.1 the formula in cell C35 is =Average(E4:H4) and represents the TrM-TrA value. This formula indicates that the cell value was calculated as the average of the bottom deflections, for the traditional imaging method (Table A), at the four cardinal points (E4, F4, G4, and H4) at 0 psig. The other entries in that column use the same formula except that the row number was incremented.

The formula in cell D35 is =Sum(Average $(\mathbf{F} 20, \mathbf{H} 20)$, Average $(\mathbf{N 2 0 , P 2 0}))$ and represents the AIM-AAM value. This formula represents the sum of the averages of the bottom deflections at 90 (F20) and 270 (H20) degrees and the top deflections at 90 (N20) and 270 (P20) degrees for the AIM data (Table B). The other entries in this column follow the same pattern.

The formula in cell E35 is ='Mech Data'!Q24 and represents the mechanical deflection. This formula indicates that the value for the mechanical deflection comes from cell Q24 on the worksheet entitled "Mech Data." The data for the mechanical deflection are contained in Appendix 1, and it can be verified that the mechanical deflection for $\mathrm{S} / \mathrm{N}$ P1458 at 0 psig is -30.3 mils as listed in Figure 14(c). Other entries in this column follow the same pattern. 
(a)

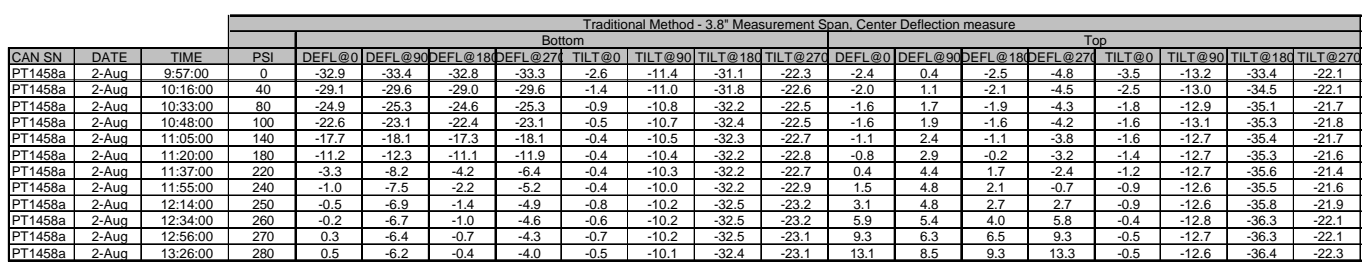

(b)

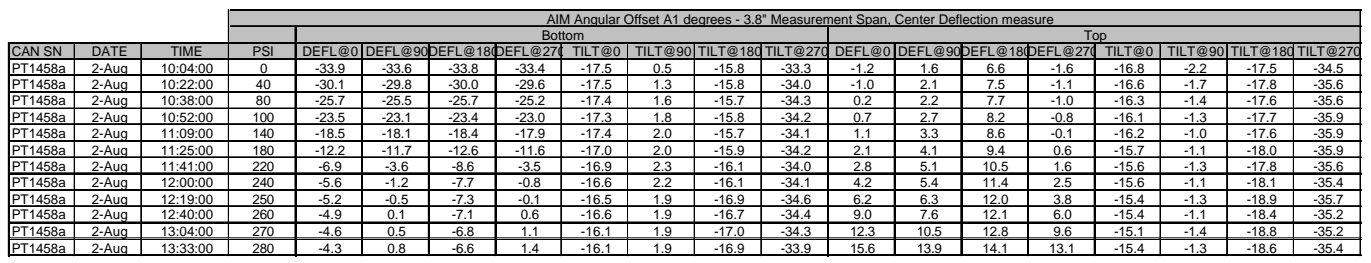

(c)

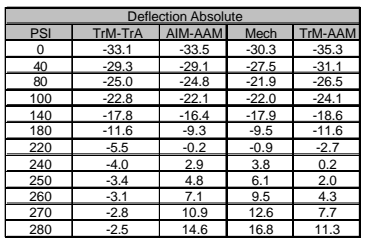

(d)

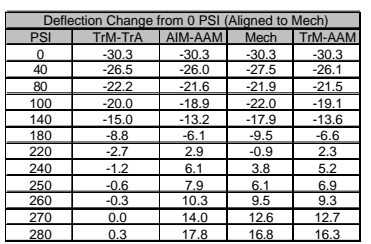

\section{Figure 14: Sample spreadsheet for S/N P1458 for the CM-NCF Analysis.}

The formula in cell F35 is =Sum(Average(E4,G4), Average(M4,04)) and represents the TrM-AAM value. This formula represents the sum of the averages of the bottom deflections at $0(\mathbf{E 4})$ and 180 (G4) degrees and the top deflections at 0 (M4) and 180 (O4) degrees for the traditional imaging data (Table A). For can S/N P1458 the phase angle was +70 degrees, thus the $0-180$ axes are the favored axes. The other entries in this column follow the same logic.

The data in Figure 14(d) derive directly from (c). Figure 14(c) provided the absolute deflection values. However, the change in deflection from a baseline value is of more interest because that is what will be tracked during surveillance of the cans. The values in Figure 14(d) are used to produce the graphs that follow this discussion. Referring to Table D in Figure A2.1, the formula in cell C61 is =C46 - C\$35 + \$E\$35 and represents the change in deflection from baseline adjusted to the initial mechanical deflection for the TrM-TrA method. The value in $\mathbf{C \$ 3 5}$ is the baseline deflection at 0 psig. The dollar sign indicates that the row assignment will not change and the change in deflection will always be measured from the 0 psig value. The quantity of $\mathbf{C 4 6}$ is the absolute deflection at 280 psig and $\mathbf{C 4 6}$ - C\$35 represents the change from baseline deflection at 280 psig. The change in deflection would range from zero to a maximum at $280 \mathrm{psig}$. However, plotting the data in this way gives no indication of the initial deflection or when the lid becomes flat. The solution to this problem is to simply add the initial mechanical (\$E\$35) deflection to the change in deflection formula, which results in the formula seen in cell C61. The same logic applies to the cells above $\mathbf{C 6 1}$ in the table. 
The formulas for the AIM-AAM method in cell D61 and the TrM-AAM method in cell F61 are of the same form as C61 and represent the change in deflection from the baseline aligned to the mechanical deflection at 0 psig. The cells for the mechanical deflection in Table D simply reference the cell numbers in Table C.

The explanation of the procedure, used to arrive at the curves on the graphs, given above also applies directly to the MD-CF data. The graphs for the MD-CF data are provided in Appendix 3 and the supporting spreadsheet data is contained in Appendix 4. A sample spreadsheet with the row and column assignments and formulas is also provided there. Due to the similarity in the calculations, no further discussion will be provided.

It was mentioned earlier in this report that the calculations to compute the slant, phase angle, and amplitude of the wobble using the tilt values from the inspection reports were performed using a LabVIEW program to automate the analysis. This program created log files which were incorporated into the spreadsheets for each can's pressure test results. A sample of a "Wobble" worksheet, for can S/N P1458, is included in Figure 15 for discussion. All worksheets for the wobble analysis are provided in Appendix 5 for review. Appendix 5 contains one page for each can that was pressure tested. Each page has the same information as that contained in Figure 15.

Figure 15, and each page in Appendix 5, contains two tables. The first is the wobble analysis results for the traditional imaging. It contains a column for the can $\mathrm{S} / \mathrm{N}$, the date and the time the data was collected, as well as the pressure for the test. In addition, the table also has the slant (S), wobble amplitude (A), and the phase angle $(\phi)$ calculated for each pressure step. The last column is labeled "Err," for error, and is basically a figure of merit of the fit to the 4 tilt values. It is not used directly but only serves as an indicator regarding the quality of the fit.

At each step, the phase angle from the traditional alignment was used to determine the optimal angle for AIM as has been discussed earlier. The phase angles were also used in the AAM selected axis algorithm to choose the favored axes for TrM-AAM. It can be seen that generally, the phase angle varied only a few degrees as the can was pressurized. The slant and wobble amplitude also only varied slightly.

The data in the second table is the same as the first except that it was derived from the AIM optimal alignment. It should be noted that the amplitude and slant numbers should be the same, but the phase angle should be zero in the optimal alignment. It can be seen that the phase angle has been reduced from a value in the range of 66 to 70 degrees to a value in the approximate range of -3 to +3 degrees. This residual nonzero phase is most likely due to deviations of the lid from the idealized shape (a flat but tilted lid) accommodated by the optimal view model. 
(a)

\begin{tabular}{|l|c|c|c|c|c|c|c|}
\cline { 5 - 8 } \multicolumn{4}{c|}{} & \multicolumn{5}{c|}{ Traditional Alignment } \\
\cline { 5 - 9 } \multicolumn{3}{c|}{} & \multicolumn{4}{c|}{ Wobble Vector } \\
\hline CAN SN & DATE & TIME & PSI & S & A & Phase & Err \\
\hline PT1458a & 2-Aug & $9: 57: 58$ & 0 & -16.38 & 15.55 & 70.01 & 0.17 \\
\hline PT1458a & 2-Aug & $10: 16: 47$ & 40 & -16.39 & 16.31 & 70.17 & 0.27 \\
\hline PT1458a & 2-Aug & $10: 33: 19$ & 80 & -16.40 & 16.78 & 69.92 & 0.27 \\
\hline PT1458a & 2-Aug & $10: 48: 19$ & 100 & -16.35 & 17.01 & 70.42 & 0.31 \\
\hline PT1458a & 2-Aug & $11: 05: 30$ & 140 & -16.36 & 17.17 & 70.02 & 0.22 \\
\hline PT1458a & 2-Aug & $11: 20: 15$ & 180 & -16.29 & 17.09 & 69.31 & 0.33 \\
\hline PT1458a & 2-Aug & $11: 37: 15$ & 220 & -16.30 & 17.08 & 68.99 & 0.28 \\
\hline PT1458a & 2-Aug & $11: 55: 30$ & 240 & -16.29 & 16.97 & 68.05 & 0.25 \\
\hline PT1458a & 2-Aug & $12: 14: 17$ & 250 & -16.63 & 16.86 & 67.38 & 0.21 \\
\hline PT1458a & 2-Aug & $12: 34: 36$ & 260 & -16.56 & 16.81 & 67.50 & 0.27 \\
\hline PT1458a & 2-Aug & $12: 56: 35$ & 270 & -16.52 & 16.62 & 67.42 & 0.26 \\
\hline PT1458a & 2-Aug & $13: 26: 38$ & 280 & -16.43 & 16.47 & 66.82 & 0.38 \\
\hline
\end{tabular}

(b)

\begin{tabular}{|c|c|c|c|c|c|c|c|}
\hline \multirow[b]{3}{*}{ CAN SN } & \multirow[b]{3}{*}{ DATE } & \multirow[b]{3}{*}{ TIME } & \multirow[b]{3}{*}{$\overline{\mathrm{PSI}}$} & \multicolumn{4}{|c|}{ Aligned position A1 -Phase TrM } \\
\hline & & & & & Wobl & lector & \\
\hline & & & & $\mathrm{s}$ & $\mathrm{A}$ & Phase & Err \\
\hline PT1458a & 2-Aug & 10:04:59 & 0 & -16.26 & 16.10 & -1.69 & 0.23 \\
\hline PT1458a & 2-Aug & 10:22:18 & 40 & -16.16 & 16.93 & -2.01 & 0.27 \\
\hline PT1458a & 2-Aug & $10: 38: 23$ & 80 & -16.20 & 17.13 & -2.29 & 0.17 \\
\hline PT1458a & 2-Aug & 10:52:56 & 100 & -16.20 & 17.32 & -2.07 & 0.12 \\
\hline PT1458a & 2-Aug & $11: 09: 54$ & 140 & -16.23 & 17.35 & -3.23 & 0.31 \\
\hline PT1458a & 2-Aug & $11: 25: 17$ & 180 & -16.24 & 17.38 & -1.83 & 0.07 \\
\hline PT1458a & 2-Aug & $11: 41: 55$ & 220 & -16.13 & 17.31 & -1.31 & 0.34 \\
\hline PT1458a & 2-Aug & $12: 00: 34$ & 240 & -16.30 & 17.52 & -0.35 & 0.07 \\
\hline PT1458a & 2-Aug & 12:19:37 & 250 & -16.70 & 17.56 & 1.52 & 0.01 \\
\hline PT1458a & 2-Aug & $12: 40: 59$ & 260 & -16.59 & 17.28 & 1.67 & 0.02 \\
\hline PT1458a & 2-Aug & 13:04:37 & 270 & -16.69 & 17.10 & 2.57 & 0.07 \\
\hline PT1458a & 2-Aug & $13: 33: 12$ & 280 & -16.64 & 16.83 & 2.77 & 0.10 \\
\hline
\end{tabular}

Figure 15: A sample of the "Wobble" worksheet. (a) Traditional alignment (b) AIM alignment.

Review of the graphs, provided in Figure 16 through Figure 25, for all ten pressure tests for the $\mathrm{CM}-\mathrm{NCF}$ analysis reveals the following general observations. First, in all ten cases the TrM-TrA curves exhibit the dead zone phenomenon, where the DR measured deflection levels off and changes little with increasing pressure while the mechanical deflection values continue to increase. The onset of the dead zone varies between the tests most likely due to differences in the initial deflection of the lid and the magnitude of the lid tilt. For lids with large initial concavity and low tilt, a pressure of 200 psig or more was required to drive the lid into the dead zone. However, for the two cans (P1958 and P3379) with the large intentional tilt the dead zone was entered as low as 80 psig. 


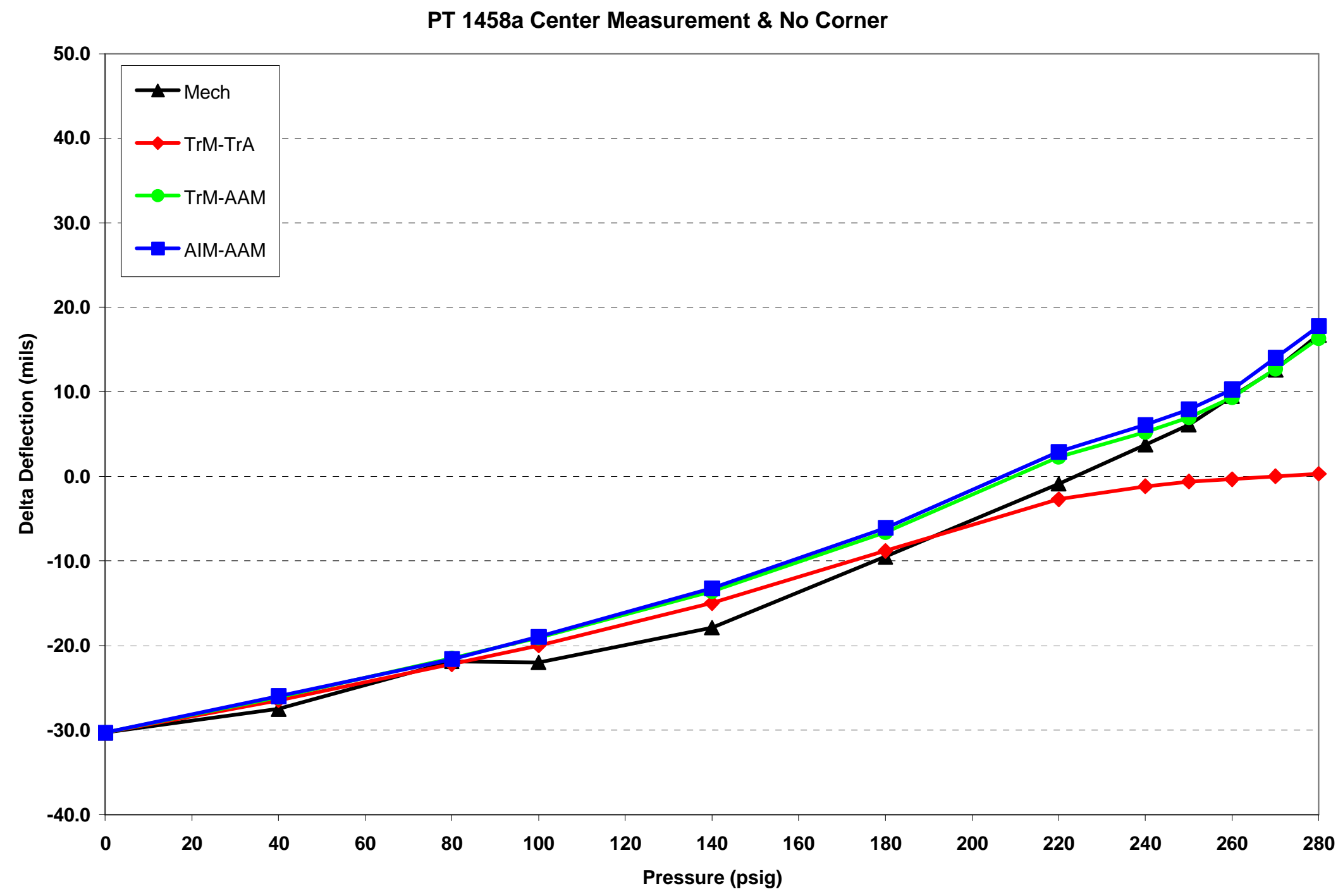

Figure 16: CM-NCF data for Can S/N P1458. 


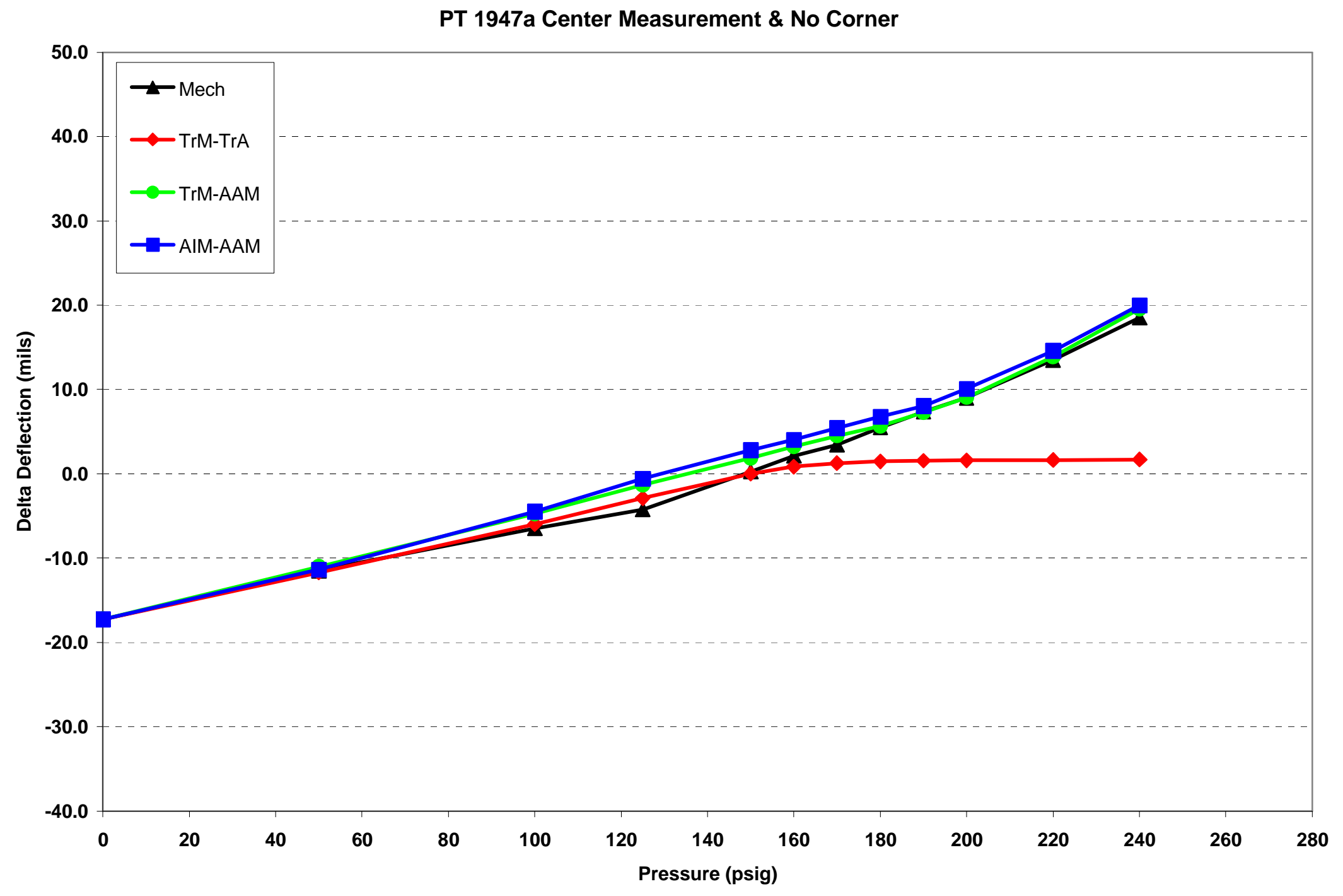

Figure 17: CM-NCF data for Can S/N P1947. 


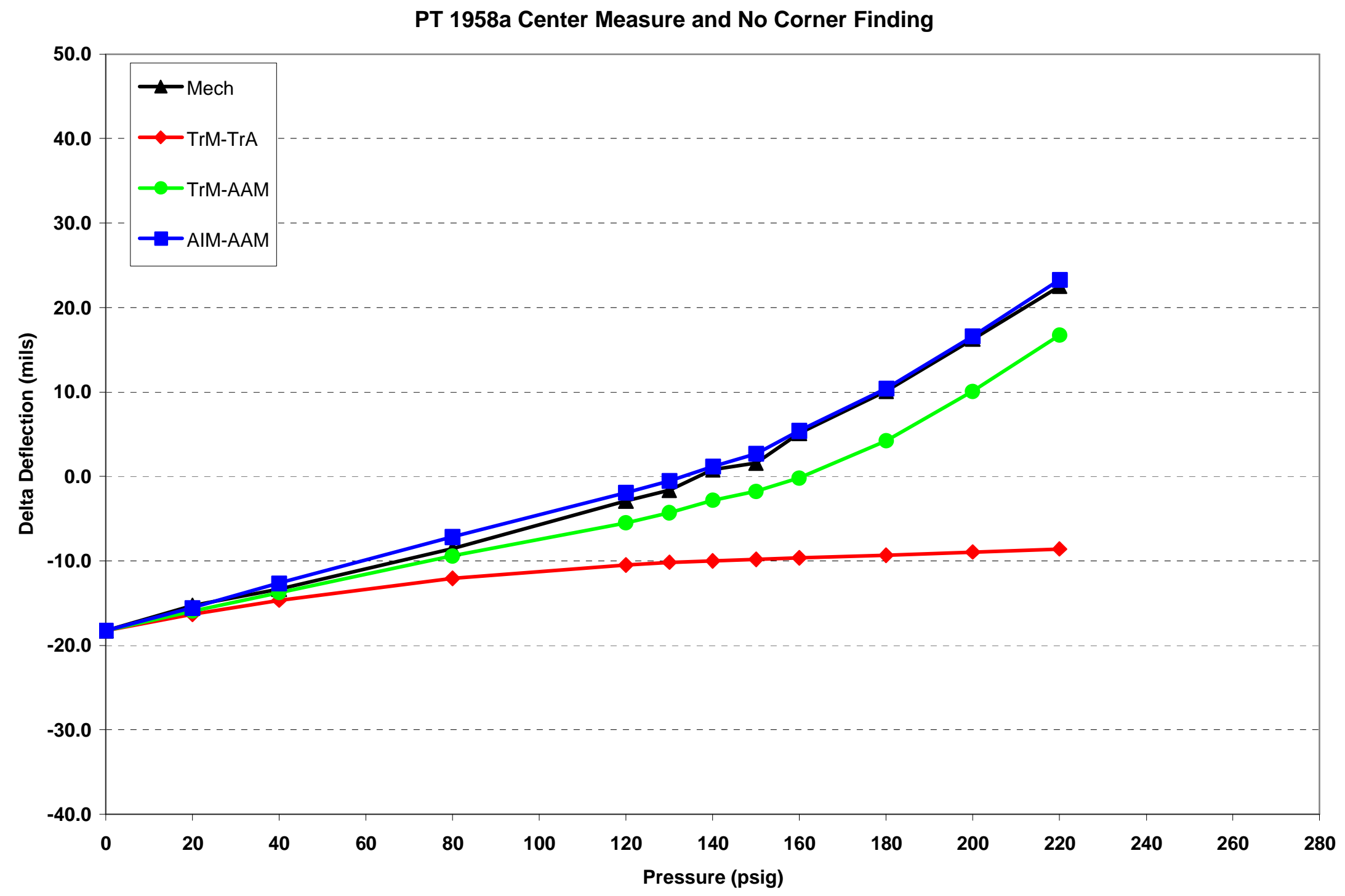

Figure 18: CM-NCF data for Can S/N P1958. 


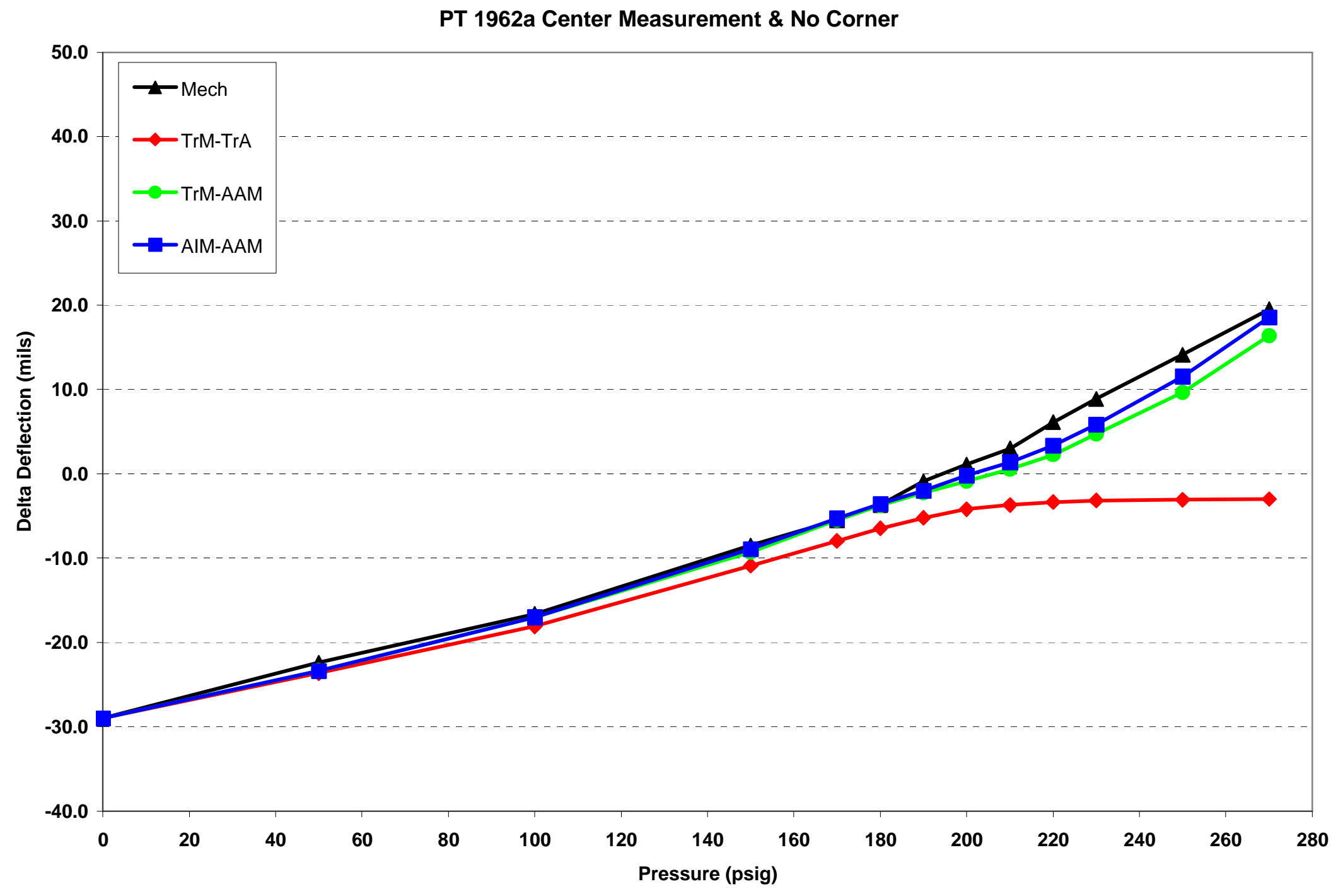

Figure 19: CM-NCF data for Can S/N P1962. 


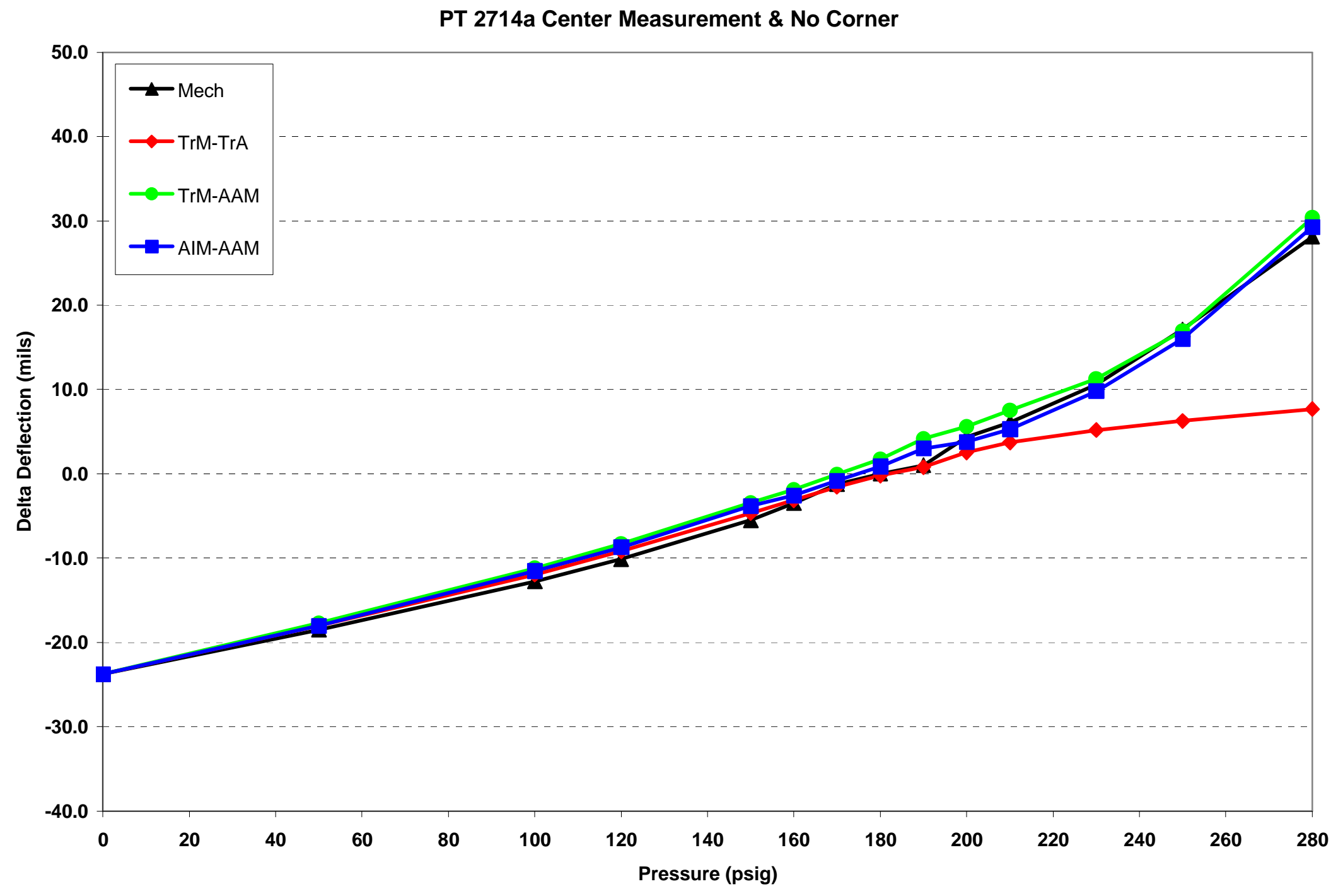

Figure 20: CM-NCF data for Can S/N P2714. 


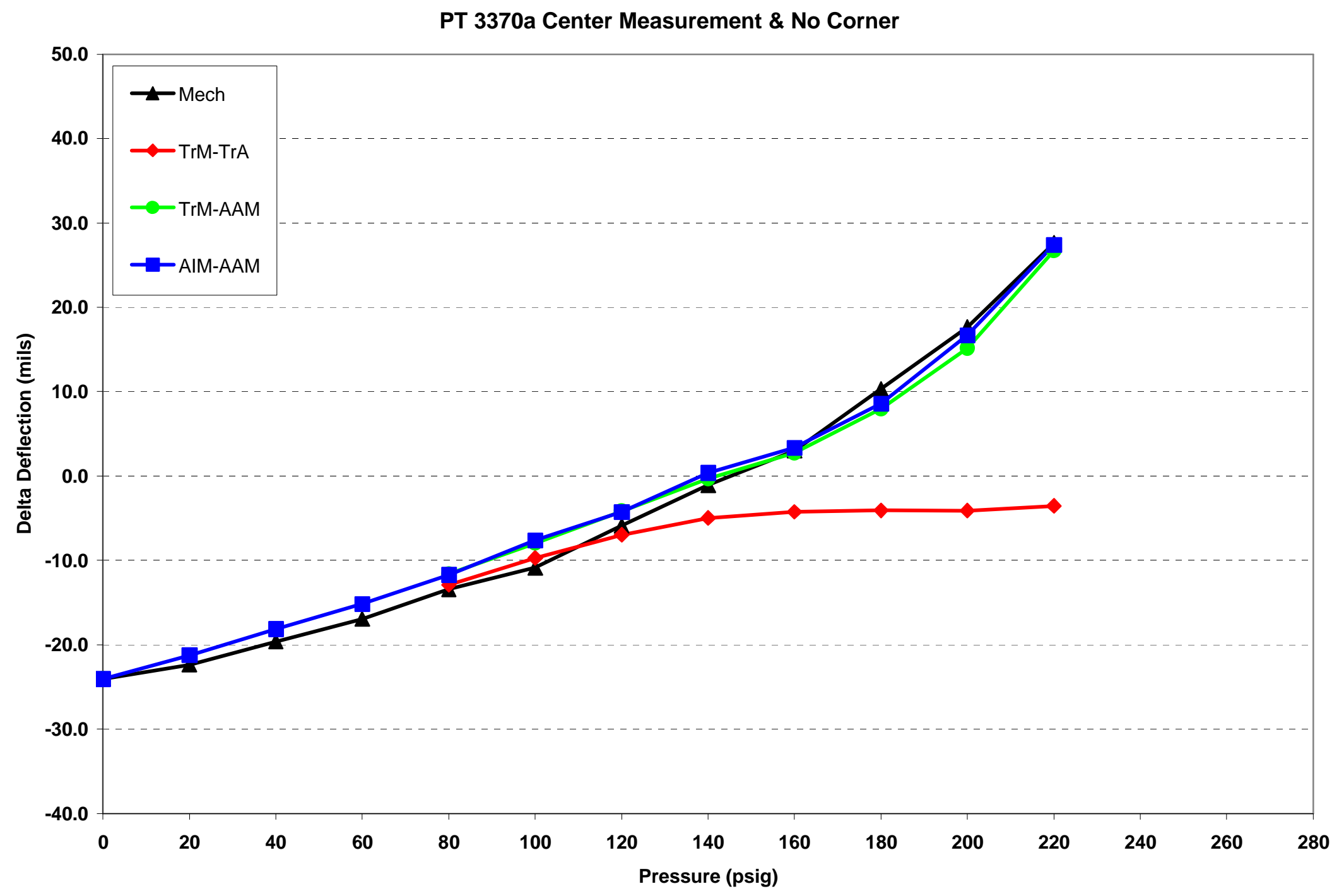

Figure 21: CM-NCF data for Can S/N P3370. 


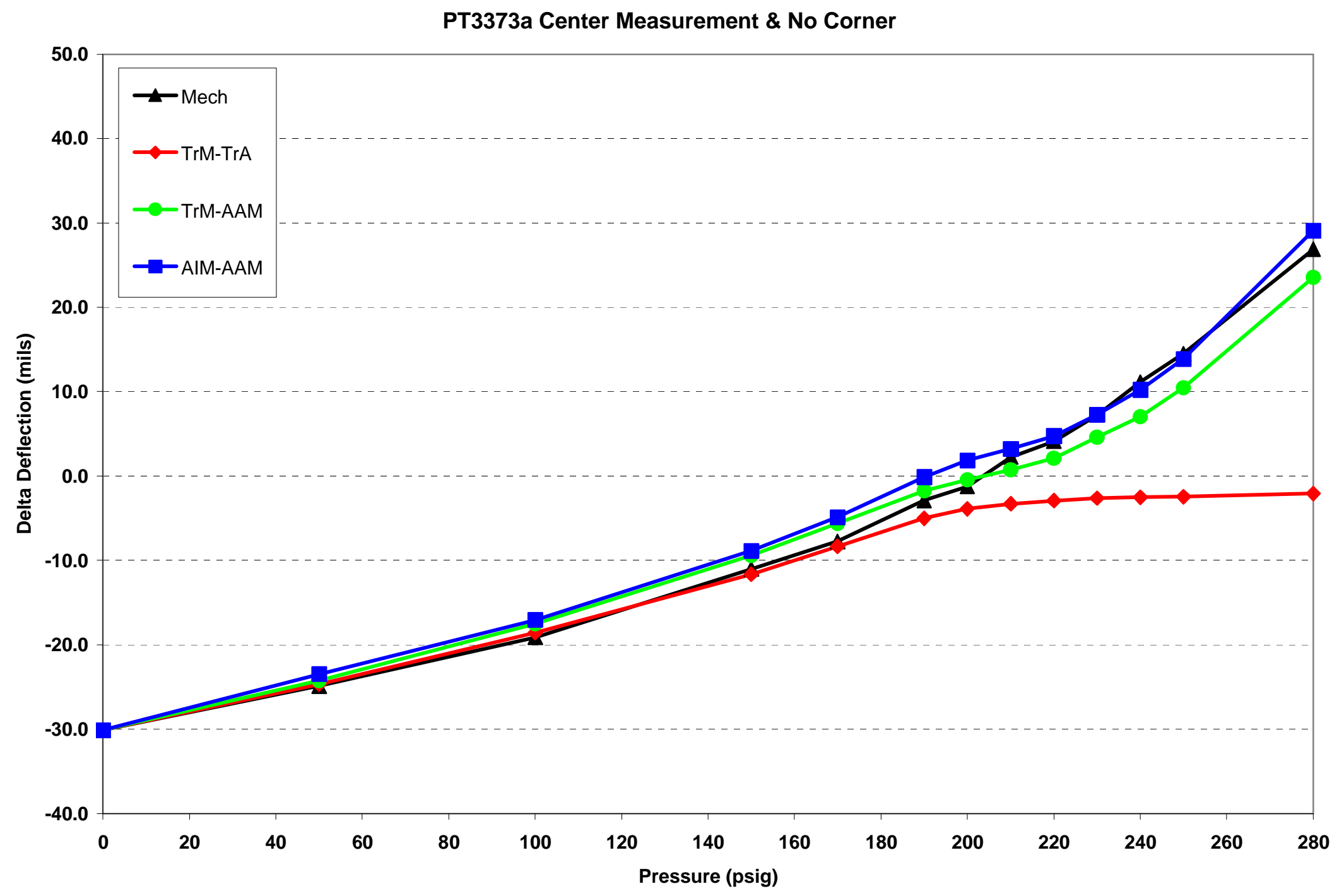

Figure 22: CM-NCF data for Can S/N P3373. 


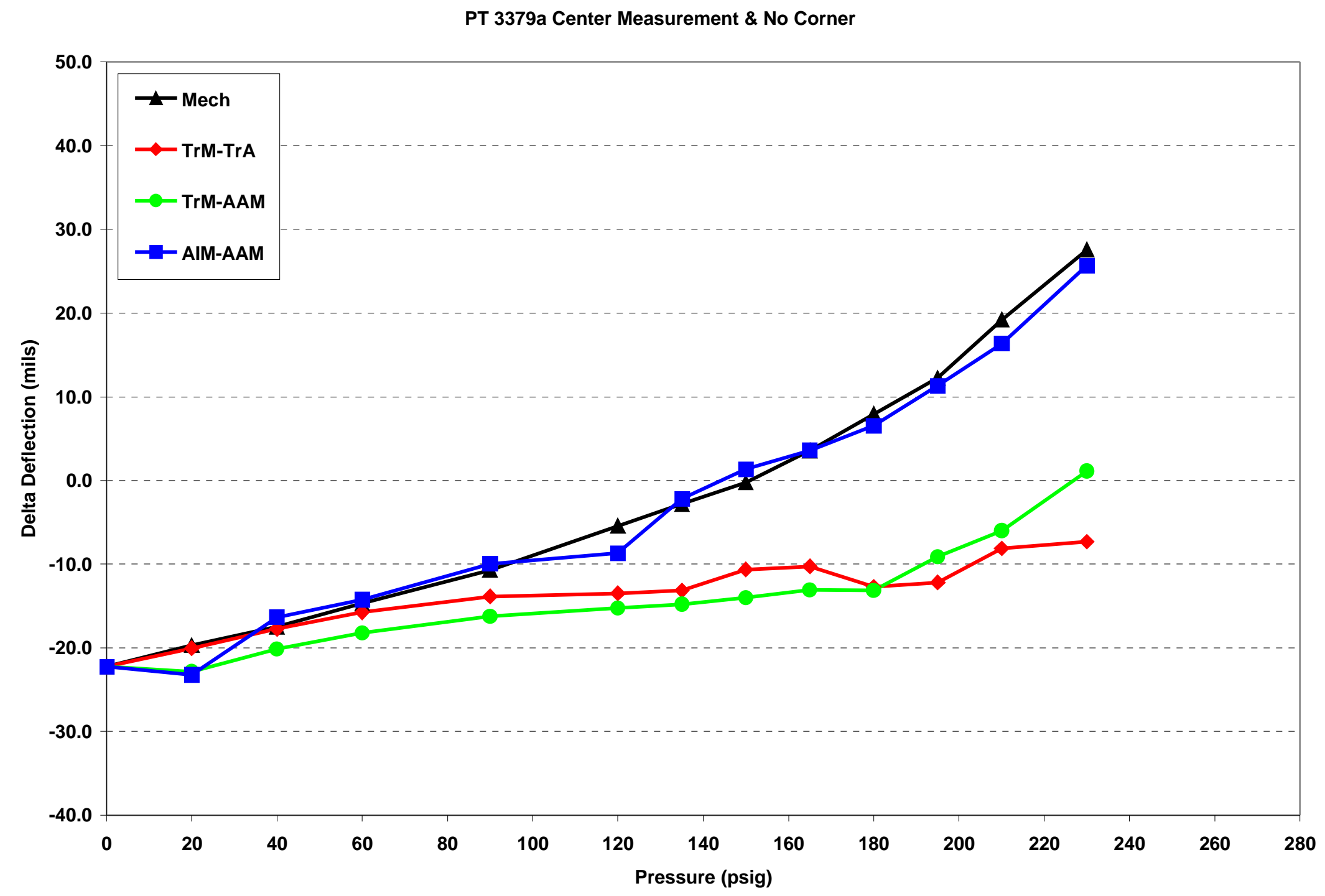

Figure 23: CM-NCF data for Can S/N P3379. 


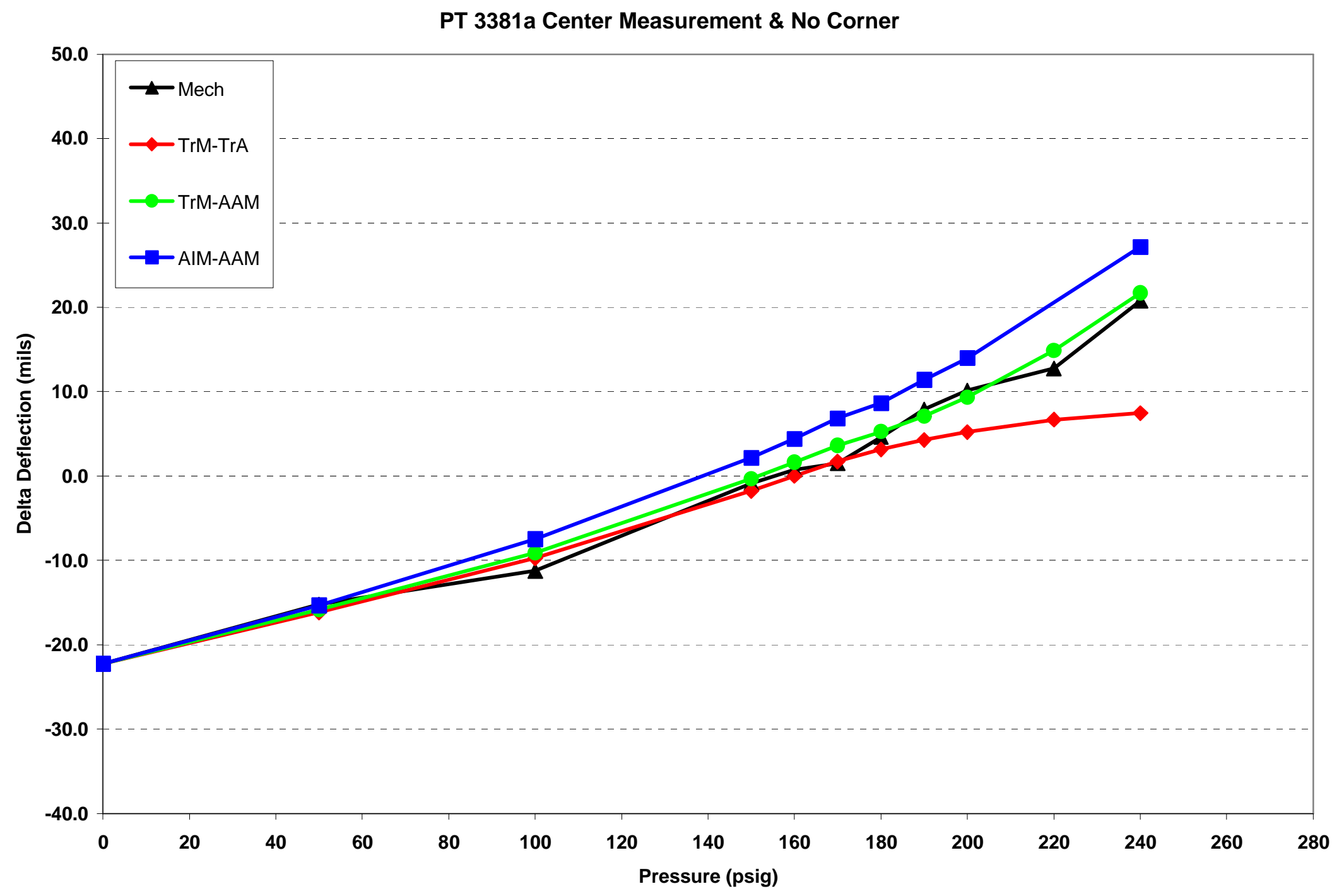

Figure 24: CM-NCF data for Can S/N P3381. 


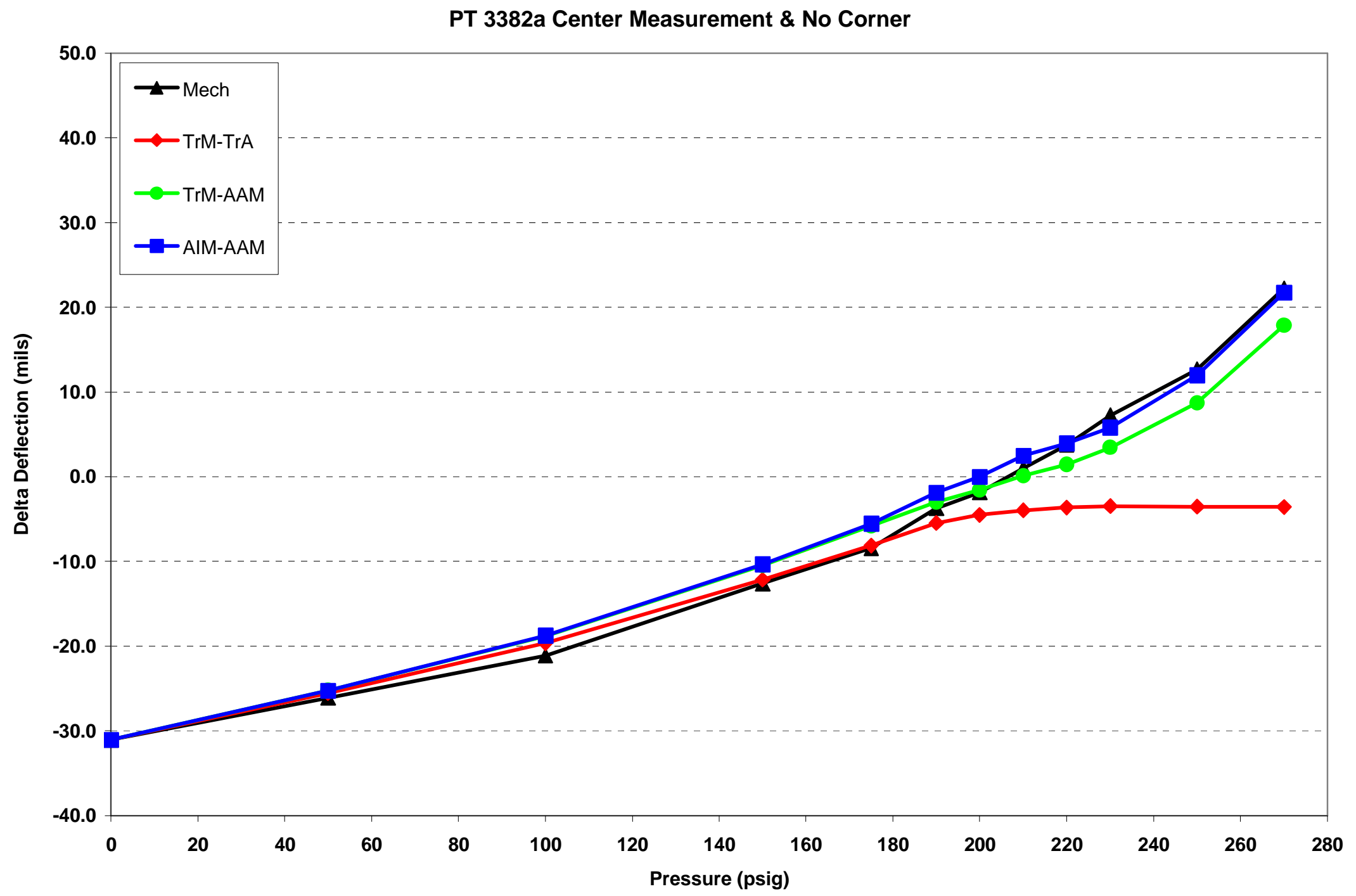

Figure 25: CM-NCF data for Can S/N P3382. 
Another observation that can be drawn from the preceding graphs is that in all cases the AIM-AAM technique tracks the mechanical deflection over the entire pressure range, even when the TrM-TrA results are in the dead zone. This is an extremely convincing piece of evidence supporting the claim that the AIM-AAM technique eliminates or drastically reduces the dead zone, which was one of the goals of the pressure testing.

Furthermore, in all cases except the largely tilted lids (P1958 and P3379), the TrM-AAM results track the mechanical results over the entire pressure range, even in the dead zone. This indicates that in a majority of cases, it may be possible to simply re-analyze existing data using the summation and selected axes algorithm to resolve dead zone issues.

Now consider the two cans with largely tilted lids. The results for S/N P1958 are shown in Figure 18. It can be seen in this figure that the TRM-AAM technique has a reasonable response after the TrM-TrA has entered the dead zone. The curve tracks the mechanical deflection, but not quite as well as the AIM-AAM results. This is explained by looking at the phase angle. In this case, the phase angle was +68 degrees (from Appendix 5, S/N P1958), with an associated optimal view angle of 22 degrees. Thus, the optimal view is only 22 degrees off the 0 degree view. Hence these results indicate that even when the wobble amplitude of the lid is large (56 mils) compared to the initial concavity (-18 mils), a reasonable amount (22 degrees) of misalignment from the optimal view can be tolerated.

The impact of simply ignoring the phase angle can also be seen in Figure 18. In this graph, the AIM-AAM results have very good agreement with the mechanical measurements and the TrM-TrA results were corrupted by the dead zone. However, the TrM-AAM results are still tracking the mechanical deflection albeit with a slightly modulated response. The modulated response is due to the 22 degree offset from the optimal view. To determine the magnitude of the error in using the TrM-AAM results consider a horizontal line drawn such that it intersects the vertical axis at +10 mils. This line would intersect the curves for the mechanical measurement and AIM-AAM at a pressure of about $180 \mathrm{psig}$. The same line intersects the TrM-AAM curve at a pressure of 200 psig. Thus, given the delta deflection measured from TrM-AAM used above, it would be inferred that the pressure was $180 \mathrm{psig}$, rather than $200 \mathrm{psig}$. Therefore, the pressure would have been underestimated by 20 psig under these conditions.

Conversely, for S/N P 3379 shown in Figure 23, the phase angle was -40 degrees, near the worst case phase angle of +/- 45 degrees, and the lid wobble amplitude was 67 mils. Under these conditions, the TrM-AAM results are just as bad as the TrM-TrA results.

The above analysis indicates that beyond a certain value the sensitivity to the phase angle can be very dramatic, when there is a large wobble amplitude present. Thus, when the magnitude of the lid wobble amplitude, A, is less than or about the same as the initial concavity, the phase angle can be neglected and the TrM-AAM results are adequate to measure lid deflection. However, when the wobble amplitude is large in comparison to the initial concavity, the phase angle becomes increasingly important, especially in the range of 20 to 45 degrees. 


\section{Related Issues}

The results described above were presented during a workshop between SRS, FH-PFP, DOE-RL, DOE-SR, and the 3013 Design Authority in early September 2003. Several technical questions arose during that workshop, which were captured as action items (Action Items 8, 9, 10 and 11).

Action item 8 involved a question related to how the AIM-AAM curve for the CM-NCF category was generated from raw data to the curves on the graphs. Action item 10 involved a question regarding how the pressure test mechanical measurements were made, calculated, and charted. These two issues have been sufficiently addressed in the preceding text of this report.

However, two technical issues, Action Items 9 and 11, have not been specifically addressed by the preceding text and will be discussed here. Action item 9 involved a question as to why the MD-CF results were different and why they have a larger variance when compared to the CM-NCF results. The differences between the MD-CF and CM$\mathrm{NCF}$ are due to the different spans for the deflection reference line. Recall that the corner finding $(\mathrm{CF})$ extrapolation uses a 4.5 -inch span and the results from the no corner finding (NCF) uses a 3.8 -inch span. The mechanical data correlates best to the NCF results because the mechanical deflection reference line was also on a 3.8 -inch span. Another reason for the larger variance seen on the MD-CF data is the fact that when the summation technique is used with the maximum deflection (MD) algorithm a larger number can result because there is no guarantee that maximum deflection will occur at the same location on the top and bottom profiles (i.e., the top and bottom deflections are less correlated). This is especially true when the lid is in transition between concave and convex as the lid can take on a complex shape. Using the center measure (CM) algorithm, the mismatch for the top and bottom deflection measurement location is much more restricted and thus reduces the variation (i.e., the degree of correlation between the top and bottom is greater).

Action Item 11 involves a question regarding how traditional imaging is used to determine the phase angle when the can is in the dead zone, and how do traditional imaging, AIM, and mechanical deflections correlate outside the dead zone. The latter part of this issue was addressed in a separate document issued by Vista Engineering Technologies and Fluor-Hanford, Reference [6]. The former part of the question will be addressed here.

Although the deflection values are impacted by adverse tilt (i.e., fore aft tilt that cannot be removed like the left-to-right tilt) conditions, tilt can be accurately measured. This argument perhaps is best supported through the use of the simple sketch (Figure 26). In Figure 26(a), most of the tilt is contained in the view shown, and as explained earlier can be removed by the ADRIS software. The small amount of dead zone is represented by the gray ellipse, and the red curve represents the bottom lid profile. It can be seen that the zero or minimal dead zone does not affect either the deflection or tilt values measured 
by ADRIS. In Figure 26(b), an additional fore-aft component of tilt results in a larger dead zone. It is clear that this larger dead zone conceals the bottom lid profile (red curve), but it can also be seen that the component of tilt in this view is accurately measured.

Thus, tilt values obtained from the traditional imaging for the purpose of the phase angle calculation are valid even when the deflection is in the dead zone. If this simple geometric explanation is not sufficient, the experimental results also bolster the argument. The AIM-AAM technique, which uses the phase angle obtained from the tilt values from traditional imaging, effectively tracks the mechanical deflection even when the traditional imaging is in the dead zone.

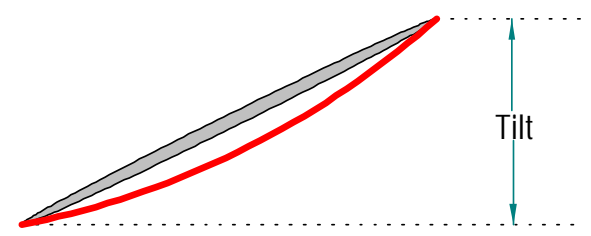

(a)

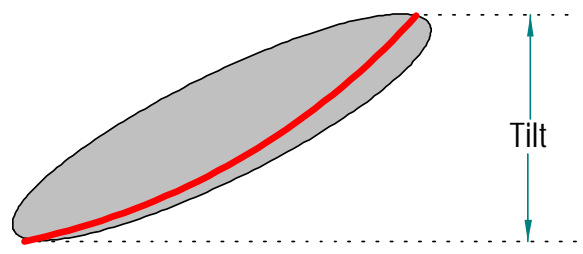

(b)

Figure 26: Sketch illustrating that tilt can be measured even when deflection measure is influenced by the dead zone.

\subsection{Conclusions}

SRTC has recently completed pressure tests on ten 3013 inner bagless transfer cans. This testing was intended to address the dead zone issue associated with low concavity, flat, or convex lids, which were outside the original parameters for the ADRIS system. The results of these tests have substantially contributed to the understanding and mitigation of the dead zone issue.

This report has provided a full, detailed explanation of the methodology for data collection and analyses. The theoretical modeling underlying the AIM Optimal View technique has been presented completely including an example of its application. The technique for the mechanical deflection measurements, which were used as the "touchstone" for the other results, has been thoroughly reviewed. In addition, all raw data has been provided in the Appendices for independent review.

For cans that have deflections that are outside of the calculated dead zone the TrM-TrA method provides a valid DR baseline. Furthermore, alternate analysis methods have been developed that will allow the acceptance of Hanford's 3013 canisters by re-analysis of existing DR data, without the need for re-imaging. (Some 3013s will require acceptance on the basis of the mechanical baseline measurement-see VET-1178-09.) These methods are based primarily on the "summation" and "selected view" algorithms. 
Review of the test data also revealed that the AIM optimal view technique successfully tracked the mechanically measured deflection through the traditional dead zone in all ten tests. It can be concluded that this technique either eliminates the dead zone or reduces it to an insignificant level. A suggested methodology for making the transition from traditional imaging to AIM has been reported in Reference [7].

The use of the summation technique in these tests represents the first time that the top deflection values have been used for tracking lid deflection. The results for the AIMAAM and TrM-AAM methods compare favorably with the mechanical deflection measurements. Both AIM-AAM and TrM-AAM were obtained using summation, therefore their agreement with the mechanical methods validates the use of the top profiles and related deflection values.

Finally, it has been demonstrated that a methodology (AIM-AAM) has been developed to evaluate cans that were previously considered uninspectable due to the effect of the dead zone. This methodology can be applied to inspections performed as part of the surveillance program. Additionally, if needed some cans may be accepted based on reanalysis of existing data using the TrM-AAM approach under certain conditions. In short, this program has successfully met the goal of mitigating the effect of the dead zone on the lid deflection measurement. 


\subsection{References}

[1] WSRC Letter EES-22726-DOC-001, Hanford Bagless Transfer System 3013 Qualification Tests Using Digital Radiographic Imaging (U), Boyd Howard and Dave Immel, August 8, 2000.

[2] Fluor Hanford Memorandum, M2E00-03-028, Test Plan to Establish/Reduce the BTC Lid Deflection Dead Zone for the Hanford 3013 Containers, K. A. JenningsMills, July 15, 2003.

[3] Vista Engineering Technologies, Technical Memorandum No. 1178-03, ADRIS: SRS-Hanford Measurement Equivalency, Dennis Douglas, et al., August 1, 2003.

[4] Proceedings of: Workshop on the Resolution of the Dead Zone in Hanford's 3013 BTCs, Resolution of DR Corner Finding Extrapolation Issue, Savannah River Site, September 3-4, 2003.

[5] Vista Engineering Technologies, Technical Memorandum No. 1178-02, ADRIS: Finding the Corners of the 3013 BTC Lid, Dennis Douglas, et al., August 5, 2003.

[6] Vista Engineering Technologies, Technical Memorandum No. 1178-08, ADRIS Imaging and Analysis: A Comparison of Traditional and Alternative DeflectionMeasurement Algorithms, Dennis Douglas, et al., (In preparation at the time of the release of this report).

[7] Vista Engineering Technologies, Technical Memorandum No. 1178-05, ADRIS Imaging and Analysis: A Comparison of Traditional Imaging Results with Optimum View Imaging Results, Dennis Douglas, et al., (In preparation at the time of the release of this report). 
Appendix 1 : Pressure Test Mechanical Deflection Data and Calculations 
Figure A1.1: Spreadsheet showing the cell assignments and formulas used in the following sheets for Table A and B entries.

(A)

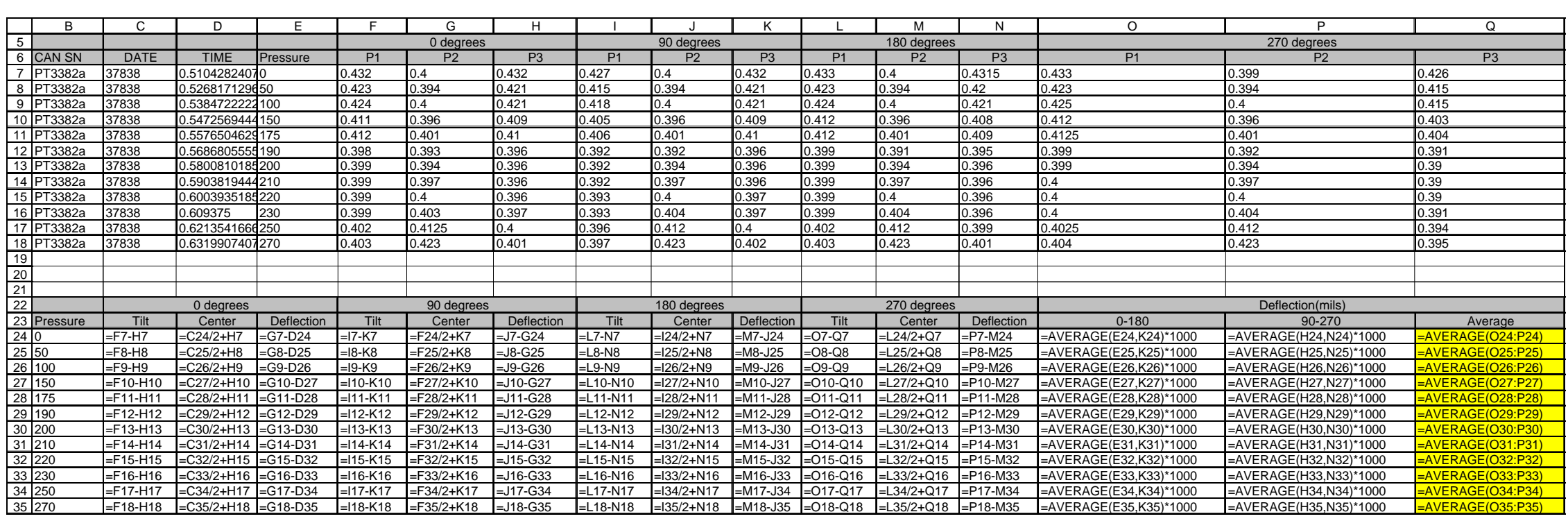




\section{S/N P1458}

Table A: Dial Indicator Raw Data. View angles correlate to AIM reference frame. Span between P1 and P3 was 3.8 inches.

\begin{tabular}{|c|c|c|c|c|c|c|c|c|c|c|c|c|c|c|c|}
\hline & & & & \multicolumn{3}{|c|}{0 degrees } & \multicolumn{3}{|c|}{90 degrees } & \multicolumn{3}{|c|}{180 degrees } & \multicolumn{3}{|c|}{270 degrees } \\
\hline CAN SN & DATE & TIME & Pressure & $\mathrm{P} 1$ & $\mathrm{P} 2$ & P3 & $\mathrm{P} 1$ & P2 & P3 & $\mathrm{P} 1$ & P2 & P3 & $\mathrm{P} 1$ & P2 & P3 \\
\hline PT1458a & 2-Aug & $10: 04: 00$ & 0 & 0.4290 & 0.3990 & 0.4305 & 0.4360 & 0.3990 & 0.4220 & 0.4280 & 0.3990 & 0.4320 & 0.4190 & 0.3990 & 0.4380 \\
\hline PT1458a & 2-Aug & $10: 22: 00$ & 40 & 0.4300 & 0.4030 & 0.4310 & 0.4370 & 0.4020 & 0.4220 & 0.4290 & 0.4030 & 0.4330 & 0.4200 & 0.4030 & 0.4400 \\
\hline PT1458a & 2 -Aug & 10:38:00 & 80 & 0.4160 & 0.3950 & 0.4180 & 0.4240 & 0.3950 & 0.4090 & 0.4160 & 0.3950 & 0.4190 & 0.4070 & 0.3950 & 0.4260 \\
\hline PT1458a & 2 -Aug & $10: 52: 00$ & 100 & 0.4170 & 0.3950 & 0.4180 & 0.4250 & 0.3950 & 0.4090 & 0.4160 & 0.3950 & 0.4190 & 0.4070 & 0.3960 & 0.4270 \\
\hline PT1458a & 2-Aug & 11:09:00 & 140 & 0.4180 & 0.4020 & 0.4190 & 0.4250 & 0.4010 & 0.4100 & 0.4170 & 0.4010 & 0.4200 & 0.4080 & 0.3970 & 0.4280 \\
\hline PT1458a & 2-Aug & $11: 25: 00$ & 180 & 0.4060 & 0.3970 & 0.4060 & 0.4130 & 0.3960 & 0.3980 & 0.4050 & 0.3960 & 0.4080 & 0.3950 & 0.3960 & 0.4150 \\
\hline PT1458a & 2-Aug & $11: 41: 00$ & 220 & 0.4070 & 0.4060 & 0.4070 & 0.4150 & 0.4060 & 0.3980 & 0.4060 & 0.4060 & 0.4090 & 0.3970 & 0.4060 & 0.4160 \\
\hline PT1458a & 2-Aug & 12:00:00 & 240 & 0.3950 & 0.3980 & 0.3940 & 0.4020 & 0.3980 & 0.3850 & 0.3940 & 0.3980 & 0.3960 & 0.3840 & 0.3980 & 0.4040 \\
\hline PT1458a & 2-Aug & 12:19:00 & 250 & 0.3960 & 0.4010 & 0.3940 & 0.4030 & 0.4010 & 0.3860 & 0.3940 & 0.4010 & 0.3970 & 0.3850 & 0.4010 & 0.4040 \\
\hline PT1458a & 2-Aug & $12: 40: 00$ & 260 & 0.3960 & 0.4050 & 0.3950 & 0.4040 & 0.4050 & 0.3860 & 0.3950 & 0.4050 & 0.3980 & 0.3850 & 0.4050 & 0.4050 \\
\hline PT1458a & 2-Aug & 13:04:00 & 270 & 0.3980 & 0.4110 & 0.3970 & 0.4060 & 0.4100 & 0.3890 & 0.3970 & 0.4100 & 0.4000 & 0.3870 & 0.4100 & 0.4070 \\
\hline PT1458a & 2-Aug & $13: 33: 00$ & 280 & 0.3990 & 0.4150 & 0.3980 & 0.4060 & 0.4150 & 0.3890 & 0.3970 & 0.4140 & 0.4000 & 0.3880 & 0.4150 & 0.4070 \\
\hline
\end{tabular}

Table B: Calculations to determine average mechanical deflection (last column).

\begin{tabular}{|c|c|c|c|c|c|c|c|c|c|c|c|c|c|c|c|}
\hline & \multicolumn{3}{|c|}{0 degrees } & \multicolumn{3}{|c|}{90 degrees } & \multicolumn{3}{|c|}{180 degrees } & \multicolumn{3}{|c|}{270 degrees } & \multicolumn{3}{|c|}{ Deflection (mils) } \\
\hline Pressure & Tilt & Center & Deflection & Tilt & Center & Deflection & Tilt & Center & Deflection & Tilt & Center & Deflection & $0-180$ & $90-270$ & Average \\
\hline 0 & -0.0015 & 0.4298 & -0.0307 & 0.0140 & 0.4290 & -0.0300 & -0.0040 & 0.4300 & -0.0310 & -0.0190 & 0.4285 & -0.0295 & -30.9 & -29.8 & -30.3 \\
\hline 40 & -0.0010 & 0.4305 & -0.0275 & 0.0150 & 0.4295 & -0.0275 & -0.0040 & 0.4310 & -0.0280 & -0.0200 & 0.4300 & -0.0270 & -27.8 & -27.3 & -27.5 \\
\hline 80 & -0.0020 & 0.4170 & -0.0220 & 0.0150 & 0.4165 & -0.0215 & -0.0030 & 0.4175 & -0.0225 & -0.0190 & 0.4165 & -0.0215 & -22.3 & -21.5 & -21.9 \\
\hline 100 & -0.0010 & 0.4175 & -0.0225 & 0.0160 & 0.4170 & -0.0220 & -0.0030 & 0.4175 & -0.0225 & -0.0200 & 0.4170 & -0.0210 & -22.5 & -21.5 & -22.0 \\
\hline 140 & -0.0010 & 0.4185 & -0.0165 & 0.0150 & 0.4175 & -0.0165 & -0.0030 & 0.4185 & -0.0175 & -0.0200 & 0.4180 & -0.0210 & -17.0 & -18.8 & -17.9 \\
\hline 180 & 0.0000 & 0.4060 & -0.0090 & 0.0150 & 0.4055 & -0.0095 & -0.0030 & 0.4065 & -0.0105 & -0.0200 & 0.4050 & -0.0090 & -9.7 & -9.2 & -9.5 \\
\hline 220 & 0.0000 & 0.4070 & -0.0010 & 0.0170 & 0.4065 & -0.0005 & -0.0030 & 0.4075 & -0.0015 & -0.0190 & 0.4065 & -0.0005 & -1.2 & -0.5 & -0.9 \\
\hline 240 & 0.0010 & 0.3945 & 0.0035 & 0.0170 & 0.3935 & 0.0045 & -0.0020 & 0.3950 & 0.0030 & -0.0200 & 0.3940 & 0.0040 & 3.3 & 4.3 & 3.8 \\
\hline 250 & 0.0020 & 0.3950 & 0.0060 & 0.0170 & 0.3945 & 0.0065 & -0.0030 & 0.3955 & 0.0055 & -0.0190 & 0.3945 & 0.0065 & 5.8 & 6.5 & 6.1 \\
\hline 260 & 0.0010 & 0.3955 & 0.0095 & 0.0180 & 0.3950 & 0.0100 & -0.0030 & 0.3965 & 0.0085 & -0.0200 & 0.3950 & 0.0100 & 9.0 & 10.0 & 9.5 \\
\hline 270 & 0.0010 & 0.3975 & 0.0135 & 0.0170 & 0.3975 & 0.0125 & -0.0030 & 0.3985 & 0.0115 & -0.0200 & 0.3970 & 0.0130 & 12.5 & 12.8 & 12.6 \\
\hline 280 & 0.0010 & 0.3985 & 0.0165 & 0.0170 & 0.3975 & 0.0175 & -0.0030 & 0.3985 & 0.0155 & -0.0190 & 0.3975 & 0.0175 & 16.0 & 17.5 & 16.8 \\
\hline
\end{tabular}

Note: All dimensional measurements are in units of inches unless otherwise indicated. 


\section{S/N P1947}

Table A: Dial Indicator Raw Data. View angles correlate to AIM reference frame. Span between P1 and P3 was 3.8 inches.

\begin{tabular}{|c|c|c|c|c|c|c|c|c|c|c|c|c|c|c|c|}
\hline & & & & \multicolumn{3}{|c|}{0 degrees } & \multicolumn{3}{|c|}{90 degrees } & \multicolumn{3}{|c|}{180 degrees } & \multicolumn{3}{|c|}{270 degrees } \\
\hline CAN SN & DATE & TIME & Pressure & $\mathrm{P} 1$ & $\mathrm{P} 2$ & P3 & $\mathrm{P} 1$ & P2 & P3 & $\mathrm{P} 1$ & P2 & P3 & $\mathrm{P} 1$ & P2 & P3 \\
\hline PT1947a & 4-Aug & $16: 35: 01$ & 0 & 0.4120 & 0.3970 & 0.4150 & 0.4110 & 0.3970 & 0.4190 & 0.4120 & 0.3970 & 0.4160 & 0.4150 & 0.3970 & 0.4140 \\
\hline PT1947a & 4-Aug & $16: 49: 35$ & 50 & 0.4140 & 0.4040 & 0.4160 & 0.4130 & 0.4040 & 0.4190 & 0.4140 & 0.4040 & 0.4170 & 0.4160 & 0.4040 & 0.4150 \\
\hline PT1947a & 4-Aug & $17: 01: 41$ & 100 & 0.4020 & 0.3970 & 0.4040 & 0.4010 & 0.3970 & 0.4080 & 0.4020 & 0.3970 & 0.4050 & 0.4050 & 0.3980 & 0.4030 \\
\hline PT1947a & 4-Aug & $17: 14: 49$ & 125 & 0.4030 & 0.4000 & 0.4050 & 0.4020 & 0.4000 & 0.4080 & 0.4030 & 0.4000 & 0.4050 & 0.4050 & 0.4000 & 0.4030 \\
\hline PT1947a & 4-Aug & $17: 27: 47$ & 150 & 0.3900 & 0.3920 & 0.3920 & 0.3890 & 0.3920 & 0.3960 & 0.3900 & 0.3920 & 0.3930 & 0.3930 & 0.3920 & 0.3910 \\
\hline PT1947a & 4-Aug & $17: 40: 32$ & 160 & 0.3920 & 0.3960 & 0.3950 & 0.3920 & 0.3960 & 0.3970 & 0.3920 & 0.3960 & 0.3950 & 0.3950 & 0.3960 & 0.3930 \\
\hline PT1947a & 4-Aug & $17: 54: 52$ & 170 & 0.3930 & 0.3980 & 0.3950 & 0.3920 & 0.3980 & 0.3970 & 0.3930 & 0.3980 & 0.3950 & 0.3965 & 0.3980 & 0.3950 \\
\hline PT1947a & 4-Aug & 18:08:49 & 180 & 0.3930 & 0.4000 & 0.3950 & 0.3920 & 0.4000 & 0.3980 & 0.3930 & 0.4000 & 0.3950 & 0.3960 & 0.4000 & 0.3940 \\
\hline PT1947a & 4-Aug & $18: 21: 32$ & 190 & 0.3930 & 0.4020 & 0.3950 & 0.3930 & 0.4020 & 0.3980 & 0.3940 & 0.4020 & 0.3950 & 0.3960 & 0.4020 & 0.3930 \\
\hline PT1947a & 4-Aug & $18: 35: 14$ & 200 & 0.3940 & 0.4040 & 0.3950 & 0.3930 & 0.4040 & 0.3980 & 0.3940 & 0.4040 & 0.3950 & 0.3970 & 0.4040 & 0.3940 \\
\hline PT1947a & 4-Aug & $18: 47: 47$ & 220 & 0.3950 & 0.4090 & 0.3950 & 0.3940 & 0.4090 & 0.3980 & 0.3950 & 0.4090 & 0.3950 & 0.3980 & 0.4090 & 0.3940 \\
\hline PT1947a & 4-Aug & 19:01:59 & 240 & 0.3960 & 0.4150 & 0.3960 & 0.3950 & 0.4150 & 0.3990 & 0.3960 & 0.4150 & 0.3960 & 0.3990 & 0.4150 & 0.3950 \\
\hline
\end{tabular}

Table B: Calculations to determine average mechanical deflection (last column).

\begin{tabular}{|c|c|c|c|c|c|c|c|c|c|c|c|c|c|c|c|}
\hline \multirow[b]{2}{*}{ Pressure } & \multicolumn{3}{|c|}{0 degrees } & \multicolumn{3}{|c|}{90 degrees } & \multicolumn{3}{|c|}{180 degrees } & \multicolumn{3}{|c|}{270 degrees } & \multicolumn{3}{|c|}{ Deflection(mils) } \\
\hline & Tilt & Center & Deflection & Tilt & Center & Deflection & Tilt & Center & Deflection & Tilt & Center & Deflection & $0-180$ & $90-270$ & Average \\
\hline 0 & -0.0030 & 0.4135 & -0.0165 & -0.0080 & 0.4150 & \begin{tabular}{|c|}
-0.0180 \\
\end{tabular} & -0.0040 & 0.4140 & \begin{tabular}{|c|}
-0.0170 \\
\end{tabular} & 0.0010 & 0.4145 & \begin{tabular}{|l|}
-0.0175 \\
\end{tabular} & -16.8 & $\begin{array}{l}-17.8 \\
\end{array}$ & -17.3 \\
\hline 50 & -0.0020 & 0.4150 & -0.0110 & -0.0060 & 0.4160 & -0.0120 & -0.0030 & 0.4155 & -0.0115 & 0.0010 & 0.4155 & -0.0115 & -11.3 & -11.8 & -11.5 \\
\hline 100 & -0.0020 & 0.4030 & -0.0060 & -0.0070 & 0.4045 & -0.0075 & -0.0030 & 0.4035 & -0.0065 & 0.0020 & 0.4040 & -0.0060 & -6.3 & -6.7 & -6.5 \\
\hline 125 & -0.0020 & 0.4040 & -0.0040 & -0.0060 & 0.4050 & -0.0050 & -0.0020 & 0.4040 & -0.0040 & 0.0020 & 0.4040 & -0.0040 & -4.0 & -4.5 & -4.3 \\
\hline 150 & -0.0020 & 0.3910 & 0.0010 & -0.0070 & 0.3925 & -0.0005 & -0.0030 & 0.3915 & 0.0005 & 0.0020 & 0.3920 & 0.0000 & 0.8 & -0.3 & 0.3 \\
\hline 160 & -0.0030 & 0.3935 & 0.0025 & -0.0050 & 0.3945 & 0.0015 & -0.0030 & 0.3935 & 0.0025 & 0.0020 & 0.3940 & 0.0020 & 2.5 & 1.8 & 2.1 \\
\hline 170 & -0.0020 & 0.3940 & 0.0040 & -0.0050 & 0.3945 & 0.0035 & -0.0020 & 0.3940 & 0.0040 & 0.0015 & 0.3958 & 0.0022 & 4.0 & 2.9 & 3.4 \\
\hline 180 & -0.0020 & 0.3940 & 0.0060 & -0.0060 & 0.3950 & 0.0050 & -0.0020 & 0.3940 & 0.0060 & 0.0020 & 0.3950 & 0.0050 & 6.0 & 5.0 & 5.5 \\
\hline 190 & -0.0020 & 0.3940 & 0.0080 & -0.0050 & 0.3955 & 0.0065 & -0.0010 & 0.3945 & 0.0075 & 0.0030 & 0.3945 & 0.0075 & 7.8 & 7.0 & 7.4 \\
\hline 200 & -0.0010 & 0.3945 & 0.0095 & -0.0050 & 0.3955 & 0.0085 & -0.0010 & 0.3945 & 0.0095 & 0.0030 & 0.3955 & 0.0085 & 9.5 & 8.5 & 9.0 \\
\hline 220 & 0.0000 & 0.3950 & 0.0140 & -0.0040 & 0.3960 & 0.0130 & 0.0000 & 0.3950 & 0.0140 & 0.0040 & 0.3960 & 0.0130 & 14.0 & 13.0 & 13.5 \\
\hline 240 & 0.0000 & 0.3960 & 0.0190 & -0.0040 & 0.3970 & 0.0180 & 0.0000 & 0.3960 & 0.0190 & 0.0040 & 0.3970 & 0.0180 & 19.0 & 18.0 & 18.5 \\
\hline
\end{tabular}

Note: All dimensional measurements are in units of inches unless otherwise indicated. 


\section{S/N P1958}

Table A: Dial Indicator Raw Data. View angles correlate to AIM reference frame. Span between P1 and P3 was 3.8 inches.

\begin{tabular}{|c|c|c|c|c|c|c|c|c|c|c|c|c|c|c|c|}
\hline & & & & \multicolumn{3}{|c|}{0 degrees } & \multicolumn{3}{|c|}{90 degrees } & \multicolumn{3}{|c|}{180 degrees } & \multicolumn{3}{|c|}{270 degrees } \\
\hline CAN SN & DATE & TIME & Pressure & $\mathrm{P} 1$ & P2 & P3 & $\mathrm{P} 1$ & P2 & P3 & $\mathrm{P} 1$ & P2 & P3 & P1 & P2 & P3 \\
\hline PT1958a & 29-Jul & $14: 32: 52$ & $\begin{array}{l}0 \\
0\end{array}$ & 0.3325 & 0.3170 & 0.3365 & 0.3095 & 0.3160 & 0.3620 & 0.3350 & 0.3165 & 0.3325 & 0.3610 & 0.3170 & 0.3100 \\
\hline \begin{tabular}{|l|} 
PT1958a \\
\end{tabular} & 29-Jul & $14: 53: 01$ & 20 & 0.3330 & 0.3195 & 0.3326 & 0.3095 & 0.3185 & 0.3615 & 0.3350 & 0.3190 & 0.3325 & 0.3610 & 0.3195 & 0.3100 \\
\hline \begin{tabular}{|l|} 
PT1958a \\
\end{tabular} & 29-Jul & $15: 07: 17$ & 40 & 0.3325 & 0.3220 & 0.3365 & 0.3095 & 0.3210 & 0.3620 & 0.3355 & 0.3210 & 0.3320 & 0.3610 & 0.3220 & 0.3100 \\
\hline \begin{tabular}{|l|} 
PT1958a \\
\end{tabular} & 29-Jul & $\begin{array}{l}15: 27: 03 \\
\end{array}$ & 80 & 0.3200 & 0.3140 & 0.3240 & 0.2970 & 0.3130 & 0.3490 & 0.3230 & 0.3135 & 0.3195 & 0.3485 & 0.3145 & 0.2975 \\
\hline \begin{tabular}{|l|} 
PT1958a \\
\end{tabular} & 29-Jul & $15: 43: 45$ & 120 & 0.3220 & 0.3210 & 0.3250 & 0.2985 & 0.3205 & 0.3505 & 0.3240 & 0.3205 & 0.3215 & 0.3500 & 0.3215 & 0.2990 \\
\hline PT1958a & 29-Jul & $16: 00: 59$ & 130 & 0.3220 & 0.3220 & 0.3255 & 0.2985 & 0.3220 & 0.3510 & 0.3240 & 0.3225 & 0.3215 & 0.3500 & 0.3230 & 0.2995 \\
\hline \begin{tabular}{|l|} 
PT1958a \\
\end{tabular} & 29-Jul & $16: 17: 07$ & 140 & 0.3235 & 0.3270 & 0.3275 & 0.3005 & 0.3260 & 0.3530 & 0.3260 & 0.3265 & 0.3235 & 0.3515 & 0.3270 & 0.3010 \\
\hline \begin{tabular}{|l|} 
PT1958a \\
\end{tabular} & 29-Jul & $16: 31: 52$ & 150 & 0.3100 & 0.3155 & 0.3140 & 0.2870 & 0.3150 & 0.3390 & 0.3130 & 0.3150 & 0.3110 & 0.3385 & 0.3110 & 0.2880 \\
\hline PT1958a & 29-Jul & $16: 48: 19$ & 160 & 0.3105 & 0.3180 & 0.3150 & 0.2870 & 0.3175 & 0.3400 & 0.3130 & 0.3180 & 0.3110 & 0.3385 & 0.3185 & 0.2880 \\
\hline \begin{tabular}{|l|} 
PT1958a \\
\end{tabular} & 29-Jul & 17:03:29 & 180 & 0.3110 & 0.3240 & 0.3160 & 0.2880 & 0.3235 & 0.3410 & 0.3140 & 0.3235 & 0.3120 & 0.3395 & 0.3245 & 0.2890 \\
\hline PT1958a & 29-Jul & $17: 16: 58$ & 200 & 0.3120 & 0.3315 & 0.3170 & 0.2890 & 0.3310 & 0.3420 & 0.3150 & 0.3310 & 0.3130 & 0.3410 & 0.3315 & 0.2910 \\
\hline \begin{tabular}{|l|} 
PT1958a \\
\end{tabular} & 29-Jul & $17: 30: 03$ & 220 & 0.3130 & 0.3390 & 0.3185 & 0.2900 & 0.3380 & 0.3435 & 0.3160 & 0.3385 & 0.3140 & 0.3420 & 0.3390 & 0.2920 \\
\hline
\end{tabular}

Table B: Calculations to determine average mechanical deflection (last column).

\begin{tabular}{|c|c|c|c|c|c|c|c|c|c|c|c|c|c|c|c|}
\hline \multirow[b]{2}{*}{ Pressure } & \multicolumn{3}{|c|}{0 degrees } & \multicolumn{3}{|c|}{90 degrees } & \multicolumn{3}{|c|}{180 degrees } & \multicolumn{3}{|c|}{270 degrees } & \multicolumn{3}{|c|}{ Deflection(mils) } \\
\hline & Tilt & Center & \begin{tabular}{|l|} 
Deflection \\
\end{tabular} & Tilt & Center & \begin{tabular}{|l|} 
Deflection \\
\end{tabular} & Tilt & Center & \begin{tabular}{|l|} 
Deflection \\
\end{tabular} & Tilt & Center & \begin{tabular}{|l|} 
Deflection \\
\end{tabular} & $0-180$ & $90-270$ & Average \\
\hline 0 & -0.0040 & 0.3345 & -0.0175 & -0.0525 & 0.3358 & \begin{tabular}{|c|}
-0.0198 \\
\end{tabular} & 0.0025 & 0.3338 & \begin{tabular}{|l|}
-0.0173 \\
\end{tabular} & 0.0510 & 0.3355 & \begin{tabular}{|c|}
-0.0185 \\
\end{tabular} & -17.4 & -19.1 & -18.3 \\
\hline 20 & 0.0004 & 0.3328 & -0.0133 & -0.0520 & 0.3355 & -0.0170 & 0.0025 & 0.3338 & -0.0148 & 0.0510 & 0.3355 & -0.0160 & -14.0 & -16.5 & -15.3 \\
\hline 40 & -0.0040 & 0.3345 & -0.0125 & -0.0525 & 0.3358 & -0.0148 & 0.0035 & 0.3338 & -0.0128 & 0.0510 & 0.3355 & -0.0135 & -12.6 & -14.1 & -13.4 \\
\hline 80 & -0.0040 & 0.3220 & -0.0080 & -0.0520 & 0.3230 & -0.0100 & 0.0035 & 0.3213 & -0.0078 & 0.0510 & 0.3230 & -0.0085 & -7.9 & -9.2 & -8.6 \\
\hline 120 & -0.0030 & 0.3235 & -0.0025 & -0.0520 & 0.3245 & -0.0040 & 0.0025 & 0.3228 & -0.0022 & 0.0510 & 0.3245 & -0.0030 & -2.4 & -3.5 & -2.9 \\
\hline 130 & -0.0035 & 0.3238 & -0.0017 & -0.0525 & 0.3248 & -0.0027 & 0.0025 & 0.3228 & -0.0002 & 0.0505 & 0.3248 & -0.0017 & -1.0 & -2.2 & -1.6 \\
\hline 140 & -0.0040 & 0.3255 & 0.0015 & -0.0525 & 0.3268 & -0.0007 & 0.0025 & 0.3248 & 0.0018 & 0.0505 & 0.3263 & 0.0008 & 1.6 & 0.0 & 0.8 \\
\hline 150 & -0.0040 & 0.3120 & 0.0035 & -0.0520 & 0.3130 & 0.0020 & 0.0020 & 0.3120 & 0.0030 & 0.0505 & 0.3133 & -0.0023 & 3.3 & -0.1 & 1.6 \\
\hline 160 & -0.0045 & 0.3128 & 0.0053 & -0.0530 & 0.3135 & 0.0040 & 0.0020 & 0.3120 & 0.0060 & 0.0505 & 0.3133 & 0.0052 & 5.6 & 4.6 & 5.1 \\
\hline 180 & -0.0050 & 0.3135 & 0.0105 & -0.0530 & 0.3145 & 0.0090 & 0.0020 & 0.3130 & 0.0105 & 0.0505 & 0.3143 & 0.0103 & 10.5 & 9.6 & 10.1 \\
\hline 200 & -0.0050 & 0.3145 & 0.0170 & -0.0530 & 0.3155 & 0.0155 & 0.0020 & 0.3140 & 0.0170 & 0.0500 & 0.3160 & 0.0155 & 17.0 & 15.5 & 16.3 \\
\hline 220 & -0.0055 & 0.3158 & 0.0233 & -0.0535 & 0.3168 & 0.0213 & 0.0020 & 0.3150 & 0.0235 & 0.0500 & 0.3170 & 0.0220 & 23.4 & 21.6 & 22.5 \\
\hline
\end{tabular}

Note: All dimensional measurements are in units of inches unless otherwise indicated. 


\section{S/N P1962}

Table A: Dial Indicator Raw Data. View angles correlate to AIM reference frame. Span between P1 and P3 was 3.8 inches.

\begin{tabular}{|c|c|c|c|c|c|c|c|c|c|c|c|c|c|c|c|}
\hline & & & & \multicolumn{3}{|c|}{0 degrees } & \multicolumn{3}{|c|}{90 degrees } & \multicolumn{3}{|c|}{180 degrees } & \multicolumn{3}{|c|}{270 degrees } \\
\hline CAN SN & DATE & TIME & Pressure & $\mathrm{P} 1$ & $\mathrm{P} 2$ & $\mathrm{P} 3$ & $\mathrm{P} 1$ & P2 & $\mathrm{P} 3$ & $\mathrm{P} 1$ & P2 & P3 & $\mathrm{P} 1$ & P2 & P3 \\
\hline PT1962a & 5-Aug & $15: 32: 32$ & $\begin{array}{l}0 \\
0\end{array}$ & 0.4320 & 0.4020 & 0.4280 & 0.4270 & 0.4010 & 0.4350 & 0.4310 & 0.4010 & 0.4290 & 0.4380 & 0.4020 & 0.4240 \\
\hline PT1962a & 5-Aug & $15: 45: 32$ & 50 & 0.4180 & 0.3950 & 0.4150 & 0.4140 & 0.3950 & 0.4220 & 0.4180 & 0.3950 & 0.4160 & 0.4250 & 0.3950 & 0.4110 \\
\hline PT1962a & 5-Aug & $15: 56: 38$ & 100 & 0.4200 & 0.4020 & 0.4150 & 0.4160 & 0.4020 & 0.4230 & 0.4190 & 0.4020 & 0.4170 & 0.4270 & 0.4020 & 0.4120 \\
\hline PT1962a & 5-Aug & $16: 08: 04$ & 150 & 0.4080 & 0.3980 & 0.4040 & 0.4030 & 0.3980 & 0.4110 & 0.4070 & 0.3980 & 0.4050 & 0.4140 & 0.3980 & 0.4000 \\
\hline PT1962a & 5-Aug & $16: 19: 53$ & 170 & 0.4080 & 0.4010 & 0.4040 & 0.4030 & 0.4010 & 0.4110 & 0.4070 & 0.4010 & 0.4050 & 0.4140 & 0.4010 & 0.4000 \\
\hline PT1962a & 5-Aug & $16: 31: 15$ & 180 & 0.4080 & 0.4030 & 0.4050 & 0.4030 & 0.4030 & 0.4110 & 0.4070 & 0.4030 & 0.4050 & 0.4145 & 0.4030 & 0.4000 \\
\hline PT1962a & 5-Aug & $16: 42: 08$ & 190 & 0.3950 & 0.3930 & 0.3920 & 0.3900 & 0.3930 & 0.3980 & 0.3950 & 0.3930 & 0.3920 & 0.4010 & 0.3930 & 0.3880 \\
\hline PT1962a & 5-Aug & $16: 53: 59$ & 200 & 0.3960 & 0.3970 & 0.3950 & 0.3920 & 0.3970 & 0.4000 & 0.3960 & 0.3970 & 0.3940 & 0.4030 & 0.3970 & 0.3910 \\
\hline PT1962a & 5-Aug & $17: 07: 07$ & 210 & 0.3970 & 0.3990 & 0.3950 & 0.3920 & 0.3990 & 0.4000 & 0.3970 & 0.3990 & 0.3940 & 0.4030 & 0.3990 & 0.3900 \\
\hline PT1962a & 5-Aug & $17: 23: 08$ & 220 & 0.3970 & 0.4020 & 0.3940 & 0.3920 & 0.4020 & 0.4000 & 0.3970 & 0.4020 & 0.3940 & 0.4030 & 0.4020 & 0.3900 \\
\hline PT1962a & 5-Aug & 17:39:01 & 230 & 0.3970 & 0.4050 & 0.3950 & 0.3930 & 0.4050 & 0.4000 & 0.3970 & 0.4050 & 0.3940 & 0.4030 & 0.4050 & 0.3900 \\
\hline PT1962a & 5-Aug & $17: 58: 24$ & 250 & 0.3970 & 0.4110 & 0.3960 & 0.3930 & 0.4110 & 0.4010 & 0.3980 & 0.4110 & 0.3940 & 0.4050 & 0.4110 & 0.3910 \\
\hline PT1962a & 5-Aug & $18: 14: 20$ & 270 & 0.3980 & 0.4180 & 0.3970 & 0.3950 & 0.4180 & 0.4020 & 0.3990 & 0.4180 & 0.3950 & 0.4050 & 0.4180 & 0.3970 \\
\hline
\end{tabular}

Table B: Calculations to determine average mechanical deflection (last column).

\begin{tabular}{|c|c|c|c|c|c|c|c|c|c|c|c|c|c|c|c|}
\hline & \multicolumn{3}{|c|}{0 degrees } & \multicolumn{3}{|c|}{90 degrees } & \multicolumn{3}{|c|}{180 degrees } & \multicolumn{3}{|c|}{270 degrees } & \multicolumn{3}{|c|}{ Deflection(mils) } \\
\hline Pressure & Tilt & Center & Deflection & Tilt & Center & Deflection & Tilt & Center & \begin{tabular}{|l|} 
Deflection \\
\end{tabular} & Tilt & Center & Deflection & $0-180$ & $90-270$ & Average \\
\hline 0 & 0.0040 & 0.4300 & $\begin{array}{l}-0.0280 \\
\end{array}$ & -0.0080 & 0.4310 & -0.0300 & 0.0020 & 0.4300 & \begin{tabular}{|l|}
-0.0290 \\
\end{tabular} & 0.0140 & 0.4310 & -0.0290 & -28.5 & -29.5 & -29.0 \\
\hline 50 & 0.0030 & 0.4165 & -0.0215 & -0.0080 & 0.4180 & -0.0230 & 0.0020 & 0.4170 & -0.0220 & 0.0140 & 0.4180 & -0.0230 & -21.8 & -23.0 & -22.4 \\
\hline 100 & 0.0050 & 0.4175 & -0.0155 & -0.0070 & 0.4195 & -0.0175 & 0.0020 & 0.4180 & -0.0160 & 0.0150 & 0.4195 & -0.0175 & -15.8 & -17.5 & -16.6 \\
\hline 150 & 0.0040 & 0.4060 & -0.0080 & -0.0080 & 0.4070 & -0.0090 & 0.0020 & 0.4060 & -0.0080 & 0.0140 & 0.4070 & -0.0090 & -8.0 & -9.0 & -8.5 \\
\hline 170 & 0.0040 & 0.4060 & -0.0050 & -0.0080 & 0.4070 & -0.0060 & 0.0020 & 0.4060 & -0.0050 & 0.0140 & 0.4070 & -0.0060 & -5.0 & -6.0 & -5.5 \\
\hline 180 & 0.0030 & 0.4065 & -0.0035 & -0.0080 & 0.4070 & -0.0040 & 0.0020 & 0.4060 & -0.0030 & 0.0145 & 0.4073 & -0.0042 & -3.2 & -4.1 & -3.7 \\
\hline 190 & 0.0030 & 0.3935 & -0.0005 & -0.0080 & 0.3940 & -0.0010 & 0.0030 & 0.3935 & 005 & 0.0130 & 0.3945 & -0.0015 & -0.5 & -1.3 & -0.9 \\
\hline 200 & 0.0010 & 0.3955 & 0.0015 & -0.0080 & 0.3960 & 0.0010 & 0.0020 & 0.3950 & 0.0020 & 0.0120 & 0.3970 & 0.0000 & 1.8 & 0.5 & 1.1 \\
\hline 210 & 0.0020 & 0.3960 & 0.0030 & -0.0080 & 0.3960 & 0.0030 & 0.0030 & 0.3955 & 0.0035 & 0.0130 & 0.3965 & 0.0025 & 3.3 & 2.8 & 3.0 \\
\hline 220 & 0.0030 & 0.3955 & 0.0065 & -0.0080 & 0.3960 & 0.0060 & 0.0030 & 0.3955 & 0.0065 & 0.0130 & 0.3965 & 0.0055 & 6.5 & 5.8 & 6.1 \\
\hline 230 & 0.0020 & 0.3960 & 0.0090 & -0.0070 & 0.3965 & 0.0085 & 0.0030 & 0.3955 & 0.0095 & 0.0130 & 0.3965 & 0.0085 & 9.3 & 8.5 & 8.9 \\
\hline 250 & 0.0010 & 0.3965 & 0.0145 & -0.0080 & 0.3970 & 0.0140 & 0.0040 & 0.3960 & 0.0150 & 0.0140 & 0.3980 & 0.0130 & 14.8 & 13.5 & 14.1 \\
\hline 270 & 0.0010 & 0.3975 & 0.0205 & -0.0070 & 0.3985 & 0.0195 & 0.0040 & 0.3970 & 0.0210 & 0.0080 & 0.4010 & 0.0170 & 20.8 & 18.3 & 19.5 \\
\hline
\end{tabular}

Note: All dimensional measurements are in units of inches unless otherwise indicated. 


\section{S/N P2714}

Table A: Dial Indicator Raw Data. View angles correlate to AIM reference frame. Span between P1 and P3 was 3.8 inches.

\begin{tabular}{|c|c|c|c|c|c|c|c|c|c|c|c|c|c|c|c|}
\hline & & & & \multicolumn{3}{|c|}{0 degrees } & \multicolumn{3}{|c|}{90 degrees } & \multicolumn{3}{|c|}{180 degrees } & \multicolumn{3}{|c|}{270 degrees } \\
\hline CAN SN & DATE & TIME & Pressure & P1 & $\mathrm{P} 2$ & P3 & P1 & P2 & P3 & P1 & P2 & P3 & P1 & P2 & P3 \\
\hline PT2714a & 2 -Aug & $14: 24: 57$ & 0 & 0.4220 & 0.4000 & 0.4270 & 0.4170 & 0.4000 & 0.4290 & 0.4250 & 0.4000 & 0.4250 & 0.4270 & 0.4000 & 0.4180 \\
\hline PT2714a & 2-Aug & 14:39:04 & 50 & 0.4100 & 0.3920 & 0.4140 & 0.4030 & 0.3920 & 0.4160 & 0.4110 & 0.3920 & 0.4110 & 0.4140 & 0.3920 & 0.4050 \\
\hline PT2714a & 2-Aug & $14: 55: 36$ & 100 & 0.4110 & 0.3990 & 0.4140 & 0.4050 & 0.3990 & 0.4170 & 0.4130 & 0.3990 & 0.4130 & 0.4150 & 0.3990 & 0.4060 \\
\hline PT2714a & $2-A u g$ & $15: 08: 51$ & 120 & 0.4120 & 0.4020 & 0.4150 & 0.4050 & 0.4020 & 0.4170 & 0.4130 & 0.4020 & 0.4130 & 0.4160 & 0.4020 & 0.4060 \\
\hline PT2714a & 2-Aug & $15: 24: 48$ & 150 & 0.3990 & 0.3940 & 0.4020 & 0.3930 & 0.3940 & 0.4040 & 0.4000 & 0.3940 & 0.4000 & 0.4030 & 0.3940 & 0.3950 \\
\hline PT2714a & 2-Aug & 15:39:09 & 160 & 0.4000 & 0.3960 & 0.4020 & 0.3930 & 0.3960 & 0.4050 & 0.4010 & 0.3970 & 0.4010 & 0.4030 & 0.3970 & 0.3950 \\
\hline PT2714a & 2-Aug & $15: 55: 11$ & 170 & 0.3990 & 0.3980 & 0.4010 & 0.3930 & 0.3980 & 0.4040 & 0.4000 & 0.3980 & 0.4000 & 0.4030 & 0.3980 & 0.3940 \\
\hline PT2714a & 2-Aug & 16:09:00 & 180 & 0.4010 & 0.4020 & 0.4050 & 0.3950 & 0.4020 & 0.4070 & 0.4030 & 0.4020 & 0.4030 & 0.4050 & 0.4020 & 0.3970 \\
\hline PT2714a & 2-Aug & $16: 24: 38$ & 190 & 0.4020 & 0.4030 & 0.4050 & 0.3960 & 0.4030 & 0.4070 & 0.4030 & 0.4030 & 0.4030 & 0.4050 & 0.4030 & 0.3950 \\
\hline PT2714a & 2-Aug & $16: 42: 30$ & 200 & 0.3880 & 0.3930 & 0.3910 & 0.3820 & 0.3930 & 0.3940 & 0.3890 & 0.3930 & 0.3900 & 0.3920 & 0.3930 & 0.3830 \\
\hline PT2714a & $2-$ Aug & $\begin{array}{l}16: 59: 39 \\
\end{array}$ & 210 & 0.3880 & 0.3950 & 0.3910 & 0.3830 & 0.3950 & 0.3940 & 0.3900 & 0.3960 & 0.3900 & 0.3930 & 0.3950 & 0.3840 \\
\hline PT2714a & 2-Aug & $17: 15: 58$ & 230 & 0.3890 & 0.4000 & 0.3920 & 0.3830 & 0.4000 & 0.3940 & 0.3910 & 0.4000 & 0.3900 & 0.3940 & 0.4010 & 0.3840 \\
\hline PT2714a & 2-Aug & $17: 30: 16$ & 250 & 0.3910 & 0.4080 & 0.3930 & 0.3850 & 0.4080 & 0.3950 & 0.3910 & 0.4080 & 0.3920 & 0.3950 & 0.4080 & 0.3850 \\
\hline PT2714a & 2-Aug & $17: 46: 22$ & 280 & 0.3930 & 0.4210 & 0.3940 & 0.3870 & 0.4210 & 0.3970 & 0.3940 & 0.4210 & 0.3930 & 0.3970 & 0.4210 & 0.3880 \\
\hline
\end{tabular}

Table B: Calculations to determine average mechanical deflection (last column).

\begin{tabular}{|c|c|c|c|c|c|c|c|c|c|c|c|c|c|c|c|}
\hline & \multicolumn{3}{|c|}{0 degrees } & \multicolumn{3}{|c|}{90 degrees } & \multicolumn{3}{|c|}{180 degrees } & \multicolumn{3}{|c|}{270 degrees } & \multicolumn{3}{|c|}{ Deflection(mils) } \\
\hline Pressure & Tilt & Center & Deflection & Tilt & Center & Deflection & Tilt & Center & Deflection & Tilt & Center & Deflection & $0-180$ & $90-270$ & Average \\
\hline 0 & -0.0050 & 0.4245 & -0.0245 & -0.0120 & 0.4230 & -0.0230 & 0.0000 & 0.4250 & -0.0250 & 0.0090 & 0.4225 & -0.0225 & -24.8 & -22.8 & -23.8 \\
\hline 50 & -0.0040 & 0.4120 & -0.0200 & -0.0130 & 0.4095 & -0.0175 & 0.0000 & 0.4110 & -0.0190 & 0.0090 & 0.4095 & -0.0175 & -19.5 & -17.5 & -18.5 \\
\hline 100 & -0.0030 & 0.4125 & -0.0135 & -0.0120 & 0.4110 & -0.0120 & 0.0000 & 0.4130 & -0.0140 & 0.0090 & 0.4105 & -0.0115 & -13.8 & -11.8 & -12.8 \\
\hline 120 & -0.0030 & 0.4135 & -0.0115 & -0.0120 & 0.4110 & -0.0090 & 0.0000 & 0.4130 & -0.0110 & 0.0100 & 0.4110 & -0.0090 & -11.3 & -9.0 & -10.1 \\
\hline 150 & -0.0030 & 0.4005 & -0.0065 & -0.0110 & 0.3985 & -0.0045 & 0.0000 & 0.4000 & -0.0060 & 0.0080 & 0.3990 & -0.0050 & -6.3 & -4.8 & -5.5 \\
\hline 160 & -0.0020 & 0.4010 & -0.0050 & -0.0120 & 0.3990 & -0.0030 & 0.0000 & 0.4010 & -0.0040 & 0.0080 & 0.3990 & -0.0020 & -4.5 & -2.5 & -3.5 \\
\hline 170 & -0.0020 & 0.4000 & -0.0020 & -0.0110 & 0.3985 & -0.0005 & 0.0000 & 0.4000 & -0.0020 & 0.0090 & 0.3985 & -0.0005 & -2.0 & -0.5 & -1.3 \\
\hline 180 & -0.0040 & 0.4030 & -0.0010 & -0.0120 & 0.4010 & 0.0010 & 0.0000 & 0.4030 & -0.0010 & 0.0080 & 0.4010 & 0.0010 & -1.0 & 1.0 & 0.0 \\
\hline 190 & -0.0030 & 0.4035 & -0.0005 & -0.0110 & 0.4015 & 0.0015 & 0.0000 & 0.4030 & 0.0000 & 0.0100 & 0.4000 & 0.0030 & -0.3 & 2.3 & 1.0 \\
\hline 200 & -0.0030 & 0.3895 & 0.0035 & -0.0120 & 0.3880 & 0.0050 & -0.0010 & 0.3895 & 0.0035 & 0.0090 & 0.3875 & 0.0055 & 3.5 & 5.3 & 4.4 \\
\hline 210 & -0.0030 & 0.3895 & 0.0055 & -0.0110 & 0.3885 & 0.0065 & 0.0000 & 0.3900 & 0.0060 & 0.0090 & 0.3885 & 0.0065 & 5.8 & 6.5 & 6.1 \\
\hline 230 & -0.0030 & 0.3905 & 0.0095 & -0.0110 & 0.3885 & 0.0115 & 0.0010 & 0.3905 & 0.0095 & 0.0100 & 0.3890 & 0.0120 & 9.5 & 11.8 & 10.6 \\
\hline 250 & -0.0020 & 0.3920 & 0.0160 & -0.0100 & 0.3900 & 0.0180 & -0.0010 & 0.3915 & 0.0165 & 0.0100 & 0.3900 & 0.0180 & 16.3 & 18.0 & 17.1 \\
\hline 280 & -0.0010 & 0.3935 & 0.0275 & -0.0100 & 0.3920 & 0.0290 & 0.0010 & 0.3935 & 0.0275 & 0.0090 & 0.3925 & 0.0285 & 27.5 & 28.8 & 28.1 \\
\hline
\end{tabular}

Note: All dimensional measurements are in units of inches unless otherwise indicated. 


\section{S/N P3370}

Table A: Dial Indicator Raw Data. View angles correlate to AIM reference frame. Span between P1 and P3 was 3.8 inches.

\begin{tabular}{|c|c|c|c|c|c|c|c|c|c|c|c|c|c|c|c|}
\hline & & & & \multicolumn{3}{|c|}{0 degrees } & \multicolumn{3}{|c|}{90 degrees } & \multicolumn{3}{|c|}{180 degrees } & \multicolumn{3}{|c|}{270 degrees } \\
\hline CAN SN & DATE & TIME & Pressure & $\mathrm{P} 1$ & $\mathrm{P} 2$ & P3 & $\mathrm{P} 1$ & P2 & P3 & $\mathrm{P} 1$ & P2 & P3 & $\mathrm{P} 1$ & P2 & P3 \\
\hline PT3370a & 1-Aug & $11: 42: 59$ & 0 & 0.4145 & 0.3880 & 0.4140 & 0.4030 & 0.3880 & 0.4190 & 0.4130 & 0.3880 & 0.4115 & 0.4175 & 0.3880 & 0.4040 \\
\hline PT3370a & 1-Aug & $12: 01: 41$ & 20 & 0.4160 & 0.3910 & 0.4150 & 0.4040 & 0.3910 & 0.4190 & 0.4130 & 0.3910 & 0.4160 & 0.4190 & 0.3910 & 0.4050 \\
\hline PT3370a & 1-Aug & $12: 12: 54$ & 40 & 0.4160 & 0.3940 & 0.4150 & 0.4040 & 0.3940 & 0.4195 & 0.4140 & 0.3940 & 0.4165 & 0.4190 & 0.3940 & 0.4050 \\
\hline PT3370a & 1-Aug & $12: 23: 32$ & 60 & 0.4030 & 0.3840 & 0.4020 & 0.3910 & 0.3840 & 0.4065 & 0.4010 & 0.3840 & 0.4040 & 0.4060 & 0.3840 & 0.3940 \\
\hline PT3370a & 1-Aug & $12: 54: 27$ & 80 & 0.4045 & 0.3880 & 0.4020 & 0.3920 & 0.3880 & 0.4070 & 0.4010 & 0.3880 & 0.4050 & 0.4070 & 0.3880 & 0.3930 \\
\hline PT3370a & 1-Aug & $13: 15: 15$ & 100 & 0.4070 & 0.3930 & 0.4050 & 0.3940 & 0.3930 & 0.4100 & 0.4030 & 0.3930 & 0.4070 & 0.4090 & 0.3930 & 0.3960 \\
\hline PT3370a & 1-Aug & $13: 40: 37$ & 120 & 0.3920 & 0.3850 & 0.3930 & 0.3810 & 0.3850 & 0.3970 & 0.3920 & 0.3850 & 0.3930 & 0.3960 & 0.3850 & 0.3830 \\
\hline PT3370a & 1-Aug & 14:13:50 & 140 & 0.3930 & 0.3900 & 0.3940 & 0.3820 & 0.3900 & 0.3970 & 0.3910 & 0.3900 & 0.3930 & 0.3965 & 0.3900 & 0.3820 \\
\hline PT3370a & 1-Aug & 14:37:29 & 160 & 0.3940 & 0.3950 & 0.3950 & 0.3830 & 0.3950 & 0.3980 & 0.3930 & 0.3960 & 0.3950 & 0.3970 & 0.3960 & 0.3850 \\
\hline PT3370a & 1-Aug & $15: 00: 19$ & 180 & 0.3950 & 0.4040 & 0.3960 & 0.3840 & 0.4040 & 0.4000 & 0.3950 & 0.4040 & 0.3950 & 0.3985 & 0.4040 & 0.3860 \\
\hline PT3370a & 1-Aug & $15: 23: 44$ & 200 & 0.3960 & 0.4130 & 0.3970 & 0.3850 & 0.4120 & 0.4010 & 0.3960 & 0.4120 & 0.3970 & 0.4000 & 0.4130 & 0.3870 \\
\hline PT3370a & 1-Aug & $15: 48: 07$ & 220 & 0.3980 & 0.4240 & 0.3990 & 0.3870 & 0.4240 & 0.4020 & 0.3970 & 0.4240 & 0.3990 & 0.4010 & 0.4240 & 0.3880 \\
\hline
\end{tabular}

Table B: Calculations to determine average mechanical deflection (last column).

\begin{tabular}{|c|c|c|c|c|c|c|c|c|c|c|c|c|c|c|c|}
\hline \multirow[b]{2}{*}{ Pressure } & \multicolumn{3}{|c|}{0 degrees } & \multicolumn{3}{|c|}{90 degrees } & \multicolumn{3}{|c|}{180 degrees } & \multicolumn{3}{|c|}{270 degrees } & \multicolumn{3}{|c|}{ Deflection(mils) } \\
\hline & Tilt & Center & Deflection & Tilt & Center & Deflection & Tilt & Center & Deflection & Tilt & Center & Deflection & $0-180$ & $90-270$ & Average \\
\hline \begin{tabular}{|l|}
0 \\
\end{tabular} & 0.0005 & 0.4143 & -0.0263 & -0.0160 & 0.4110 & \begin{tabular}{|l|}
-0.0230 \\
\end{tabular} & 0.0015 & 0.4123 & -0.0243 & 0.0135 & 0.4108 & -0.0228 & -25.3 & -22.9 & -24.1 \\
\hline 20 & 0.0010 & 0.4155 & -0.0245 & -0.0150 & 0.4115 & -0.0205 & -0.0030 & 0.4145 & -0.0235 & 0.0140 & 0.4120 & -0.0210 & -24.0 & -20.8 & -22.4 \\
\hline 40 & 0.0010 & 0.4155 & -0.0215 & -0.0155 & 0.4118 & -0.0178 & -0.0025 & 0.4153 & -0.0213 & 0.0140 & 0.4120 & -0.0180 & -21.4 & -17.9 & -19.6 \\
\hline 60 & 0.0010 & 0.4025 & -0.0185 & -0.0155 & 0.3988 & -0.0148 & -0.0030 & 0.4025 & -0.0185 & 0.0120 & 0.4000 & -0.0160 & -18.5 & -15.4 & -16.9 \\
\hline 80 & 0.0025 & 0.4033 & -0.0153 & -0.0150 & 0.3995 & -0.0115 & -0.0040 & 0.4030 & -0.0150 & 0.0140 & 0.4000 & -0.0120 & -15.1 & -11.8 & -13.4 \\
\hline 100 & 0.0020 & 0.4060 & -0.0130 & -0.0160 & 0.4020 & -0.0090 & -0.0040 & 0.4050 & -0.0120 & 0.0130 & 0.4025 & -0.0095 & -12.5 & -9.2 & -10.9 \\
\hline 120 & -0.0010 & 0.3925 & -0.0075 & -0.0160 & 0.3890 & -0.0040 & -0.0010 & 0.3925 & -0.0075 & 0.0130 & 0.3895 & -0.0045 & -7.5 & -4.3 & -5.9 \\
\hline 140 & -0.0010 & 0.3935 & -0.0035 & -0.0150 & 0.3895 & 0.0005 & -0.0020 & 0.3920 & -0.0020 & 0.0145 & 0.3893 & 0.0008 & -2.8 & 0.6 & -1.1 \\
\hline 160 & -0.0010 & 0.3945 & 0.0005 & -0.0150 & 0.3905 & 0.0045 & -0.0020 & 0.3940 & 0.0020 & 0.0120 & 0.3910 & 0.0050 & 1.3 & 4.8 & 3.0 \\
\hline 180 & -0.0010 & 0.3955 & 0.0085 & -0.0160 & 0.3920 & 0.0120 & 0.0000 & 0.3950 & 0.0090 & 0.0125 & 0.3923 & 0.0118 & 8.8 & 11.9 & 10.3 \\
\hline 200 & -0.0010 & 0.3965 & 0.0165 & -0.0160 & 0.3930 & 0.0190 & -0.0010 & 0.3965 & 0.0155 & 0.0130 & 0.3935 & 0.0195 & 16.0 & 19.3 & 17.6 \\
\hline 220 & -0.0010 & 0.3985 & 0.0255 & -0.0150 & 0.3945 & 0.0295 & -0.0020 & 0.3980 & 0.0260 & 0.0130 & 0.3945 & 0.0295 & 25.8 & 29.5 & 27.6 \\
\hline
\end{tabular}

Note: All dimensional measurements are in units of inches unless otherwise indicated. 


\section{S/N P3373}

Table A: Dial Indicator Raw Data. View angles correlate to AIM reference frame. Span between P1 and P3 was 3.8 inches.

\begin{tabular}{|c|c|c|c|c|c|c|c|c|c|c|c|c|c|c|c|}
\hline & & & & \multicolumn{3}{|c|}{0 degrees } & \multicolumn{3}{|c|}{90 degrees } & \multicolumn{3}{|c|}{180 degrees } & \multicolumn{3}{|c|}{270 degrees } \\
\hline CAN SN & DATE & TIME & Pressure & $\mathrm{P} 1$ & $\mathrm{P} 2$ & P3 & $\mathrm{P} 1$ & $\mathrm{P} 2$ & P3 & $\mathrm{P} 1$ & P2 & P3 & $\mathrm{P} 1$ & P2 & P3 \\
\hline PT3373a & 4-Aug & 9:23:07 & 0 & 0.4160 & 0.3880 & 0.4200 & 0.4115 & 0.3880 & 0.4260 & 0.4170 & 0.3880 & 0.4180 & 0.4230 & 0.3880 & 0.4135 \\
\hline PT3373a & 4-Aug & $9: 54: 32$ & 50 & 0.4180 & 0.3940 & 0.4190 & 0.4130 & 0.3940 & 0.4260 & 0.4160 & 0.3940 & 0.4200 & 0.4240 & 0.3940 & 0.4150 \\
\hline PT3373a & 4-Aug & $10: 09: 52$ & 100 & 0.4060 & 0.3890 & 0.4100 & 0.4010 & 0.3890 & 0.4160 & 0.4070 & 0.3890 & 0.4080 & 0.4140 & 0.3890 & 0.4030 \\
\hline PT3373a & 4-Aug & $10: 23: 49$ & 150 & 0.4080 & 0.3990 & 0.4110 & 0.4030 & 0.3990 & 0.4180 & 0.4100 & 0.3990 & 0.4090 & 0.4160 & 0.3990 & 0.4050 \\
\hline PT3373a & 4-Aug & $10: 42: 26$ & 170 & 0.3950 & 0.3890 & 0.3980 & 0.3900 & 0.3890 & 0.4040 & 0.3960 & 0.3890 & 0.3960 & 0.4030 & 0.3890 & 0.3920 \\
\hline PT3373a & 4-Aug & $10: 57: 46$ & 190 & 0.3950 & 0.3940 & 0.3990 & 0.3910 & 0.3940 & 0.4050 & 0.3970 & 0.3950 & 0.3960 & 0.4030 & 0.3950 & 0.3930 \\
\hline PT3373a & 4-Aug & $11: 10: 06$ & 200 & 0.3960 & 0.3950 & 0.3990 & 0.3910 & 0.3970 & 0.4050 & 0.3980 & 0.3970 & 0.3960 & 0.4040 & 0.3970 & 0.3930 \\
\hline PT3373a & 4-Aug & $11: 22: 32$ & 210 & 0.3960 & 0.4000 & 0.3990 & 0.3910 & 0.4000 & 0.4050 & 0.3980 & 0.4000 & 0.3960 & 0.4040 & 0.4000 & 0.3930 \\
\hline PT3373a & 4-Aug & $11: 39: 12$ & 220 & 0.3960 & 0.4020 & 0.3990 & 0.3920 & 0.4020 & 0.4040 & 0.3980 & 0.4020 & 0.3970 & 0.4040 & 0.4020 & 0.3930 \\
\hline PT3373a & 4-Aug & $\overline{12: 05: 34}$ & 230 & 0.3970 & 0.4060 & 0.4000 & 0.3920 & 0.4060 & 0.4060 & 0.3990 & 0.4060 & 0.3970 & 0.4050 & 0.4060 & 0.3940 \\
\hline PT3373a & 4-Aug & $12: 22: 17$ & 240 & 0.3970 & 0.4100 & 0.4000 & 0.3920 & 0.4100 & 0.4060 & 0.3990 & 0.4100 & 0.3970 & 0.4050 & 0.4100 & 0.3950 \\
\hline РT3373a & 4-Aug & $12: 34: 46$ & 250 & 0.3980 & 0.4150 & 0.4020 & 0.3940 & 0.4150 & 0.4080 & 0.4010 & 0.4150 & 0.3990 & 0.4070 & 0.4150 & 0.3950 \\
\hline PT3373a & 4-Aug & $12: 48: 44$ & 280 & 0.3890 & 0.4170 & 0.3920 & 0.3835 & 0.4170 & 0.3970 & 0.3900 & 0.4170 & 0.3890 & 0.3965 & 0.4170 & 0.3840 \\
\hline
\end{tabular}

Table B: Calculations to determine average mechanical deflection (last column).

\begin{tabular}{|c|c|c|c|c|c|c|c|c|c|c|c|c|c|c|c|}
\hline \multirow[b]{2}{*}{ Pressure } & \multicolumn{3}{|c|}{0 degrees } & \multicolumn{3}{|c|}{90 degrees } & \multicolumn{3}{|c|}{180 degrees } & \multicolumn{3}{|c|}{270 degrees } & \multicolumn{3}{|c|}{ Deflection(mils) } \\
\hline & Tilt & Center & Deflection & Tilt & Center & Deflection & Tilt & Center & \begin{tabular}{|l|} 
Deflection \\
\end{tabular} & Tilt & Center & Deflection & $0-180$ & $90-270$ & Average \\
\hline 0 & -0.0040 & 0.4180 & $\begin{array}{l}-0.0300 \\
\end{array}$ & -0.0145 & 0.4188 & -0.0307 & -0.0010 & 0.4175 & \begin{tabular}{|l|}
-0.0295 \\
\end{tabular} & 0.0095 & 0.4183 & -0.0303 & -29.8 & -30.5 & -30.1 \\
\hline 50 & -0.0010 & 0.4185 & -0.0245 & -0.0130 & 0.4195 & -0.0255 & -0.0040 & 0.4180 & -0.0240 & 0.0090 & 0.4195 & -0.0255 & -24.3 & -25.5 & -24.9 \\
\hline 100 & -0.0040 & 0.4080 & -0.0190 & -0.0150 & 0.4085 & -0.0195 & -0.0010 & 0.4075 & -0.0185 & 0.0110 & 0.4085 & -0.0195 & -18.8 & -19.5 & -19.1 \\
\hline 150 & -0.0030 & 0.4095 & -0.0105 & -0.0150 & 0.4105 & -0.0115 & 0.0010 & 0.4095 & -0.0105 & 0.0110 & 0.4105 & -0.0115 & -10.5 & -11.5 & -11.0 \\
\hline 170 & -0.0030 & 0.3965 & -0.0075 & -0.0140 & 0.3970 & -0.0080 & 0.0000 & 0.3960 & -0.0070 & 0.0110 & 0.3975 & -0.0085 & -7.3 & -8.3 & -7.8 \\
\hline 190 & -0.0040 & 0.3970 & -0.0030 & -0.0140 & 0.3980 & -0.0040 & 0.0010 & 0.3965 & -0.0015 & 0.0100 & 0.3980 & -0.0030 & -2.3 & -3.5 & -2.9 \\
\hline 200 & -0.0030 & 0.3975 & -0.0025 & -0.0140 & 0.3980 & -0.0010 & 0.0020 & 0.3970 & 0.0 & 0.0110 & 0.3985 & 015 & -1.3 & -1.3 & -1.3 \\
\hline 210 & -0.0030 & 0.3975 & 0.0025 & -0.0140 & 0.3980 & 0.0020 & 0.0020 & 0.3970 & 0.0030 & 0.0110 & 0.3985 & 0.0015 & 2.8 & 1.8 & 2.3 \\
\hline 220 & -0.0030 & 0.3975 & 0.0045 & -0.0120 & 0.3980 & 0.0040 & 0.0010 & 0.3975 & 0.0045 & 0.0110 & 0.3985 & 0.0035 & 4.5 & 3.8 & 4.1 \\
\hline 230 & -0.0030 & 0.3985 & 0.0075 & -0.0140 & 0.3990 & 0.0070 & 0.0020 & 0.3980 & 0.0080 & 0.0110 & 0.3995 & 0.0065 & 7.8 & 6.8 & 7.3 \\
\hline 240 & -0.0030 & 0.3985 & 0.0115 & -0.0140 & 0.3990 & 0.0110 & 0.0020 & 0.3980 & 0.0120 & 0.0100 & 0.4000 & 0.0100 & 11.8 & 10.5 & 11.1 \\
\hline 250 & -0.0040 & 0.4000 & 0.0150 & -0.0140 & 0.4010 & 0.0140 & 0.0020 & 0.4000 & 0.0150 & 0.0120 & 0.4010 & 0.0140 & 15.0 & 14.0 & 14.5 \\
\hline 280 & -0.0030 & 0.3905 & 0.0265 & -0.0135 & 0.3903 & 0.0268 & 0.0010 & 0.3895 & 0.0275 & 0.0125 & 0.3903 & 0.0268 & 27.0 & 26.8 & 26.9 \\
\hline
\end{tabular}

Note: All dimensional measurements are in units of inches unless otherwise indicated. 


\section{S/N P3379}

Table A: Dial Indicator Raw Data. View angles correlate to AIM reference frame. Span between P1 and P3 was 3.8 inches.

\begin{tabular}{|c|c|c|c|c|c|c|c|c|c|c|c|c|c|c|c|}
\hline & & & & \multicolumn{3}{|c|}{0 degrees } & \multicolumn{3}{|c|}{90 degrees } & \multicolumn{3}{|c|}{180 degrees } & \multicolumn{3}{|c|}{270 degrees } \\
\hline CAN SN & DATE & TIME & Pressure & $\mathrm{P} 1$ & $\mathrm{P} 2$ & P3 & $\mathrm{P} 1$ & P2 & P3 & $\mathrm{P} 1$ & P2 & P3 & $\mathrm{P} 1$ & P2 & P3 \\
\hline PT3379a & 31-Jul & $11: 17: 00$ & 0 & 0.4320 & 0.4120 & 0.4360 & 0.4655 & 0.4120 & 0.4030 & 0.4380 & 0.4120 & 0.4315 & 0.4050 & 0.4120 & 0.4630 \\
\hline PT3379a & 31-Jul & $11: 43: 00$ & 20 & 0.4365 & 0.4145 & 0.4310 & 0.4655 & 0.4145 & 0.4030 & 0.4335 & 0.4145 & 0.4355 & 0.4040 & 0.4140 & 0.4635 \\
\hline PT3379a & 31-Jul & 12:09:00 & 40 & 0.4190 & 0.4035 & 0.4230 & 0.4520 & 0.4035 & 0.3895 & 0.4255 & 0.4035 & 0.4180 & 0.3910 & 0.4035 & 0.4500 \\
\hline PT3379a & 31-Jul & $12: 37: 00$ & 60 & 0.4200 & 0.4065 & 0.4230 & 0.4520 & 0.4070 & 0.3900 & 0.4260 & 0.4070 & 0.4185 & 0.3920 & 0.4065 & 0.4500 \\
\hline$\overline{\text { PT3379a }}$ & 31-Jul & 13:02:00 & 90 & 0.4210 & 0.4120 & 0.4250 & 0.4535 & 0.4120 & 0.3910 & 0.4275 & 0.4120 & 0.4195 & 0.3925 & 0.4120 & 0.4515 \\
\hline PT3379a & 31-Jul & 13:21:00 & 120 & 0.4150 & 0.4060 & 0.4080 & 0.4425 & 0.4060 & 0.3805 & 0.4105 & 0.4060 & 0.4130 & 0.3810 & 0.4060 & 0.4410 \\
\hline PT3379a & 31-Jul & $13: 50: 00$ & 135 & 0.4125 & 0.4100 & 0.4140 & 0.4395 & 0.4100 & 0.3855 & 0.4160 & 0.4100 & 0.4110 & 0.3875 & 0.4100 & 0.4365 \\
\hline PT3379a & 31-Jul & $14: 16: 00$ & 150 & 0.4125 & 0.4130 & 0.4150 & 0.4400 & 0.4130 & 0.3860 & 0.4175 & 0.4135 & 0.4110 & 0.3880 & 0.4130 & 0.4370 \\
\hline PT3379a & 31-Jul & $14: 42: 00$ & 165 & 0.4125 & 0.4170 & 0.4150 & 0.4420 & 0.4175 & 0.3845 & 0.4185 & 0.4175 & 0.4110 & 0.3855 & 0.4170 & 0.4405 \\
\hline PT3379a & 31-Jul & $15: 07: 00$ & 180 & 0.4140 & 0.4220 & 0.4140 & 0.4415 & 0.4220 & 0.3855 & 0.4180 & 0.4220 & 0.4120 & 0.3840 & 0.4220 & 0.4435 \\
\hline PT3379a & 31-Jul & $15: 30: 00$ & 195 & 0.4100 & 0.4270 & 0.4200 & 0.4400 & 0.4270 & 0.3880 & 0.4230 & 0.4270 & 0.4090 & 0.3900 & 0.4270 & 0.4380 \\
\hline РT3379a & 31-Jul & 15:56:00 & 210 & 0.4160 & 0.4360 & 0.4175 & 0.4425 & 0.4360 & 0.3910 & 0.4200 & 0.4360 & 0.4150 & 0.3920 & 0.4360 & 0.4405 \\
\hline PT3379a & 31-Jul & $16: 23: 00$ & 230 & 0.4175 & 0.4455 & 0.4190 & 0.4436 & 0.4455 & 0.3925 & 0.4210 & 0.4460 & 0.4160 & 0.3940 & 0.4455 & 0.4410 \\
\hline
\end{tabular}

Table B: Calculations to determine average mechanical deflection (last column).

\begin{tabular}{|c|c|c|c|c|c|c|c|c|c|c|c|c|c|c|c|}
\hline \multirow[b]{2}{*}{ Pressure } & \multicolumn{3}{|c|}{0 degrees } & \multicolumn{3}{|c|}{90 degrees } & \multicolumn{3}{|c|}{180 degrees } & \multicolumn{3}{|c|}{270 degrees } & \multicolumn{3}{|c|}{ Deflection(mils) } \\
\hline & Tilt & Center & Deflection & Tilt & Center & Deflection & Tilt & Center & \begin{tabular}{|l|} 
Deflection \\
\end{tabular} & Tilt & Center & \begin{tabular}{|l|} 
Deflection \\
\end{tabular} & $0-180$ & $90-270$ & Average \\
\hline 0 & -0.0040 & 0.4340 & -0.0220 & 0.0625 & 0.4343 & -0.0223 & 0.0065 & 0.4348 & -0.0228 & -0.0580 & 0.4340 & -0.0220 & -22.4 & -22.1 & -22.3 \\
\hline 20 & 0.0055 & 0.4338 & -0.0193 & 0.0625 & 0.4343 & -0.0198 & -0.0020 & 0.4345 & -0.0200 & -0.0595 & 0.4338 & -0.0198 & -19.6 & -19.8 & -19.7 \\
\hline 40 & -0.0040 & 0.4210 & -0.0175 & 0.0625 & 0.4208 & -0.0173 & 0.0075 & 0.4218 & -0.0182 & -0.0590 & 0.4205 & -0.0170 & -17.9 & -17.1 & -17.5 \\
\hline 60 & -0.0030 & 0.4215 & -0.0150 & 0.0620 & 0.4210 & -0.0140 & 0.0075 & 0.4223 & -0.0153 & -0.0580 & 0.4210 & -0.0145 & -15.1 & -14.3 & -14.7 \\
\hline 90 & -0.0040 & 0.4230 & -0.0110 & 0.0625 & 0.4223 & -0.0103 & 0.0080 & 0.4235 & -0.0115 & -0.0590 & 0.4220 & -0.0100 & -11.3 & -10.1 & -10.7 \\
\hline 120 & 0.0070 & 0.4115 & -0.0055 & 0.0620 & 0.4115 & -0.0055 & -0.0025 & 0.4118 & -0.0057 & -0.0600 & 0.4110 & -0.0050 & -5.6 & -5.2 & -5.4 \\
\hline 135 & -0.0015 & 0.4133 & -0.0033 & 0.0540 & 0.4125 & -0.0025 & 0.0050 & 0.4135 & -0.0035 & -0.0490 & 0.4120 & -0.0020 & -3.4 & -2.3 & -2.8 \\
\hline 150 & -0.0025 & 0.4138 & -0.0007 & 0.0540 & 0.4130 & 0.0000 & 0.0065 & 0.4143 & -0.0008 & -0.0490 & 0.4125 & 0.0005 & -0.8 & 0.3 & -0.3 \\
\hline 165 & -0.0025 & 0.4138 & 0.0033 & 0.0575 & 0.4133 & 0.0042 & 0.0075 & 0.4148 & 0.0028 & -0.0550 & 0.4130 & 0.0040 & 3.0 & 4.1 & 3.6 \\
\hline 180 & 0.0000 & 0.4140 & 0.0080 & 0.0560 & 0.4135 & 0.0085 & 0.0060 & 0.4150 & 0.0070 & -0.0595 & 0.4138 & 0.0082 & 7.5 & 8.4 & 7.9 \\
\hline 195 & -0.0100 & 0.4150 & 0.0120 & 0.0520 & 0.4140 & 0.0130 & 0.0140 & 0.4160 & 0.0110 & -0.0480 & 0.4140 & 0.0130 & 11.5 & 13.0 & 12.3 \\
\hline 210 & -0.0015 & 0.4168 & 0.0193 & 0.0515 & 0.4168 & 0.0193 & 0.0050 & 0.4175 & 0.0185 & -0.0485 & 0.4163 & 0.0198 & 18.9 & 19.5 & 19.2 \\
\hline 230 & -0.0015 & 0.4183 & 0.0273 & 0.0511 & 0.4181 & 0.0275 & 0.0050 & 0.4185 & 0.0275 & -0.0470 & 0.4175 & 0.0280 & 27.4 & 27.7 & 27.6 \\
\hline
\end{tabular}

Note: All dimensional measurements are in units of inches unless otherwise indicated. 


\section{S/N P3381}

Table A: Dial Indicator Raw Data. View angles correlate to AIM reference frame. Span between P1 and P3 was 3.8 inches.

\begin{tabular}{|c|c|c|c|c|c|c|c|c|c|c|c|c|c|c|c|}
\hline & & & & \multicolumn{3}{|c|}{0 degrees } & \multicolumn{3}{|c|}{90 degrees } & \multicolumn{3}{|c|}{180 degrees } & \multicolumn{3}{|c|}{270 degrees } \\
\hline CAN SN & DATE & TIME & Pressure & P1 & P2 & P3 & P1 & P2 & P3 & $\mathrm{P} 1$ & P2 & P3 & $\mathrm{P} 1$ & P2 & P3 \\
\hline PT3381a & 4-Aug & $13: 26: 00$ & $\begin{array}{l}0 \\
\end{array}$ & 0.4200 & 0.4000 & 0.4230 & 0.4170 & 0.4000 & 0.4300 & 0.4210 & 0.4000 & 0.4210 & 0.4280 & 0.4000 & 0.4180 \\
\hline PT3381a & 4-Aug & $13: 43: 00$ & 50 & 0.4080 & 0.3950 & 0.4110 & 0.4050 & 0.3950 & 0.4180 & 0.4090 & 0.3950 & 0.4100 & 0.4150 & 0.3950 & 0.4060 \\
\hline PT3381a & 4-Aug & 13:58:00 & 100 & 0.4100 & 0.4000 & 0.4110 & 0.4060 & 0.4000 & 0.4180 & 0.4100 & 0.4000 & 0.4110 & 0.4160 & 0.4000 & 0.4080 \\
\hline PT3381a & 4-Aug & 14:13:00 & 150 & 0.3990 & 0.3980 & 0.3990 & 0.3940 & 0.3980 & 0.4020 & 0.3980 & 0.3980 & 0.4000 & 0.4040 & 0.3980 & 0.3950 \\
\hline PT3381a & 4-Aug & $14: 28: 00$ & 160 & 0.3990 & 0.4000 & 0.3990 & 0.3940 & 0.4000 & 0.4050 & 0.3980 & 0.4000 & 0.4000 & 0.4040 & 0.4000 & 0.3950 \\
\hline РT3381a & 4-Aug & 14:45:00 & 170 & 0.4000 & 0.4010 & 0.3990 & 0.3950 & 0.4010 & 0.4050 & 0.3980 & 0.4010 & 0.4000 & 0.4040 & 0.4010 & 0.3950 \\
\hline PT3381a & 4-Aug & 15:00:00 & 180 & 0.3860 & 0.3910 & 0.3860 & 0.3810 & 0.3900 & 0.3920 & 0.3850 & 0.3910 & 0.3870 & 0.3900 & 0.3910 & 0.3820 \\
\hline PT3381a & 4-Aug & 15:19:00 & 190 & 0.3870 & 0.3950 & 0.3870 & 0.3820 & 0.3950 & 0.3930 & 0.3850 & 0.3940 & 0.3880 & 0.3900 & 0.3950 & 0.3830 \\
\hline PT3381a & 4-Aug & $15: 35: 00$ & 200 & 0.3890 & 0.3990 & 0.3890 & 0.3840 & 0.3990 & 0.3940 & 0.3870 & 0.3990 & 0.3910 & 0.3920 & 0.3990 & 0.3850 \\
\hline PT3381a & 4-Aug & 15:58:00 & 220 & 0.3970 & 0.4060 & 0.3910 & 0.3880 & 0.4050 & 0.3940 & 0.3890 & 0.4050 & 0.3990 & 0.3920 & 0.4050 & 0.3900 \\
\hline РT3381a & 4-Aug & $16: 14: 00$ & 240 & 0.3920 & 0.4110 & 0.3900 & 0.3860 & 0.4120 & 0.3960 & 0.3890 & 0.4110 & 0.3920 & 0.3950 & 0.4120 & 0.3860 \\
\hline
\end{tabular}

Table B: Calculations to determine average mechanical deflection (last column).

\begin{tabular}{|c|c|c|c|c|c|c|c|c|c|c|c|c|c|c|c|}
\hline & \multicolumn{3}{|c|}{0 degrees } & \multicolumn{3}{|c|}{90 degrees } & \multicolumn{3}{|c|}{180 degrees } & \multicolumn{3}{|c|}{270 degrees } & \multicolumn{3}{|c|}{ Deflection(mils) } \\
\hline Pressure & Tilt & Center & Deflection & Tilt & Center & Deflection & Tilt & Center & Deflection & Tilt & Center & Deflection & $0-180$ & $90-270$ & Average \\
\hline 0 & -0.0030 & 0.4215 & -0.0215 & -0.0130 & 0.4235 & -0.0235 & 0.0000 & 0.4210 & -0.0210 & 0.0100 & 0.4230 & -0.0230 & -21.3 & -23.3 & -22.3 \\
\hline 50 & -0.0030 & 0.4095 & -0.0145 & -0.0130 & 0.4115 & -0.0165 & -0.0010 & 0.4095 & -0.0145 & 0.0090 & 0.4105 & -0.0155 & -14.5 & -16.0 & -15.3 \\
\hline 100 & -0.0010 & 0.4105 & -0.0105 & -0.0120 & 0.4120 & -0.0120 & -0.0010 & 0.4105 & -0.0105 & 0.0080 & 0.4120 & -0.0120 & -10.5 & $\begin{array}{l}-12.0 \\
\end{array}$ & -11.3 \\
\hline 150 & 0.0000 & 0.3990 & -0.0010 & -0.0080 & 0.3980 & 0.0000 & -0.0020 & 0.3990 & -0.0010 & 0.0090 & 0.3995 & -0.0015 & -1.0 & -0.8 & -0.9 \\
\hline 160 & 0.0000 & 0.3990 & 0.0010 & -0.0110 & 0.3995 & 0.0005 & -0.0020 & 0.3990 & 0.0010 & 0.0090 & 0.3995 & 0.0005 & 1.0 & 0.5 & 0.8 \\
\hline 170 & 0.0010 & 0.3995 & 0.0015 & -0.0100 & 0.4000 & 0.0010 & -0.0020 & 0.3990 & 0.0020 & 0.0090 & 0.3995 & 0.0015 & 1.8 & 1.3 & 1.5 \\
\hline 180 & 0.0000 & 0.3860 & 0.0050 & -0.0110 & 0.3865 & 0.0035 & -0.0020 & 0.3860 & 0.0050 & 0.0080 & 0.3860 & 0.0050 & 5.0 & 4.3 & 4.6 \\
\hline 190 & 0.0000 & 0.3870 & 0.0080 & -0.0110 & 0.3875 & 0.0075 & -0.0030 & 0.3865 & 0.0075 & 0.0070 & 0.3865 & 0.0085 & 7.8 & 8.0 & 7.9 \\
\hline 200 & 0.0000 & 0.3890 & 0.0100 & -0.0100 & 0.3890 & 0.0100 & -0.0040 & 0.3890 & 0.0100 & 0.0070 & 0.3885 & 0.0105 & 10.0 & 10.3 & 10.1 \\
\hline 220 & 0.0060 & 0.3940 & 0.0120 & -0.0060 & 0.3910 & 0.0140 & -0.0100 & 0.3940 & 0.0110 & 0.0020 & 0.3910 & 0.0140 & 11.5 & 14.0 & 12.8 \\
\hline 240 & 0.0020 & 0.3910 & 0.0200 & -0.0100 & 0.3910 & 0.0210 & -0.0030 & 0.3905 & 0.0205 & 0.0090 & 0.3905 & 0.0215 & 20.3 & 21.3 & 20.8 \\
\hline
\end{tabular}

Note: All dimensional measurements are in units of inches unless otherwise indicated. 


\section{S/N P3382}

Table A: Dial Indicator Raw Data. View angles correlate to AIM reference frame. Span between P1 and P3 was 3.8 inches.

\begin{tabular}{|c|c|c|c|c|c|c|c|c|c|c|c|c|c|c|c|}
\hline & & & & \multicolumn{3}{|c|}{0 degrees } & \multicolumn{3}{|c|}{90 degrees } & \multicolumn{3}{|c|}{180 degrees } & \multicolumn{3}{|c|}{270 degrees } \\
\hline CAN SN & DATE & TIME & Pressure & $\mathrm{P} 1$ & $\mathrm{P} 2$ & P3 & $\mathrm{P} 1$ & P2 & P3 & $\mathrm{P} 1$ & P2 & P3 & $\mathrm{P} 1$ & P2 & P3 \\
\hline PT3382a & 5-Aug & $12: 15: 01$ & $\begin{array}{l}0 \\
\end{array}$ & 0.4320 & 0.4000 & 0.4320 & 0.4270 & 0.4000 & 0.4320 & 0.4330 & 0.4000 & 0.4315 & 0.4330 & 0.3990 & 0.4260 \\
\hline PT3382a & 5-Aug & $12: 38: 37$ & 50 & 0.4230 & 0.3940 & 0.4210 & 0.4150 & 0.3940 & 0.4210 & 0.4230 & 0.3940 & 0.4200 & 0.4230 & 0.3940 & 0.4150 \\
\hline PT3382a & 5-Aug & $12: 55: 24$ & 100 & 0.4240 & 0.4000 & 0.4210 & 0.4180 & 0.4000 & 0.4210 & 0.4240 & 0.4000 & 0.4210 & 0.4250 & 0.4000 & 0.4150 \\
\hline PT3382a & 5-Aug & 13:08:03 & 150 & 0.4110 & 0.3960 & 0.4090 & 0.4050 & 0.3960 & 0.4090 & 0.4120 & 0.3960 & 0.4080 & 0.4120 & 0.3960 & 0.4030 \\
\hline РT3382a & 5-Aug & 13:23:01 & 175 & 0.4120 & 0.4010 & 0.4100 & 0.4060 & 0.4010 & 0.4100 & 0.4120 & 0.4010 & 0.4090 & 0.4125 & 0.4010 & 0.4040 \\
\hline PT3382a & 5-Aug & $13: 38: 54$ & 190 & 0.3980 & 0.3930 & 0.3960 & 0.3920 & 0.3920 & 0.3960 & 0.3990 & 0.3910 & 0.3950 & 0.3990 & 0.3920 & 0.3910 \\
\hline PT3382a & 5-Aug & $13: 55: 19$ & 200 & 0.3990 & 0.3940 & 0.3960 & 0.3920 & 0.3940 & 0.3960 & 0.3990 & 0.3940 & 0.3960 & 0.3990 & 0.3940 & 0.3900 \\
\hline PT3382a & 5-Aug & $14: 10: 09$ & 210 & 0.3990 & 0.3970 & 0.3960 & 0.3920 & 0.3970 & 0.3960 & 0.3990 & 0.3970 & 0.3960 & 0.4000 & 0.3970 & 0.3900 \\
\hline PT3382a & 5-Aug & $14: 24: 34$ & 220 & 0.3990 & 0.4000 & 0.3960 & 0.3930 & 0.4000 & 0.3970 & 0.3990 & 0.4000 & 0.3960 & 0.4000 & 0.4000 & 0.3900 \\
\hline PT3382a & 5-Aug & $14: 37: 30$ & 230 & 0.3990 & 0.4030 & 0.3970 & 0.3930 & 0.4040 & 0.3970 & 0.3990 & 0.4040 & 0.3960 & 0.4000 & 0.4040 & 0.3910 \\
\hline PT3382a & 5-Aug & $14: 54: 45$ & 250 & 0.4020 & 0.4125 & 0.4000 & 0.3960 & 0.4120 & 0.4000 & 0.4020 & 0.4120 & 0.3990 & 0.4025 & 0.4120 & 0.3940 \\
\hline PT3382a & 5-Aug & $15: 10: 04$ & 270 & 0.4030 & 0.4230 & 0.4010 & 0.3970 & 0.4230 & 0.4020 & 0.4030 & 0.4230 & 0.4010 & 0.4040 & 0.4230 & 0.3950 \\
\hline
\end{tabular}

Table B: Calculations to determine average mechanical deflection (last column).

\begin{tabular}{|c|c|c|c|c|c|c|c|c|c|c|c|c|c|c|c|}
\hline \multirow[b]{2}{*}{ Pressure } & \multicolumn{3}{|c|}{0 degrees } & \multicolumn{3}{|c|}{90 degrees } & \multicolumn{3}{|c|}{180 degrees } & \multicolumn{3}{|c|}{270 degrees } & \multicolumn{3}{|c|}{ Deflection(mils) } \\
\hline & Tilt & Center & Deflection & Tilt & Center & Deflection & Tilt & Center & Deflection & Tilt & Center & Deflection & $0-180$ & $90-270$ & Average \\
\hline \begin{tabular}{|l|}
0 \\
\end{tabular} & 0.0000 & 0.4320 & -0.0320 & -0.0050 & 0.4295 & \begin{tabular}{|l|}
-0.0295 \\
\end{tabular} & 0.0015 & 0.4323 & -0.0323 & 0.0070 & 0.4295 & -0.0305 & -32.1 & -30.0 & -31.1 \\
\hline 50 & 0.0020 & 0.4220 & -0.0280 & -0.0060 & 0.4180 & -0.0240 & 0.0030 & 0.4215 & -0.0275 & 0.0080 & 0.4190 & -0.0250 & -27.8 & -24.5 & -26.1 \\
\hline 100 & 0.0030 & 0.4225 & -0.0225 & -0.0030 & 0.4195 & -0.0195 & 0.0030 & 0.4225 & -0.0225 & 0.0100 & 0.4200 & -0.0200 & -22.5 & -19.8 & -21.1 \\
\hline 150 & 0.0020 & 0.4100 & -0.0140 & -0.0040 & 0.4070 & -0.0110 & 0.0040 & 0.4100 & -0.0140 & 0.0090 & 0.4075 & -0.0115 & -14.0 & -11.3 & -12.6 \\
\hline 175 & 0.0020 & 0.4110 & -0.0100 & -0.0040 & 0.4080 & -0.0070 & 0.0030 & 0.4105 & -0.0095 & 0.0085 & 0.4083 & -0.0072 & -9.7 & -7.1 & -8.4 \\
\hline 190 & 0.0020 & 0.3970 & -0.0040 & -0.0040 & 0.3940 & -0.0020 & 0.0040 & 0.3970 & -0.0060 & 0.0080 & 0.3950 & -0.0030 & -5.0 & -2.5 & -3.8 \\
\hline 200 & 0.0030 & 0.3975 & -0.0035 & -0.0040 & 0.3940 & 0.0000 & 0.0030 & 0.3975 & -0.0035 & 0.0090 & 0.3945 & -0.0005 & -3.5 & -0.3 & -1.9 \\
\hline 210 & 0.0030 & 0.3975 & -0.0005 & -0.0040 & 0.3940 & 0.0030 & 0.0030 & 0.3975 & -0.0005 & 0.0100 & 0.3950 & 0.0020 & -0.5 & 2.5 & 1.0 \\
\hline 220 & 0.0030 & 0.3975 & 0.0025 & -0.0040 & 0.3950 & 0.0050 & 0.0030 & 0.3975 & 0.0025 & 0.0100 & 0.3950 & 0.0050 & 2.5 & 5.0 & 3.8 \\
\hline 230 & 0.0020 & 0.3980 & 0.0050 & -0.0040 & 0.3950 & 0.0090 & 0.0030 & 0.3975 & 0.0065 & 0.0090 & 0.3955 & 0.0085 & 5.8 & 8.8 & 7.3 \\
\hline 250 & 0.0020 & 0.4010 & 0.0115 & -0.0040 & 0.3980 & 0.0140 & 0.0030 & 0.4005 & 0.0115 & 0.0085 & 0.3983 & 0.0138 & 11.5 & 13.9 & 12.7 \\
\hline 270 & 0.0020 & 0.4020 & 0.0210 & -0.0050 & 0.3995 & 0.0235 & 0.0020 & 0.4020 & 0.0210 & 0.0090 & 0.3995 & 0.0235 & 21.0 & 23.5 & 22.3 \\
\hline
\end{tabular}

Note: All dimensional measurements are in units of inches unless otherwise indicated. 
Appendix 2 : Spreadsheet Data Supporting the Pressure Test Graphs for the CM-NCF Analysis. 
Figure A2.1: Spreadsheet showing the cell assignments and formulas used in the following sheets for Table A, B, C and D entries.

Table A

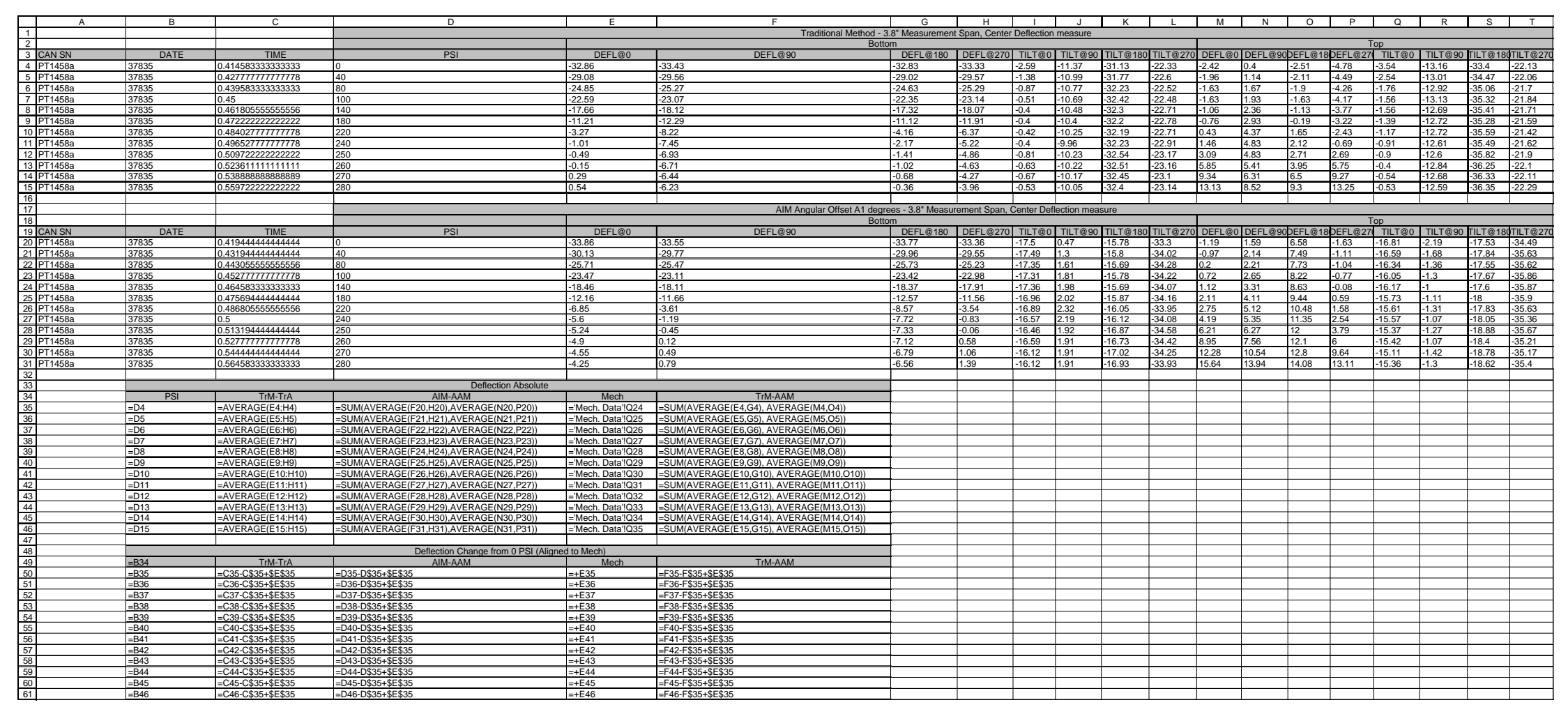




\section{S/N P1458}

Table A

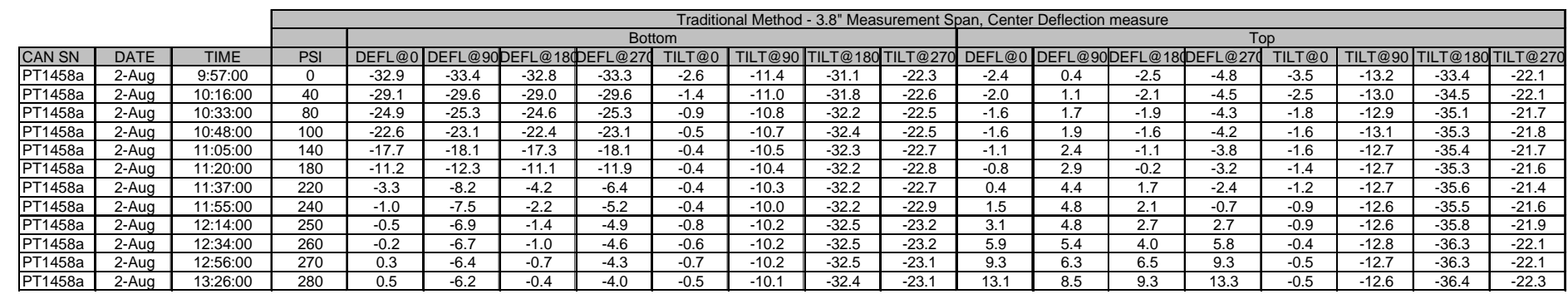

AlM Angular Offset A1 degrees - 3.8" Measurement Span, Center Deflection measure

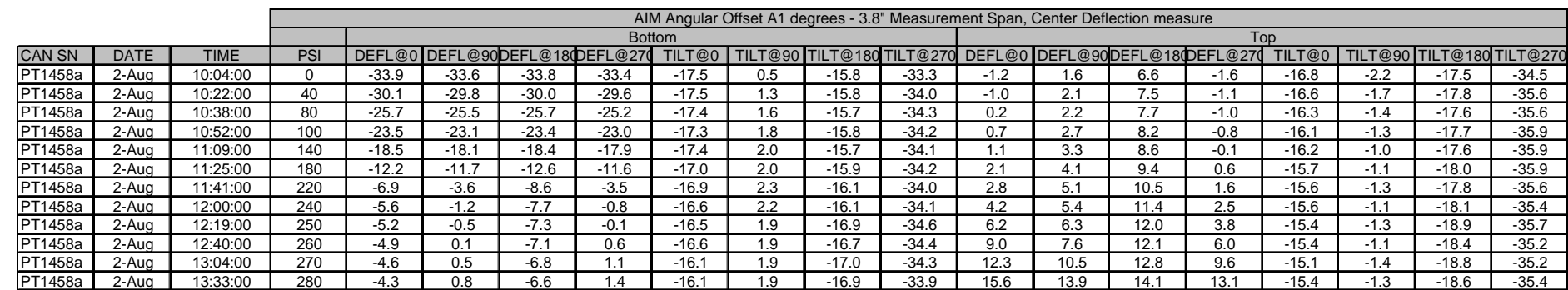

Table C
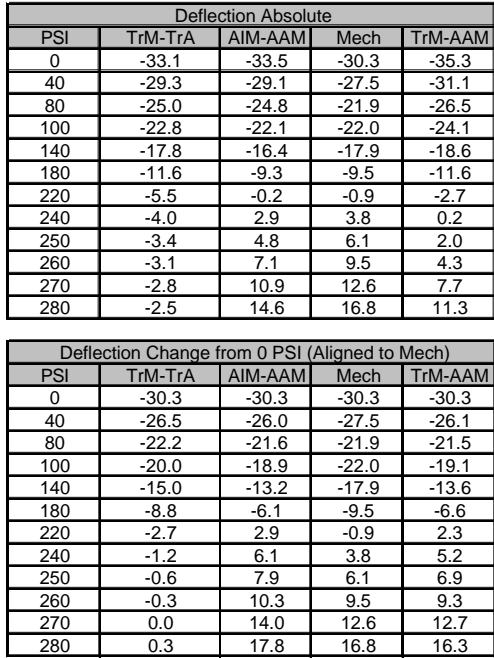

Table D

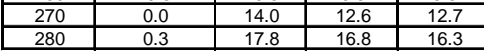




\section{S/N P1947}

Table A

Table B

Table C

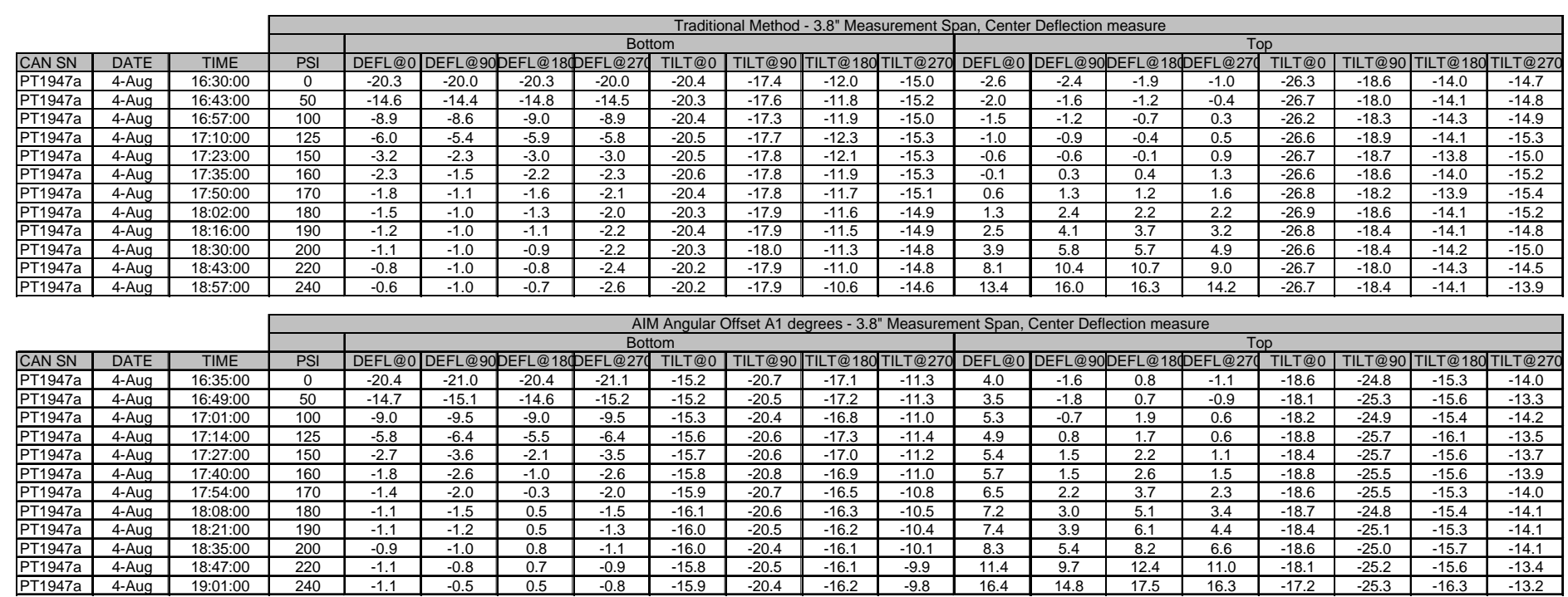
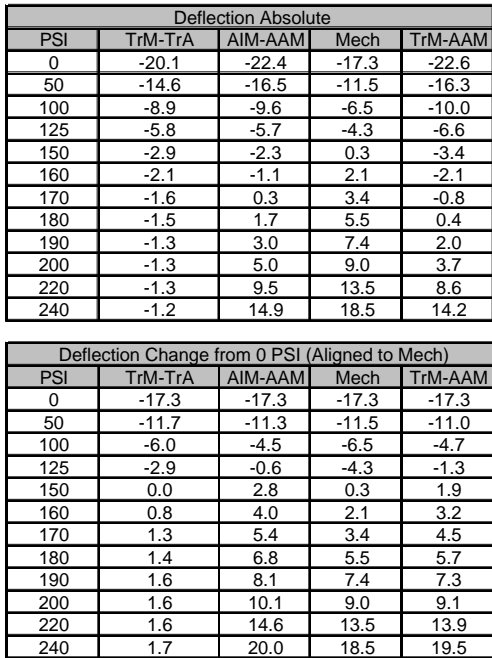

Table D

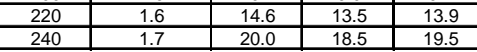




\section{S/N P1958}

Table A

Table B

Table C

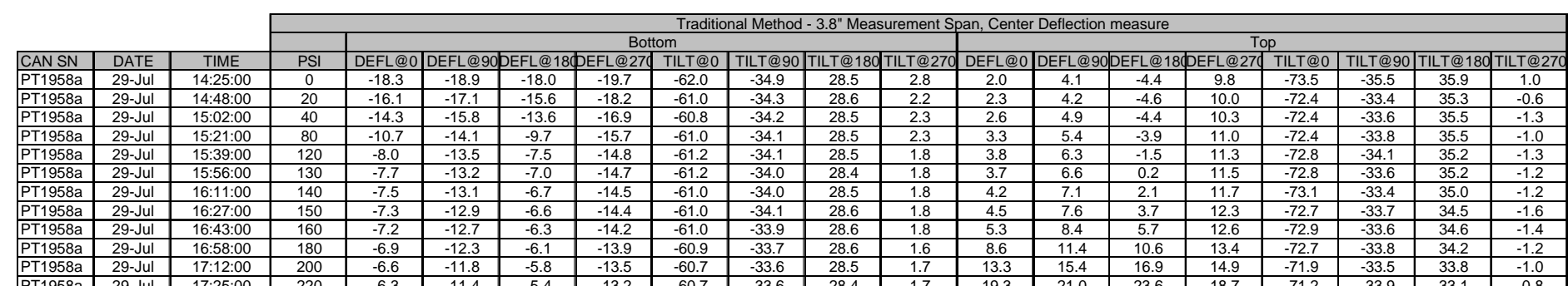

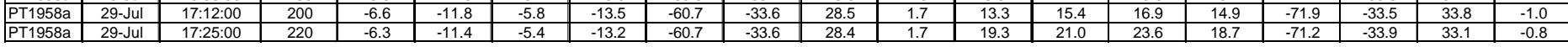

\begin{tabular}{|c|c|c|c|c|c|}
\hline & & & & & \\
\hline & & $\overline{\mathrm{TIM}}$ & $P S \mid$ & & $\overline{D E F L}$ \\
\hline PT1958a & 29-Jul & 14:32:00 & 0 & -18.6 & $\frac{17.6}{-17.6}$ \\
\hline & 29-Jul| & 14:53:00 & & & \\
\hline PT1958a & & 15:07:00 & 40 & -15.8 & \\
\hline $\begin{array}{l}\text { PT1958a } \\
\end{array}$ & 29-Jul & $15: 27: 00$ & 80 & & -1.0 \\
\hline $\begin{array}{l}\text { PT1958a } \\
\text { PTT1958 }\end{array}$ & & 15:43:00 & $\frac{120}{120}$ & -13.3 & -3.1 \\
\hline$\frac{P 1958 a}{\text { PT1958a }}$ & 29-Jul & 16:00:00 & $\frac{130}{130}$ & $\begin{array}{l}-13.1 \\
\frac{1}{1}\end{array}$ & $\frac{-2.1}{1.1}$ \\
\hline PT1958a & $\frac{29-\text {-JuI }}{29 .-1 u l}$ & $\frac{10.17 .00}{16 \cdot 31 \cdot 00}$ & $\frac{740}{150}$ & $\frac{-1.0}{-128}$ & $\frac{-1.0}{-0.6}$ \\
\hline PT1958a & 29-Jul & $16: 48 \cdot 00$ & 160 & $\frac{1.126}{-126}$ & $\begin{array}{l}-0.6 \\
0.6\end{array}$ \\
\hline PT1958a & 29-Jul & 17:03:00 & 180 & -12.2 & 0.9 \\
\hline $\begin{array}{l}\text { PT1958a } \\
\text { PT1959 }\end{array}$ & $\begin{array}{l}\text { 29-Jul } \\
20 \text { - }\end{array}$ & 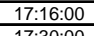 & $\begin{array}{l}200 \\
200\end{array}$ & $\begin{array}{l}-11.9 \\
-115\end{array}$ & 1.2 \\
\hline & & & & & \\
\hline & & & Aivenf & & \\
\hline & $\frac{P S I}{0}$ & $\frac{T r M-T r A}{-187}$ & $\frac{A I M-A A C}{-178}$ & $\frac{\text { Mech }}{-183}$ & TrM-AAC \\
\hline & 20 & -16.8 & -15.1 & -15.3 & -17.0 \\
\hline & 40 & -15.1 & -12.2 & -13.4 & -14.8 \\
\hline & & -12.5 & -6.7 & -8.6 & \\
\hline & 120 & -10.9 & -1.4 & -2.9 & \\
\hline & 130 & -10.6 & 0.0 & -1.6 & \\
\hline & 140 & $\begin{array}{l}-10.4 \\
102\end{array}$ & 1.6 & 0.8 & -3.9 \\
\hline & 160 & $\frac{-10.3}{-101}$ & $\frac{3.2}{59}$ & $\frac{1.6}{51}$ & $\begin{array}{r}-2.9 \\
1.2\end{array}$ \\
\hline & 180 & $\begin{array}{l}-9.8 \\
\end{array}$ & $\frac{10.9}{10.9}$ & $\begin{array}{ll}10.1 \\
\end{array}$ & 3.1. \\
\hline & 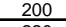 & -9.4 & 17.1 & 16.3 & \\
\hline & 220 & -9.0 & 23.7 & 22.5 & 15.6 \\
\hline
\end{tabular}

AlM Angular Offset A1 degrees - 3.8" Measurement Span, Center Deflection measure

\begin{tabular}{l|l|l|l|l|l|}
\hline Top & \\
\hline TILT@0 & TILT@90 & TLLT@180 TILT@27 \\
\hline
\end{tabular}

\begin{tabular}{|c|c|c|c|c|c|c|c|c|c|c|c|c|c|c|c|c|c|c|c|}
\hline & & 14:32:00 & 0 & -18.6 & -17.6 & -17.2 & -17.5 & -16.0 & -64.6 & -16.3 & 32.3 & 17.9 & -1.7 & 10.8 & 1.3 & -22.5 & -68.4 & -10.8 & 30.5 \\
\hline & & & 20 & -17.1 & -15.2 & -15.5 & -15.2 & & -63.9 & & 31.9 & & -1.4 & & 1.6 & -21.9 & -68.3 & & \\
\hline & 29-Jul & & 40 & & -12.8 & -14.1 & $\begin{array}{r}-12.8 \\
\end{array}$ & & -63.9 & & & & -1.2 & & 2.4 & & -67.7 & & \\
\hline & 29-Jul & & 80 & & -7.8 & & -7.7 & & -63.9 & & 31.9 & & -0.6 & 12.4 & 2.7 & -22.8 & $\begin{array}{l}-68.2 \\
6.1\end{array}$ & & \\
\hline $\begin{array}{l}\text { PT1958a } \\
\end{array}$ & 29-Jul & 15:43:00 & $\frac{120}{120}$ & $\begin{array}{r}-13.3 \\
12 . \\
\end{array}$ & -3.1 & -11.6 & -3.0 & -15.6 & -63.8 & & 31.3 & & 0.7 & $\frac{13.0}{12.1}$ & 2.6 & $\frac{-22.1}{2.1}$ & $\begin{array}{l}-69.1 \\
6.0\end{array}$ & & 31.2 \\
\hline & 29-Jul & 16:00:00 & 130 & -13.1 & -2.1 & -11.3 & -2.0 & -15.8 & -63.7 & $\begin{array}{l}-16.7 \\
\end{array}$ & 31.3 & & 1.1 & $\frac{13.1}{1.2}$ & 3.0 & $\frac{-21.8}{20}$ & $\begin{array}{l}-68.9 \\
0.7\end{array}$ & & 31.4 \\
\hline $\begin{array}{l}\text { PT1958a } \\
\text { PT1958 }\end{array}$ & 29-Jul & $\frac{16: 17}{16 \cdot 31}$ & $\frac{140}{150}$ & $\frac{-13.0}{-128}$ & -1.0 & $\begin{array}{l}-11.1 \\
\end{array}$ & $\begin{array}{r}-1.1 \\
\end{array}$ & $\begin{array}{r}-15.6 \\
-15.7\end{array}$ & $\frac{-63.9}{-636}$ & & $\frac{31.3}{31.1}$ & 19. & $\frac{2.1}{35}$ & & & & & & $\frac{31.6}{219}$ \\
\hline $\begin{array}{l}\text { PT1958a } \\
\text { PT1958a }\end{array}$ & 29-Jul & & $\begin{array}{l}150 \\
160\end{array}$ & $\frac{-12}{1-12}$ & $\begin{array}{l}-0.6 \\
0.6\end{array}$ & $\begin{array}{l}-11.0 \\
-107\end{array}$ & $\begin{array}{l}-0.5 \\
02\end{array}$ & $\begin{array}{r}-15.7 \\
-15.8\end{array}$ & & & & & $\frac{3.5}{5.5}$ & & & & & & $\frac{31.9}{322}$ \\
\hline$\frac{11958 a}{\text { PT1958a }}$ & $\frac{\text { 29--Jul }}{\text { 29-Jul }}$ & $\begin{array}{l}17: 04: 00 \\
17: 03\end{array}$ & $\frac{160}{180}$ & $\frac{-12.6}{-12.2}$ & $\begin{array}{l}0.6 \\
0.9\end{array}$ & $\begin{array}{l}-10.7 \\
-10.3\end{array}$ & 0.2 & $\begin{array}{l}-15.8 \\
-15.9\end{array}$ & $\begin{array}{l}-63.6 \\
-63.3\end{array}$ & $\frac{-16.5}{-16.5}$ & 31.3 & 21.1 & $\begin{array}{l}5.5 \\
10.1 \\
\end{array}$ & 15.3 & 10. & $\frac{-2.3 .3}{-22.0}$ & $\begin{array}{l}-68.9 \\
-68.9\end{array}$ & -11.2 & $\frac{32.2}{32.6}$ \\
\hline $\begin{array}{l}\text { PT1958a } \\
\end{array}$ & 29-Jul & \begin{tabular}{l|l}
$17: 16: 00$ \\
\end{tabular} & 200 & -11.9 & 1.2 & $\begin{array}{l}-9.9 \\
\end{array}$ & 0.6 & $\begin{array}{l}-16.0 \\
\end{array}$ & -63.2 & $\begin{array}{l}-16.3 \\
\end{array}$ & 31.3 & 21.7 & 16.0 & 18.6 & 16.3 & -22.1 & -69.6 & -11.8 & $\begin{array}{l}\frac{3.2 .0}{33.0} \\
\end{array}$ \\
\hline & & & & -11.5 & 1.4 & -9.4 & 0.9 & -15.8 & -63.0 & -16.4 & 31.5 & 22 & & & & & & & \\
\hline
\end{tabular}

\begin{tabular}{|c|c|c|c|c|}
\hline \multicolumn{5}{|c|}{ Deflection Change from 0 PSI (Aligned to Mech) } \\
\hline PSI & TrM-TrA & AIM-AAC & Mech & TrM-AAC \\
\hline & -18.3 & -18.3 & $\frac{-18.3}{-153 .}$ & \\
\hline & -16.3 & -15.6 & -15.3 & \\
\hline & $-\frac{14.7}{1.7}$ & -12.7 & -13.4 & -13.7 \\
\hline & -12.1 & -7.2 & -8.6 & -9.4 \\
\hline$\frac{120}{130}$ & $\frac{-10.5}{-1.2}$ & 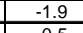 & -2.9 & -5.5 \\
\hline 130 & $\frac{-10.2}{10.0}$ & -0.5 & -1.6 & -4.3 \\
\hline$\frac{140}{150}$ & $\frac{-10.0}{9.8}$ & $\frac{1.2}{27}$ & 0.8 & -2.8 \\
\hline$\frac{150}{160}$ & -9.8 & 2.7 & $\frac{1.6}{51}$ & 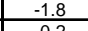 \\
\hline$\frac{160}{180}$ & 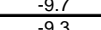 & $\frac{5.4}{104}$ & $\frac{5.1}{101}$ & $\frac{-0.2}{42}$ \\
\hline 200 & $\frac{-9.0}{-9.0}$ & $\frac{1.4}{16.6}$ & 16.3 & $\frac{4.2}{10.1}$ \\
\hline & & 23.3 & & \\
\hline
\end{tabular}




\section{S/N P1962}

Table A

Table B

Table C
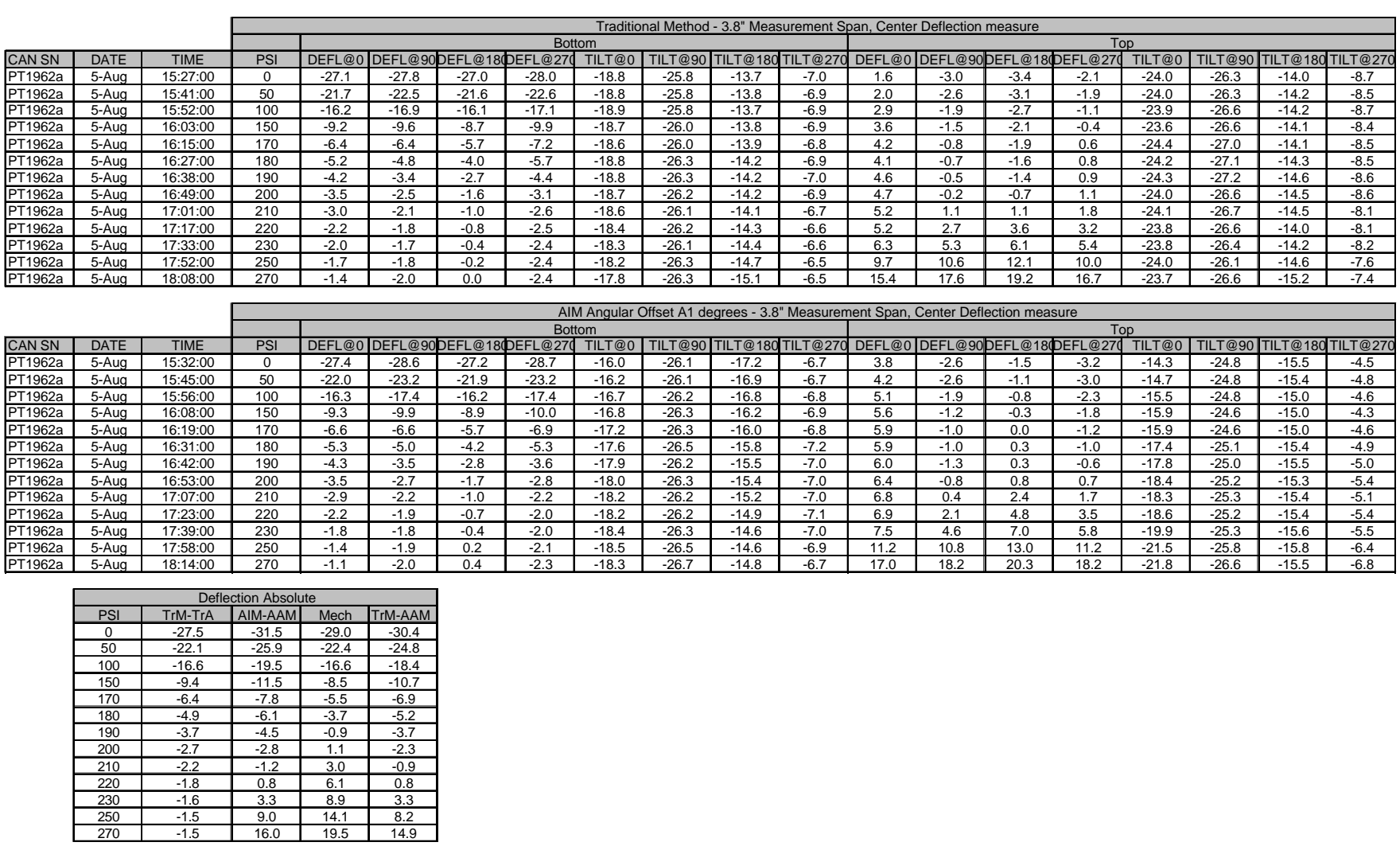

Table D

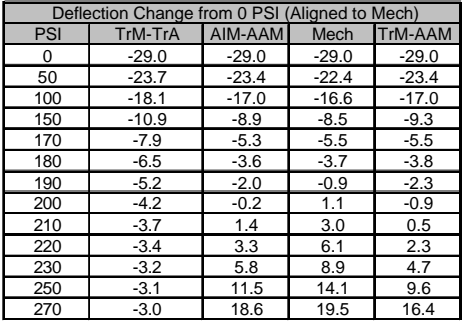




\section{S/N P2714}

Table A

Table B

Table C

Table D
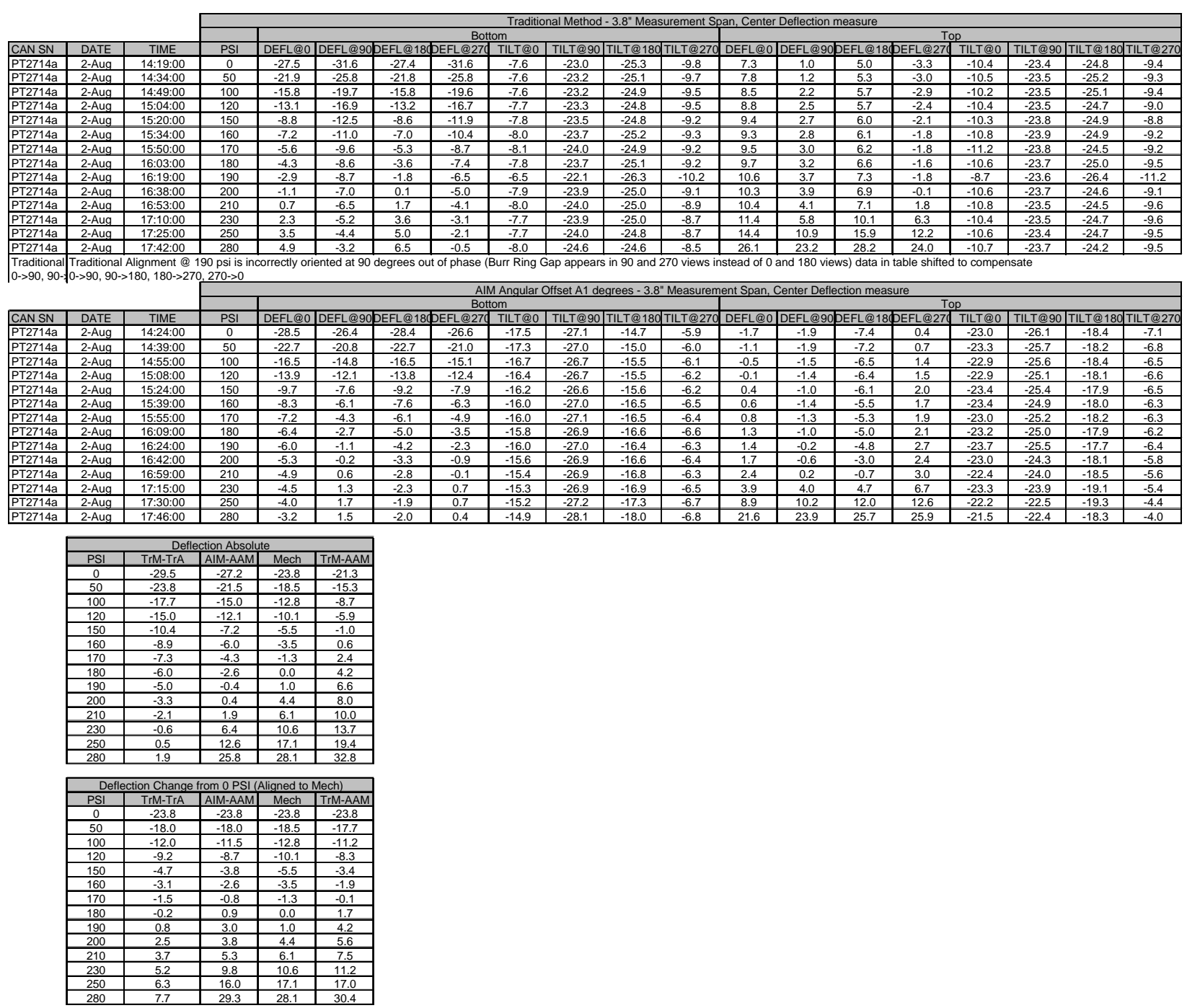


\section{S/N P3370}

Table A

Table B

Table C

\begin{tabular}{|c|c|c|c|c|c|c|c|c|c|c|c|c|c|c|c|c|c|c|c|}
\hline \multirow{3}{*}{\begin{tabular}{|l|} 
CAN SN \\
PT3370a \\
\end{tabular}} & \multirow{3}{*}{$\begin{array}{l}\text { DATE } \\
\text { 1-Aug } \\
\end{array}$} & \multirow{4}{*}{$\begin{array}{c}\text { TIME } \\
11: 32: 00 \\
\end{array}$} & \multicolumn{17}{|c|}{ Traditional Method - $3.8^{\prime \prime}$ Measurement Span, Center Deflection measure } \\
\hline & & & \multirow{3}{*}{\begin{tabular}{|l|l|} 
PSI \\
0 \\
\end{tabular}} & \multicolumn{5}{|c|}{\begin{tabular}{|c|} 
Bottom \\
DEFL@0|DEFL@90pEFL@18dDEFL@27d TILT@0
\end{tabular}} & \multirow{2}{*}{\begin{tabular}{|l|} 
TILT@90 \\
-22.5 \\
\end{tabular}} & \multirow{2}{*}{\begin{tabular}{|l|} 
TILT@18 \\
-29.4 \\
\end{tabular}} & \multirow{3}{*}{$\frac{\sigma \text { TILT@27 }}{-10.5}$} & \multirow{2}{*}{\multicolumn{4}{|c|}{\begin{tabular}{|l|l|l} 
& \\
DEFL@0 & DEFL@90 & \\
0.9 & -2.4 & -1.0 \\
\end{tabular}}} & \multirow{2}{*}{$\begin{array}{l}\text { lop } \\
7 \text { TILT@0 } \\
-3.5\end{array}$} & \multirow{3}{*}{\begin{tabular}{|l} 
TILT@90 \\
-18.6 \\
\end{tabular}} & \multirow{3}{*}{\begin{tabular}{|l} 
TILT@18 \\
-32.9 \\
\end{tabular}} & \multirow{3}{*}{\begin{tabular}{|l|l|l|} 
TILT@270 \\
-14.2 \\
\end{tabular}} \\
\hline & & & & $\frac{-21.1}{-1.1}$ & \begin{tabular}{|c|c|c|}
-23.1 \\
-23.0
\end{tabular} & -21.0 & $\frac{-23.3}{-10}$ & -3.1 & & & & & & & & & & & \\
\hline & & & & & & & & & & & & & & & & & & & \\
\hline & & & & & & & & & & & & & & & & & & & \\
\hline PT3370a & 1-Aug & 12:45:00 & 80 & -10.0 & -12.0 & -9.8 & -11.9 & -3.1 & -23.0 & -30.2 & -10.5 & 2.4 & -1.2 & 0.0 & -5.6 & -3.3 & -18.9 & -33.2 & -14.6 \\
\hline PT3370a & 1-Aug & $13: 08: 00$ & 100 & -6.8 & -9.1 & -6.4 & -8.7 & -3.1 & -23.1 & -30.2 & -10.4 & 2.7 & -0.8 & 0.5 & -5.3 & -3.5 & -18.8 & -33.1 & -14.5 \\
\hline 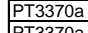 & 1-Aug & 13:28:00 & 120 & -3.4 & -7.6 & -3.0 & -6.1 & -3.0 & -23.4 & -30.1 & -10.1 & 3.2 & -0.4 & 0.8 & -4.7 & -3.4 & -18.9 & -32.9 & -14.6 \\
\hline $\begin{array}{l}\text { PT3370a } \\
\text { PT3370a }\end{array}$ & $\frac{1-\text { Aug }}{1-A u g}$ & $\frac{13: 59: 00}{14 \cdot 0200}$ & $\frac{140}{160}$ & -0.7 & -6.8 & 0.8 & $\frac{-5.3}{52}$ & -2.7 & -23.6 & 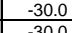 & $\begin{array}{r}-9.8 \\
\end{array}$ & $\frac{3.7}{5.0}$ & 0.2 & $\frac{1.5}{40}$ & $\frac{-3.0}{25}$ & $\begin{array}{l}-3.3 \\
37\end{array}$ & $\begin{array}{r}-18.8 \\
186\end{array}$ & $\begin{array}{l}-33.0 \\
332\end{array}$ & $\begin{array}{l}-14.4 \\
146\end{array}$ \\
\hline$\frac{\text { PT } 3370 \mathrm{a}}{\text { PT3370a }}$ & $\frac{\text { 1-Aug }}{\text { 1-Aug }}$ & $\begin{array}{l}14: 25: 00 \\
14: 49: 00\end{array}$ & $\begin{array}{l}160 \\
180 \\
\end{array}$ & 0.66 & $\begin{array}{l}-6.3 \\
-5.9 \\
\end{array}$ & $\begin{array}{l}1.8 \\
1.8 \\
\end{array}$ & $\begin{array}{l}-5.2 \\
-4.8 \\
\end{array}$ & $\begin{array}{l}-2.8 \\
-2.8\end{array}$ & $\begin{array}{l}-23.9 \\
-24.3\end{array}$ & $\frac{-30.0}{-30.0}$ & $\begin{array}{l}-9.4 \\
-9.2\end{array}$ & $\frac{5.0}{9.3}$ & $\frac{1.2}{4.4}$ & $\begin{array}{l}4.0 \\
10.3\end{array}$ & $\begin{array}{l}2.5 \\
9.3 \\
\end{array}$ & $\begin{array}{l}-3.7 \\
-3.6 \\
\end{array}$ & $\begin{array}{l}-18.6 \\
-18.6\end{array}$ & $\begin{array}{r}-33.2 \\
-33.6 \\
\end{array}$ & $\begin{array}{l}-14.6 \\
-14.6\end{array}$ \\
\hline PT3370a & 1-Aug & 15:13:00 & 200 & -0.4 & -5.6 & 1.8 & $\begin{array}{r}-4.3 \\
\end{array}$ & -2.4 & -24.4 & -29.9 & -8.8 & 16.4 & 11.4 & 18.5 & 17.1 & $\begin{array}{l} \\
\end{array}$ & $\begin{array}{l}-18.3 \\
\end{array}$ & -33.5 & $\begin{array}{l}-13.7 \\
\end{array}$ \\
\hline PT3370a & 1-Aug & 15:37:00 & 220 & 0.5 & -5.0 & 2.0 & -3.8 & -2.4 & -24.4 & & -8.6 & 27.7 & 22.1 & 29.3 & 26.9 & -3.5 & -18.4 & -33.1 & -13.3 \\
\hline
\end{tabular}

It was assumed that we would use the phase angle calculated at 0 psi throughout the tests. This procedural error was corrected at $80 \mathrm{ps}$.

AlM Angular Offset A1 degrees - 3.8" Measurement Span, Center Deflection measure

\begin{tabular}{|c|c|c|c|c|c|c|c|c|c|c|c|c|c|c|c|c|c|c|c|}
\hline \multirow{2}{*}{\multicolumn{3}{|c|}{\begin{tabular}{l|l|l} 
AN SN & DATE & TIME \\
\end{tabular}}} & \multirow{2}{*}{ PSI } & \multicolumn{8}{|c|}{ Bottom } & \\
\hline & & & & DERLLU & & & & $\begin{array}{l}\text { TILT@0 } \\
\end{array}$ & 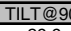 & & & & & & & & & & \\
\hline$\frac{\mid \text { PT3370a }}{\text { PT3370a }}$ & $\frac{1 \text {-1-ug }}{\text { 1-Aug }}$ & $\frac{11: 42: 00}{12: 01: 00}$ & $\frac{0}{20}+x-10$ & $\frac{-23.7}{-21.0}$ & $\frac{-21.3}{-18.6}$ & $\frac{-23.9}{-21.2}$ & $\frac{-21.3}{-18.7}$ & $\frac{-17.1}{-17.5}$ & $\frac{-29.9}{-30.1}$ & $\frac{-15.7}{-15.9}$ & $\frac{-3.0}{-3.0}$ & $\frac{1.6}{1.8}$ & $\frac{4.1}{4.5}$ & $\begin{array}{r}-4.9 \\
-4.7\end{array}$ & $\frac{1.7}{1.7}$ & $\frac{-11.2}{-11.3}$ & $\frac{-29.7}{-29.8}$ & $\frac{-22.3}{-22.0}$ & $\begin{array}{r}2.0 \\
2.0 \\
\end{array}$ \\
\hline PT3370a & 1-Aug & $12: 12: 00$ & 40 & -18.1 & -15.8 & -18.3 & -15.9 & -17.6 & -30.1 & -15.7 & -3.1 & 2.1 & 4.8 & -4.5 & 2.0 & -11.2 & -29.5 & -22.2 & \\
\hline & 1-Aug & & 60 & -15.3 & -12.9 & -15.2 & -13.0 & -18.0 & -30.2 & -15.7 & -3.1 & 2.3 & 4.7 & -4.1 & 2.2 & -11.6 & & & \\
\hline & & & & & -10.0 & -12.2 & -10.2 & & & & -3.4 & 3.7 & 5.5 & -3.2 & 2.6 & -11.6 & -29.6 & -22.8 & \\
\hline PT3370a & 1-Aug & $13: 15: 00$ & 100 & -9.4 & -6.7 & -8.8 & -6.7 & -17.0 & -31.0 & -16.9 & -3.4 & 4.6 & 6.2 & -2.6 & 3.3 & -11.1 & -29.1 & -22.8 & 1.3 \\
\hline & 1-Aug & & 120 & -8.1 & -2.8 & -6.4 & -2.9 & -20.6 & -30.6 & -13.2 & -3.2 & 2.4 & 5.1 & -4.2 & 3.3 & -12.6 & -29.7 & -21.0 & 1.9 \\
\hline \begin{tabular}{|l|l|} 
PT3370a \\
P33370a
\end{tabular} & 1-Aug & & $\frac{140}{160}$ & -7.6 & $\frac{1.2}{28}$ & $\begin{array}{c}-5.4 \\
-5.2\end{array}$ & $\frac{1.3}{30}$ & $\frac{-21.2}{-21.6}$ & & & & $\frac{2.8}{3 .}$ & $\frac{5.4}{6.5}$ & $\frac{-2.7}{31}$ & & & & & \\
\hline \begin{tabular}{|l|} 
PT3370a \\
PT3370a
\end{tabular} & $\frac{1 \text {-Aug }}{1 \text {-Aug }}$ & $\begin{array}{l}14: 37: 00 \\
1500000\end{array}$ & $\frac{160}{180}$ & $\frac{-6.8}{-6.4}$ & 2.8 & $\begin{array}{r}-5.2 \\
-48 \\
\end{array}$ & 3.0 & $\frac{-21.6}{-22.1}$ & $\frac{-31.2}{31 .}$ & $\begin{array}{r}-11.5 \\
-111 .\end{array}$ & $\begin{array}{r}-3.2 \\
-30 \\
\end{array} \mathrm{r} \mathrm{x}$ & $\frac{3.3}{6.8}$ & $\frac{6.5}{116}$ & $\begin{array}{l}3.1 \\
97\end{array}$ & $\frac{5.7}{109}$ & $\frac{-13.3}{-1.5}$ & $\frac{-29.8}{3.34}$ & $\begin{array}{l}-19.6 \\
18.9\end{array}$ & $\frac{1.8}{n .8}$ \\
\hline$\frac{\mid 3 / 330 a}{\text { PT3370a }}$ & $\frac{1 \text {-Aug }}{\text { 1-Aug }}$ & $\frac{115: 00: 00}{15: 23: 00}$ & $\frac{180}{200}$ & $\frac{-6.4}{-6.0}$ & $\frac{2.9}{3.1}$ & $\frac{-4.8}{-4.1}$ & $\frac{3.1}{3.5}$ & $\frac{-22.1}{-21.7}$ & $\frac{-31.8}{-32.6}$ & $\frac{-\frac{-11.1}{-11.3}}{4}$ & & $\frac{6.8}{14.3}$ & $\frac{11.6}{19.4}$ & $\frac{9.7}{17.4}$ & $\frac{10.9}{18.7}$ & $\frac{-14.5}{-14.5}$ & $\begin{array}{l}-30.4 \\
-30.8 \\
\end{array}$ & $\frac{-18.8}{-18.2}$ & \\
\hline
\end{tabular}

\begin{tabular}{|l|l|l|l|l|l|l|l|l|l|l|l|l|l|l|l|l|l|l|l|}
\hline PT370a & 1 -Aug & $15: 23: 00$ & 200 & -6.0 & 3.1 & -4.1 & 3.5 & -21.7 & -32.6 & -11.3 & -2.7 & 14.3 & 19.4 & 17.4 & 18.7 & -14.5 & -30.8 & -18.2 & 0.6 \\
\hline PT3370a & 1 -Aug & $15: 48: 00$ & 220 & -5.5 & 3.4 & -3.4 & 4.1 & -21.5 & -33.1 & -11.7 & -26 & 25.3 & 29.5 & 27.8 & 29.1 & -14.7 & -30.9 & -17.5 & 0.0 \\
\hline
\end{tabular}
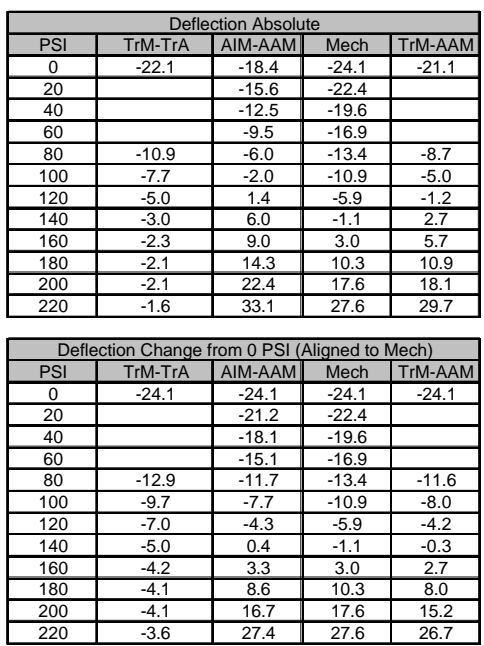

Table D 


\section{S/N P3373}

Table A

Table B

Table C
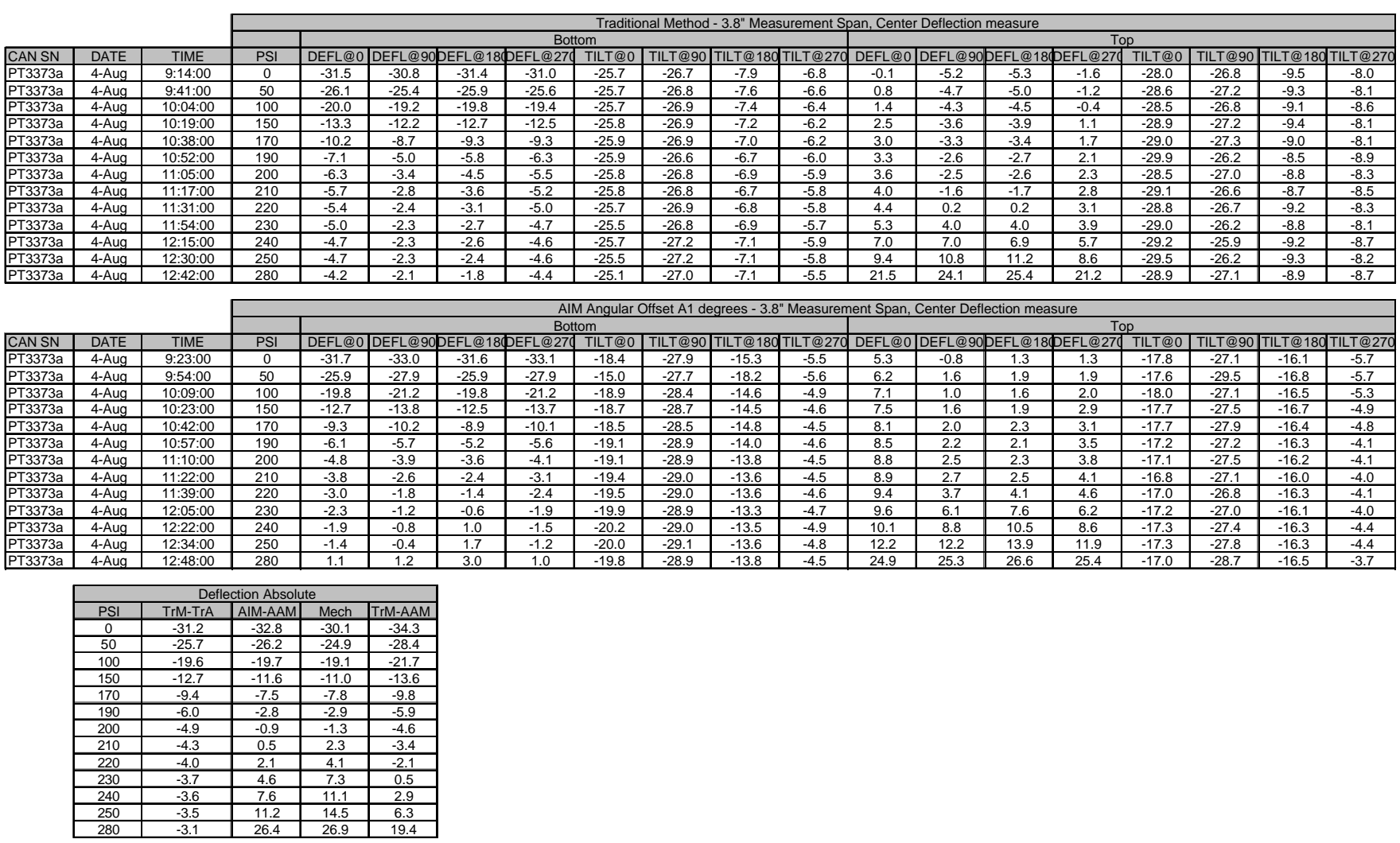

Table D

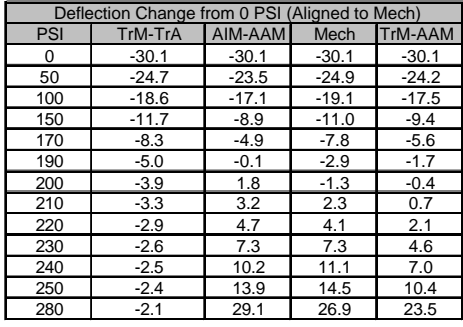




\section{S/N P3379}

Table A

Table B

Table C
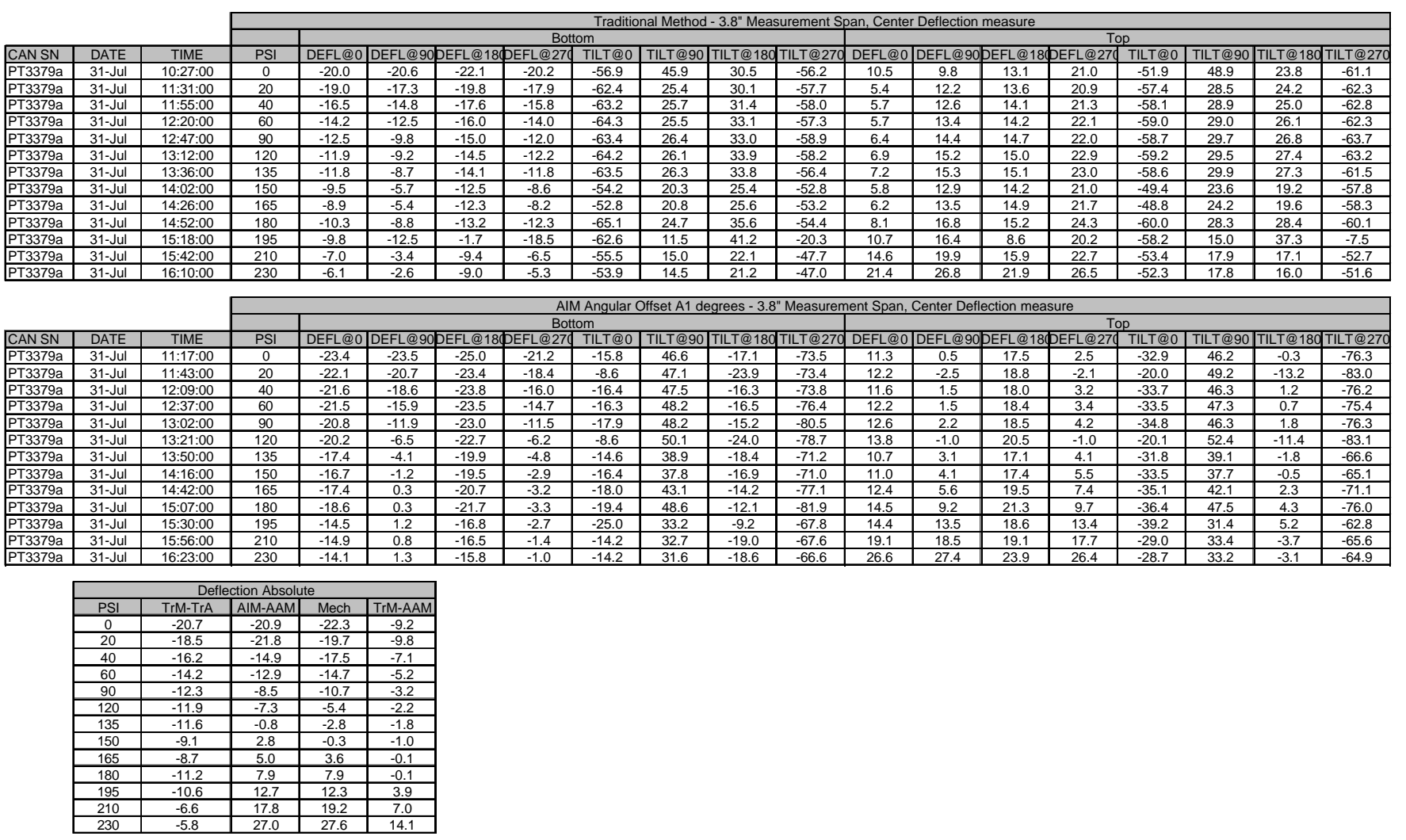

Table D

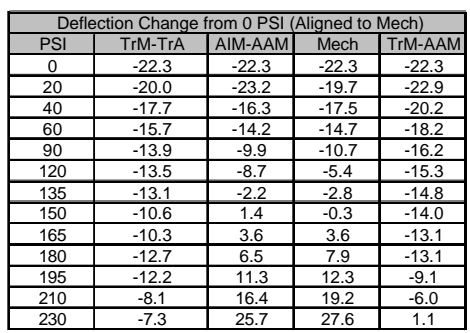




\section{S/N P3381}
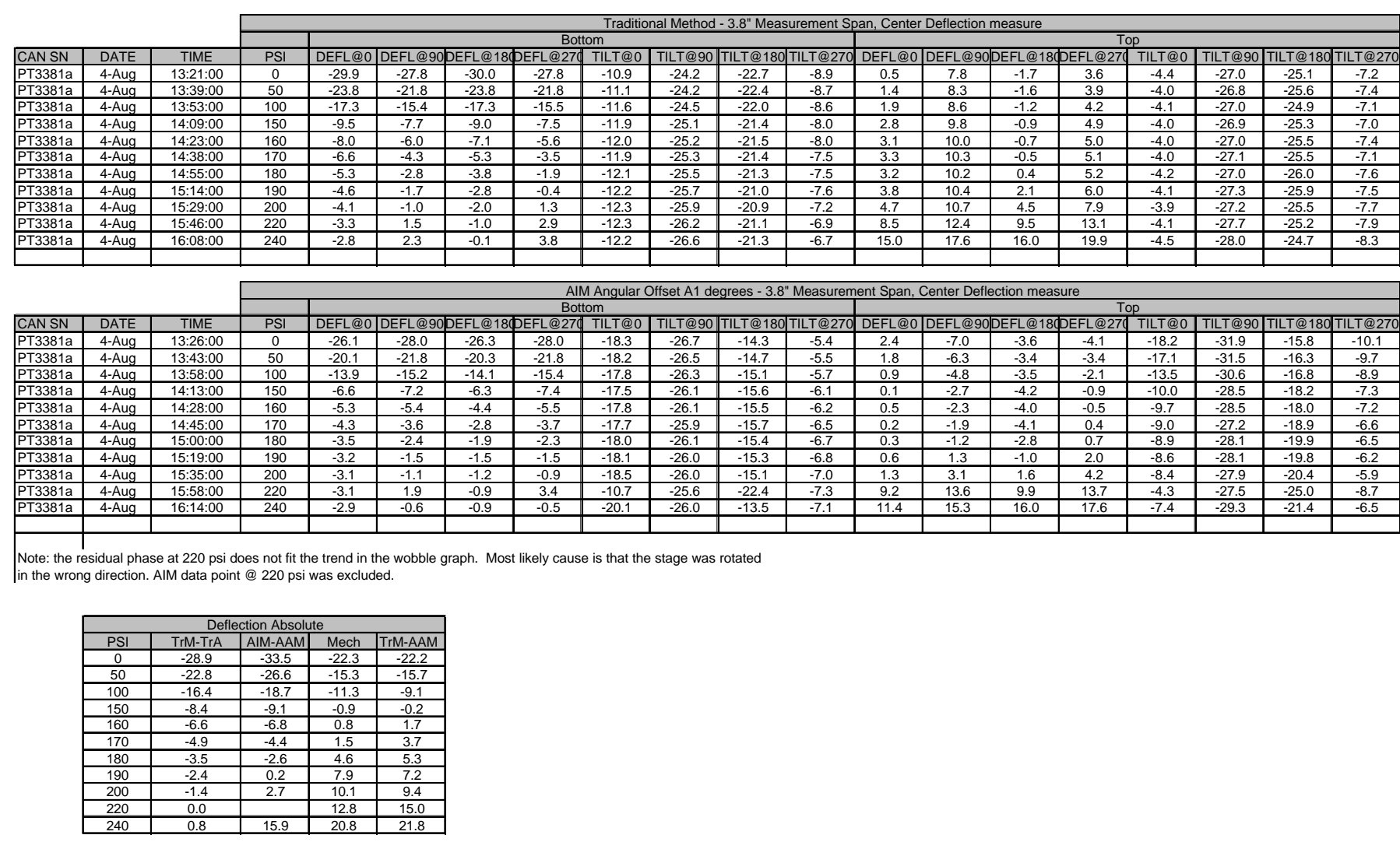

Table D

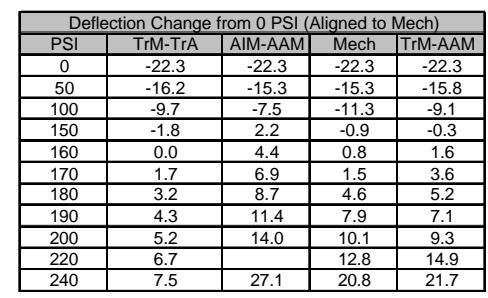




\section{S/N P3382}

Table A

Table B

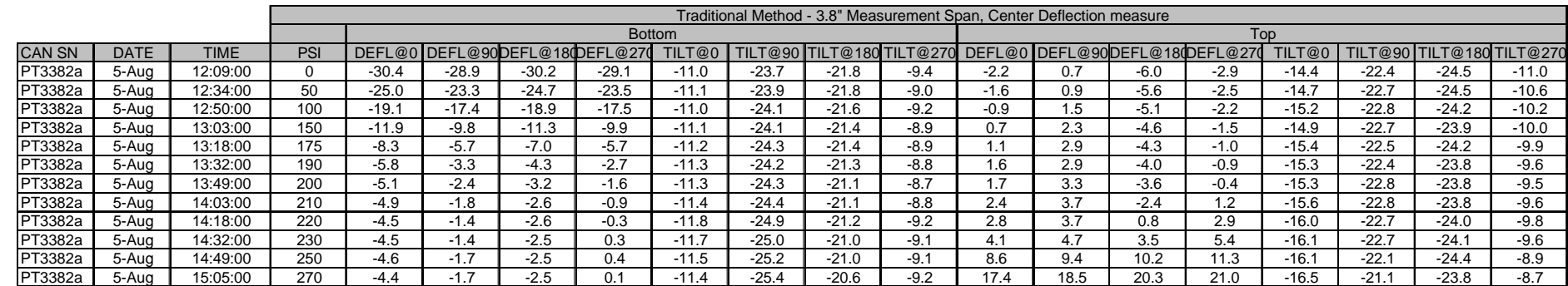

AlM Angular Offset A1 degrees - 3.8" Measurement Span, Center Deflection measure

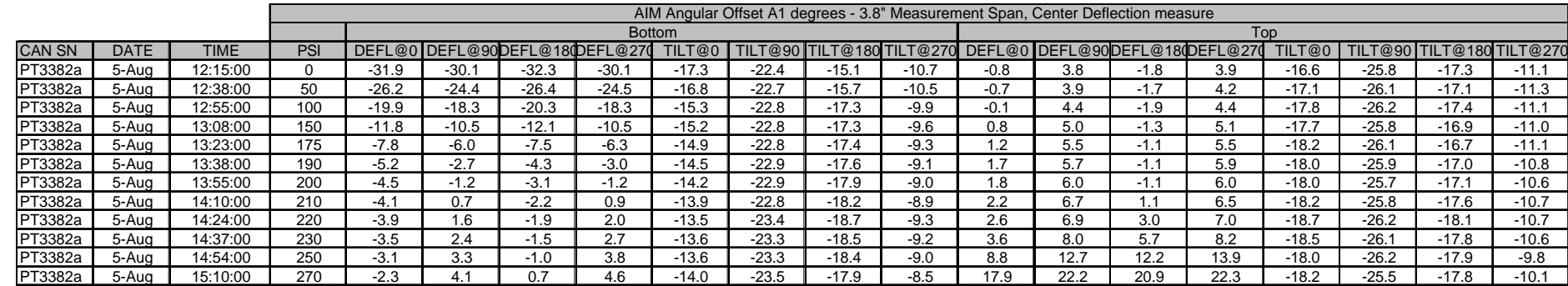

Table C
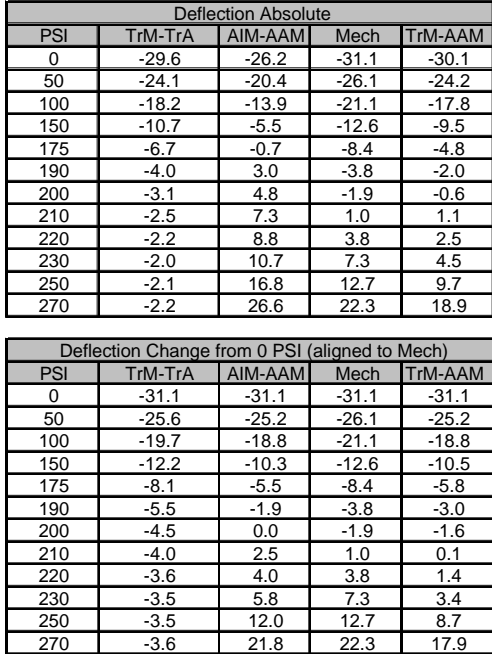

Table D

\begin{tabular}{|l|l|l|l|l|}
\hline 250 & -3.5 & 12.0 & 12.7 & 8.7 \\
\hline 270 & -3.6 & 21.8 & 22.3 & 17.9 \\
\hline
\end{tabular} 
Appendix 3 : Pressure Test Graphs for the MD-CF Analysis 


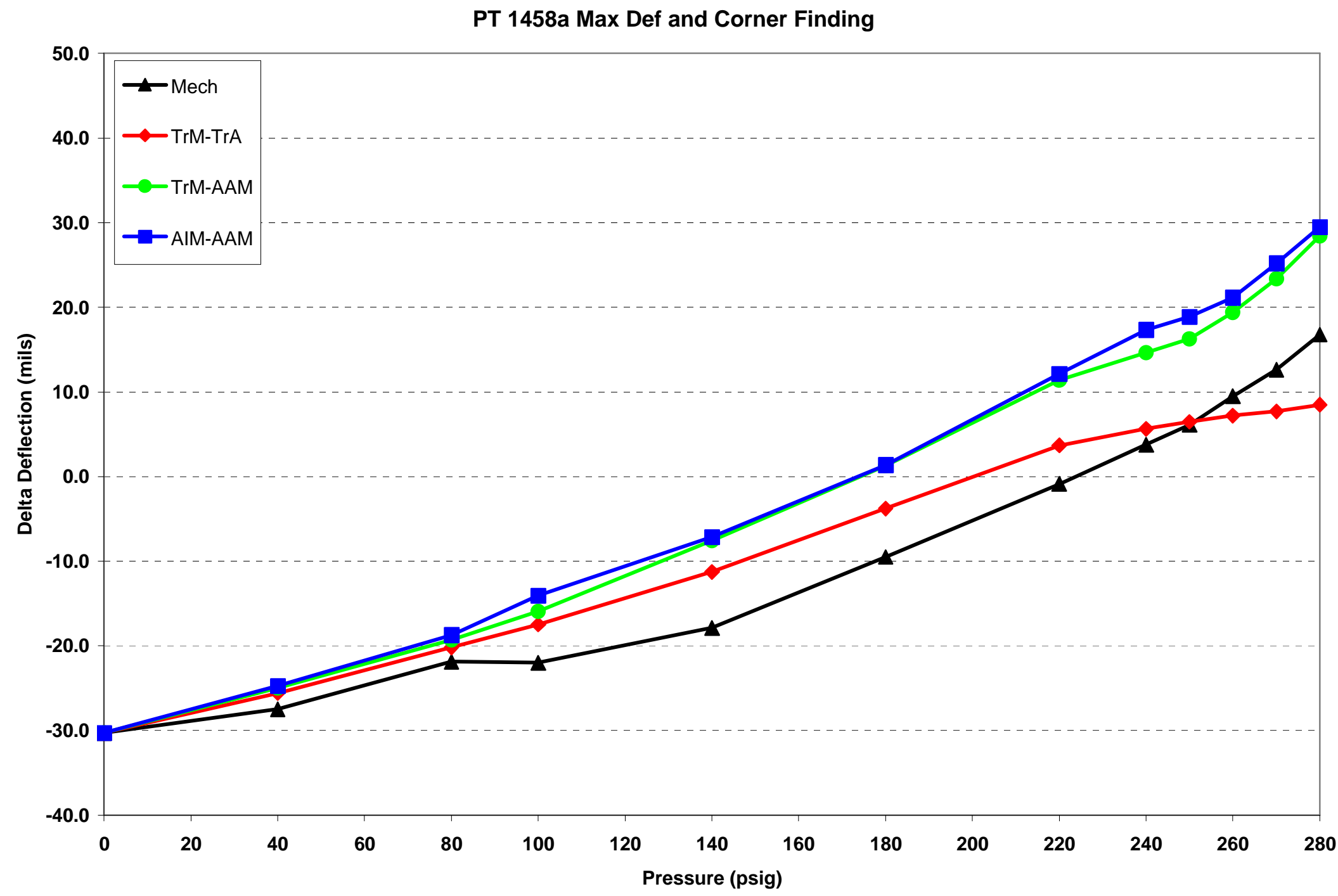




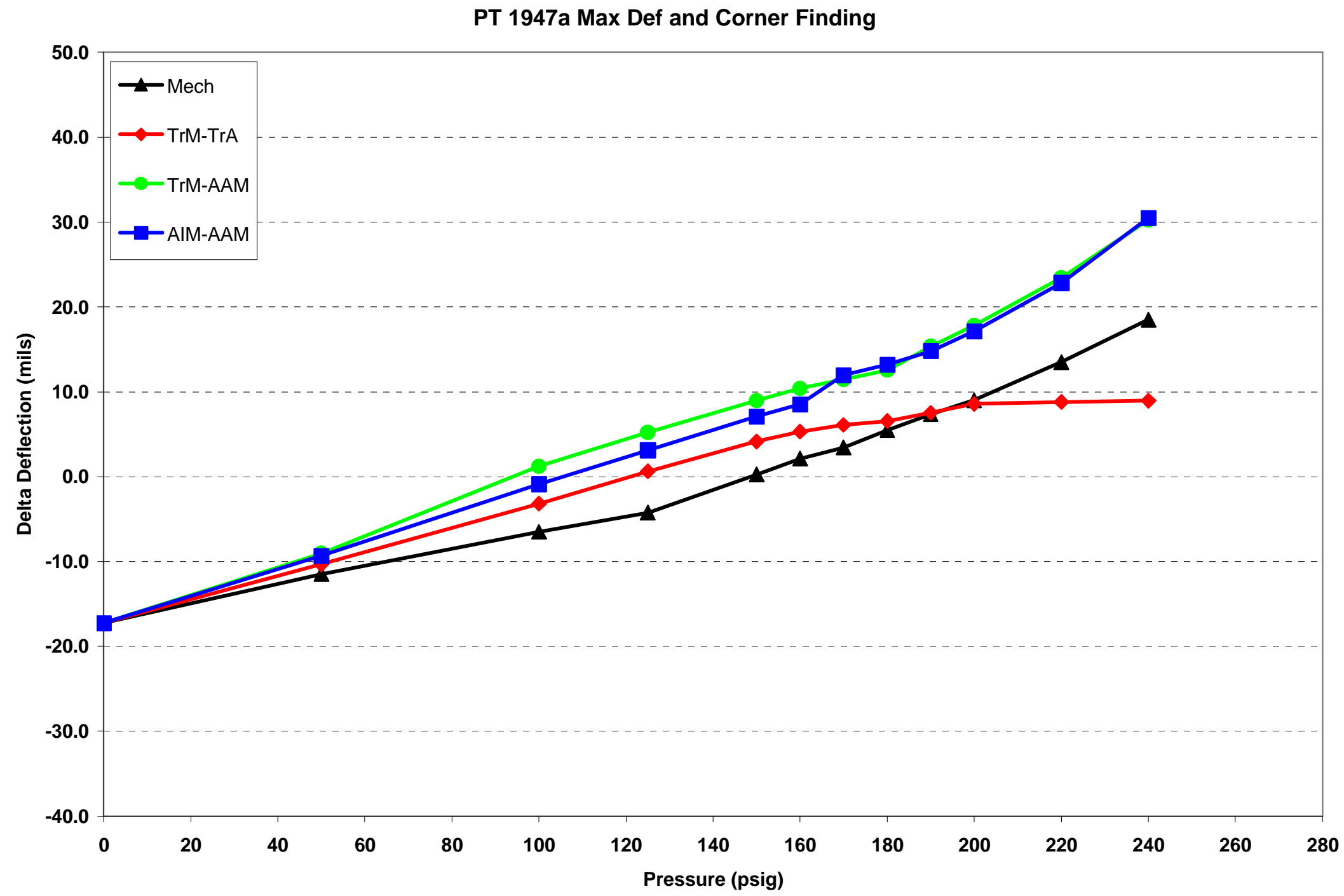




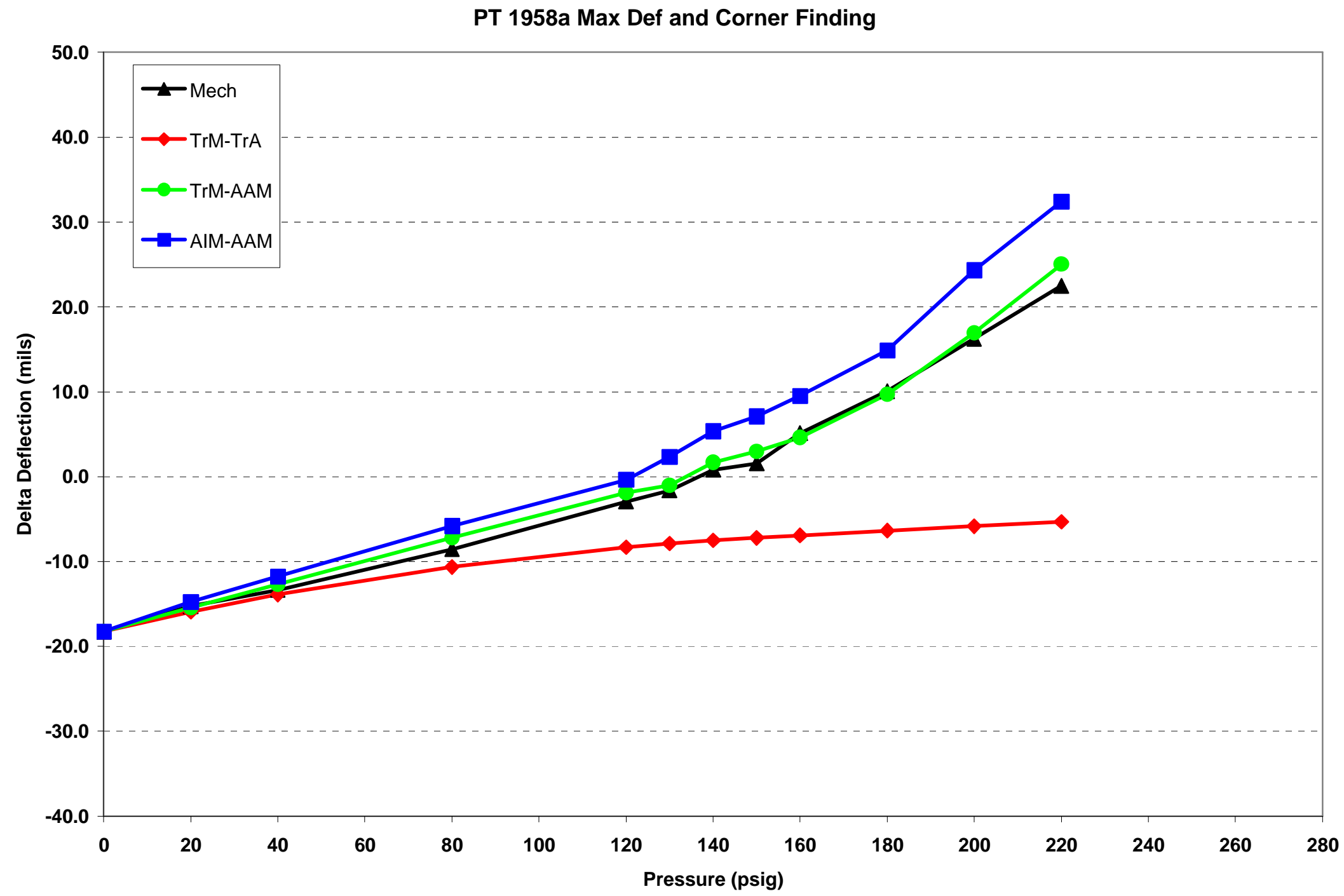




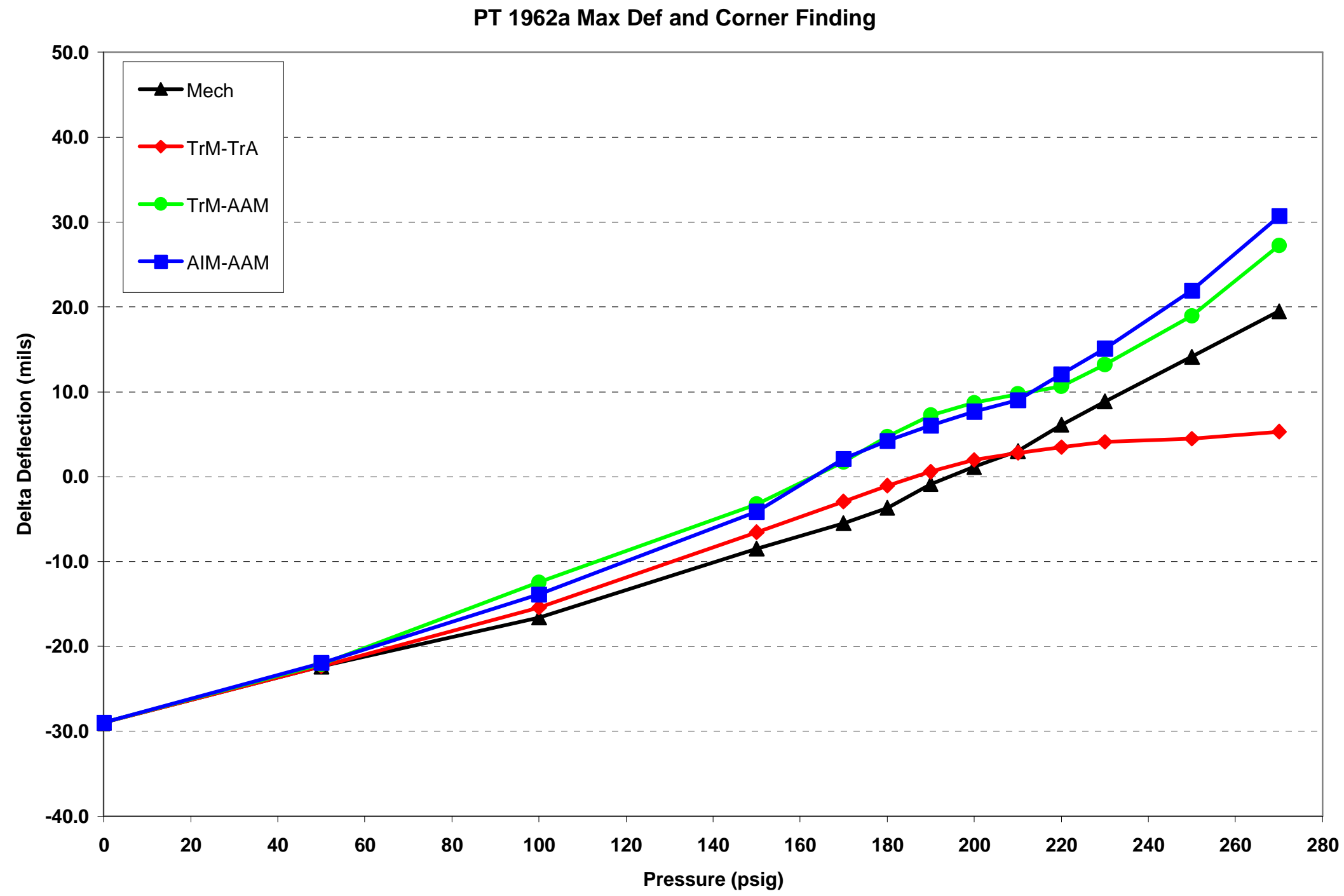




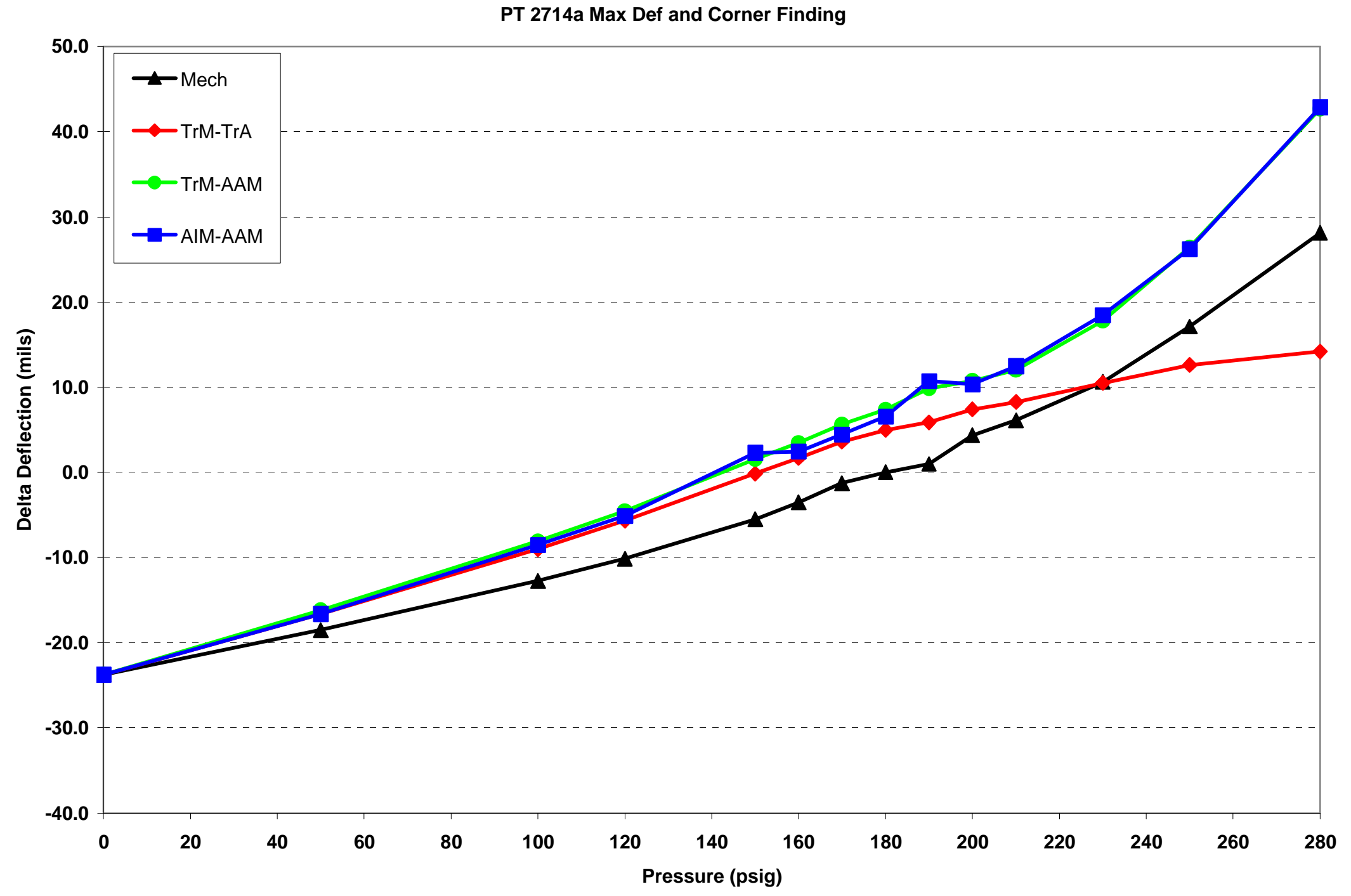




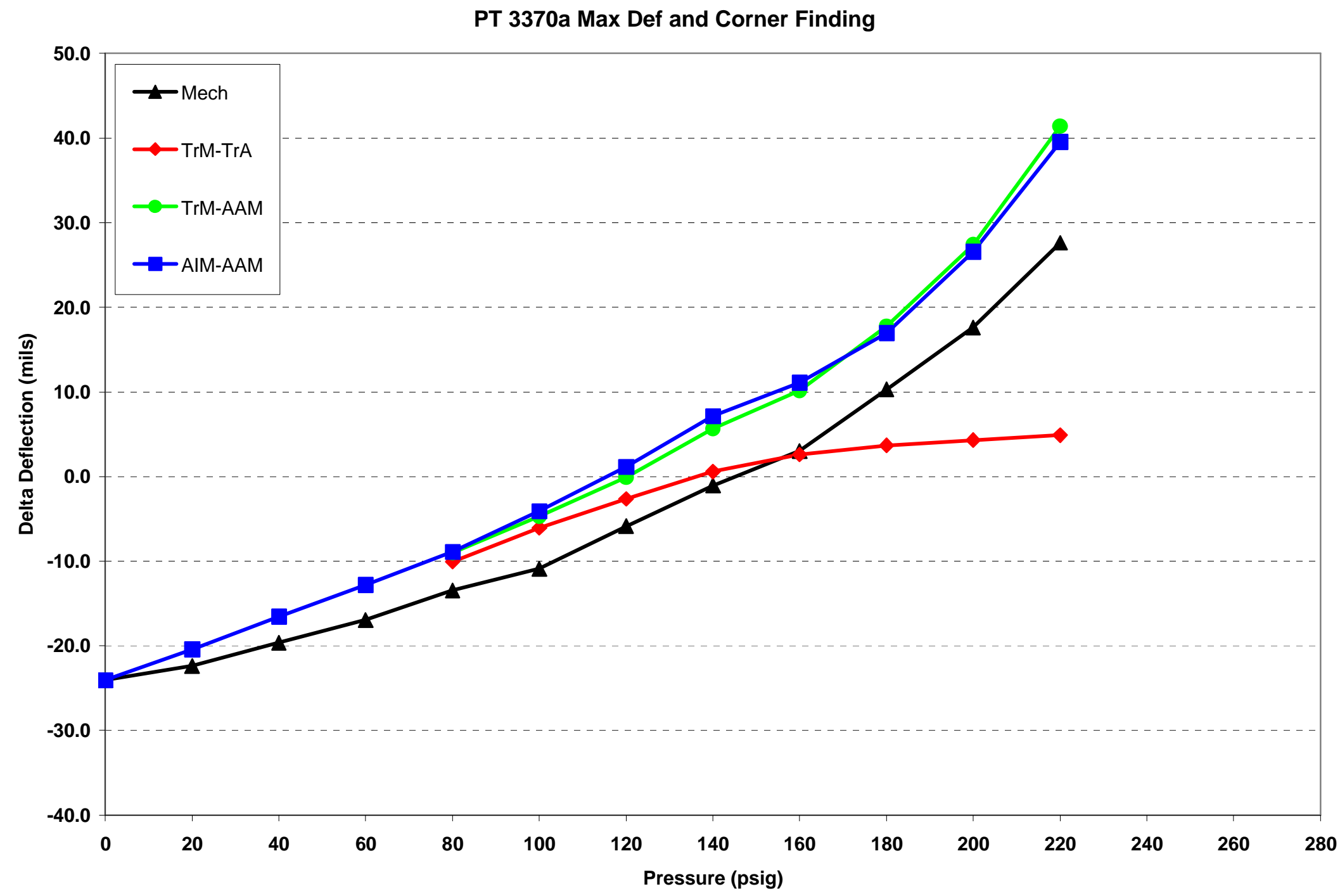




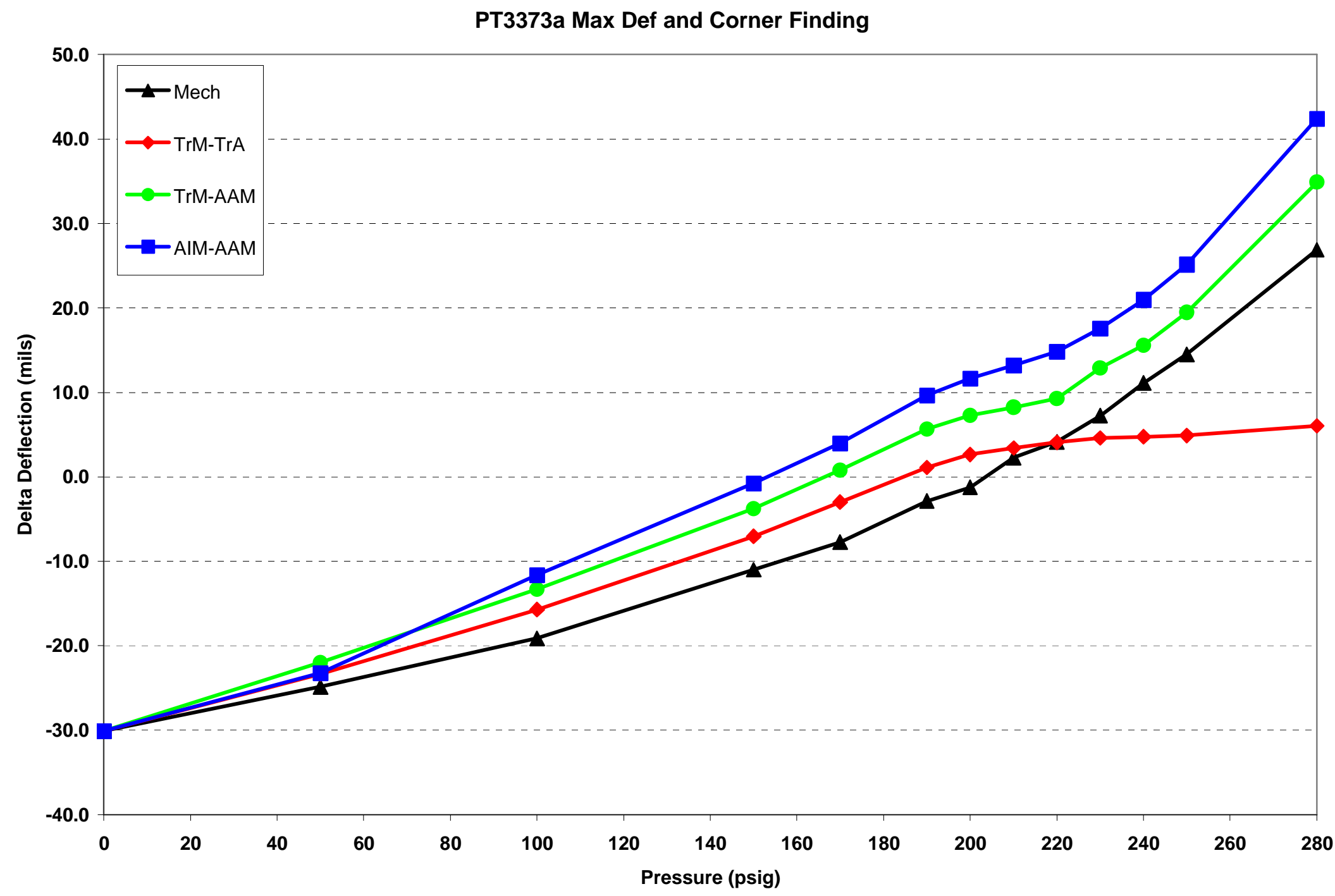




\section{PT 3379a Max Def and Corner Finding}

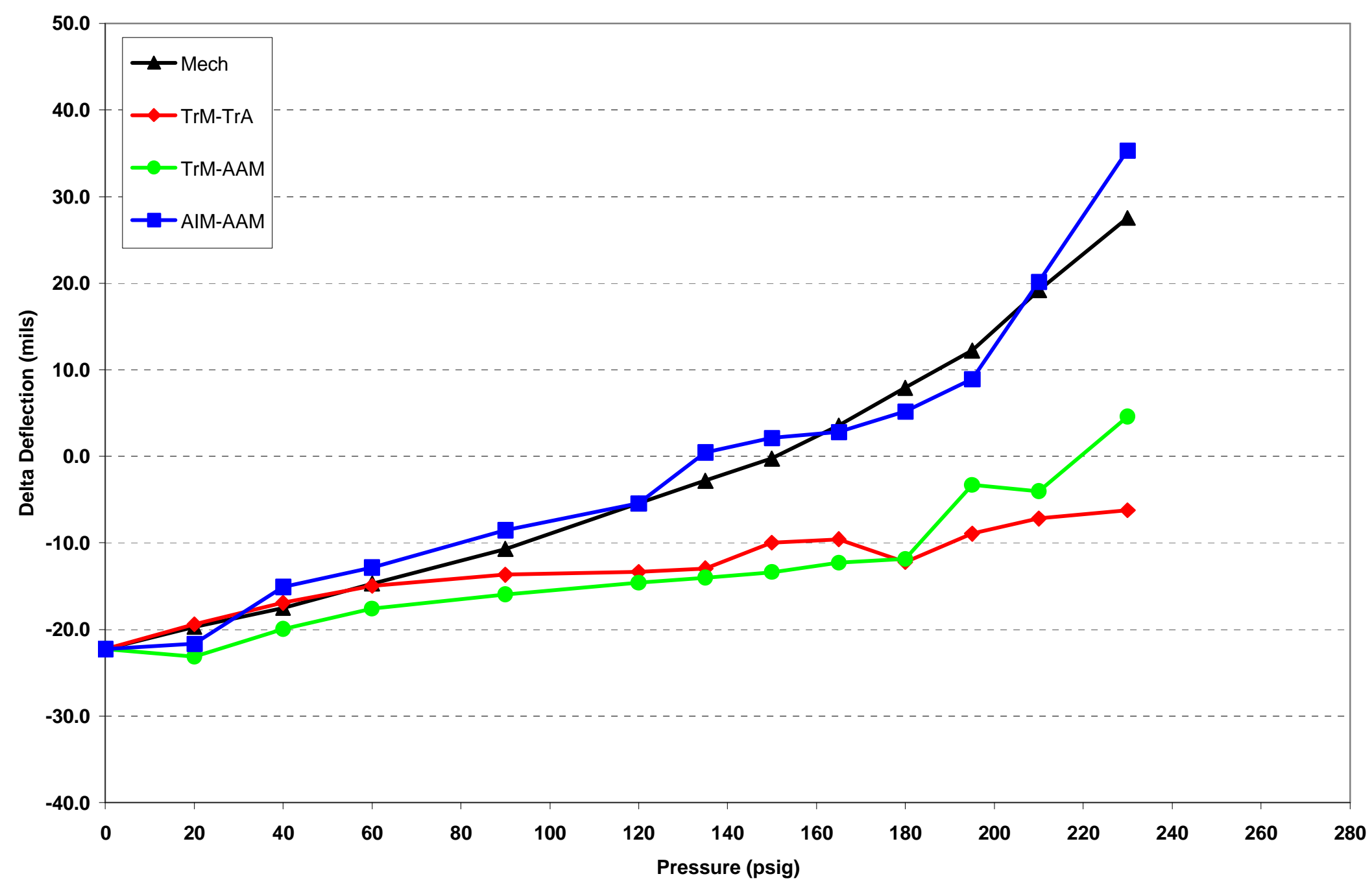




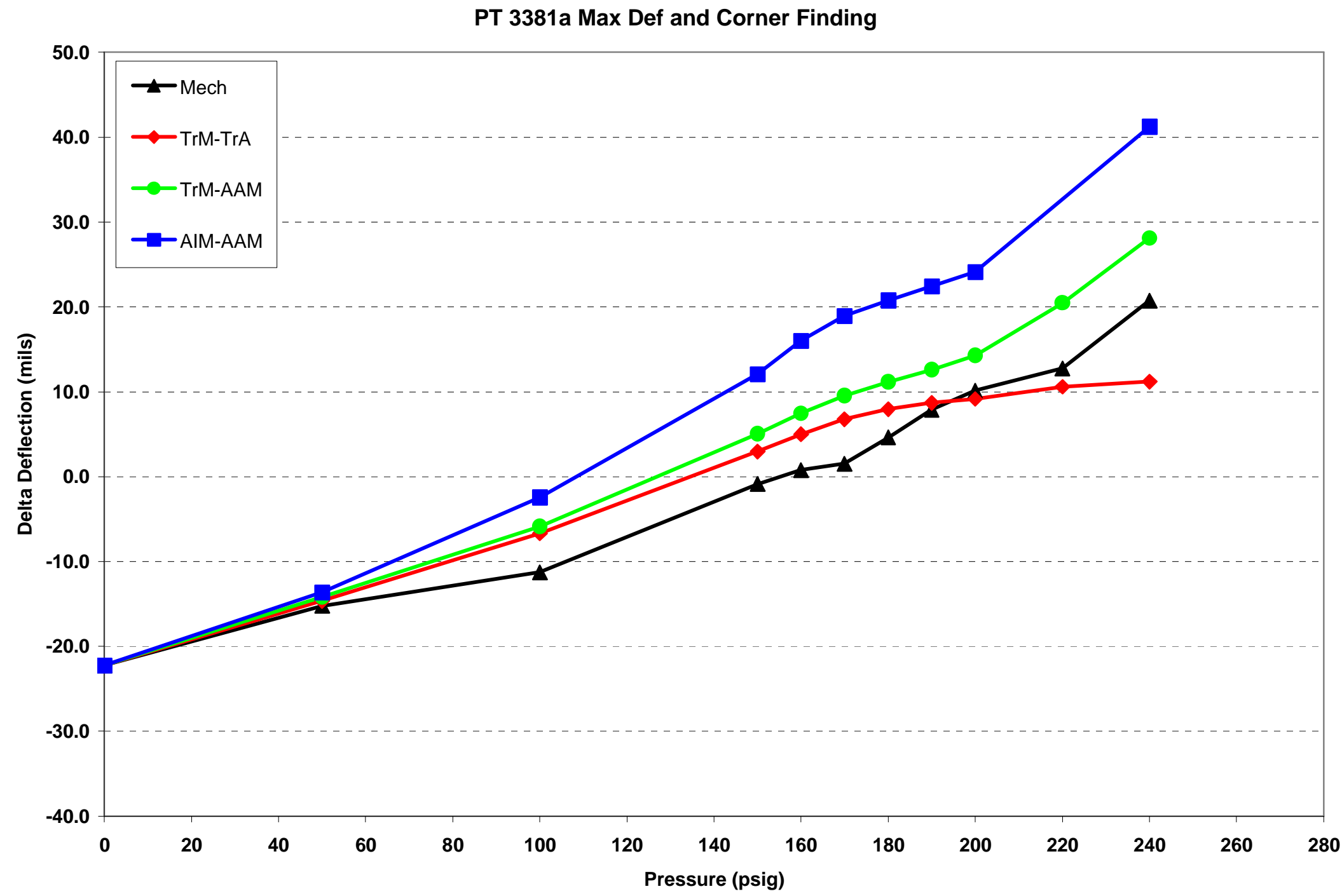




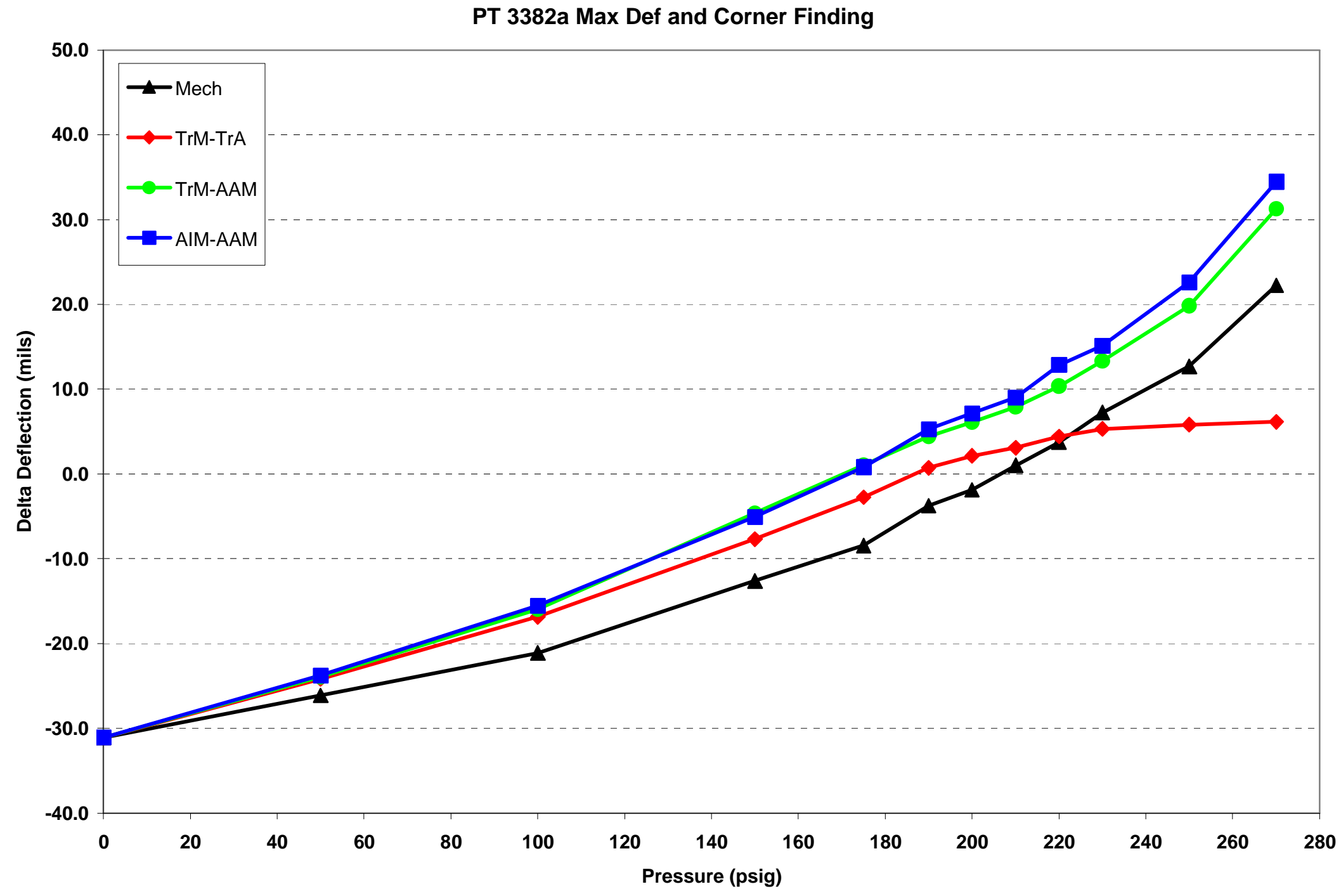




\section{Appendix 4 : Spreadsheet Data Supporting the Pressure Test Graphs for the MD-CF Analysis.}


Table A

Figure A4.1: Spreadsheet showing the cell assignments and formulas used in the following sheets for Tables A, B, C and D entries.

Table B

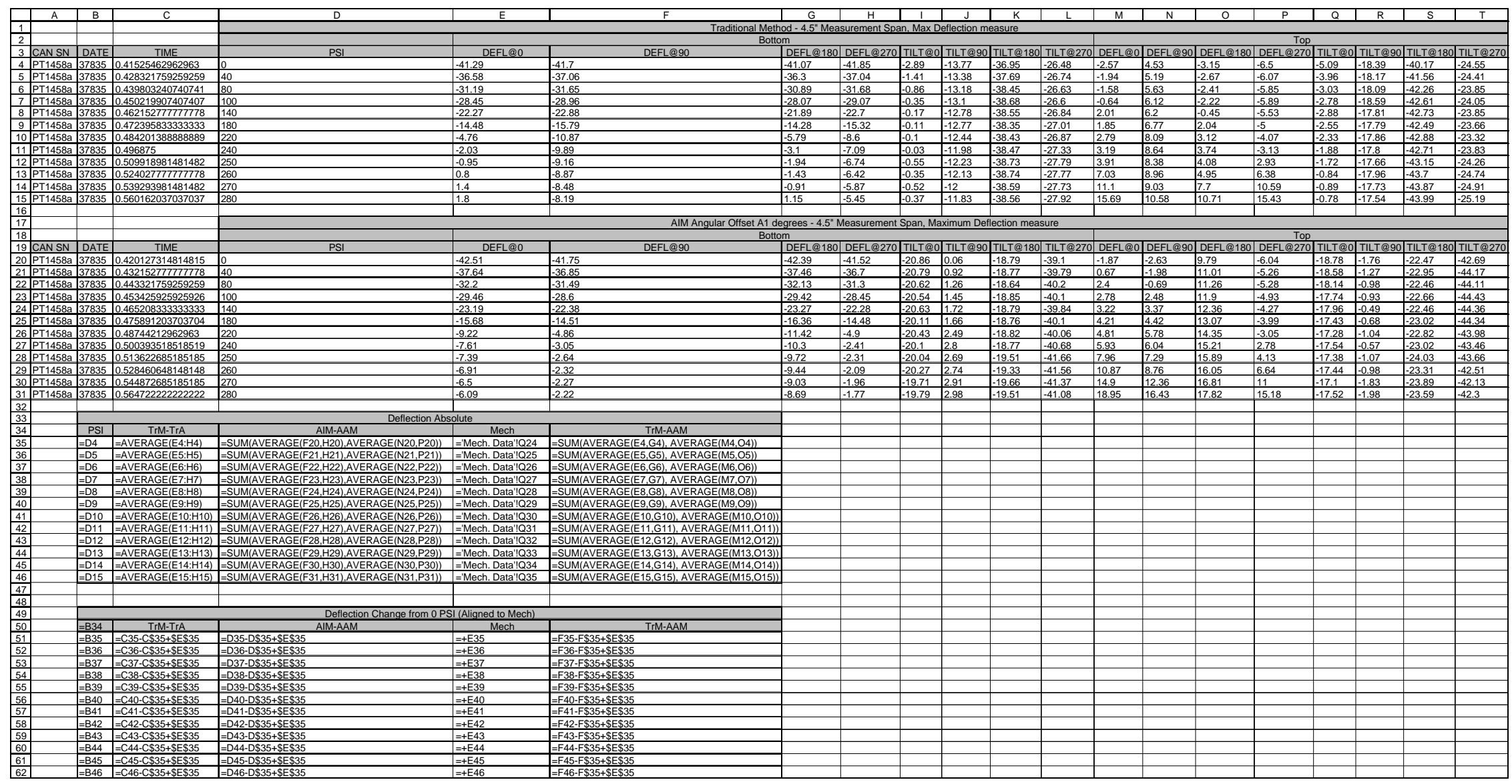

\section{Table D}




\section{S/N P1458}

Table A

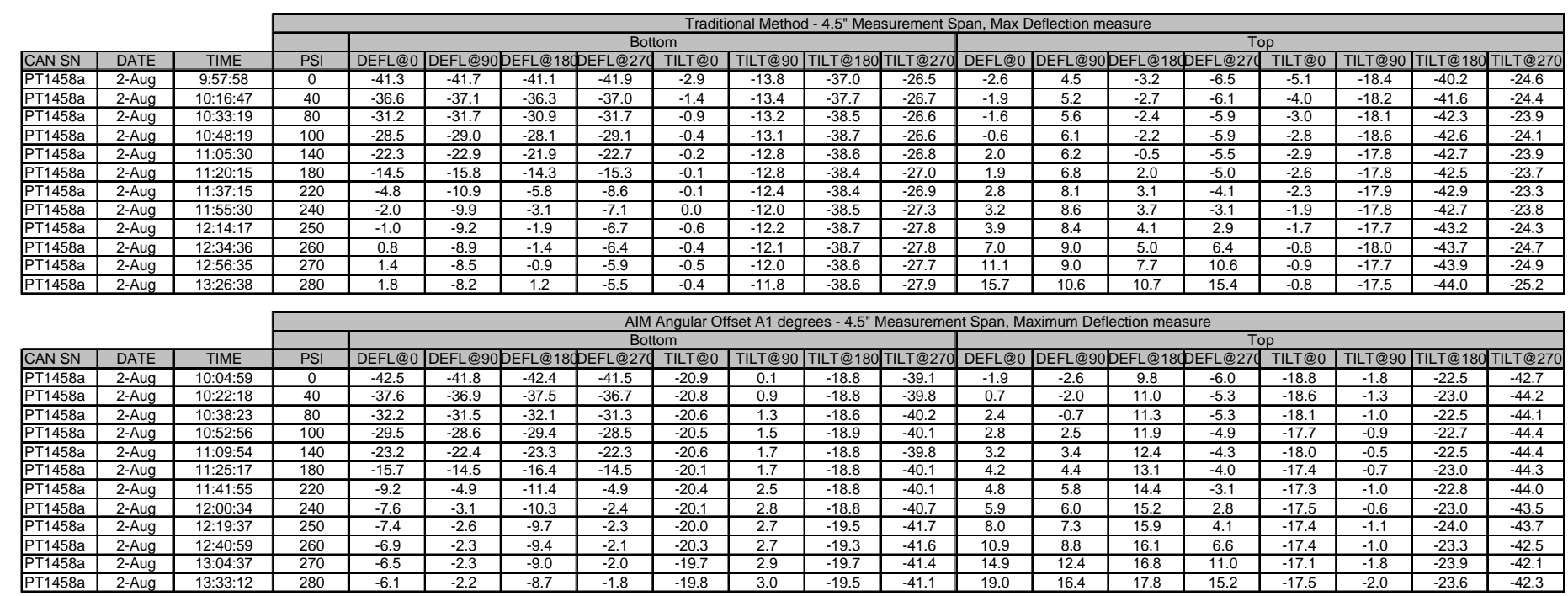

Table C

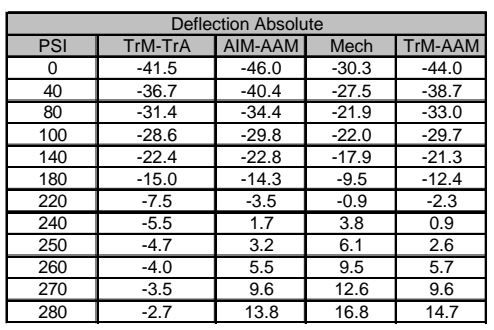

Table D

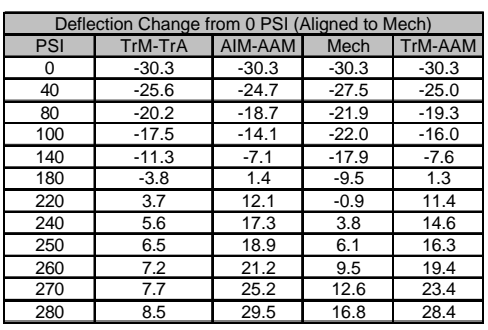




\section{S/N P1947}

Table A

\begin{tabular}{|c|c|c|c|c|c|c|c|c|c|c|c|c|c|c|c|c|c|c|c|}
\hline & & & & & & & & & & & & & & & & & & & \\
\hline & DATE & & PSI & DEFL@ & & & & $\frac{\text { om }}{\text { TILTC }}$ & & & |TILT@27 & \begin{tabular}{|l|} 
DEFL@@ \\
\end{tabular} & DEFL@S & DEFL@18 & $\overline{E F F[@ 2}$ & \begin{tabular}{|l|l|l|l|} 
TLT@0 \\
\end{tabular} & D TILT@9C & |TILT@ & IILT@2 \\
\hline & 4-Aug & $30: 4$ & 0 & $\begin{array}{r}-25.5 \\
.94\end{array}$ & -25.6 & -25.4 & -25.6 & $\frac{-24}{6-24}$ & $\frac{-21.3}{21.3}$ & $\frac{14 .}{-1 .}$ & \begin{tabular}{|l|l|}
-17.5 \\
-179 \\
\end{tabular} & $\begin{array}{r}-3.1 \\
\end{array}$ & \begin{tabular}{|l|l}
-2.9 \\
\end{tabular} & $\begin{array}{r}-2.0 \\
\end{array}$ & 2.4 & & & \begin{tabular}{|l|l|}
-16.9 \\
\end{tabular} & -18.6 \\
\hline & & & $\frac{50}{100}$ & $\begin{array}{l}-18.4 \\
-11.3\end{array}$ & $\frac{-18.6}{-11.5}$ & $\frac{-18.6}{-11.3}$ & $\frac{-18.8}{-11.7}$ & & $\begin{array}{l}-21.3 \\
-21.1 \\
\end{array}$ & & $\frac{-17.8}{-17.5}$ & & & $\frac{-0.4}{1.6}$ & & & & $\frac{-17.0}{-17.3}$ & \begin{tabular}{|c|}
-18.8 \\
-1.99
\end{tabular} \\
\hline & & & & & & & & & & & & & 1.9 & 1.4 & & & & $\frac{-1.3}{-17.0}$ & $\begin{array}{l}-\frac{-18.9}{-19.6} \\
\end{array}$ \\
\hline & & 17:23:04 & 150 & -4.3 & -4.0 & -3.8 & -4. & -2 & 21.5 & -14.0 & -11 & & & $\frac{1.4}{1.4}$ & 3.8 & & & -16.6 & $\begin{array}{l}-19.1 \\
-19.1 \\
\end{array}$ \\
\hline & & 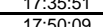 & $\begin{array}{ll}160 \\
170\end{array}$ & $\frac{-2.5}{2.2}$ & $\frac{-2.8}{20}$ & $\frac{-2.6}{-1.6}$ & -3 & & 217 & 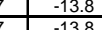 & & $\frac{3.4}{34}$ & 25 & $\frac{1.1}{17}$ & $\frac{4.4}{47}$ & & & $\frac{-16.8}{1-1.8}$ & \begin{tabular}{|l|}
$-\frac{19.3}{-197}$ \\
-197
\end{tabular} \\
\hline & & 18:02:59 & 180 & -1.5 & $\frac{-1.4}{-1.4}$ & -1.2 & -2. & -24.5 & $\frac{-21.9}{-21.9}$ & -13.7 & & 3.6 & & 2.8 & & & & $\frac{-17.0}{1-1.0}$ & \\
\hline & & & & & & & & & & & & & & & & & & & 18.7 \\
\hline & 4-Aug & & & 1.2 & 1.2 & 1.5 & -2.2 & -24.4 & -22.0 & -13.4 & -10. & 4.9 & & 6.6 & & & 222.8 & $\begin{array}{cc}-17.0 \\
11.04\end{array}$ & -19.1 \\
\hline & $\frac{4 \text { 4.Aug }}{\text { 4-Augg }}$ & & & & & 1.9 & & & & & & $\overline{5.6}$ & $\frac{10.5}{8.7}$ & & & & & 16.9 & $\frac{-18.2}{-16.8}$ \\
\hline & & & & & & & & M Angular of & Pifset $A 1$ de & Degrees -4.55 & $5^{\prime \prime}$ Measurem & 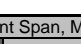 & Maximum Def & flection $\mathrm{me}$. & easure & & & & \\
\hline & DATE & & PSI & & & & & om TILT@ & & & & & JEFL & FFL@18 & 88DEFL & & ILT@9 & ULT@ & \\
\hline TT1947a & $\begin{array}{l}\text { 4-Aug } \\
\text { 4-Aug }\end{array}$ & $\begin{array}{l}16: 35: 01 \\
16: 49 \cdot 35\end{array}$ & $\frac{0}{50}$ & $\begin{array}{l}-26.2 \\
-190\end{array}$ & $\frac{-26.3}{-1.89}$ & $\frac{-26.3}{190}$ & $\frac{-26.4}{-190}$ & & & & & 6.3 & $\frac{-4.2}{3.5}$ & $\begin{array}{l}1.7 \\
20\end{array}$ & \begin{tabular}{|l|}
-1.4 \\
\end{tabular} & 6 & $\begin{array}{l}-30.5 \\
13\end{array}$ & $\begin{array}{c}-18.1 \\
184\end{array}$ & $\frac{-10.5}{156}$ \\
\hline & $\frac{4-A g}{4 . A g}$ & & & $\frac{-12.0}{-12.0}$ & & & & & $\begin{array}{l}-2.8 .8 \\
-24.8\end{array}$ & & & & & $\frac{2.3}{3.3}$ & 1.8 & & -30.6 & $\frac{1.46}{-1.2 .2}$ & $\frac{-15.5}{-17.0}$ \\
\hline & 4-Aug & $\begin{array}{l}17: 14: 49 \\
171 ; 71\end{array}$ & 125 & -8.0 & -8.11 & -7.7 & -8.1 & -18.2 & -25.2 & -21.2 & -13.3 & 7.8 & -2.8 & 3.1 & 1.5 & -24.6 & -31.5 & -19.3 & $\begin{array}{ll}-15.9 \\
1.92\end{array}$ \\
\hline & & $\begin{array}{l}17: 27: 77 \\
17: 202\end{array}$ & & $\begin{array}{l}-4.9 \\
-29\end{array}$ & -4.8 & $\frac{-4.3}{3.3}$ & & & -25.00 & & & 8.2 & & & & & $\begin{array}{l}-31.6 \\
-314\end{array}$ & -18.6 & $\begin{array}{l}-16.2 \\
16.5 \\
16.5\end{array}$ \\
\hline at7a & 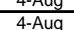 & 1774.52 & $\frac{100}{170}$ & -3.3. & -2.6 & -2.4 & -2.8 & $\begin{array}{l}-11.5 \\
-17.9\end{array}$ & - -24.0 & -20.6 & -12.6 & 9.4 & 2.4 & 4.8 & 2.45 & $\frac{-24.4}{-22.1}$ & $\frac{-3.4}{-31.3}$ & $\frac{-18.6}{-18.2}$ & $\begin{array}{l}-\frac{-16.5}{-16.8} \\
\end{array}$ \\
\hline & 4-Aug & $18: 08$ & 180 & $\begin{array}{l}-2.9 \\
2.9\end{array}$ & -2.1 & -1.7 & -2.5 & -17.9 & -2 & -20. & -12.3 & 9.8 & 3.2 & 6.2 & 4.0 & & -30.4 & -18.4 & -16. \\
\hline & 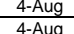 & 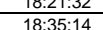 & $\frac{190}{200}$ & $\frac{-2.8}{-26}$ & $\frac{-1.6}{-1.4}$ & $\frac{-1.4}{-1.1}$ & $\frac{-2.1}{-19}$ & $\frac{-11.1}{-177}$ & $\begin{array}{l}-24.5 \\
-243\end{array}$ & $\frac{-2.2}{-20.1}$ & $\frac{-1.2 .2}{-1.19}$ & $\frac{10.0}{10.7}$ & $\frac{4.4}{6.1}$ & $\frac{1.2}{97}$ & $\frac{5.1}{76}$ & & $\begin{array}{l}-30.9 \\
-30.8\end{array}$ & $\frac{-18.2}{-18.8}$ & $\begin{array}{l}-\frac{16.9}{1-167} \\
167\end{array}$ \\
\hline & 4-Aug & & & & -0.8 & & & & & & & & & & & & & & $\begin{array}{l}-1.7 .7 \\
-15.6 \\
\end{array}$ \\
\hline & 4-Aug & & $\frac{20}{20}$ & $\frac{-3.5}{24}$ & & & & & & & $\frac{-11.8}{-11.8}$ & $\begin{array}{l}19.4 \\
\end{array}$ & $\frac{17.3}{17.3}$ & & & $\begin{array}{l}-2.1 .4 \\
\end{array}$ & \begin{tabular}{|c|c|} 
& -31.2 \\
\end{tabular} & \begin{tabular}{|l|l|}
-10.2 \\
-19.2
\end{tabular} & \begin{tabular}{|l|l|}
-15.0 \\
-15.2
\end{tabular} \\
\hline
\end{tabular}

Table C

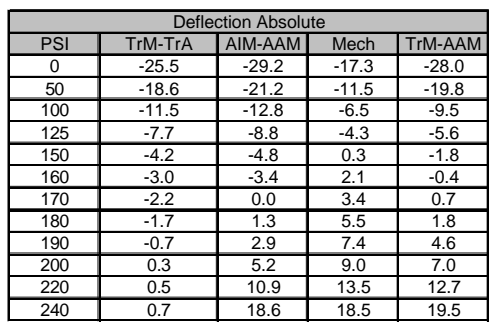

Table D

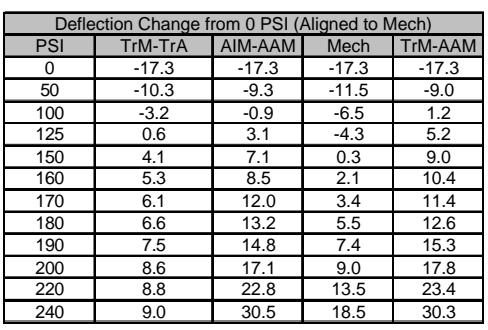




\section{S/N P1958}

Table A

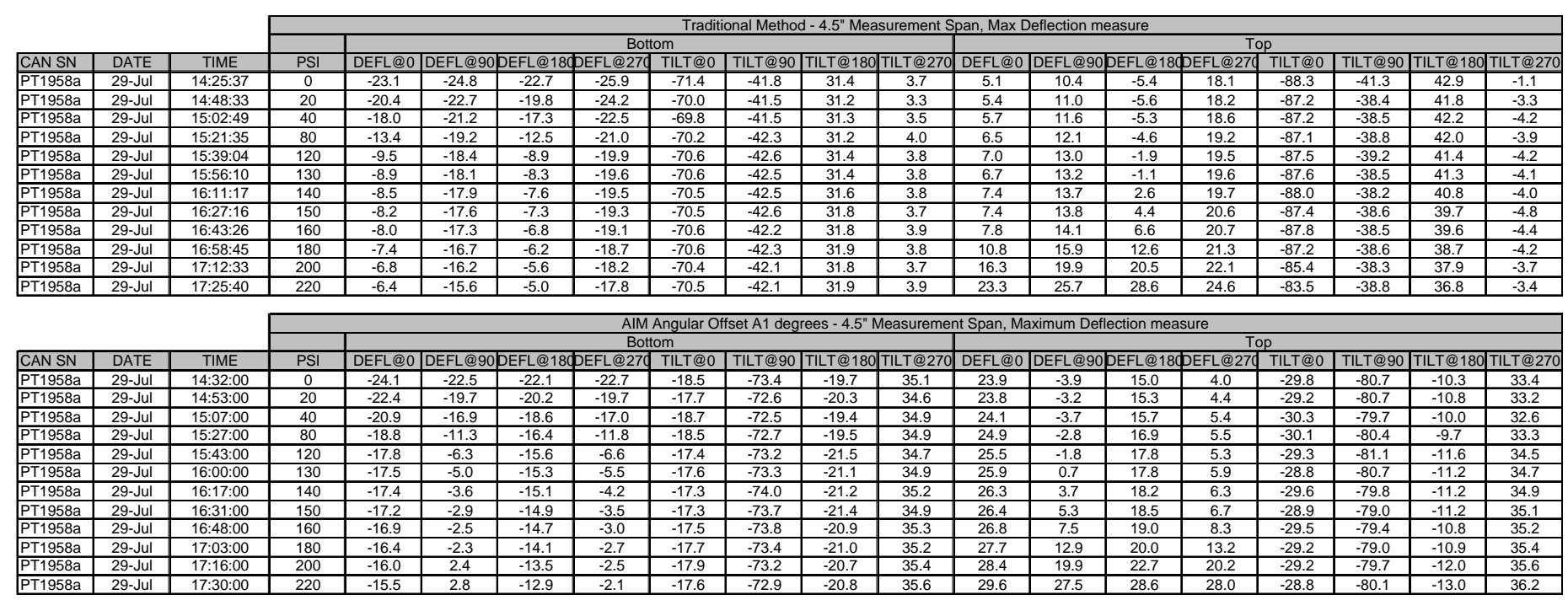

Table C

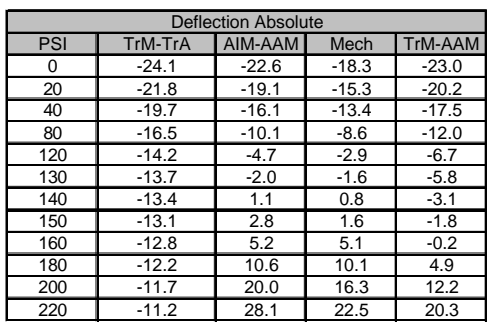

Table D

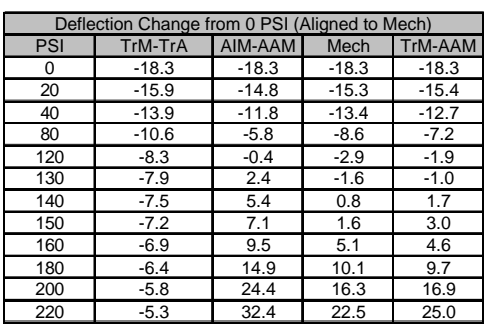




\section{S/N P1962}

Table A

Table B

Table C
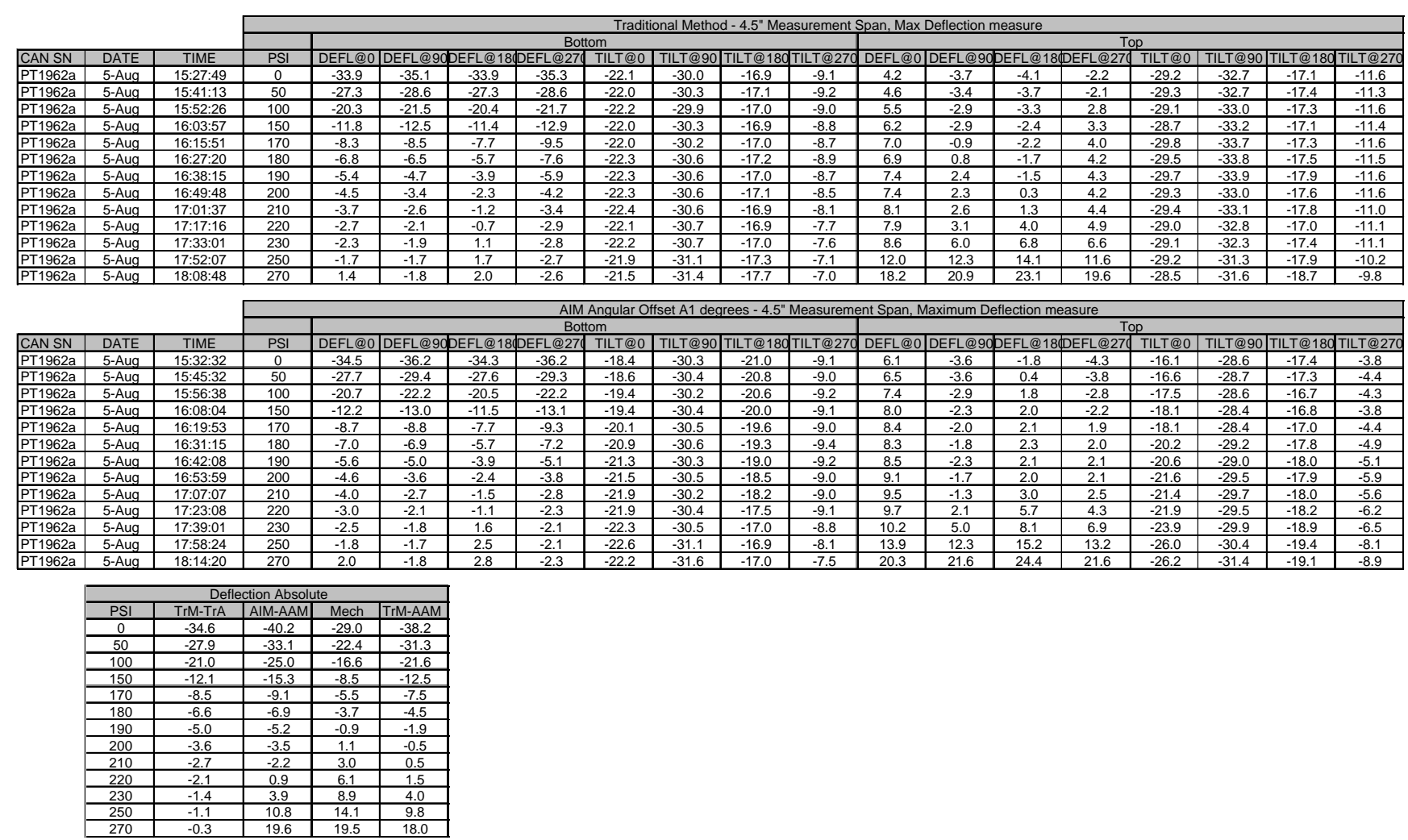

Table D

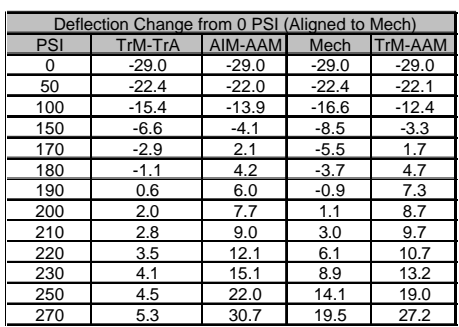




\section{S/N P2714}

Table A

Table B

Table C
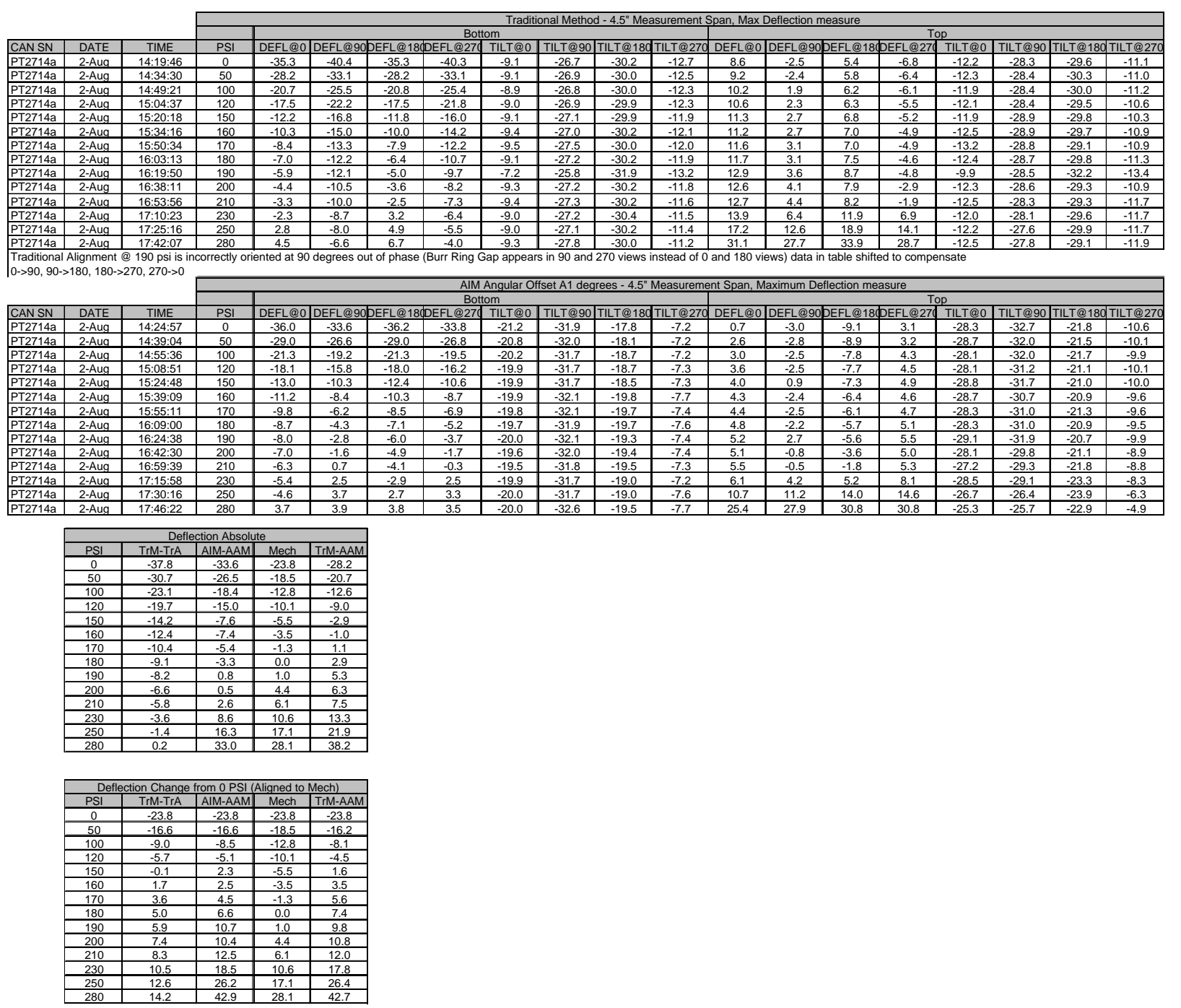

Table D 


\section{S/N P3370}

Table A

\begin{tabular}{|c|c|c|c|c|c|c|c|c|c|c|c|c|c|c|c|c|c|c|c|}
\hline \multirow{3}{*}{\begin{tabular}{|l|} 
CAN SN \\
PT3370a
\end{tabular}} & \multirow{3}{*}{\begin{tabular}{|l|} 
DATE \\
1-Aug
\end{tabular}} & \multirow{3}{*}{$\begin{array}{c}\text { TIME } \\
11: 32: 13\end{array}$} & \\
\hline & & & PSI & $\overline{\mathrm{DEFLC}}$ & & & & TILT@0 & & & & & & & & TILT@0 & & |TILT@180 & TILT@ \\
\hline & & & 0 & -26.4 & -28.9 & -26.3 & $\begin{array}{r}-29.1 \\
\end{array}$ & -3.9 & -26.9 & -35.1 & -12.6 & \begin{tabular}{|l|l}
3.5 \\
\end{tabular} & -2.4 & 2.4 & -7.7 & -4.4 & \begin{tabular}{|l|l|}
-22.6 \\
\end{tabular} & -38.3 & -16.8 \\
\hline & & & & & & & & & & & & & & & & & & & \\
\hline & & & & & & & & & & & & & & & & & & & \\
\hline $\begin{array}{l}\text { PT3370a } \\
\text { PT33770a }\end{array}$ & 1-Aug & $\begin{array}{l}12: 45: 21 \\
130.08\end{array}$ & 80 & -12.4 & $\frac{-15.1}{-11.5}$ & $\frac{-12.2}{-79}$ & $\begin{array}{r}-14.9 \\
-108\end{array}$ & $\begin{array}{l}-4.0 \\
-4.0\end{array}$ & $\frac{-27.6}{-278}$ & -35.7 & $\frac{-12.5}{-123}$ & $\frac{4.7}{4.9}$ & $\frac{2.5}{27}$ & $\frac{3.2}{3.4}$ & $\frac{-6.4}{6.1}$ & $\frac{-4.1}{-4.2}$ & $\begin{array}{l}-23.0 \\
-228 \\
\end{array}$ & $\begin{array}{r}-38.5 \\
385\end{array}$ & $\frac{-17.2}{171}$ \\
\hline $\begin{array}{l}\text { PT3370a } \\
\text { PT370a }\end{array}$ & $\begin{array}{l}\text { 1-Aug } \\
\text {-Aug }\end{array}$ & $\begin{array}{l}13: 08: 16 \\
13: 49\end{array}$ & $\frac{100}{120}$ & $\begin{array}{l}-8.4 \\
-4.2 \\
\end{array}$ & $\begin{array}{l}-11.5 \\
-9.5 \\
\end{array}$ & $\begin{array}{l}-1.9 \\
-3.6 \\
\end{array}$ & $\begin{array}{l}-10.8 \\
-7.6 \\
\end{array}$ & $\begin{array}{l}-4.0 \\
-3.7 \\
\end{array}$ & $\begin{array}{r}-27.8 \\
-28.2 \\
\end{array}$ & $\begin{array}{l}-35.8 \\
-35.6\end{array}$ & $\begin{array}{l}-12.3 \\
-11.9\end{array}$ & $\begin{array}{l}\frac{4.9}{5.4} \\
\end{array}$ & $\frac{2.1}{3.0}$ & $\begin{array}{l}3.4 \\
3.7\end{array}$ & $\begin{array}{l}-6.1 \\
-5.3 \\
\end{array}$ & $\begin{array}{l}-4.2 \\
-4.1\end{array}$ & $\begin{array}{l}-2.8 \\
-23.0\end{array}$ & $\begin{array}{r}-38.5 \\
-38.0 \\
\end{array}$ & $\begin{array}{l}-11.1 \\
-17.4\end{array}$ \\
\hline PT3370a & 1-Aug & 13:59:13 & 140 & 1.0 & -8.1 & 1.4 & -6.3 & -3.7 & -28.5 & -35.4 & -11.2 & 5.8 & 3.3 & 4.4 & -3.4 & -4.1 & -22.8 & -38.2 & -17.2 \\
\hline PT3370a & 1-Aug & 14:25:12 & 160 & 4.4 & -7.5 & 5.1 & -5.9 & -4.5 & -29.0 & $\begin{array}{l}-34.8 \\
\end{array}$ & -10.4 & 6.9 & 3.9 & 5.4 & 3.3 & -4.5 & -22.5 & -38.5 & -17.6 \\
\hline $\begin{array}{l}\text { PT3370a } \\
\text { DT20270 }\end{array}$ & 1-Aug & $\begin{array}{c}14: 49: 39 \\
15 \cdot 12: 12\end{array}$ & 180 & 6.1 & -6.9 & $\begin{array}{l}6.5 \\
\end{array}$ & $\begin{array}{l}-5.4 \\
\end{array}$ & -5.2 & $\frac{-29.4}{20.5}$ & $\begin{array}{r}-34.0 \\
2.7\end{array}$ & $\begin{array}{l}-9.9 \\
\end{array}$ & 11.6 & 5.7 & 12.6 & 111.6 & $\begin{array}{l}-4.3 \\
\end{array}$ & -22.4 & $\begin{array}{l}-39.8 \\
\end{array}$ & -18.0 \\
\hline $\begin{array}{l}\text { PTT370a } \\
\text { PT33700a }\end{array}$ & 1-Aug & $\begin{array}{l}15: 13: 13 \\
15.37 \cdot 17\end{array}$ & $\frac{200}{200}$ & 6.6 & $\begin{array}{c}-6.3 \\
-5.6\end{array}$ & $\begin{array}{l}7.1 \\
75\end{array}$ & $\begin{array}{l}-4.7 \\
-3.9\end{array}$ & $\begin{array}{l}-4.9 \\
-50\end{array}$ & -29.5 & -33.7 & $\begin{array}{r}-9.4 \\
9.1\end{array}$ & $\begin{array}{l}19.9 \\
336\end{array}$ & $\frac{13.9}{269}$ & $\begin{array}{l}22.6 \\
358\end{array}$ & $\frac{21.3}{332}$ & $\begin{array}{l}-4.3 \\
-4.0\end{array}$ & $\begin{array}{r}-21.7 \\
-21.4\end{array}$ & $\begin{array}{r}-39.9 \\
-395\end{array}$ & $\begin{array}{r}-16.8 \\
-16.3\end{array}$ \\
\hline & & 15:37:12 & 220 & & & & & -5.0 & -29.6 & -33.6 & -9.1 & & & & & & & & \\
\hline
\end{tabular}
We assumed that we would use the phase angle calculated at 0 psi throughout the tests. This procedural error was corrected at $80 \mathrm{ps}$

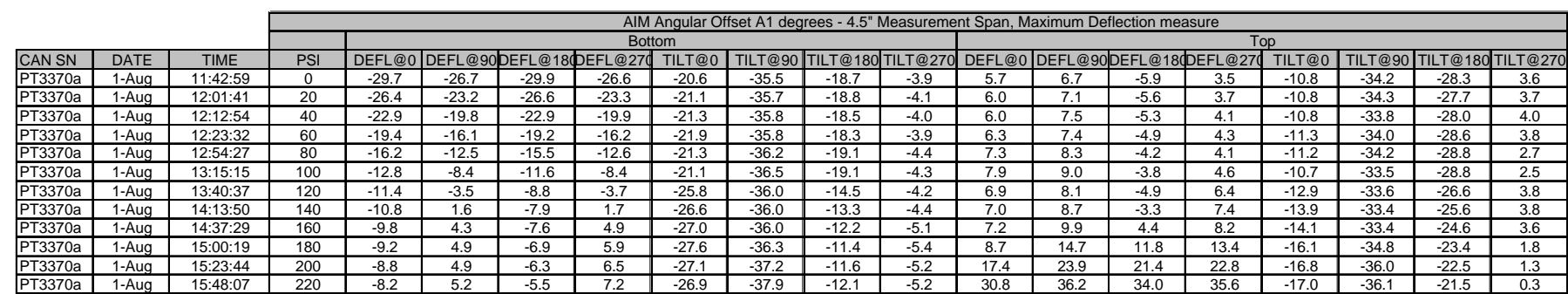

\begin{tabular}{|c|c|c|c|c|}
\hline \multicolumn{5}{|c|}{ Deflection Absolute } \\
\hline PSI & TrM-TrA & AlM-AAM & Mech & TrM-AAM \\
\hline 0 & -27.7 & -21.6 & -24.1 & -23.4 \\
\hline 20 & & -1.9 & -22.4 & \\
\hline 40 & & -14.1 & -19.6 & \\
\hline 60 & & -1.3 & -1.9 & \\
\hline 80 & -13.6 & -6.4 & -13.4 & -8.3 \\
\hline 100 & -9.7 & -1.6 & -1.9 & -4.0 \\
\hline 120 & -6.2 & 3.6 & -5.9 & 0.6 \\
\hline 140 & -3.0 & 9.7 & -1.1 & 6.3 \\
\hline 160 & -1.0 & 13.6 & 3.0 & 10.8 \\
\hline 180 & 0.1 & 19.5 & 10.3 & 18.4 \\
\hline 200 & 0.7 & 29.1 & 17.6 & 28.1 \\
\hline 220 & 1.3 & 42.1 & 27.6 & 42.1 \\
\hline \multicolumn{5}{|c|}{} \\
\hline \multicolumn{5}{|c|}{} \\
\hline
\end{tabular}

Table D

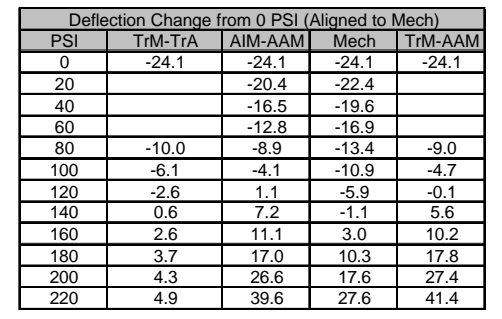




\section{S/N P3373}

Table A

Table B

Table C

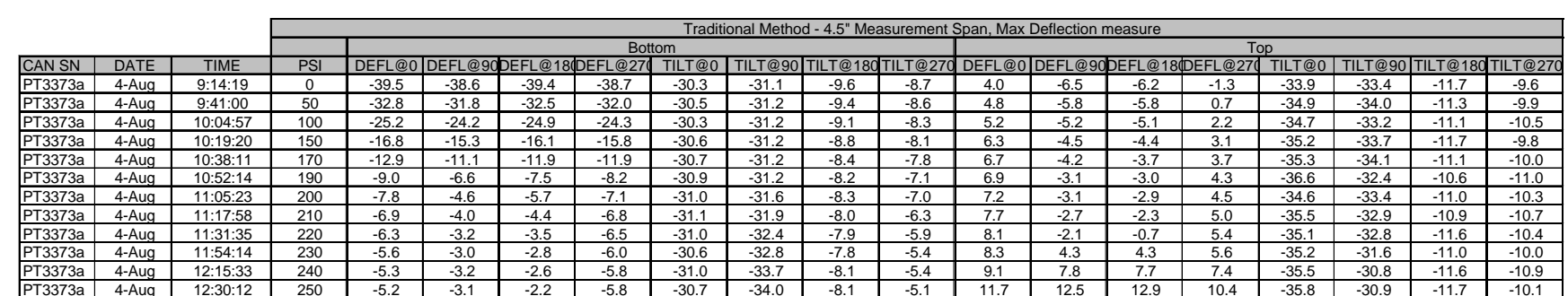

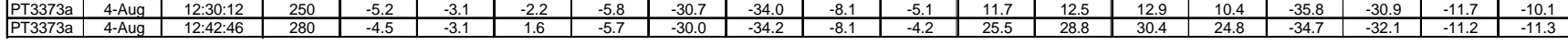

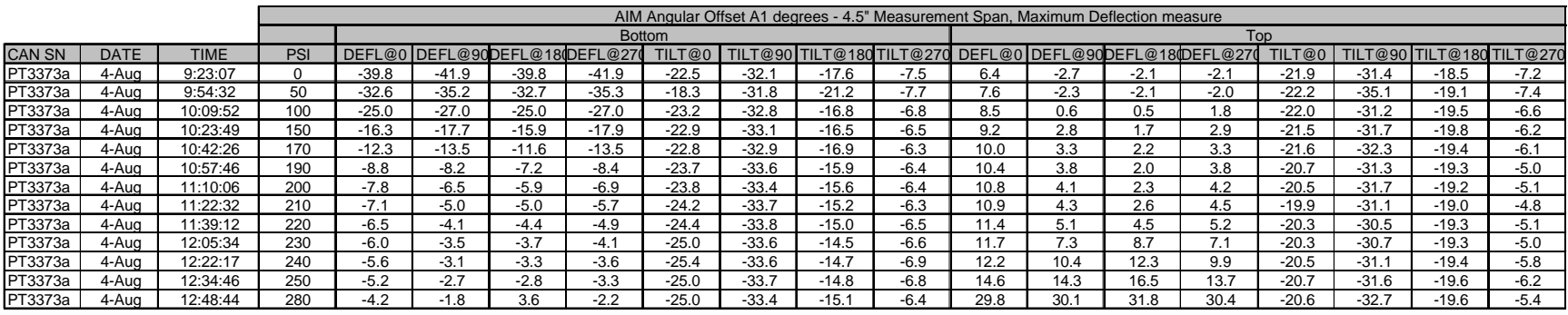
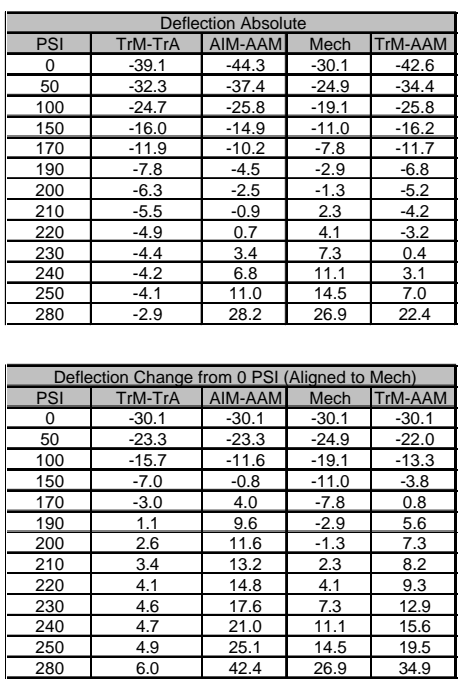

Table D 


\section{S/N P3379}

Table A

Table B

Table C
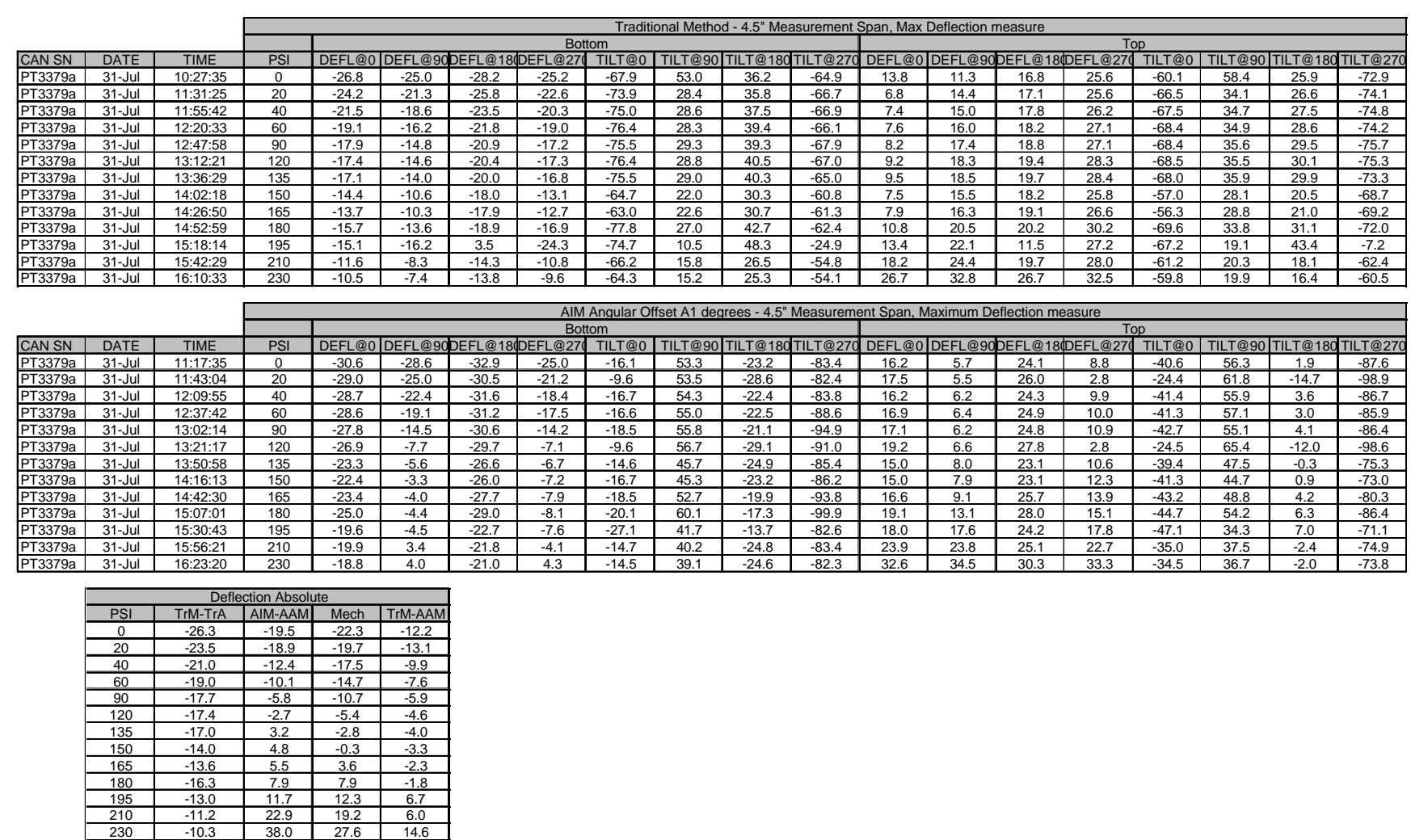

Deflection Change from 0 PSI (Aligned to Mech)

Table D

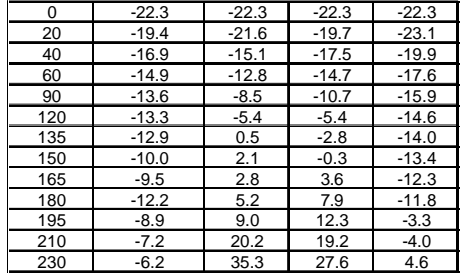




\section{S/N P3381}

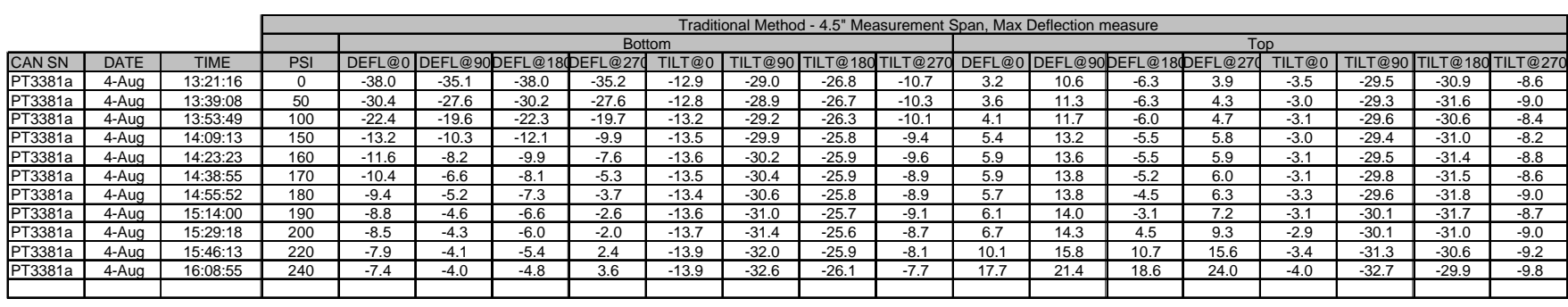

\begin{tabular}{|c|c|c|c|c|c|c|c|c|c|c|c|c|c|c|c|c|c|c|c|}
\hline & & & & & & & & Angular & el $A \mid$ de & rees $-4.5^{5}$ & Measurem & nt Span, & aximun & Deflection $\mathrm{me}$ & asure & & & & \\
\hline CANSN & DATE & TIME & $\overline{P S \mid}$ & & $\mathrm{FE}$ & & & Iom & & & & & & ODEFI@18 & DEFL@2 & T TILT@O & & TUTC18 & TILT@ \\
\hline & 4-Aug & 13:26:03 & & $\frac{-32.8}{-32}$ & -35.1 & -33.1 & -35.0 & & -32.6 & -16.8 & -6.2 & 8.5 & $\frac{-1.3}{-8.3}$ & -3.5 & -4.9 & \begin{tabular}{|l|l|} 
& -25.7 \\
\end{tabular} & -38.0 & $\frac{11101018}{-17.7}$ & $\frac{1121(2,1 / 1}{-13.1}$ \\
\hline & 4-Aug & 13:43:54 & 50 & -25.3 & -27.3 & -25.6 & -27.4 & -21.9 & -32.2 & -17.3 & $\begin{array}{l}-6.3 \\
\end{array}$ & 7.3 & -7.6 & -3.3 & -3.7 & -24.0 & -36.9 & -18.2 & -12.4 \\
\hline $81 a$ & 4-Aug & $\begin{array}{l}13: 58: 31 \\
10.12: 34\end{array}$ & $\frac{100}{150}$ & $\frac{-17.7}{9.7}$ & -19.1 & -18.0 & -19.4 & $\frac{-21.4}{-0.7}$ & -31.8 & -17.7 & -6.7 & 4.7 & $\begin{array}{l}-5.7 \\
13\end{array}$ & -3.7 & 0.7 & -18.1 & -35.1 & -18.8 & -10.9 \\
\hline $\begin{array}{l}\text { PT3381a } \\
\text { PT3381a }\end{array}$ & $\frac{\text { 4-Aug }}{\text { 4-Aug }}$ & $\frac{14: 13: 34}{14: 23: 33}$ & $\frac{150}{160}$ & $\frac{-8.7}{-71}$ & $\frac{-9.2}{-7.1}$ & $\frac{-8.3}{-6.0}$ & $\frac{-9.6}{-7.3}$ & $\frac{-20.7}{-208}$ & $\frac{-31.4}{-31.5}$ & $\begin{array}{r}-18.4 \\
184 \\
\end{array}$ & $\begin{aligned}-7.4 \\
75\end{aligned}$ & $\frac{2.2}{23}$ & $\frac{1.3}{4.3}$ & $\frac{-5.1}{48}$ & $\frac{3.0}{3.5}$ & $\begin{array}{l}-12.6 \\
12.1\end{array}$ & $\frac{-31.2}{311}$ & $\frac{-20.7}{203}$ & -8.3 \\
\hline PT3381a & 4-Aug & $14: 45: 13$ & 170 & -5.7 & -4.9 & -4.1 & -5.0 & $\begin{array}{l}-20.0 \\
-20.6 \\
\end{array}$ & $\begin{array}{l}-0.51 .0 \\
-31.0\end{array}$ & $\begin{array}{l}-10.4 \\
-18.8 \\
\end{array}$ & $\frac{-7.9}{.7 .9}$ & $\frac{2.0}{1.8}$ & $\begin{array}{l}4.0 \\
5.0\end{array}$ & $\begin{array}{l}-4.0 \\
-5.2\end{array}$ & $\frac{0.5}{4.1}$ & $\frac{-\frac{1<.1}{-10.9}}{-10}$ & $\begin{array}{l}-3.1 \\
-28.9 \\
\end{array}$ & $\begin{array}{l}-21.5 \\
-21.6\end{array}$ & $\begin{array}{l}-8.0 \\
-6.9 \\
\end{array}$ \\
\hline & 4-Aug & 15:00:30 & 180 & -4.6 & -3.3 & -2.8 & -3.2 & -20.8 & -31.3 & -18.6 & -8.0 & 1.8 & 5.1 & -4.1 & 4.2 & -10.8 & -30.3 & -22.9 & -6.9 \\
\hline & & & 190 & & & & & & & -18.8 & -8.3 & & & -3.1 & 4.6 & & -30.5 & -22.9 & -6.5 \\
\hline 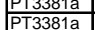 & $\frac{\text { 4-Aug }}{\text { 4-Aug }}$ & $\frac{15: 35: 56}{15: 58: 09}$ & $\frac{200}{220}$ & $\frac{-3.7}{-8.4}$ & $\frac{-1.3}{-4.0}$ & $\frac{-1.3}{-6.0}$ & $\frac{-1.4}{2.9}$ & $\frac{-20.9}{-11.9}$ & $\frac{-31.0}{-31.3}$ & $\frac{-18.8}{-27.4}$ & $\frac{-8.8}{-8.4}$ & $\frac{2.3}{10.7}$ & $\frac{6.8}{16.7}$ & $\frac{-1.9}{11.1}$ & $\frac{\frac{5.4}{16.5}}{1.5}$ & $\frac{-9.9}{-3.8}$ & $\frac{-3.2}{-31.4}$ & $\frac{-23.9}{-30.2}$ & $\frac{-.0}{-10.4}$ \\
\hline PT $3381 \mathrm{a}$ & 4-Aug & 16:14:10 & 240 & -3.3 & 1.7 & 2.7 & 3.2 & -23.0 & -30.7 & -16.9 & -10.1 & 12.8 & 18.2 & 18.4 & 20.7 & -8.3 & -34.0 & -26.2 & -7.0 \\
\hline & & & & & & & & & & & & & & & & & & & \\
\hline
\end{tabular}

Note: the residual phase at 220 psi does not fit the trend in the wobble graph. Most likely cause is that the stage was rotated

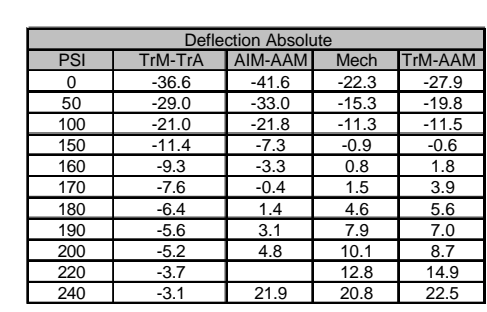

Table D

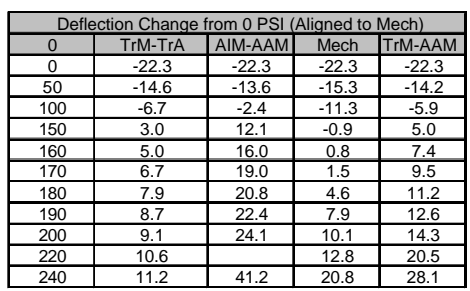




\section{S/N P3382}

Table A

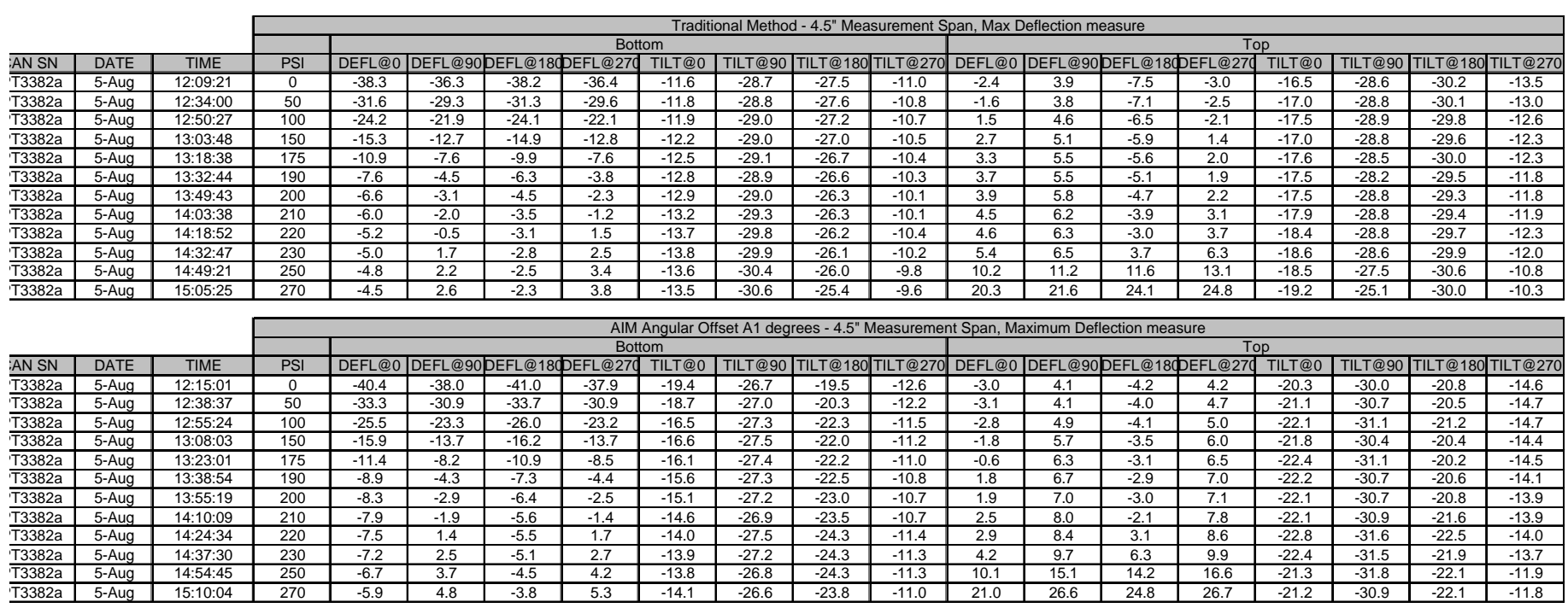

Table C

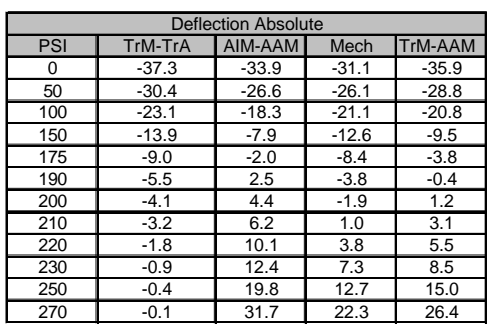

Table D

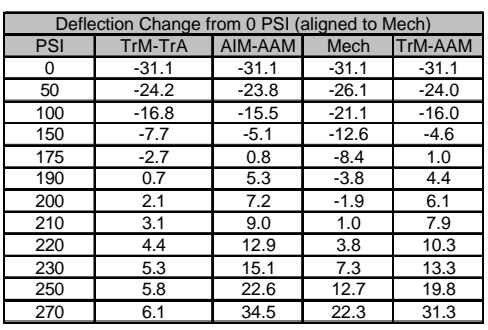


Appendix 5 : Wobble Analysis (Slant, Phase Angle, and Wobble Amplitude) 


\section{S/N P1458}

\begin{tabular}{|c|c|c|c|c|c|c|c|}
\hline & & & & & raditio & lignmen & \\
\hline & & & & & Wob & lector & \\
\hline CAN SN & DATE & TIME & PSI & $\mathrm{S}$ & $A$ & Phase & Err \\
\hline PT1458a & 2 -Aug & $9: 57: 58$ & 0 & -16.38 & 15.55 & 70.01 & 0.17 \\
\hline PT1458a & $2-A u g$ & $10: 16: 47$ & 40 & -16.39 & 16.31 & 70.17 & 0.27 \\
\hline PT1458a & $2-A u g$ & $10: 33: 19$ & 80 & -16.40 & 16.78 & 69.92 & 0.27 \\
\hline PT1458a & $2-A u g$ & $10: 48: 19$ & 100 & -16.35 & 17.01 & 70.42 & 0.31 \\
\hline PT1458a & 2-Aug & $11: 05: 30$ & 140 & -16.36 & $\overline{17.17}$ & 70.02 & 0.22 \\
\hline PT1458a & 2-Aug & $11: 20: 15$ & 180 & -16.29 & 17.09 & 69.31 & 0.33 \\
\hline PT1458a & 2-Aug & $11: 37: 15$ & 220 & -16.30 & 17.08 & 68.99 & 0.28 \\
\hline PT1458a & 2-Aug & $11: 55: 30$ & 240 & -16.29 & 16.97 & 68.05 & 0.25 \\
\hline PT1458a & 2-Aug & $12: 14: 17$ & 250 & -16.63 & 16.86 & 67.38 & 0.21 \\
\hline PT1458a & 2 -Aug & $12: 34: 36$ & 260 & -16.56 & 16.81 & 67.50 & 0.27 \\
\hline PT1458a & 2 -Aug & $12: 56: 35$ & 270 & -16.52 & 16.62 & 67.42 & 0.26 \\
\hline PT1458a & 2-Aug & $13: 26: 38$ & 280 & -16.43 & 16.47 & 66.82 & 0.38 \\
\hline
\end{tabular}

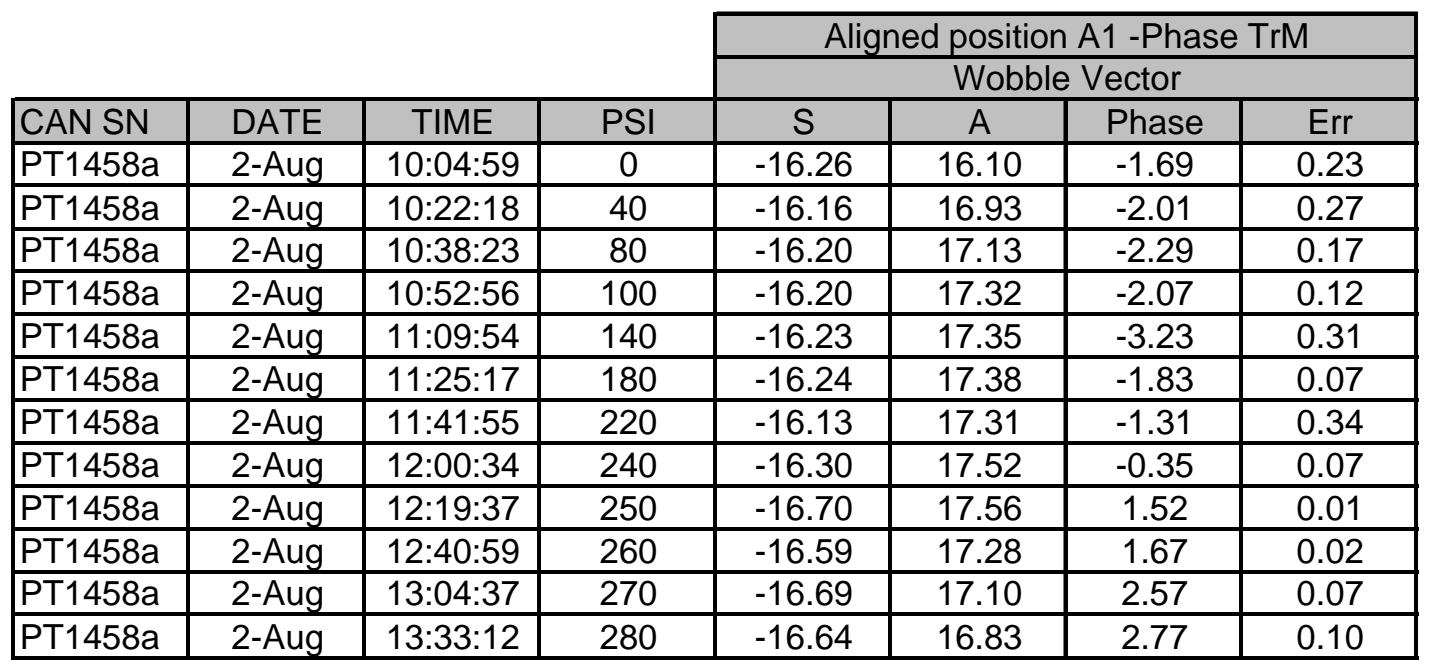




\section{S/N P1947}

\begin{tabular}{|l|c|c|c|c|c|c|c|}
\cline { 4 - 7 } \multicolumn{2}{c}{} & \multicolumn{4}{c|}{ Traditional Alignment } \\
\cline { 5 - 8 } \multicolumn{2}{c}{} & & \multicolumn{4}{c|}{ Wobble Vector } \\
\hline CAN SN & DATE & TIME & PSI & S & A & Phase & Err \\
\hline PT1947a & 4-Aug & $16: 30: 45$ & 0 & -16.19 & -3.66 & 73.63 & 0.06 \\
\hline PT1947a & 4-Aug & $16: 43: 23$ & 50 & -16.22 & -4.02 & 77.54 & 0.13 \\
\hline PT1947a & 4-Aug & $16: 57: 15$ & 100 & -16.16 & -4.05 & 73.53 & 0.12 \\
\hline PT1947a & 4-Aug & $17: 10: 23$ & 125 & -16.47 & -3.96 & 75.68 & 0.11 \\
\hline PT1947a & 4-Aug & $17: 23: 04$ & 150 & -16.34 & -4.11 & 75.03 & 0.06 \\
\hline PT1947a & 4-Aug & $17: 35: 51$ & 160 & -16.32 & -4.27 & 74.80 & 0.07 \\
\hline PT1947a & 4-Aug & $17: 50: 09$ & 170 & -16.22 & -4.43 & 73.56 & 0.15 \\
\hline PT1947a & 4-Aug & $18: 02: 59$ & 180 & -16.12 & -4.45 & 71.93 & 0.20 \\
\hline PT1947a & 4-Aug & $18: 16: 55$ & 190 & -15.98 & -4.61 & 72.87 & 0.24 \\
\hline PT1947a & 4-Aug & $18: 30: 31$ & 200 & -15.87 & -4.68 & 73.44 & 0.31 \\
\hline PT1947a & 4-Aug & $18: 43: 05$ & 220 & -15.75 & -4.89 & 76.00 & 0.44 \\
\hline PT1947a & 4-Aug & $18: 57: 24$ & 240 & -15.68 & -5.16 & 77.50 & 0.64 \\
\hline
\end{tabular}

\begin{tabular}{|c|c|c|c|c|c|c|c|}
\hline & \multicolumn{4}{|c|}{ Aligned position A1 -Phase TrM } \\
\hline & & & & \multicolumn{4}{|c|}{ Wobble Vector } \\
\hline CAN SN & DATE & TIME & PSI & $\mathrm{S}$ & $\mathrm{A}$ & Phase & Err \\
\hline PT1947a & 4-Aug & $16: 35: 01$ & 0 & -16.07 & -4.32 & -10.34 & 0.04 \\
\hline PT1947a & 4-Aug & $16: 49: 35$ & 50 & -16.05 & -4.42 & -11.58 & 0.26 \\
\hline PT1947a & 4-Aug & $17: 01: 41$ & 100 & -15.87 & -4.55 & -8.07 & 0.22 \\
\hline PT1947a & 4-Aug & $17: 14: 49$ & 125 & -16.31 & -4.50 & -8.93 & 0.29 \\
\hline PT1947a & 4-Aug & $17: 27: 47$ & 150 & -16.05 & -4.60 & -5.40 & 0.31 \\
\hline PT1947a & 4-Aug & $17: 40: 32$ & 160 & -16.05 & -4.91 & -3.24 & 0.31 \\
\hline PT1947a & 4-Aug & $17: 54: 52$ & 170 & -15.91 & -5.05 & -0.96 & 0.38 \\
\hline PT1947a & 4-Aug & $18: 08: 49$ & 180 & -15.84 & -5.16 & 1.85 & 0.35 \\
\hline PT1947a & 4-Aug & $18: 21: 32$ & 190 & -15.73 & -5.37 & 2.75 & 0.36 \\
\hline PT1947a & 4-Aug & $18: 35: 14$ & 200 & -15.62 & -5.42 & 4.23 & 0.38 \\
\hline PT1947a & 4-Aug & $18: 47: 47$ & 220 & -15.52 & -5.63 & 4.18 & 0.45 \\
\hline PT1947a & 4-Aug & 19:01:59 & 240 & -15.53 & -5.65 & 3.26 & 0.59 \\
\hline
\end{tabular}




\section{S/N P1958}

\begin{tabular}{|c|c|c|c|c|c|c|c|}
\hline & & & & & raditior & lignmen & \\
\hline & & & & & Wobl & lector & \\
\hline CAN SN & DATE & TIME & PSI & $\mathrm{S}$ & $A$ & Phase & Err \\
\hline PT1958a & 29-Jul & $14: 25: 37$ & 0 & -19.08 & -56.00 & 68.44 & 0.37 \\
\hline PT1958a & 29-Jul & $14: 48: 33$ & 20 & -18.85 & -55.21 & 68.90 & 0.19 \\
\hline PT1958a & 29-Jul & $15: 02: 49$ & 40 & -18.64 & -55.20 & 68.45 & 0.24 \\
\hline PT1958a & 29-Jul & $15: 21: 35$ & 80 & -18.77 & -55.86 & 68.04 & 0.35 \\
\hline PT1958a & 29-Jul & $15: 39: 04$ & 120 & -19.04 & -56.55 & 68.63 & 0.38 \\
\hline PT1958a & 29-Jul & $15: 56: 10$ & 130 & -18.89 & -56.91 & 68.86 & 0.36 \\
\hline PT1958a & 29-Jul & $16: 11: 17$ & 140 & -18.69 & -57.12 & 69.03 & 0.35 \\
\hline PT1958a & 29-Jul & $16: 27: 16$ & 150 & -18.67 & -57.39 & 69.30 & 0.35 \\
\hline PT1958a & 29-Jul & $16: 43: 26$ & 160 & -18.76 & -57.38 & 69.30 & 0.37 \\
\hline PT1958a & 29-Jul & $16: 58: 45$ & 180 & -18.70 & -57.30 & 69.40 & 0.37 \\
\hline PT1958a & 29-Jul & $17: 12: 33$ & 200 & -18.92 & -57.17 & 69.39 & 0.25 \\
\hline PT1958a & 29-Jul & $17: 25: 40$ & 220 & -18.72 & -57.00 & 69.35 & 0.27 \\
\hline
\end{tabular}

\begin{tabular}{|c|c|c|c|c|c|c|c|}
\hline & & & & & d positic & A1-Phas & \\
\hline & & & & & Wobl & Vector & \\
\hline CAN SN & DATE & TIME & PSI & $\mathrm{S}$ & A & Phase & Err \\
\hline PT1958a & 29-Jul & $14: 32: 00$ & 0 & -18.86 & -55.53 & 0.58 & 0.18 \\
\hline PT1958a & 29-Jul & $14: 53: 00$ & 20 & -18.92 & -55.06 & -0.13 & 0.17 \\
\hline PT1958a & 29-Jul & 15:07:00 & 40 & -18.76 & -55.11 & 0.72 & 0.11 \\
\hline PT1958a & 29-Jul & $15: 27: 00$ & 80 & -18.75 & -55.29 & 0.17 & 0.10 \\
\hline PT1958a & 29-Jul & $15: 43: 00$ & 120 & -19.02 & -55.59 & -1.55 & 0.08 \\
\hline PT1958a & 29-Jul & $16: 00: 00$ & 130 & -19.07 & -55.78 & -1.39 & 0.09 \\
\hline PT1958a & 29-Jul & $16: 17: 00$ & 140 & -19.05 & -56.37 & -1.56 & 0.03 \\
\hline PT1958a & 29-Jul & $16: 31: 00$ & 150 & -18.98 & -56.15 & -1.66 & 0.15 \\
\hline PT1958a & 29-Jul & $16: 48: 00$ & 160 & -19.03 & -56.23 & -1.52 & 0.02 \\
\hline PT1958a & 29-Jul & 17:03:00 & 180 & -19.07 & -56.09 & -1.27 & 0.19 \\
\hline PT1958a & 29-Jul & $17: 16: 00$ & 200 & -19.07 & -55.97 & -1.26 & 0.16 \\
\hline PT1958a & 29-Jul & $17: 30: 00$ & 220 & -18.90 & -55.88 & -1.39 & 0.32 \\
\hline
\end{tabular}




\section{S/N P1962}

\begin{tabular}{|c|c|c|c|c|c|c|c|}
\hline & & & & \multicolumn{4}{|c|}{ Traditional Alignment } \\
\hline & & & & \multicolumn{4}{|c|}{ Wobble Vector } \\
\hline CAN SN & DATE & TIME & PSI & $\mathrm{S}$ & A & Phase & Err \\
\hline PT1962a & 5-Aug & $15: 27: 00$ & 0 & -16.29 & -9.18 & 21.38 & 0.22 \\
\hline PT1962a & 5-Aug & 15:41:00 & 50 & -16.24 & -9.44 & 19.90 & 0.14 \\
\hline PT1962a & 5-Aug & 15:52:00 & 100 & -16.26 & -9.57 & 18.77 & 0.09 \\
\hline PT1962a & 5-Aug & 16:03:00 & 150 & -16.28 & -9.54 & 18.01 & 0.18 \\
\hline PT1962a & 5-Aug & $16: 15: 00$ & 170 & -16.25 & -9.73 & 16.65 & 0.11 \\
\hline PT1962a & 5-Aug & $16: 27: 00$ & 180 & -16.54 & -9.83 & 14.61 & 0.10 \\
\hline PT1962a & 5-Aug & $16: 38: 00$ & 190 & -16.50 & -9.87 & 14.36 & 0.11 \\
\hline PT1962a & 5-Aug & $16: 49: 00$ & 200 & -16.41 & -10.00 & 13.27 & 0.10 \\
\hline PT1962a & 5-Aug & $17: 01: 00$ & 210 & -16.35 & -10.08 & 12.68 & 0.14 \\
\hline PT1962a & 5-Aug & $17: 17: 00$ & 220 & -16.32 & -10.17 & 11.63 & 0.05 \\
\hline PT1962a & 5-Aug & 17:33:00 & 230 & -16.26 & -9.96 & 9.85 & 0.05 \\
\hline PT1962a & 5-Aug & $17: 52: 00$ & 250 & -16.25 & -9.60 & 7.05 & 0.02 \\
\hline PT1962a & 5-Aug & 18:08:00 & 270 & -16.20 & -8.97 & 5.02 & 0.11 \\
\hline
\end{tabular}

\begin{tabular}{|c|c|c|c|c|c|c|c|}
\hline & & & \multicolumn{4}{|c|}{ Aligned position A1 -Phase TrM } \\
\hline & & & & \multicolumn{4}{|c|}{ Wobble Vector } \\
\hline CAN SN & DATE & TIME & PSI & $\mathrm{S}$ & A & Phase & Err \\
\hline PT1962a & 5-Aug & $15: 32: 00$ & 0 & -16.47 & -9.30 & 1.78 & 0.08 \\
\hline PT1962a & $5-A u g$ & $15: 45: 00$ & 50 & -16.48 & -9.38 & 0.90 & 0.06 \\
\hline PT1962a & 5-Aug & $15: 56: 00$ & 100 & -16.55 & -9.48 & 2.87 & 0.10 \\
\hline PT1962a & 5-Aug & 16:08:00 & 150 & -16.59 & -9.64 & 4.53 & 0.11 \\
\hline PT1962a & 5-Aug & 16:19:00 & 170 & -16.61 & -9.89 & 5.99 & 0.01 \\
\hline PT1962a & 5-Aug & $16: 31: 00$ & 180 & -16.91 & -9.95 & 6.97 & 0.09 \\
\hline PT1962a & 5-Aug & $16: 42: 00$ & 190 & -16.83 & -10.00 & 8.69 & 0.01 \\
\hline PT1962a & 5-Aug & $16: 53: 00$ & 200 & -16.79 & -10.05 & 10.25 & 0.06 \\
\hline PT1962a & 5-Aug & $17: 07: 00$ & 210 & -16.85 & -10.23 & 11.25 & 0.04 \\
\hline PT1962a & 5-Aug & $17: 23: 00$ & 220 & -16.78 & -10.29 & 12.56 & 0.18 \\
\hline PT1962a & 5-Aug & 17:39:00 & 230 & -16.77 & -10.41 & 12.57 & 0.21 \\
\hline PT1962a & 5-Aug & $17: 58: 00$ & 250 & -16.62 & -10.29 & 11.12 & 0.06 \\
\hline PT1962a & $5-$ Aug & $18: 14: 00$ & 270 & -16.40 & -9.85 & 8.52 & 0.02 \\
\hline
\end{tabular}




\section{S/N P2714}

\begin{tabular}{|l|c|c|c|c|c|c|c|}
\cline { 4 - 7 } \multicolumn{2}{c}{} & \multicolumn{4}{c|}{ Traditional Alignment } \\
\cline { 5 - 8 } \multicolumn{2}{c}{} & \multicolumn{4}{c|}{ Wobble Vector } \\
\hline CAN SN & DATE & TIME & PSI & S & A & Phase & Err \\
\hline PT2714a & 2-Aug & $14: 19: 46$ & 0 & -16.42 & -10.62 & -53.21 & 0.04 \\
\hline PT2714a & 2-Aug & $14: 34: 30$ & 50 & -16.33 & -10.65 & -52.17 & 0.10 \\
\hline PT2714a & 2-Aug & $14: 49: 21$ & 100 & -16.36 & -10.73 & -51.22 & 0.18 \\
\hline PT2714a & 2-Aug & $15: 04: 37$ & 120 & -16.43 & -10.70 & -49.86 & 0.27 \\
\hline PT2714a & 2-Aug & $15: 20: 18$ & 150 & -16.43 & -10.88 & -49.04 & 0.20 \\
\hline PT2714a & 2-Aug & $15: 34: 16$ & 160 & -16.58 & -10.98 & -48.44 & 0.07 \\
\hline PT2714a & 2-Aug & $15: 50: 34$ & 170 & -16.68 & -11.04 & -47.09 & 0.19 \\
\hline PT2714a & 2-Aug & $16: 03: 13$ & 180 & -16.59 & -11.16 & -48.27 & 0.15 \\
\hline PT2714a & 2-Aug & $16: 19: 50$ & 190 & -16.29 & -11.21 & $\mathbf{3 3 . 0 2}$ & $\mathbf{0 . 0 9}$ \\
\hline PT2714a & 2-Aug & $16: 38: 11$ & 200 & -16.55 & -11.32 & -47.02 & 0.20 \\
\hline PT2714a & 2-Aug & $16: 53: 56$ & 210 & -16.57 & -11.36 & -46.10 & 0.16 \\
\hline PT2714a & 2-Aug & $17: 10: 23$ & 230 & -16.50 & -11.62 & -46.53 & 0.11 \\
\hline PT2714a & 2-Aug & $17: 25: 16$ & 250 & -16.42 & -11.77 & -45.43 & 0.19 \\
\hline PT2714a & 2-Aug & $17: 42: 07$ & 280 & -16.59 & -11.89 & -43.56 & 0.22 \\
\hline
\end{tabular}

Note: Phase Angle @ 190 psi does not agree with other phase angles.

Review of images indicate a 90 degree burr ring misalignment.

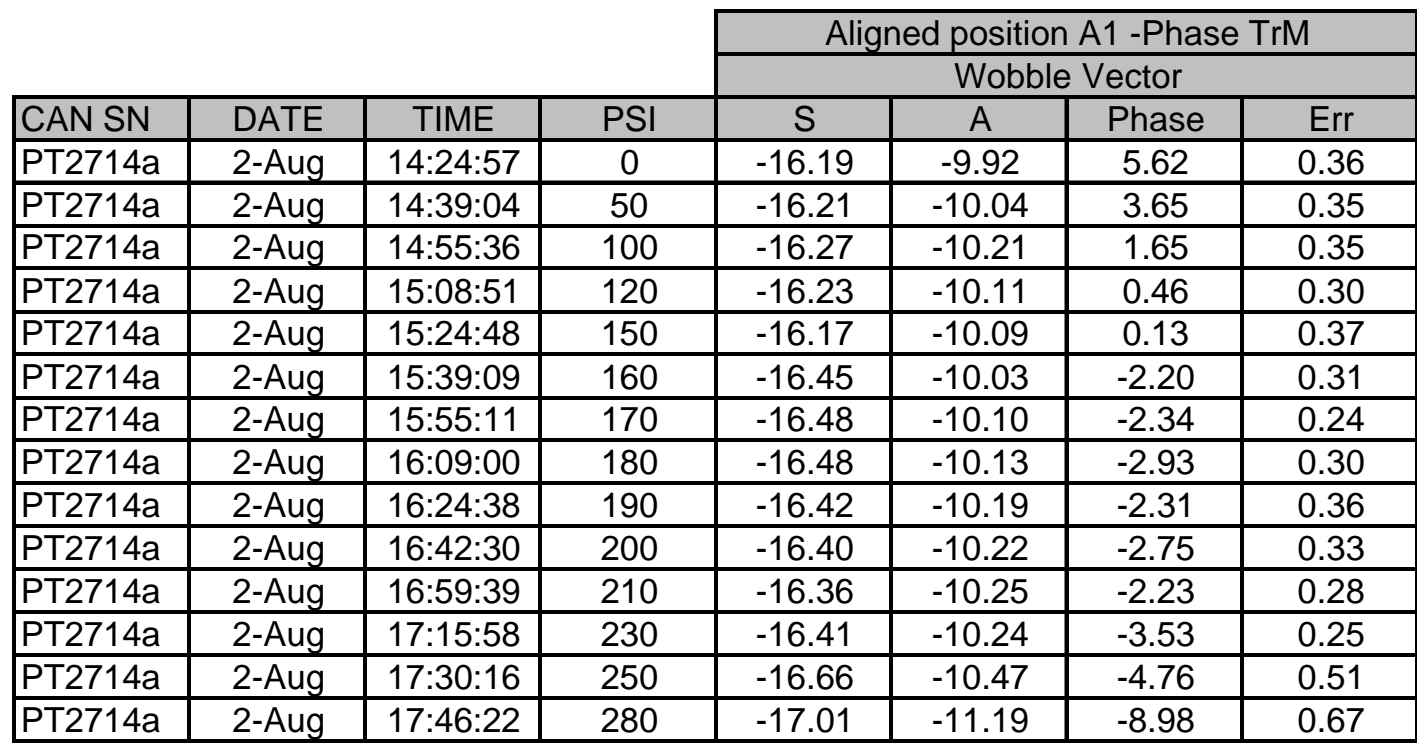




\section{S/N P3370}

\begin{tabular}{|l|c|c|c|c|c|c|c|}
\cline { 5 - 7 } \multicolumn{2}{c}{} & \multicolumn{5}{c|}{ Traditional Alignment } \\
\cline { 5 - 8 } & \multicolumn{3}{c}{} & \multicolumn{4}{c|}{ Wobble Vector } \\
\hline CAN SN & DATE & TIME & PSI & S & A & Phase & Err \\
\hline & & & & -16.41 & -14.74 & -69.72 & 0.10 \\
\hline & & & & & & & \\
\hline & & & & & & & \\
\hline PT3370a & 1 1-Aug & $12: 45: 21$ & 80 & -16.67 & -14.98 & -67.90 & 0.03 \\
\hline PT3370a & 1 -Aug & $13: 08: 16$ & 100 & -16.66 & -15.01 & -66.65 & 0.08 \\
\hline PT3370a & 1 -Aug & $13: 28: 49$ & 120 & -16.64 & -15.21 & -64.41 & 0.15 \\
\hline PT3370a & 1 -Aug & $13: 59: 13$ & 140 & -16.60 & -15.35 & -62.28 & 0.20 \\
\hline PT3370a & 1 -Aug & $14: 25: 12$ & 160 & -16.64 & -14.90 & -59.42 & 0.17 \\
\hline PT3370a & $1-$ Aug & $14: 49: 39$ & 180 & -16.68 & -14.86 & -57.61 & 0.25 \\
\hline PT3370a & 1 -Aug & $15: 13: 13$ & 200 & -16.42 & -15.45 & -57.60 & 0.32 \\
\hline PT3370a & $1-$ Aug & $15: 37: 12$ & 220 & -16.35 & -15.64 & -57.83 & 0.26 \\
\hline
\end{tabular}

\begin{tabular}{|c|c|c|c|c|c|c|c|}
\hline & & & & \multicolumn{4}{|c|}{ Aligned position A1 -Phase TrM } \\
\hline & & & & \multicolumn{4}{|c|}{ Wobble Vector } \\
\hline CAN SN & DATE & TIME & PSI & $\mathrm{S}$ & A & Phase & Err \\
\hline PT3370a & $1-$ Aug & $11: 42: 59$ & 0 & -16.56 & -13.66 & -0.88 & 0.02 \\
\hline PT3370a & 1-Aug & $12: 01: 41$ & 20 & -16.76 & -13.74 & -0.47 & 0.02 \\
\hline PT3370a & 1-Aug & 12:12:54 & 40 & -16.57 & -13.80 & -0.05 & 0.08 \\
\hline PT3370a & 1-Aug & $12: 23: 32$ & 60 & -16.72 & -13.90 & 0.83 & 0.08 \\
\hline PT3370a & 1-Aug & $12: 54: 27$ & 80 & -17.07 & -13.90 & -3.52 & 0.06 \\
\hline PT3370a & 1-Aug & $13: 15: 15$ & 100 & -17.25 & -13.89 & -4.84 & 0.05 \\
\hline PT3370a & 1-Aug & $13: 40: 37$ & 120 & -17.04 & -14.13 & 12.72 & 0.09 \\
\hline PT3370a & 1-Aug & $14: 13: 50$ & 140 & -17.03 & -14.65 & 16.80 & 0.08 \\
\hline PT3370a & 1-Aug & $14: 37: 29$ & 160 & -17.20 & -15.07 & 19.57 & 0.27 \\
\hline PT3370a & 1-Aug & 15:00:19 & 180 & -17.42 & -16.01 & 20.27 & 0.49 \\
\hline PT3370a & 1-Aug & $15: 23: 44$ & 200 & -17.53 & -16.58 & 17.93 & 0.69 \\
\hline PT3370a & 1-Aug & $15: 48: 07$ & 220 & -17.61 & -16.68 & 16.03 & $0.7 \varepsilon$ \\
\hline
\end{tabular}




\section{S/N P3373}

\begin{tabular}{|c|c|c|c|c|c|c|c|}
\hline & & & & & Tradition & lignmen & \\
\hline & & & & & Wobb & ector & \\
\hline CAN SN & DATE & TIME & PSI & $S$ & A & Phase & Err \\
\hline PT3373a & 4-Aug & $9: 14: 19$ & 0 & -16.68 & -13.38 & 41.94 & 0.16 \\
\hline PT3373a & 4-Aug & $9: 41: 08$ & 50 & -16.61 & -13.52 & 41.06 & 0.00 \\
\hline PT3373a & 4-Aug & $10: 04: 57$ & 100 & -16.48 & $\begin{array}{l}-13.72 \\
\end{array}$ & 40.93 & 0.12 \\
\hline РT3373a & 4-Aug & 10:19:20 & 150 & -16.57 & -13.79 & 41.20 & 0.07 \\
\hline PT3373a & 4-Aug & 10:38:11 & 170 & -16.49 & -14.08 & 41.66 & 0.05 \\
\hline PT3373a & 4-Aug & $10: 52: 14$ & 190 & -16.33 & -14.64 & 40.42 & 0.08 \\
\hline PT3373a & 4-Aug & $11: 05: 23$ & 200 & -16.39 & -14.70 & 40.11 & 0.05 \\
\hline PT3373a & 4-Aug & $11: 17: 58$ & 210 & -16.37 & -14.83 & 39.48 & 0.05 \\
\hline PT3373a & 4-Aug & $11: 31: 35$ & 220 & -16.33 & -14.99 & 38.89 & 0.12 \\
\hline PT3373a & 4-Aug & $11: 54: 14$ & 230 & -16.40 & -14.83 & 38.10 & 0.15 \\
\hline PT3373a & 4-Aug & $12: 15: 33$ & 240 & -16.59 & -14.71 & 38.02 & 0.17 \\
\hline PT3373a & 4-Aug & $12: 30: 12$ & 250 & -16.43 & -14.26 & 37.95 & 0.18 \\
\hline PT3373a & 4-Aug & $12: 42: 46$ & 280 & -15.99 & -13.06 & 39.65 & 0.17 \\
\hline
\end{tabular}

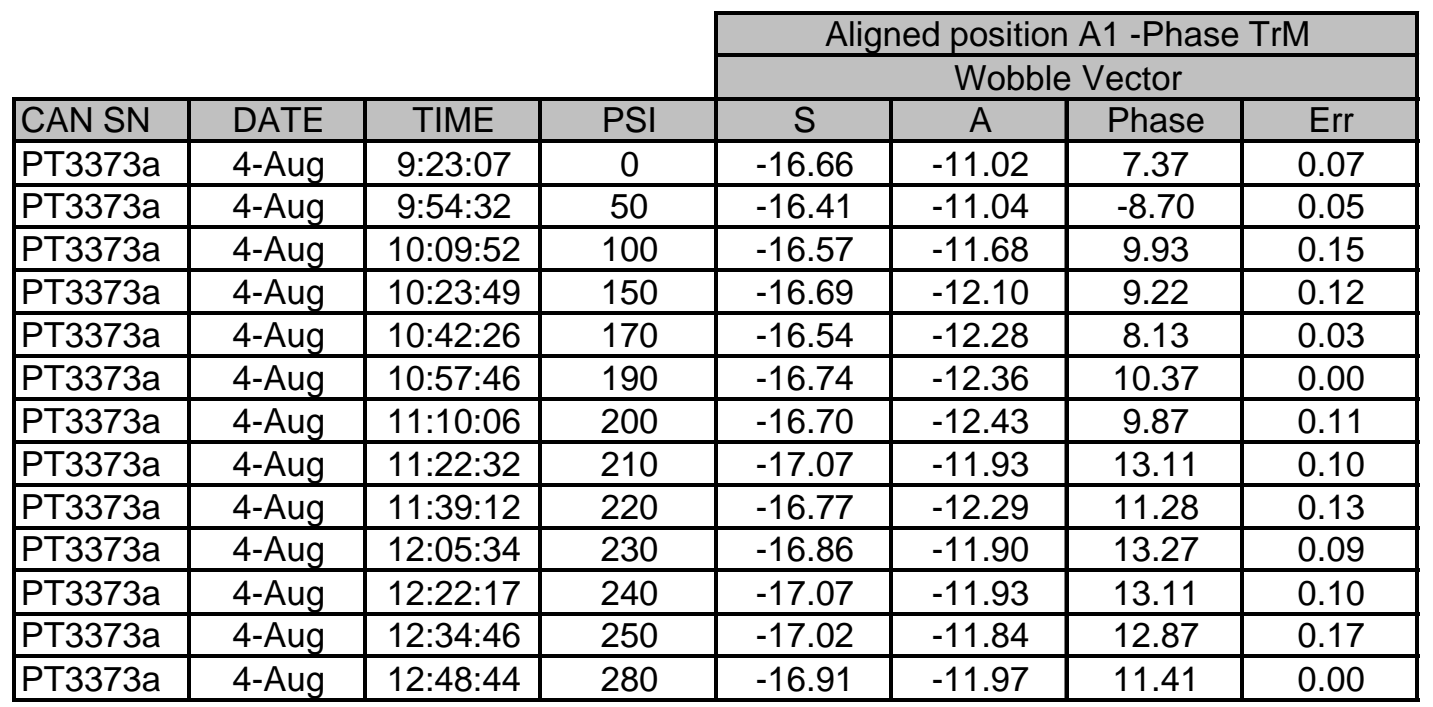




\section{S/N P3379}

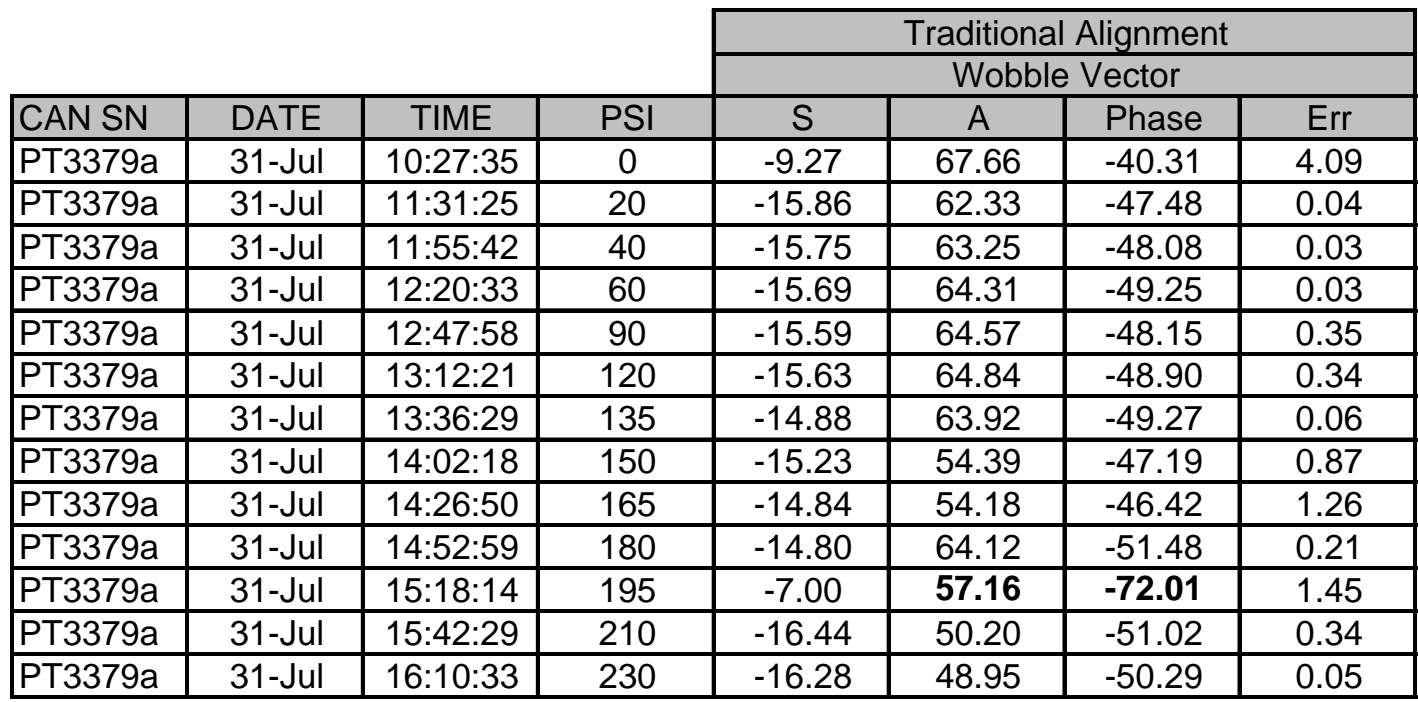

It appears from review of the image files that the can slipped as it was rotated due to the tubing attached at 195 psig

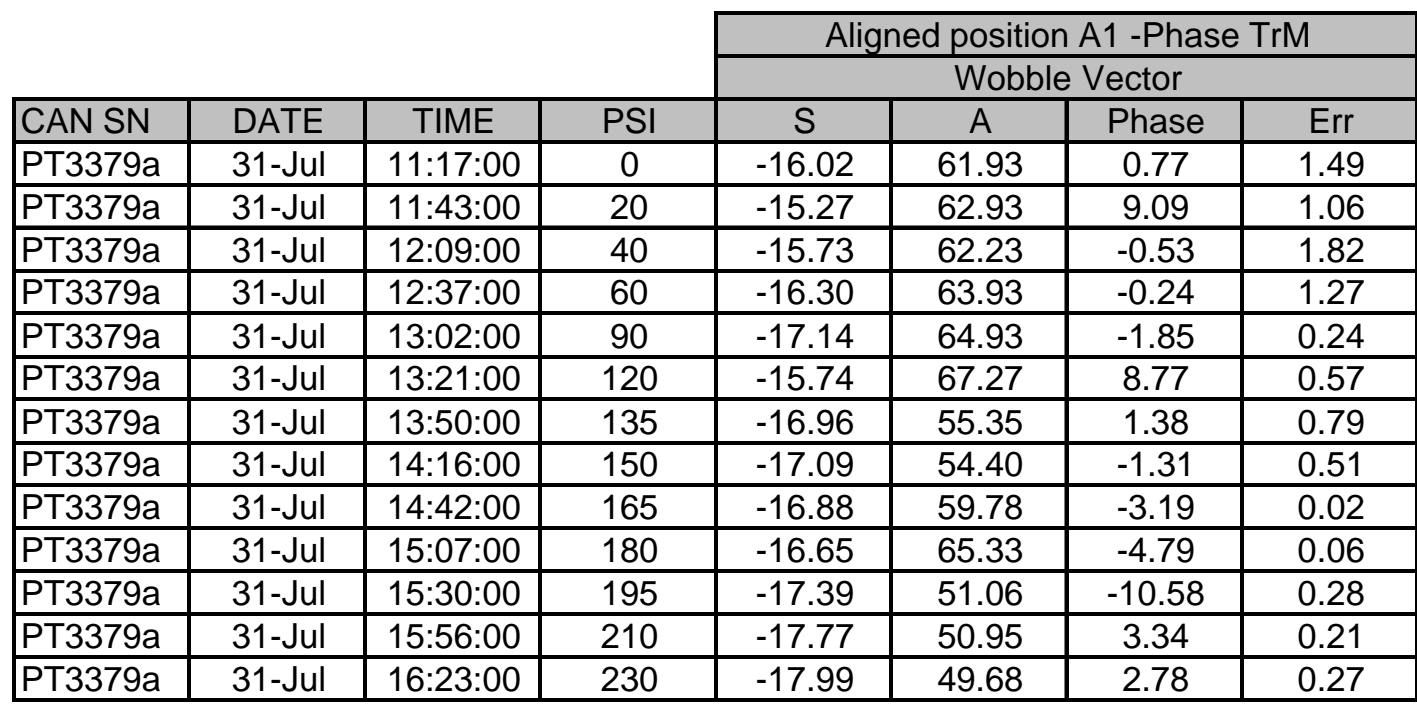




\section{S/N P3381}

\begin{tabular}{|c|c|c|c|c|c|c|c|}
\hline & \multicolumn{4}{|c|}{ Traditional Alignment } \\
\hline & & & & \multicolumn{4}{|c|}{ Wobble Vector } \\
\hline CAN SN & DATE & $\overline{\text { TIME }}$ & $\mathrm{PSI}$ & $\mathrm{S}$ & $A$ & Phase & Err \\
\hline PT3381a & 4-Aug & $13: 21: 00$ & 0 & -16.60 & -9.68 & -38.17 & 0.35 \\
\hline PT3381a & 4-Aug & 13:39:00 & 50 & -16.55 & -9.69 & -36.14 & 0.19 \\
\hline PT3381a & 4-Aug & $13: 53: 00$ & 100 & -16.73 & -9.51 & -31.73 & 0.24 \\
\hline PT3381a & 4-Aug & 14:09:00 & 150 & -16.68 & -9.69 & -26.70 & 0.08 \\
\hline PT3381a & 4-Aug & $14: 23: 00$ & 160 & -16.72 & -9.81 & -26.11 & 0.17 \\
\hline PT3381a & 4-Aug & $14: 38: 00$ & 170 & -16.64 & -10.02 & -25.44 & 0.24 \\
\hline PT3381a & 4-Aug & $14: 55: 00$ & 180 & -16.74 & -10.07 & -24.90 & 0.17 \\
\hline PT3381a & 4-Aug & $15: 14: 00$ & 190 & -16.78 & -10.21 & -23.94 & 0.07 \\
\hline PT3381a & 4-Aug & $15: 29: 00$ & 200 & -16.82 & 10.36 & -22.57 & 0.12 \\
\hline PT3381a & 4-Aug & $15: 46: 00$ & 220 & -16.67 & -10.73 & -23.20 & 0.13 \\
\hline PT3381a & 4-Aug & $16: 08: 00$ & 240 & -16.65 & -10.83 & -23.12 & 0.19 \\
\hline
\end{tabular}

\begin{tabular}{|l|c|c|c|c|c|c|c|}
\cline { 4 - 8 } \multicolumn{2}{c}{} & \multicolumn{5}{c|}{ Aligned position A1-Phase TrM } \\
\cline { 5 - 8 } \multicolumn{2}{c}{} & \multicolumn{3}{c}{ Cobble Vector } \\
\hline CAN SN & DATE & TIME & PSI & S & A & Phase & Err \\
\hline PT3381a & 4-Aug & $13: 26: 00$ & 0 & -16.16 & -11.42 & 12.40 & 0.42 \\
\hline PT3381a & 4-Aug & $13: 43: 00$ & 50 & -16.24 & -11.08 & 10.66 & 0.35 \\
\hline PT3381a & 4-Aug & $13: 58: 00$ & 100 & -16.37 & -10.64 & 8.95 & 0.29 \\
\hline PT3381a & 4-Aug & $14: 13: 00$ & 150 & -16.48 & -10.35 & 7.03 & 0.30 \\
\hline PT3381a & 4-Aug & $14: 28: 00$ & 160 & -16.49 & -10.20 & 7.60 & 0.37 \\
\hline PT3381a & 4-Aug & $14: 45: 00$ & 170 & -16.56 & -9.78 & 7.91 & 0.31 \\
\hline PT3381a & 4-Aug & $15: 00: 00$ & 180 & -16.69 & -9.80 & 9.71 & 0.15 \\
\hline PT3381a & 4-Aug & $15: 19: 00$ & 190 & -16.75 & -9.61 & 12.59 & 0.22 \\
\hline PT3381a & 4-Aug & $15: 35: 00$ & 200 & -16.81 & -9.65 & 17.28 & 0.18 \\
\hline PT3381a & 4-Aug & $\mathbf{1 5 : 5 8 : 0 0}$ & $\mathbf{2 2 0}$ & -16.43 & $\mathbf{- 1 0 . 6 4}$ & $\mathbf{- 3 1 . 8 6}$ & $\mathbf{0 . 1 4}$ \\
\hline PT3381a & 4-Aug & $16: 14: 00$ & 240 & -17.01 & -11.31 & 31.09 & 0.24 \\
\hline
\end{tabular}

Note: the residual phase at 220 psi does not fit the trend in the data. Most likely cause is that the stage was rotated in the wrong direction. 


\section{S/N P3382}

\begin{tabular}{|c|c|c|c|c|c|c|c|}
\hline & & & & & raditio & lignmen & \\
\hline & & & & & Wob & lector & \\
\hline CAN SN & DATE & TIME & PSI & $\mathrm{S}$ & $A$ & Phase & Err \\
\hline PT3382a & 5-Aug & $12: 09: 21$ & 0 & -16.43 & -8.75 & -41.25 & 0.20 \\
\hline PT3382a & 5-Aug & $12: 34: 00$ & 50 & -16.48 & -8.69 & -39.91 & 0.23 \\
\hline PT3382a & 5-Aug & $12: 50: 27$ & 100 & -16.43 & -8.80 & -36.44 & 0.30 \\
\hline PT3382a & 5-Aug & $13: 03: 48$ & 150 & -16.45 & -8.83 & -36.11 & 0.15 \\
\hline PT3382a & 5-Aug & $13: 18: 38$ & 175 & -16.42 & -8.91 & -34.90 & 0.22 \\
\hline PT3382a & 5-Aug & $13: 32: 44$ & 190 & -16.40 & -8.90 & -34.10 & 0.17 \\
\hline PT3382a & 5-Aug & $13: 49: 43$ & 200 & -16.38 & -8.96 & -33.05 & 0.14 \\
\hline PT3382a & 5-Aug & $14: 03: 38$ & 210 & -16.49 & -8.96 & -31.70 & 0.24 \\
\hline PT3382a & 5-Aug & $14: 18: 52$ & 220 & $\begin{array}{l}-16.73 \\
\end{array}$ & -8.86 & -29.79 & 0.29 \\
\hline PT3382a & 5-Aug & $14: 32: 47$ & 230 & -16.72 & -9.09 & -29.58 & 0.40 \\
\hline PT3382a & 5-Aug & $14: 49: 21$ & 250 & -16.55 & -9.05 & $\begin{array}{l}-29.73 \\
\end{array}$ & 0.58 \\
\hline PT3382a & 5-Aug & $15: 05: 25$ & 270 & -16.38 & -8.59 & -30.80 & 0.78 \\
\hline
\end{tabular}

\begin{tabular}{|c|c|c|c|c|c|c|c|}
\hline & & & & \multicolumn{4}{|c|}{ Aligned position A1 -Phase TrM } \\
\hline & & & & \multicolumn{4}{|c|}{ Wobble Vector } \\
\hline CAN SN & DATE & TIME & PSI & $\mathrm{S}$ & A & Phase & Err \\
\hline PT3382a & 5 -Aug & $12: 15: 01$ & 0 & -16.35 & -6.26 & 10.27 & 0.11 \\
\hline PT3382a & 5 -Aug & $12: 38: 37$ & 50 & -16.39 & -6.19 & 4.72 & 0.00 \\
\hline PT3382a & 5-Aug & 12:55:24 & 100 & -16.32 & -6.57 & -7.02 & 0.05 \\
\hline PT3382a & 5-Aug & 13:08:03 & 150 & -16.23 & -6.60 & -7.15 & 0.14 \\
\hline PT3382a & 5-Aug & 13:23:01 & 175 & -16.12 & -6.77 & -8.49 & 0.13 \\
\hline PT3382a & 5-Aug & $13: 38: 54$ & 190 & -16.07 & -6.96 & -9.80 & 0.08 \\
\hline PT3382a & 5-Aug & $13: 55: 19$ & 200 & -15.99 & -7.04 & -11.55 & 0.11 \\
\hline PT3382a & 5-Aug & $14: 10: 09$ & 210 & -15.92 & -7.01 & -13.19 & 0.12 \\
\hline PT3382a & 5-Aug & $14: 24: 34$ & 220 & -16.22 & -7.08 & -16.05 & 0.03 \\
\hline PT3382a & 5-Aug & 14:37:30 & 230 & -16.22 & -7.11 & -14.44 & 0.02 \\
\hline PT3382a & 5-Aug & $14: 54: 45$ & 250 & -16.09 & -7.36 & -12.38 & 0.02 \\
\hline PT3382a & 5-Aug & 15:10:04 & 270 & -15.90 & -7.75 & -7.88 & 0.01 \\
\hline
\end{tabular}

